\title{
WestVirginiaUniversity
}

THE RESEARCH REPOSITORY @ WVU

Graduate Theses, Dissertations, and Problem Reports

2009

\section{Hydroponic production of selected flower and herb crops in red lava rock}

Victoria Elizabeth Gonzalez-Lerma

West Virginia University

Follow this and additional works at: https://researchrepository.wvu.edu/etd

\section{Recommended Citation}

Gonzalez-Lerma, Victoria Elizabeth, "Hydroponic production of selected flower and herb crops in red lava rock" (2009). Graduate Theses, Dissertations, and Problem Reports. 2796.

https://researchrepository.wvu.edu/etd/2796

This Thesis is protected by copyright and/or related rights. It has been brought to you by the The Research Repository @ WVU with permission from the rights-holder(s). You are free to use this Thesis in any way that is permitted by the copyright and related rights legislation that applies to your use. For other uses you must obtain permission from the rights-holder(s) directly, unless additional rights are indicated by a Creative Commons license in the record and/ or on the work itself. This Thesis has been accepted for inclusion in WVU Graduate Theses, Dissertations, and Problem Reports collection by an authorized administrator of The Research Repository @ WVU. For more information, please contact researchrepository@mail.wvu.edu. 
Hydroponic Production of Selected Flower and Herb Crops in Red Lava Rock

\author{
Victoria Elizabeth González-Lerma
}

\begin{abstract}
Thesis submitted to the
Davis College of Agriculture, Forestry, and Consumer Sciences at West Virginia University

in partial fulfillment of the requirements for the degree of
\end{abstract}

Master of Science

in

Horticulture

\author{
Sven Verlinden, Ph.D., Chair \\ William B. Bryan, Ph.D. \\ Todd West, Ph.D.
}

Division of Plant and Soil Sciences

Morgantown, West Virginia

2009

Keywords: Tezontle, Crop diversification, Irrigation regimens, Alternative growing medium. 


\section{ABSTRACT \\ "Hydroponic Production of Selected Flower and Herb Crops in Red Lava Rock" \\ Victoria Elizabeth González-Lerma}

In terms of cost and availability, it is important that new materials are tested as a hydroponics soil-less media, especially in areas where traditional hydroponic media such as rockwool and perlite are not available or cost prohibitive. Red lava rock or "Tezontle" has potential as a media due to its physical characteristics and cost. However, limited experience has been gained with this material as a hydroponic media for crops outside of tomato, pepper, melon, and tomatillo. In an attempt to diversify hydroponic crop production systems in semi-arid regions of Mexico, red lava rock (tezontle)-based hydroponic systems were tested in three experiments designed to study the effect of watering regimens on the growth and development of four herbs (basil, thyme, rosemary, and mint) and one ornamental (sunflowers). In Experiment 1 plants were watered at $80 \%, 100 \%$ and $120 \%$ of container capacity. In Experiments 2 and 3 plants were irrigated applying the same amount of water at each irrigation but at five different treatment levels (every other day, once a day, two times a day alternated with one time the next day, two times in a day, and three times in a day).

In general, the growth and performance of plants improved as the amount of irrigation water increased. In the three experiments, all plants suffered drought stress in treatments receiving the least irrigation and therefore also produced the lowest yields. However, each of the plant species included in this study showed different response patterns to irrigation amount and frequency. Thyme, despite its low yield in the low watering level (80\%) in Experiment 1 and less frequent irrigation treatment (every other day irrigation) in Experiments 2 and 3, performed best in terms of marketable characteristics (width of stems and size of leaves), in these low water applications. In addition, thyme showed low yields in the treatments receiving the most irrigation suggesting that thyme can be grown with relatively low amounts of water at each application or less frequent water application than any of the other crops included in this study. In conclusion, basil, thyme, rosemary, sunflowers and mint can be successfully grown in a greenhouse tezontle-based hydroponic system with a low input of water. Although plants receiving the lowest irrigation showed low yields, they still showed acceptable marketable characteristics to be sold fresh or dried. 


\section{Acknowledgments}

I would like to thank everyone at West Virginia University who has helped me pursue this academic and personal goal.

Foremost, I need to express thanks to my advisor, Dr. Sven Verlinden, for giving me the opportunity to participate as a graduate student in this project. Thank you, Dr. Verlinden, for believing in my capabilities to study, work and conduct research in a foreign country and in a foreign language. Thank you for the knowledge you have passed on to me as a professor and advisor. I truly appreciate your support and willingness to always make time for me, even in your busiest days. Above of all, I really want to thank you for working shoulder by shoulder (or letter by letter) with me from the beginning to the end of this thesis...It certainly has been one of the biggest challenges that I have ever had to meet in my life!!

I would like to thank the great WVU greenhouse staff, especially Sue Myers and Gail Sikorsky for their tremendous help and advice. I also appreciate all of the help from Carol, Allen and the students (Damon, Heather, Zacchary and JT) who helped me in my research.

I really want to, need to, and should express my enormous gratitude to Dr. William B. Bryan for advising, supporting and helping me in so many ways. Thank you, Dr. Bryan, for always giving me the strength and encouragement throughout my stay at WVU. Also thanks for your big help with this thesis!!

I am in infinite debt to Dr. Domingo Mata-Padrino for all of the time, advice, and support that he has given me in my research and this thesis and also as a friend. Muchísimas gracias Domingo!!

I really want to thank my family for always supporting and helping me in many ways. Thanks Silvia Lerma, Felipe González and Will González...esto es suyo también!! 
Finally, I would like to express thanks to all of my friends in Morgantown who have giving me lots and lots of support and advice, in addition to many beautiful moments. Very special thanks to Mr. Richard Eddy, Marcela and Jim Whetsell, Maximo Martinez, Hannah Schrum, Evan Anderson, Lola and Nel Medellín-Contreras, Katey Buckland, Patricia Simoni, Tiara King, Sherry Forquer, Evans Basweti, Ma. Camila Jaramillo, Amada and Don McDowell, Dalieli and César Silva-Bencomo, and Romina and Fernando Perea-Brugal. Thank you guys very much for your friendship; it has been wonderful knowing you!! 


\section{Table of Contents}

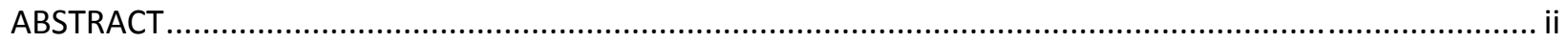

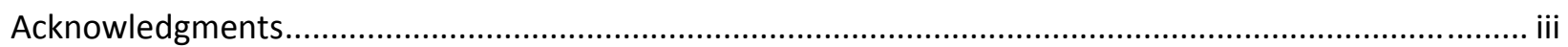

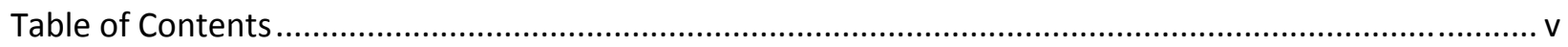

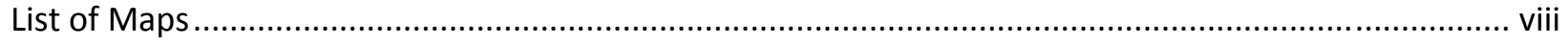

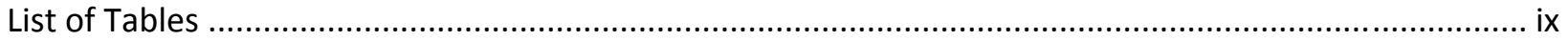

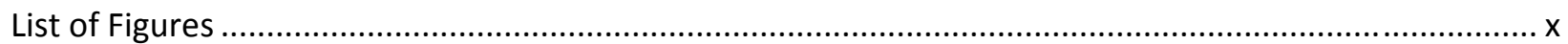

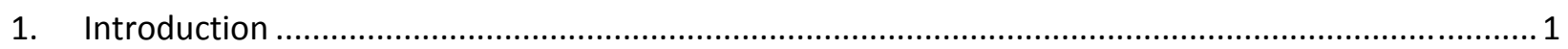

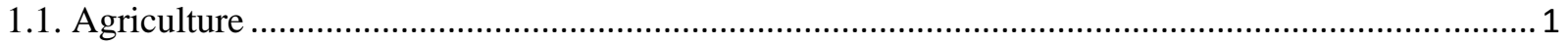

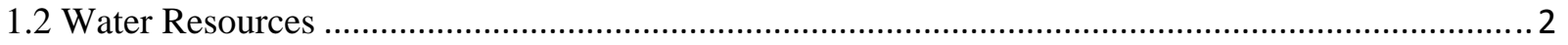

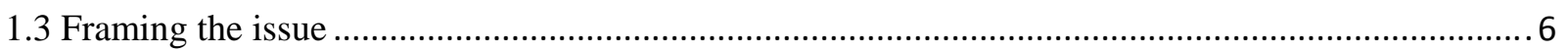

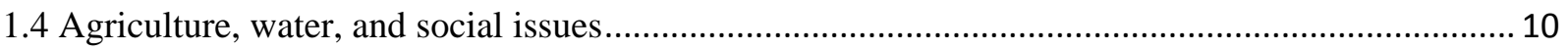

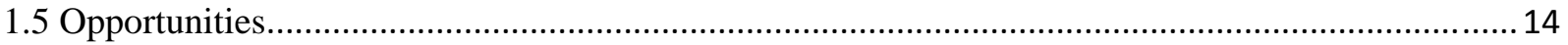

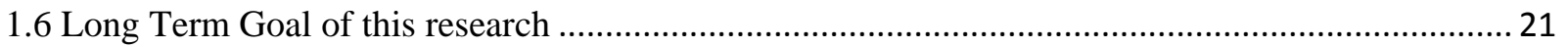

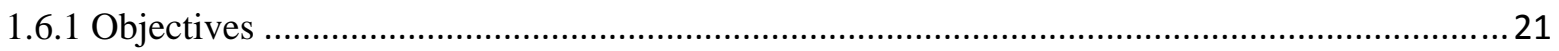

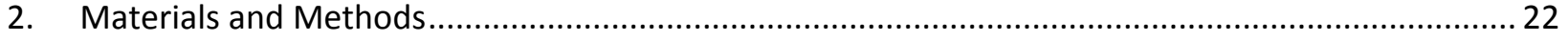

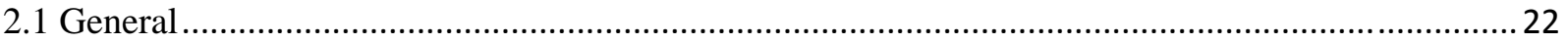

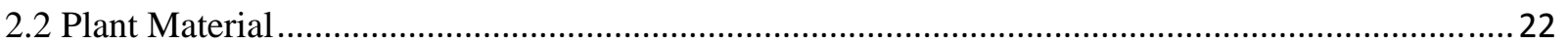

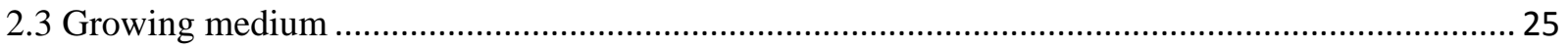

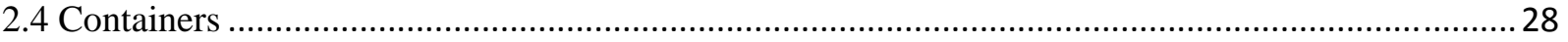

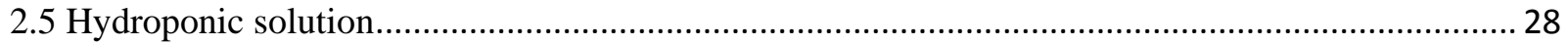

2.6 Experiment 1: Watering with 80, 100 \& 120\% of container capacity ........................................... 30

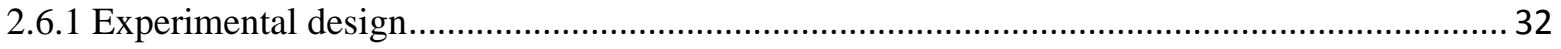

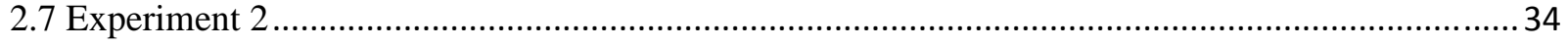

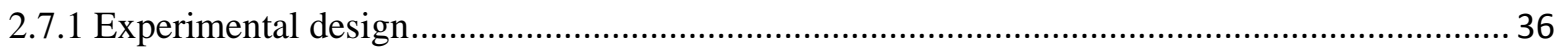

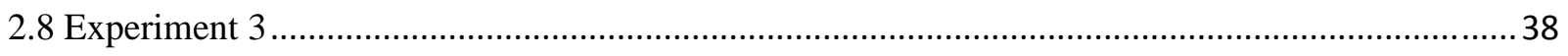

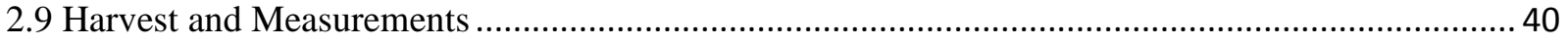

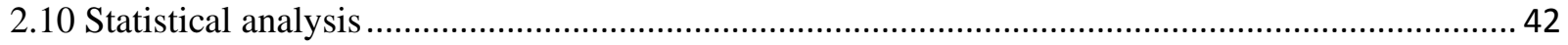

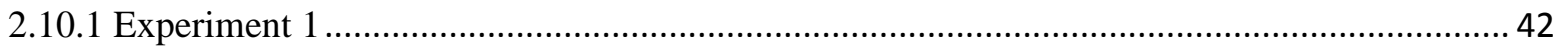

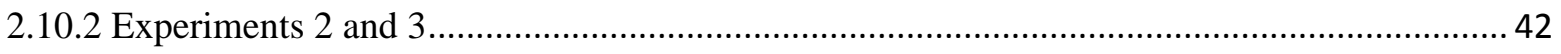

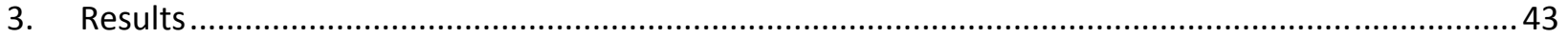




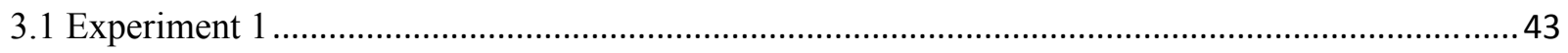

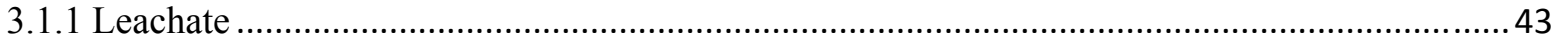

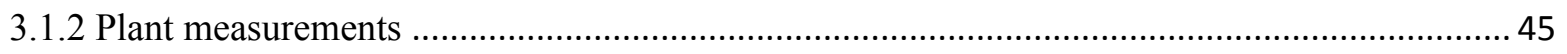

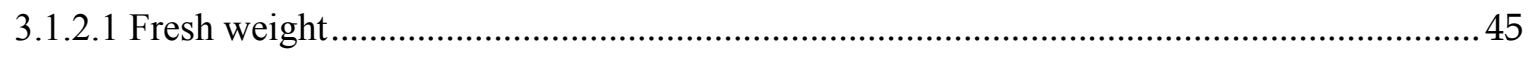

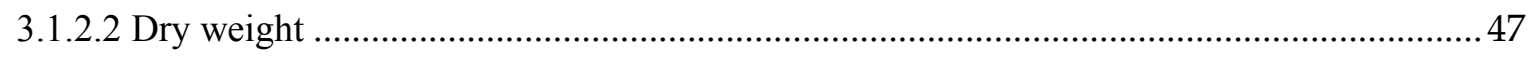

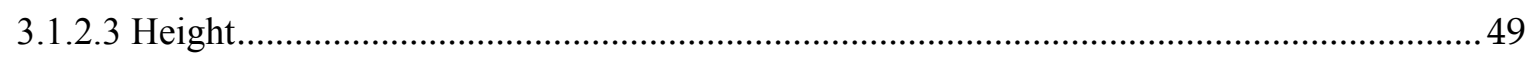

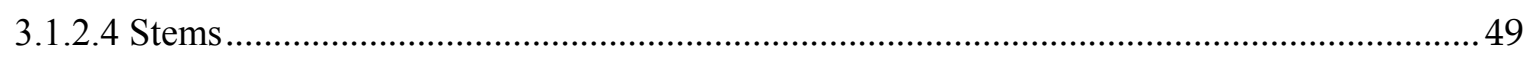

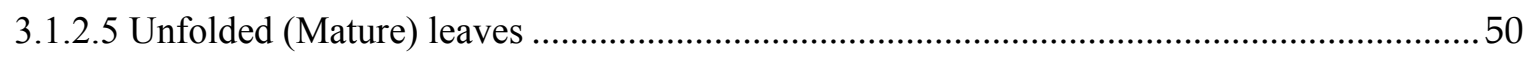

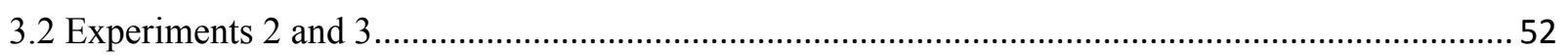

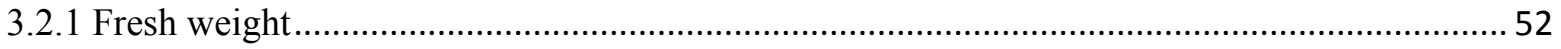

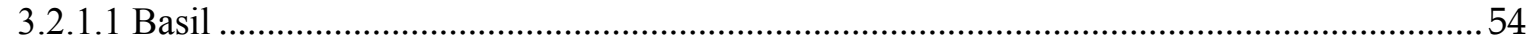

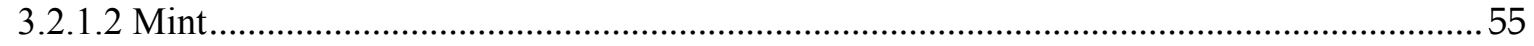

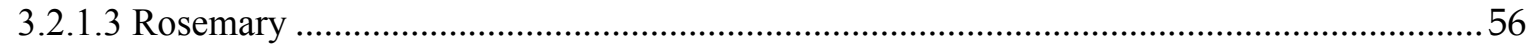

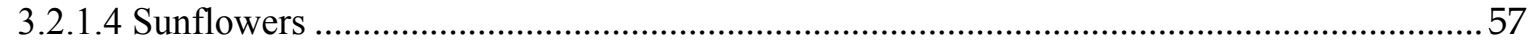

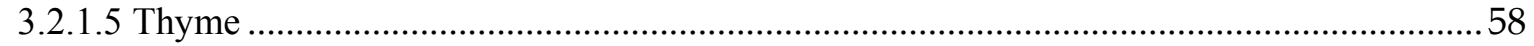

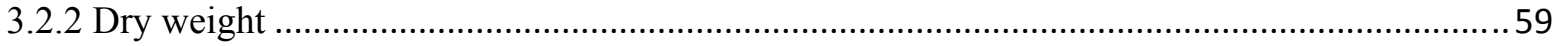

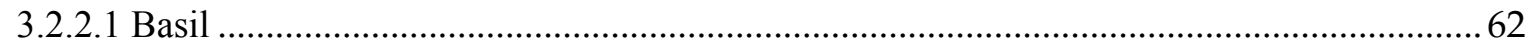

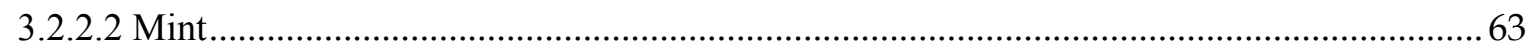

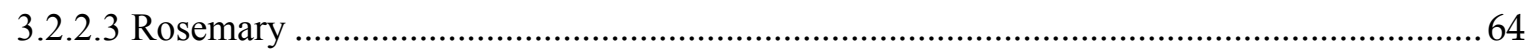

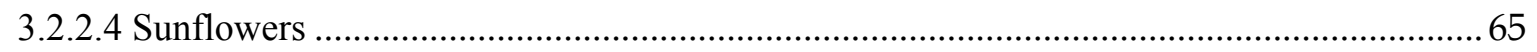

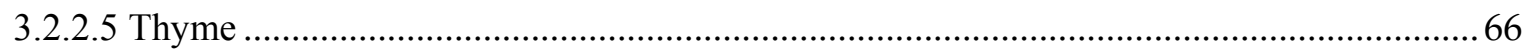

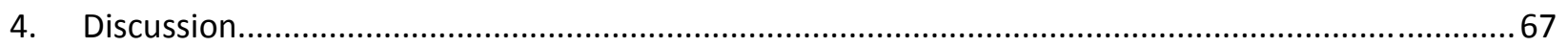

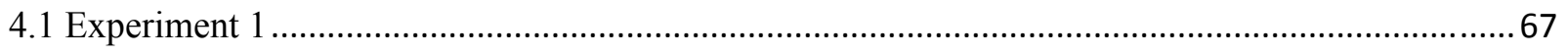

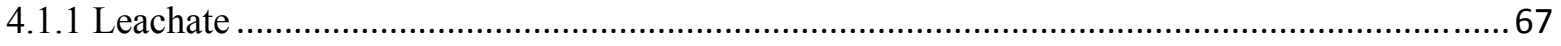

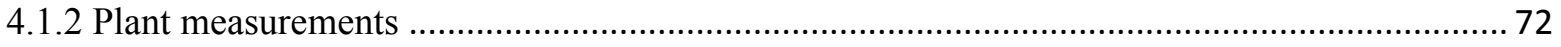

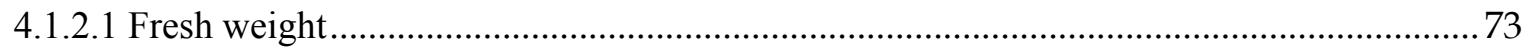

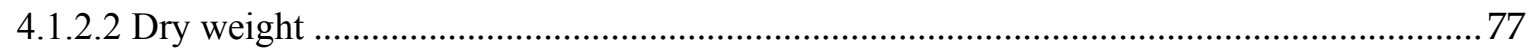

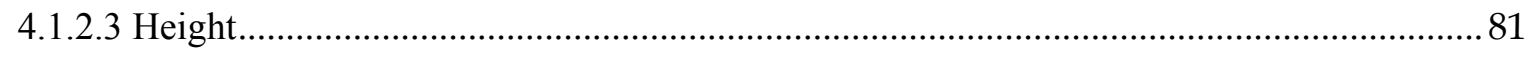

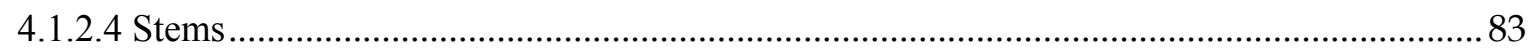

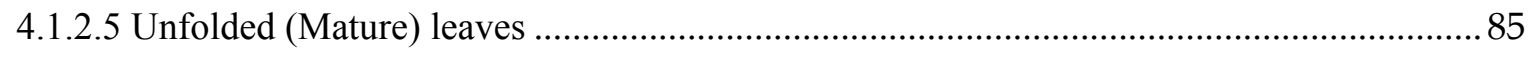

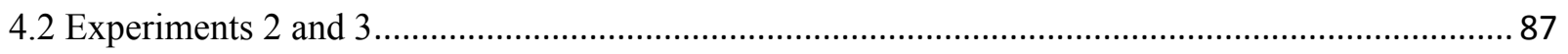

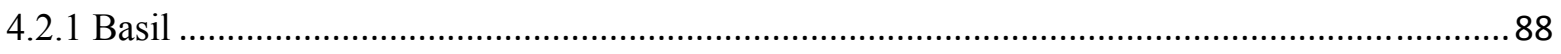

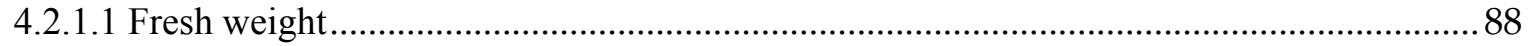




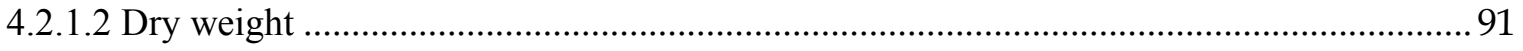

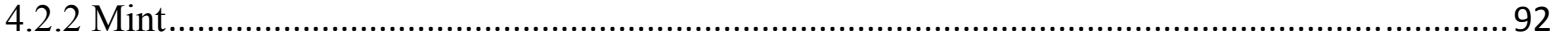

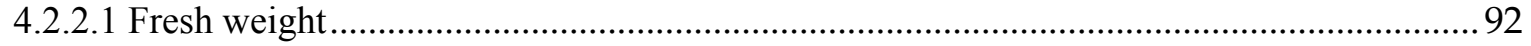

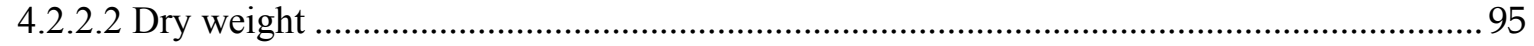

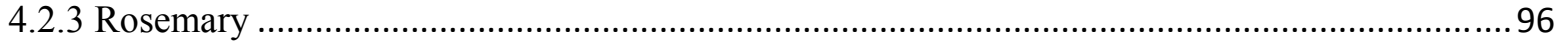

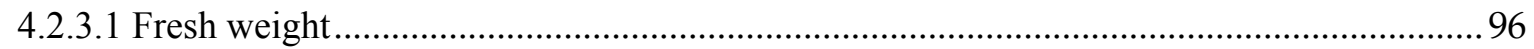

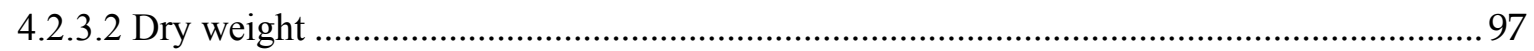

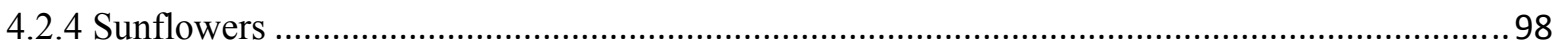

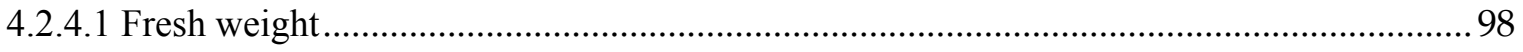

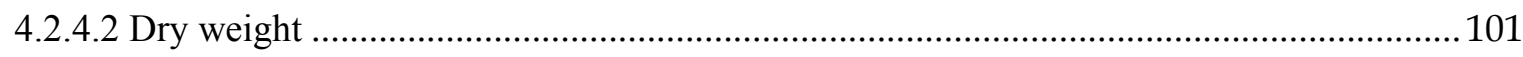

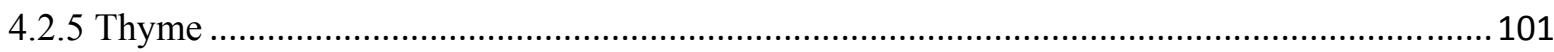

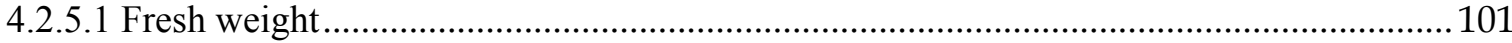

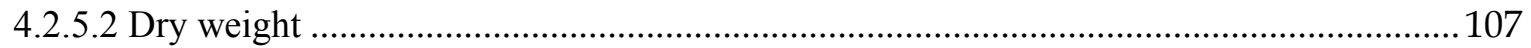

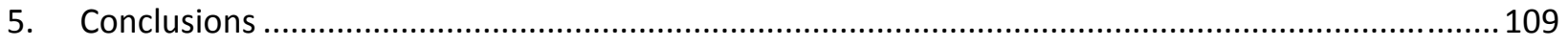

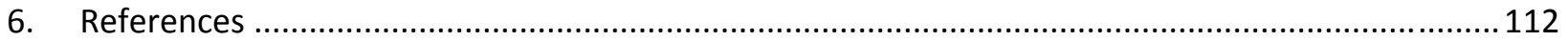

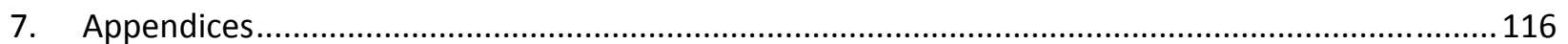

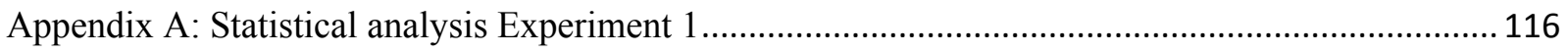

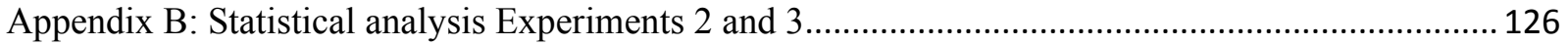

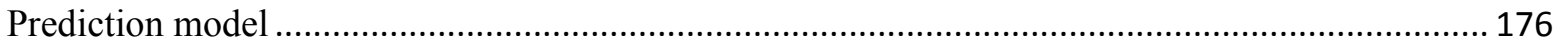




\section{List of Maps}

Map 1.1. States of Mexico and region of "El Bajío"........................................................... 2

Map 1.2. Rainfall in Mexico (1971-2000)........................................................................ 3

Map 1.3. Location of the Lerma-Chapala-Santiago river basin and rivers in the area of central

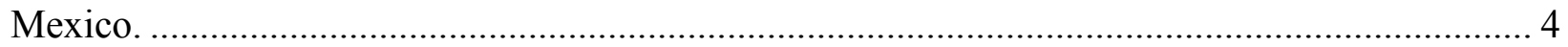

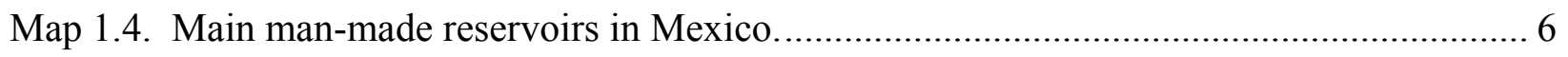

Map 1.5. Depleted aquifers in each water administrative region of Mexico 2007.................... 9

Map 1.6. Location of the volcanoes crossing horizontally Central Mexico............................ 19 


\section{List of Tables}

Table 2.1. Preliminary analysis of Tezontle ........................................................................ 28

Table 2.2. Chemical composition and concentration of the modified Hoagland's All - Nitrate

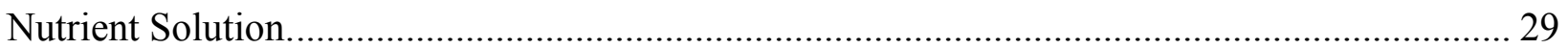

Table 2.3. Analysis of the Tezontle mix used as growing medium in Experiment 3................ 39 


\section{List of Figures}

Figure 2.1. Process of crushing the red lava rock to make the medium used in this research..... 26

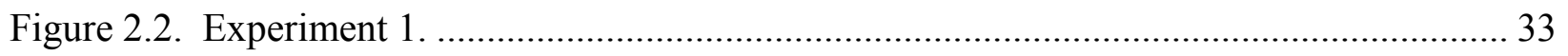

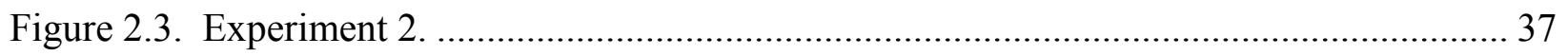

Figure 2.4. Gilson shaker used to sieve the red lava rock for experiment 3.............................. 38

Figure 3.1. Leachate generated by the three water treatments in Experiment 1 1........................ 43

Figure 3.2. Leachate mean per plant species in Experiment 1.................................................. 44

Figure 3.3. Total fresh weight for the three water treatments $(80 \%, 100 \%$ and $120 \%)$ )............. 45

Figure 3.4. Fresh weight by treatment for the five plants species.............................................. 46

Figure 3.5. Total dry weight for the three water treatments $(80 \%, 100 \%$ and $120 \%) \ldots \ldots \ldots \ldots \ldots . . . .47$

Figure 3.6. Dry weight per treatment for the five plants species............................................. 48

Figure 3.7. Number of stems (means) per species and per treatment for each of the plants species.

Figure 3.8 Number of mature leaves per water treatment in Basil. .......................................... 51

Figure 3.9. Comparison of the total fresh weight between the five different treatments. ........... 52

Figure 3.10. Comparison of the total fresh weight between the five different plant species....... 53

Figure 3.11. Comparison of fresh weight between the five different plant species per watering

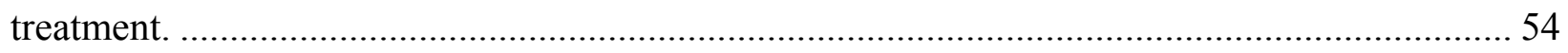

Figure 3.12. Comparison of fresh weight among the five different watering treatments in basil.

Figure 3.13. Comparison of fresh weight among the five different watering treatments in mint. 
Figure 3.14. Comparison of fresh weight among the five different watering treatments in rosemary.

Figure 3.15. Comparison of fresh weight among the five different watering treatments in sunflowers. 58

Figure 3.16. Comparison of fresh weight among the five different watering treatments in thyme. 59

Figure 3.17. Comparison of the total dry weight between the five different treatments. 60

Figure 3.18. Comparison of the total dry weight between the five different plant species. 60

Figure 3.19. Comparison of dry weight between the five different plant species per watering treatment. 61

Figure 3.20. Comparison of dry weight among the five different watering treatments in basil.. 62 Figure 3.21. Comparison of dry weight among the five different watering treatments in mint. . 63 Figure 3.22. Comparison of dry weight among the five different watering treatments in rosemary. 64

Figure 3.23. Comparison of dry weight among the five different watering treatments in sunflowers. 65

Figure 3.24. Comparison of dry weight among the five different watering treatments in thyme. 66

Figure 4.1. Root systems of four of the plants species studied......................................... 69

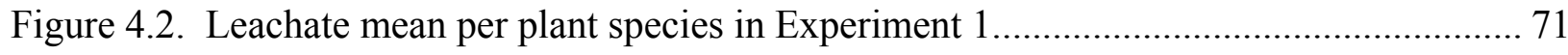

Figure 4.3. Mint plant with a severe infestation of spider mites (Tetranychus urticae)............. 72

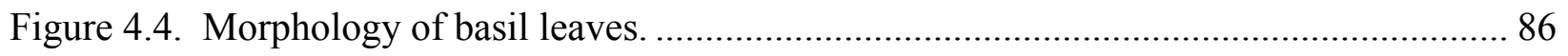

Figure 4.5. Comparison of basil plants between the five different watering regimens. ............. 89 
Figure 4.6. Comparison of the morphology of a basil plant before the first harvest and before the fourth harvest (Experiment 2). 90

Figure 4.7. Basil plants from Treatment 2 and Treatment 3 before the third harvest (Experiment 2). 91

Figure 4.8. Mint plant from Treatment 0.5 (Harvest 2 of Experiment 3) infested by spider mites (Tetranychus urticae). 93

Figure 4.9. Comparison of the morphology of mint plants in Treatment 1 and Treatment 1.5 before the third harvest in experiment 2 . 93

Figure 4.10. Comparison of the morphology of mint plants in Treatment 2 and Treatment 3 before the third harvest in experiment 2 . 95

Figure 4.11. Comparison of the morphology of rosemary plants in the five different treatments (second harvest in experiment 2). 97

Figure 4.12. Sunflowers being transplanted and newly transplanted. 98

Figure 4.13. Comparison of the morphology of sunflowers in the five different treatments from the first harvest in experiment 2 . 99

Figure 4.14. Comparison of the morphology of some of the sunflowers harvested in the first harvest of experiment 3 in the Treatments $3,2,1.5$, and 1 . 100

Figure 4.15. Comparison of the morphology of thyme in the treatment receiving the least amount of irrigation (Treatment 0.5 -irrigated every other day), and the treatment receiving the highest number of irrigations per day (Treatment 3-irrigated three times in a day). 103

Figure 4.16. Adventitious roots in two thyme plants in Treatment 3 (irrigated three times a day). 104

Figure 4.17. Comparison of recently harvested thyme plants at the end of experiment 2........ 106 
Figure 4.18. Thyme plant grown under Treatment 1.5 conditions (irrigated two times a day alternated with one time the next day) ..................................................................... 107

Figure 7.1. Fresh weight prediction model.................................................................. 177

Figure 7.2. Dry weight prediction model...................................................................... 178 


\section{Hydroponic Production of Selected Flower and Herb Crops in Red Lava \\ Rock.}

\section{Introduction}

\subsection{Agriculture}

Agriculture has always been one of the main economic activities in Mexico. Despite the fact that during the second half of the last century the country went through an "industrialization phenomenon", agriculture has remained an important economic activity in Mexico. In the past decade this activity diminished its contribution to the gross domestic product (GDP) from $8 \%$ in 1993 to about 3.8\% in 2005 (CIA 2006; Levine, 2007). However, 18\% of the labor force remains associated with agriculture, implying a greater influence on society as a whole than the relatively small contribution to GDP suggests (Levine, 2007). Mexico has two important agricultural production areas, one located in the Northwest and one in the central region of the country. Each of this geographical area includes several states. Cereals, fruits, as well as vegetables are the main commodities produced in these regions.

The central region of the country is the one of most interest to the research discussed in this thesis. The central region is well known as one of the most important areas of cereal and vegetable production in Mexico. Included in this area of the country is the "El Bajío" region, a large flat area largely dedicated to agriculture (Bassols, 1989). Corn, beans, wheat, sorghum, strawberries, peppers, and alfalfa are among the chief crops grown in this region. "El Bajío" is located in the state of Guanajuato, and parts of Jalisco, Michoacán and Querétaro. Although in some literature the states of Aguascalientes, San Luis Potosí, and Hidalgo are also included in 
this area (Map 1.1). This region has fertile soils and approximately 500,000 ha of irrigated lands (Marañón and Wester, 2000). Of particular interest to the research described here are the states of Querétaro and Guanajuato.

Map 1.1. States of Mexico and region of "El Bajío".

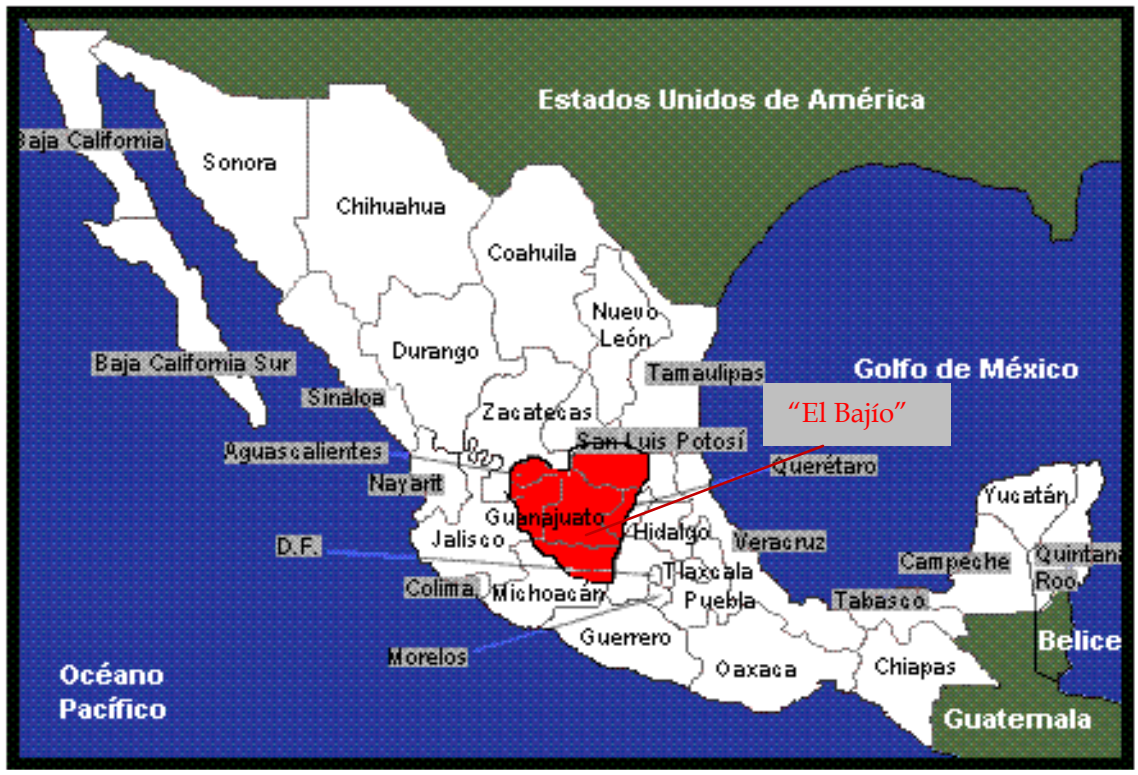

Source: Sistemas de Información Geográfica S.A. 1989. (Spanish acronym for Geographical Information Systems).

\subsection{Water Resources}

The central area is classified as semi-arid with one rainy season during the year that runs approximately from June to August. This area reports annual precipitation of around $800 \mathrm{~mm}$ (Bassols, 1989) with some areas receiving less than $500 \mathrm{~mm}$ to over 1,000 $\mathrm{mm}$ of precipitation per year (CNA, 1999; Levine, 2007). In a climate such as this, it would be very difficult to practice intensive agriculture without irrigation. Map 1.2 shows the distribution of the rainfall (mm) in Mexico from 1971 to 2000. The rainfall in the region El Bajío can be clearly observed on the map. 


\section{Map 1.2. Rainfall in Mexico (1971-2000).}

The area of El Bajío is highlighted in the center of the map and it can be observed that it has a precipitation of $500-750 \mathrm{~mm}$.

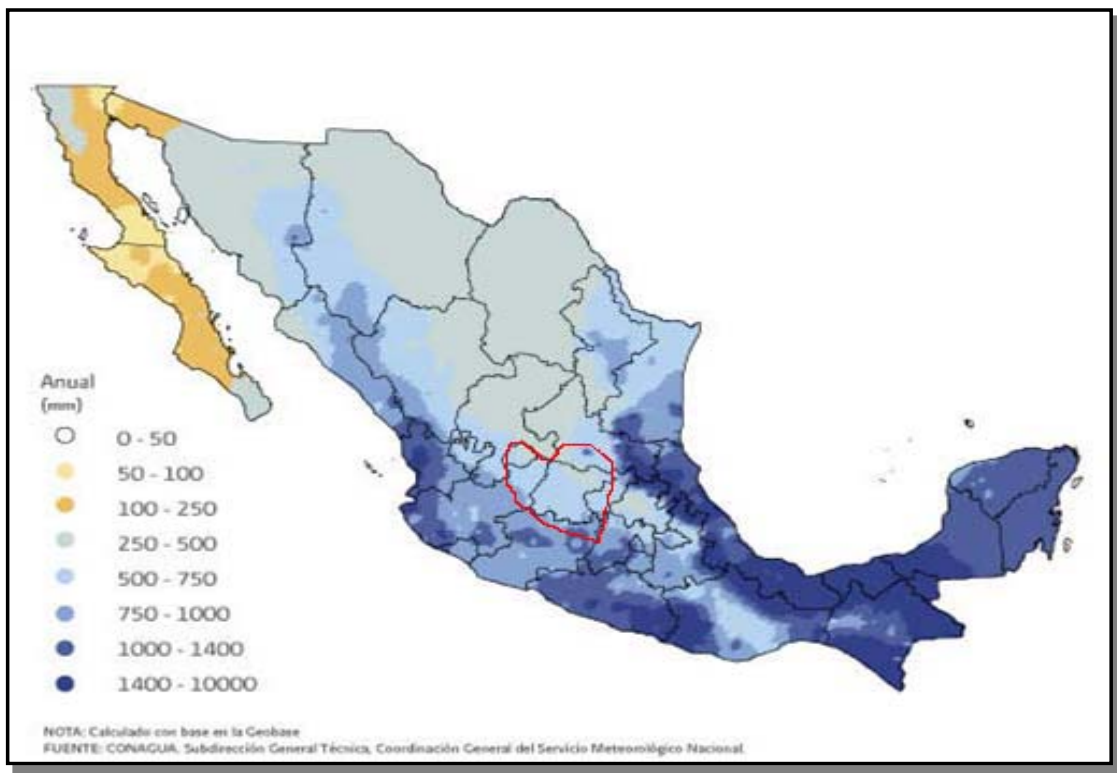

Source: CONAGUA, (Comisión Nacional del Agua) (Spanish acronym for National Commission of Water), 2008.

The main surface waters in the central area of the country include rivers and natural and man-made reservoirs. The most important river in this region is the "Lerma" (Catoira, 2004). This river originates in the "Valley of Toluca" (State of Mexico) at 2600 meters above sea level, and runs for $750 \mathrm{~km}$ toward "Chapala lake" (Jalisco) (Wester, et al. 2001; Catoira, 2004). During a normal pluviometric period this river reaches the Pacific Ocean under the name of "Santiago". These rivers therefore form the Lerma-Chapala-Santiago river basin (Wester, et al. 2001; Catoira, 2004) (Map 1.3). 
Map 1.3. Location of the Lerma-Chapala-Santiago river basin and rivers in the area of central Mexico.

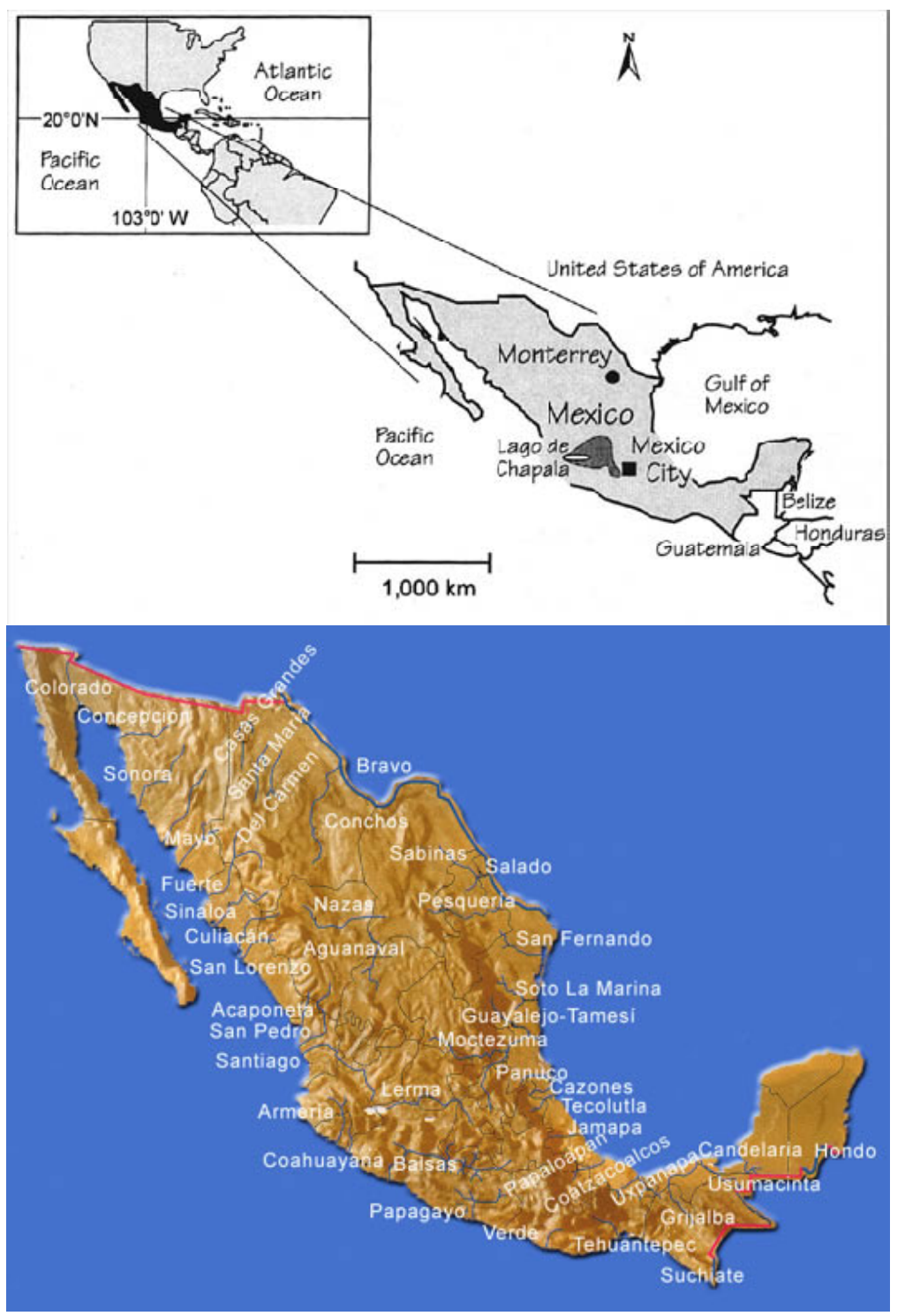

Source: Mestre, 1997. http://www.language.iastate.edu/sp304/2003/mx/informacion.htm

Other rivers located in this area such as the Tigre, Querétaro, Laja, and Turbio are tributaries of the "Lerma". Within the "Lerma-Chapala-Santiago River Basin" the "LermaChapala sub-basin" has a surface of $54,300 \mathrm{Km}^{2}$. This sub-basin is part of five states: Querétaro, Guanajuato, Michoacán, México, and Jalisco (Wester, et al. 2001; Catoira, 2004). The "Lerma- 
Chapala River Basin" is the largest river basin in Mexico, providing water to approximately 700,000 ha of irrigated land, and municipal and industrial water for about 15 million people, in addition to water for "Lake Chapala", the largest lake in the country (Levine, 2007). From a hydrological perspective, $77 \%\left(23,700 \mathrm{Km}^{2}\right)$ of the state of Guanajuato is part of the "LermaChapala River Basin” (CEASG, 1999a; Marañón and Wester, 2000).

In the state of Guanajuato the "Peñuelitas lagoon" is the most important natural water reservoir. Guanajuato has twenty-three man-made reservoirs. The most important water reservoir within this group is "Presa Solís" followed by "Presa Ignacio Allende", "Presa La Purísima", and "Presa La Gavia". The rest of man-made reservoirs ("San Juan de Llanos", "Los Reyes", "Neutla", "El Palote”, “Tres Villas", “El Sauz”, "Balsas”, and “Álvaro Obregón” among others) have smaller water capacity. All of these reservoirs are used for irrigation, except for "El Conejo II", "Santa Efigenia", "Los Castillos", "Ortega", "Chichimequillas", and "La Gavia” which are used to control water levels on rivers in the region. The dam called "Paso de vaqueros" has the purpose of supplying water to the municipality of San Luis de la Paz in the north part of the state. At the moment two new water reservoirs to control the water level of rivers are in the planning stages: "Presa Sepio" and "Mariches" (CEAG, 2004) (Spanish acronym for State Commission of Water of Guanajuato). Man-made reservoirs located in the state of Querétaro are "El Batán", "San Pedro Huimilpan", "Ceja de Bravo", and "Santa Catarina". However, most of them do not have an important water storage capacity. On map 1.4 one can observe the main man-made reservoirs and their storage capacity throughout the country. In addition on this map (1.4) two of the man-made reservoirs already mentioned can be identified. 


\section{Map 1.4. Main man-made reservoirs in Mexico.}

The map shows the main reservoirs for their storage capacity (millions of cubic meters). The reservoirs of Solís (Guanajuato) and Ceja de Bravo (Querétaro) can be seen on the map.

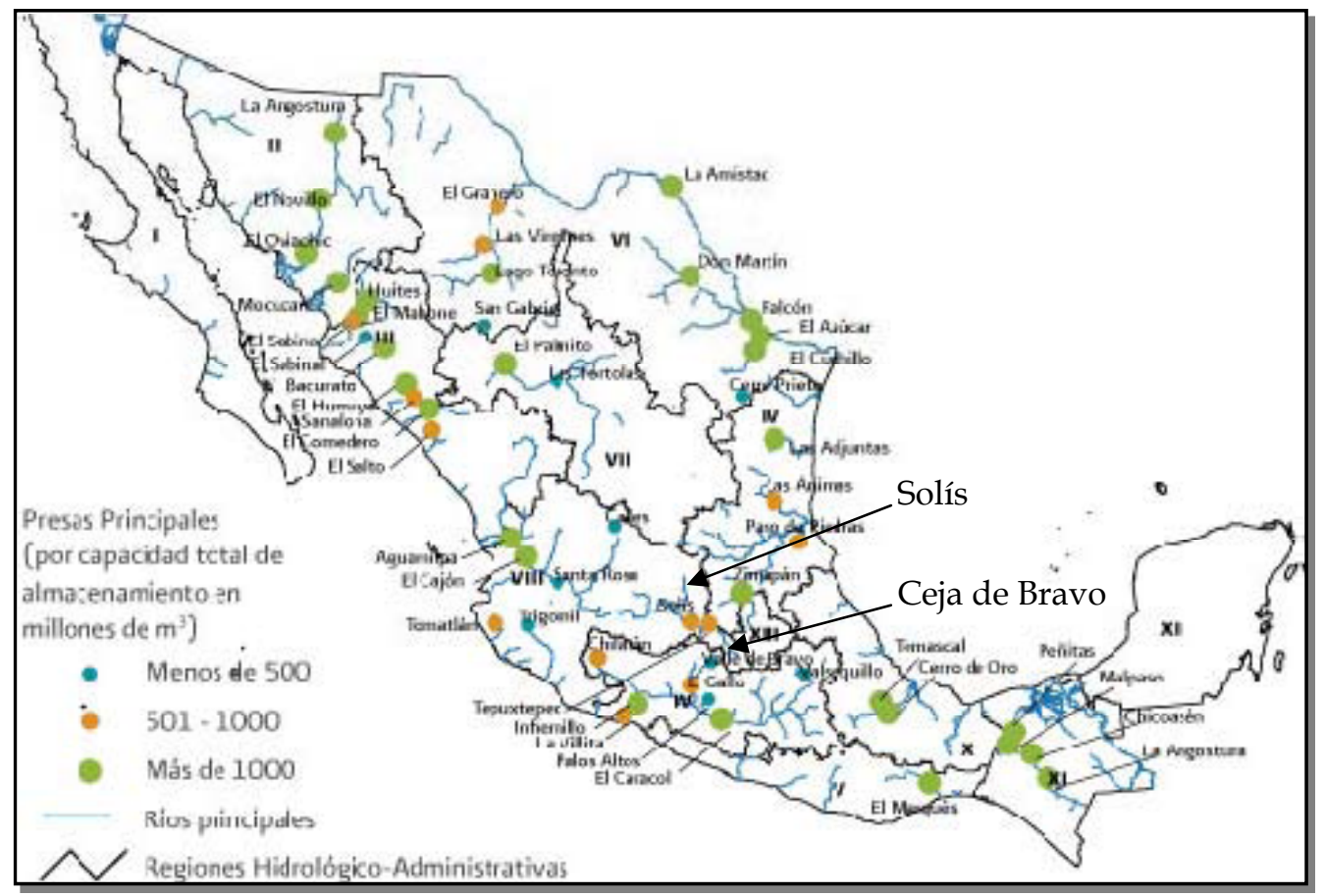

Source: CONAGUA (Comisión Nacional del Agua) (National Commission of Water for its acronyms in Spanish), 2008.

\subsection{Framing the issue}

The state of Guanajuato is a very critical area in Mexico when trying to illustrate the reduction of water levels in natural and man-made reservoirs, including the current and future impacts this may have on agriculture and other human activity. The natural reservoirs of the central area of Mexico were much larger thousands of years ago, but their size has diminished over time due to desertification -which progressed rapidly until the $19^{\text {th }}$ century, continuing until today albeit at a slower pace- (Bassols, 1989). Other human impacts such as the fast growth of several cities, the development of industrial activities, and the increase of irrigated agriculture 
practiced mainly by international companies in this area of Mexico have also contributed to their dramatic decline (Bassols, 1989). Nevertheless, these surface waters supplied enough water for human consumption and agriculture until the $20^{\text {th }}$ century. Although this state occupies just $1.6 \%$ of the national territory of Mexico it has more than $12 \%$ of the total of wells in the country (CEASG, 1998) (Spanish acronym for State Commission of Water Sanitation of Guanajuato) (Marañón and Wester, 2000).

In the case of the Lerma-Chapala River Basin agriculture utilizes approximately $60 \%$ of the surface supply and almost $80 \%$ of the groundwater. Most of the urban supply within the basin is derived from groundwater, as is the industrial supply (Levine, 2007). The main cause in the reduction of the water levels in the reservoirs in this region is the increase of the use of irrigation in agricultural production. Since the 1980's Mexico has slowly switched crop production from grains (corn, wheat, sorgum), beans and alfalfa to vegetables in order to participate in international markets. This new crop production brought economical prosperity to the area, but many new wells had to be drilled to supply this more intensively managed production system with water. Seventy-five to $85 \%$ of the groundwater extracted in the state of Guanajuato in 1990's was used in agriculture. The area in vegetable cultivation using groundwater increased from 10,000 ha to 50,000 ha between 1980 and 1998. During this period of time the value of vegetable exports went from US\$ 10 to US\$170 million (COFOSE) (Spanish acronym for Commission for Exterior Trade Promotion) with the main vegetable products being broccoli, cauliflower, garlic, and asparagus. Right now, the region of "El Bajío" is the main producer of frozen and processed vegetables in Mexico (Bivings and Runsten, 1992; Marañón and Wester, 2000). 
To further illustrate the issues and problems surrounding water use, some of the rivers and dams in the area have been polluted with man-made contaminants in recent decades. The quality of water of some rivers (Querétaro, Turbio, and Morelia) has been diminished due to the untreated water discharges from industries as well as the cities of Querétaro, and Morelia in the state of Querétaro; and León in the state of Guanajuato. The same has happened to the river "Lerma" which is polluted by discharges from the cities of Toluca (state of México) and Salamanca (state of Guanajuato).

In addition, water use is far from optimum. According to the CNA, 2008 (Spanish acronym for Water National Commission) the average use efficiency including surface supply and groundwater is about $60 \%$ in agriculture, $70 \%$ for urban water supply, and $90 \%$ for the industrial water supply (Marañón and Wester, 2000).

To make matters worse this area of Mexico has many expanding cities with significant industrial activity, and growth in agriculture with and without irrigation. Surface water supply can no longer sustain existing agricultural production.

In addition, the annual availability of water per person in this area is low, less than 1,000 $\mathrm{m}^{3}$ compared to the national average of 4,997 $\mathrm{m}^{3}$ (CNA, 1998; de Anda et al., 1998; Marañón and Wester, 2000). Clearly, the issues and problems surrounding water availability and use are many, and some efforts are being made to alleviate pressure on water resources.

The management of superficial water was transferred from the government to users in 1992. In 1997, to manage groundwater, "Aquifer Management Councils" or COTAS (Spanish acronym for Groundwater Technical Committee) were created (Catoira, 2004). These committees are supported by the government of the state where the aquifer is located, and/or by the National Water Commission (CNA Spanish acronym). Each of these councils is in charge of 
one aquifer. The councils are intended to foster agreement of all the users of the aquifer on ways in which usage can be reduced while considering the differing needs of the users (Levine, 2007). Within the "Lerma-Chapala Basin" just the states of Guanajuato and Querétaro have COTAS (Marañón and Wester, 2000).

Furthermore, the country has been divided into 13 water administrative regions taking into account the many water/river basin(s) as the basic unit(s) of administration. These administrative regions are made up of groups of basins respecting the borders of the states or municipalities in order to ease the organization of the social and economic aspects surrounding water use in each region. Most of the state of Guanajuato is in region VIII, and most of the state of Querétaro can be found in region IX. In map 1.5 the aquifers that have been over-exploited in each water administrative region in the country are depicted.

\section{Map 1.5. Depleted aquifers in each water administrative region of Mexico 2007.}

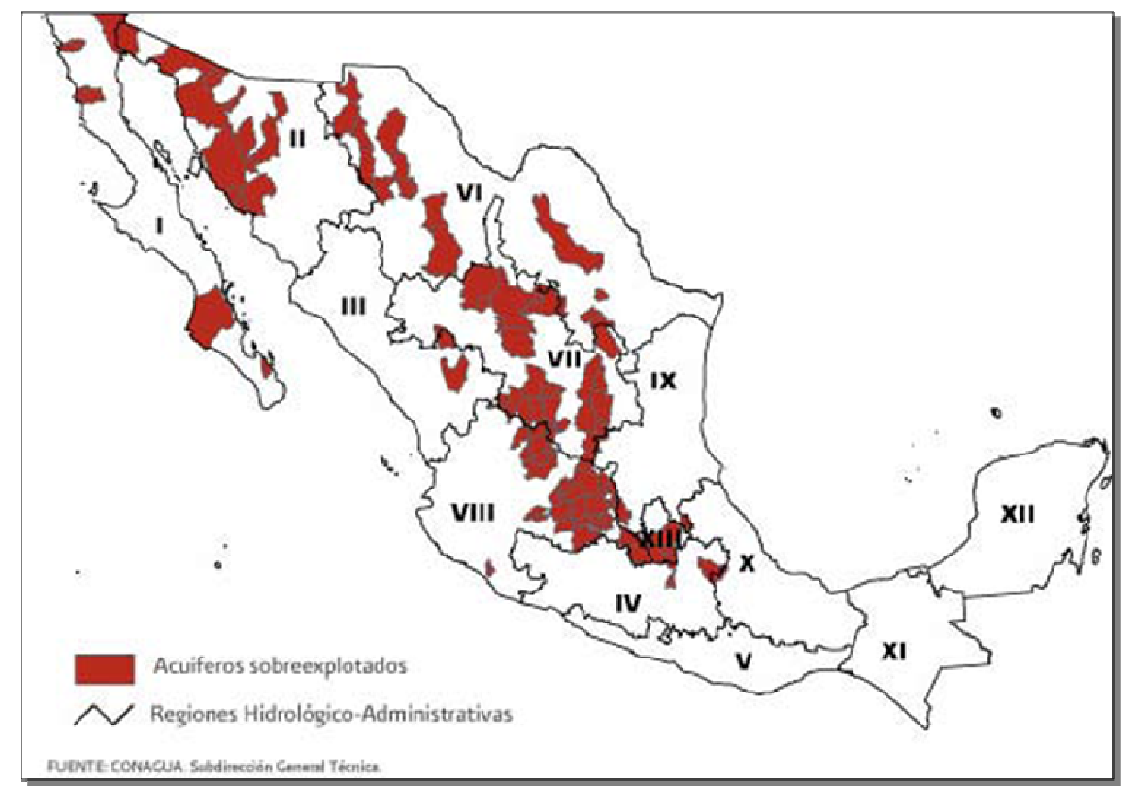

Source: CONAGUA (Comisión Nacional del Agua) (Spanish acronym for National Commission of Water), 2008. 


\subsection{Agriculture, water, and social issues}

Since 1940's the policies related to water use and extraction have favored commercial agriculture. These policies have lead to an agrarian structure with marked differences related to the distribution of supplies, income levels, and productivity (Wionczek, 1982; Maranón and Wester, 2000). Agricultural production in the central region of Mexico is divided into two sectors: big producers, including international companies, and small and mid-size local producers. The large national and international companies own or lease large swaths of land. These companies produce monocultures of vegetables in greenhouses and in open fields and obtain high yields of good quality due to highly automated production, imported knowledge, and frequent irrigation. Most of the water used by these companies comes from their own wells, unlike small producers who do not have their own wells, and have to pay for irrigation water. These advantages allow large companies to obtain high yields and profits since most of their production can be exported or sold at high prices in affluent Mexican cities. Small producers own much smaller pieces of land, do not have their own wells, and depend on the rainy season and/or purchased water for irrigation. Many cannot afford or do not automate agricultural activities for a variety of reasons: limited financial resources, the size of their operation, and also due to the lack of knowledge and/or information about new and "affordable" technologies. These farmers often consume their own produce since most of them are very poor. To solve or minimize these deficiencies small producers in this area of Mexico, and in general all around the country, are organized into associations and/or cooperatives to help them purchase supplies and sell products. However, the quality and yields of crops, and therefore their profits are still much lower than those of big producers. 
At the same time a social phenomenon is taking place among people working in agriculture in Mexico: migration to large Mexican cities and to the United States of America (U. S. A.). For several decades now, people from rural communities have been migrating to the main cities in Mexico or even to the U. S. A. in order to earn higher incomes. During the period of 1995-2000 people who migrated from Mexico to the U. S. A. were mostly from Central, West and Southern Mexico. The main states supplying migrants were Jalisco (10.9\%), Michoacán (10.5\%), Guanajuato (10.4\%), State of Mexico (8.1\%), and Veracruz (5.0\%). These states constituted $44.9 \%$ of the total migrants during this period (INEGI, 2005) (Spanish acronym for National Institute of Statistics, Geography and Informatics).

More and more people are leaving rural communities, and less people want to work in agriculture. Many of them prefer to find another kind of job in a big city or even do the same work in the U. S. A. but with better pay (up to ten times more per hour than what they can earn in Mexico). According to the EREM (Spanish acronym for Survey about international Exmigrants Reintegration in Central-West urban areas of Mexico) the average salary earned in the U. S. A. by male ex-migrants from the states of Jalisco and Zacatecas was approximately US\$1,400 at the end of the 1990s. That means up to five times more than the average salary in the central-west part of Mexico at the same time (Papail, 2003).

López Villar (INEGI, 2006) cited that three quarters of the people migrating to the United States are men. Within the period of 1995-2000, of the 1.5 million people who migrated to the U. S. A. 1.1 million were men (75.5\%) and approximately 368,000 were women (24.5\%) (INEGI, 2005). The migrant population going to the United States is young: 9 of 10 Mexican migrants are between 15 and 49 years old and fall into the economically active worker category. This 
phenomenon causes important changes in the population structure in Mexican communities with a number of drastic economical and social consequences as a result.

According to Elena Zúñiga, director of CONAPO (Spanish acronym for National Population Council) (Televisa News interview, 2005), in many rural communities only old people and women with their children are left, resulting in a disintegrated family and community structure. In these communities women take on the responsibility of providing for their families as well as their community (Horbath, 2004). Women do the work that the men in their family used to do before they migrated. Mexico City and the states of Guanajuato, and Michoacán have the highest female index (number of women per $100 \mathrm{men}$ ) in the country: 109.3, 108.8, and 108.6 respectively, which denotes very high number of women in the population. This population structure is highly correlated to the migratory trends in those states (INEGI, 2005). Migration is a very old tradition in some Mexican communities, small towns and even cities. When people do not find good job opportunities in their community or even in the state, and know that some of their relatives who migrated find themselves in a better economic situation, the only viable option for most of young men is to migrate. The result is that once the children of migrants are old enough, they also migrate. "...My son did the same than his father, his uncles and most of the men in Ixmiquilpan (state of Hidalgo)...he was studying high school and he realized that there was not enough money at home..." declared a woman in an interview (Televisa news, 2005). According to the results of the ENADID (Spanish acronym for National Poll of Demographic Tendency) poll of 1997, 4.8\% of the Mexican population older than 14 years of age (without taking into account the border states) had worked or searched for a job in the U. S. A. (8.7\% of men and $1.2 \%$ of women) (Papail, 2003). 
However, migrants who leave for the U. S. A. are not always the poorest people. Migrants need a considerable amount of money to meet expenses during the travel to the border; usually they need to pay someone to help them to cross it; and of course they need money while they search for a job. The decision of someone to migrate originates from evaluating the capacity of the local market to offer effective opportunities to retain him/her in that place. But this evaluation does not only depend on the situation of a community, it is also based on the regional context (Horbath, 2004).

The mechanisms that can stop migration are the generation of local jobs, not only the number of them, but also their quality. Right now, Mexico has many limitations to the creation of new job opportunities, limitations not only generated by the government, but also private companies. Therefore, any feasible solution has to involve the initiation or continuation of a job in the migrant's community independent of government or business help. In other words, selfemployment or local community based businesses should be the driving force in job creation. Some surveys done in several Mexican states of the central-west region show that the impact of the migrant's money on the creation of small businesses is very important. Most of these businesses were created in the following areas: commerce $(32.3 \%)$, agriculture $(23.7 \%)$, and services (14.9\%). Almost half of them were created in the 1990's (Papail, 2003).

As mentioned previously, small-scale producers are usually grouped into associations to facilitate their work and arrangements related to the production and sales of their products. So, potential migrants could organize in the same way to start a well-designed and organized project. In addition, since migrant candidates or seasonal migrants have to save money to go or go back to the U. S. A., they could, if they had a feasible job opportunity in their area, invest their savings and time on planning and starting a business instead of migrating. In this context it is interesting 
to note that the international ex-migrants belong in much higher numbers to the group of selfemployed than those who never migrated (Papail, 2003). Recent figures on migrants to the U. S. A. show that close to $22 \%$ of the male migrants, and $11 \%$ of the females had a well-defined project to initiate once they come back to Mexico. Among these groups, a third of the men (34.1\%), and a fourth $(27.5 \%)$ of the women left with the idea to save money to start a business once they come back to Mexico (Papail, 2003). However, it is very probable based on past and current trends that these jobs do not fill the needs of the community, and as a consequence do not contribute to the reduction of migration from those areas. In order to change the way people (including the seasonal migrants and potential migrants) in central Mexico spend their savings especially in areas with high migratory populations it is necessary that they receive advice, knowledge, and support. It is necessary people receive expert advice, but also economic and/or labor support to help them initiate a new activity that will stabilize the community.

\subsection{Opportunities}

Upon analyzing the actual agricultural situation in Mexico and the sociological characteristics of the area of interest (central Mexico) as described above, a project was initiated by the Universidad Autónoma de Querétaro and West Virginia University funded by Higher Education for Development (HED), a branch of United States Agency for International Development (USAID), to increase productivity and living standards of small-scale farmers. The main participants in this project were West Virginia University, the USAID, the University of Querétaro, the Council for Science and Technology of Querétaro and several small to mid-size vegetable producers in Mexico. The name of the project was "WVU-Querétaro Partnership for Greenhouse Technology for Semi-arid Areas of Mexico". The main objective of the project was 
to increase productivity and living standards of small-scale farmers by the development, implementation and transfer of greenhouse technology (engineering and horticulture) appropriate for the rural semiarid regions of the states of Querétaro and Guanajuato. As the sponsor of this project, the USAID funded it to teach and advice Mexican people in both countries (producers in Mexico and Mexican students in U. S. A.) on greenhouse technology, thereby developing human capital. Professors from both universities (WVU and Autónoma de Querétaro) were in charge of outreach to producers and communities and organized workshops in Querétaro for small-scale producers and students on starting or continuing to work with greenhouse technology. Also, these experts helped those small-scale producers to build greenhouses mainly in the state of Querétaro. In addition, within this project graduate students from Mexico were able to work at WVU in research projects. The objective of this exchange of students was to research greenhouse technology in the U. S. A. and to apply this knowledge in Mexico. The research described in this document has as its main goal to improve greenhouse crop production for people in central Mexico.

Greenhouse technology has enormous potential to overcome some of the previously described hurdles to sustainable agricultural production and therefore solve some of the social problems tied to a lack of profitable agriculture. When taking into account the overall agricultural and social characteristics of central Mexico, such as its limited water availability, male emigration, small land holdings, hydroponic greenhouse production has been proposed as a more suitable, sustainable, and profitable production system than the current field and subsistence farming employed in the region. Hydroponics is a technology for growing plants in nutrient solutions (water containing fertilizers) with or without the use of medium (sand, gravel, 
vermiculite, rock wool, perlite, peat moss, coir, or sawdust) to provide mechanical support (Jensen, 1997).

Hydroponics has many advantages over in-ground production including reduced root diseases (Reed, 1996; Rodríguez et al., 2006) more efficient use of fertilizers and water (Jensen, 1997; Schwarz, 1995; Rodríguez et al., 2006); higher plant density (Rodriguez et al., 2006), and cultivation of crops where normal field production would not be possible (Jensen, 1999). Hydroponics has been used mainly to produce commercial greenhouse vegetable and ornamental crops ultimately reducing production costs and economic losses; and increasing yields per unit area. Therefore this practice can lead to considerably higher profits. Thus, all of these benefits make hydroponics a perfect companion to greenhouse production.

Greenhouse production allows better control of the environment in which plants are grown. Since the greenhouse is a closed structure, environmental conditions such as temperature and humidity can be controlled by opening and closing greenhouse vents, often accomplished by an automated procedure. In addition, the entrance of pathogens (insects, fungi, bacteria, nematodes) in the greenhouse can be better controlled than in the open field. Usually in a greenhouse plants are grown in pots rather than in the ground, limiting the necessity for heavy machinery or hard physical work to prepare the soil. Therefore greenhouse technology is well suited to a female, elder, or even juvenile (type of population in some communities in the area as mentioned before) labor force. On the other hand, hydroponics allows for production on land with limited water resources and soil of lower quality while conventional agriculture is limited by these factors. These are exactly the situations that some smaller growers deal with on a regular basis. In short, hydroponic greenhouse production has many of the characteristics that are needed when trying to formulate an agricultural production system suitable for small 
communities in central Mexico. The potential benefits are many and include higher yields and quality, diversification of the crop mix all hopefully leading to higher incomes. In the states of Querétaro and especially Guanajuato ground water and aquifers are being depleted considerably since the agricultural and industrial activity has seen sustained growth for some years now. Thus, the better use of water that hydroponics allows (Jensen, 1997; Schwarz, 1995; Cestoni et al., 2002; Irizarry, 2006) is one of the main reasons this technique should be adopted for the production of a variety of crops in the area of interest, and therefore also in this project.

An important aspect to consider in hydroponics is the medium used. Hydroponics requires a sterile medium which is generally an inert solid material with two main functions: anchoring the roots in a well-aerated environment while protecting them from excessive light, and holding water and nutrients needed for plant growth and development. The term medium or substrate applies to all solid material placed in a container or bag, that either in a pure form or mixed, allows the development of the root system, and the crop growth (Abad and Noguera, 1998; Muñoz and Castellanos, 2003). Hydroponic systems replace soil, while still providing the function of soils: nutrient and water retention, and plant support (Nelson, 2003). Therefore, any material that gives required support to the plant and aeration to the roots, while acting as a reservoir for water and nutrients can be used as a suitable growth medium. Another good reason to replace soil with a sterile medium is the reduced chemical use, especially methyl bromide, as a soil fumigant (Cantliffe and Vansickle, 2001; Rodríguez et. al., 2006).

Many materials can be used as a soil-less medium for hydroponics production. Sand and gravel have been studied extensively and are good candidates because of their physical characteristics, availability, and cheap cost. However, these materials are not always readily available where crop production takes place. After shipping and disposal costs are added (both 
materials are very heavy) their final price often makes them poor candidates as hydroponic media.

In the United States, rock wool and perlite are the most common soil-less media used in hydroponics because of their physical characteristics, availability, relatively cheap cost, and light weight (Brentlinger, 1999; Schwarz, 1995; Rodríguez et. al., 2006). However, the use of rockwool has decreased as a result of difficulty of disposal (Bohme, 1995; Schwarz, 1995; Rodríguez et. al., 2006). Therefore, medium characteristics, disposal, and cost are the main considerations when choosing a material as a soil-less medium in a hydroponics plant production while at the same time safeguarding the high yields and economic returns hydroponics can provide. With these limitations in mind it is important that new materials are tested as a soil-less media, especially where commonly used media are too expensive or environmentally questionable.

Red lava rock or "Tezontle" (name in one of the Mexican native languages) has the potential as a medium wherever the material is available. It is an igneous porous rock ranging in color from golden, red to black that has been used in the U. S. A. in the construction and landscaping industries. However, it has been used extensively in some regions of Mexico as a hydroponic medium for some years (Muñoz and Castellanos, 2003). The reason for its use in Mexico is its availability, cheap cost, and easy disposal. A belt of at least twenty inactive volcanoes crosses Mexico horizontally in the center of the country. These volcanoes are located in twelve states from the "Revillagigedo islands" in the Pacific Ocean to the state of Veracruz bordering the Gulf of Mexico. These inactive volcanoes are the principal source of Tezontle, the main reason the material is well known in the region and used for many purposes other than 
hydroponics -some of the Mexican Pyramids were made with Tezontle -. The map 1.6 shows the location of these volcanoes.

\section{Map 1.6. Location of the volcanoes crossing horizontally Central Mexico.}

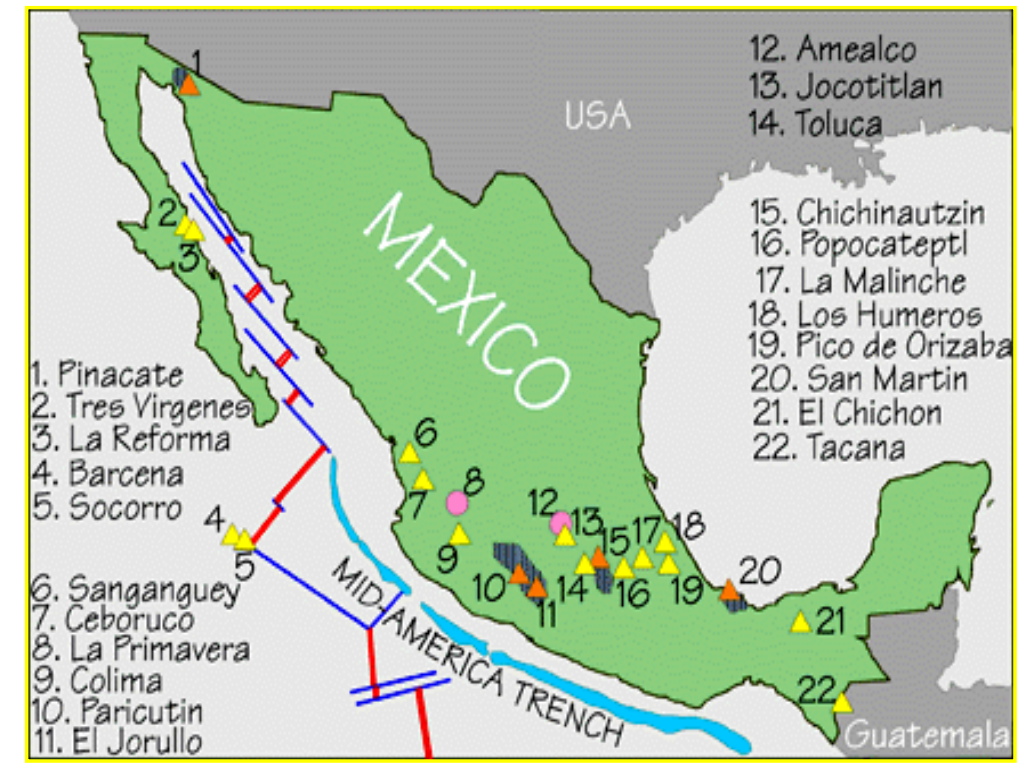

In the last couple of decades Tezontle was found to be a cheap substitute for rock wool. It is light in weight, shows high levels of aeration and can retain water effectively, depending on the particle size. Gizas and Savvas (2007) mention that both aeration and water availability in the rizhosphere strongly depend on the physical properties of the substrates, which in turn are conditioned by the shape and size of their constituent particles (Da Silva, 1993; Hanan, 1981; Raviv, 2002). Tezontle can be easily crushed to the desired size, an important characteristic for any hydroponic medium as one looks to optimize aeration and water holding capacity for a specific crop.

Nevertheless, in Mexico and even in other countries limited experience has been gained with Tezontle as a hydroponic medium for crops outside of tomato, pepper, melon, and tomatillo. 
Limited published materials are available on crops routinely grown in this material, with even less research being carried out and published on minor crops. People growing vegetables in red lava rock or Tezontle have obtained reasonably good yields, and moderate quality when compared to international standards. However, in the same area and throughout Mexico these vegetables are also produced in the field, and in greenhouses using soil or peat moss. Competition not only with these conventionally grown vegetables but also imported vegetables of high quality suggests that small producers should diversify their production in order to alleviate direct competition with large growers to remain in business and stay profitable.

Hydroponic greenhouse technology also allows growing plants other than vegetables. In this region for example, cut flowers and herbs are barely cultivated, however they are in high demand. Especially cut flowers have a high commercial value in the markets of this region, and throughout all of Mexico. Furthermore, the climate of the area (natural light and temperature) allows for the production of many species of cut flowers year-around in a greenhouse with practically no automation, which implies a lower infrastructure investment for the producer. The commercial value for herbs is not as high as for cut flowers. Nevertheless, their demand is continuous due to the traditional Mexican cuisine that includes many of them. So, even if income for herbs would not be as high as cut flowers it could provide for a very steady and reliable income especially in big cities where women usually do not have kitchen gardens. Restaurants, grocery stores, and markets could also be continuous buyers of herbs. In conclusion, a producer could easily grow herbs and cut flowers in a "cheap construction" greenhouse to diversify production beyond traditional greenhouse vegetable production of tomatoes, peppers, and melons. 


\subsection{Long Term Goal of this research}

The goal of the proposed research was to develop production protocols to diversify hydroponic crop production in central México. High value crops that could be produced with a low water input in a Tezontle-based hydroponic system would benefit local central Mexican producers and would allow them to diversify their crop production.

In order to achieve this goal, a number of herbs and one ornamental species with high commercial value were grown in Tezontle under low, medium, and high watering regimens. The specific research objectives were focused on water use efficiency and the development of production protocols for alternative crops.

\subsubsection{Objectives}

- Determine the feasibility of growing ornamental and herb crops in Tezontle.

- Determine the water use of ornamental and herb crops grown in a Tezontle hydroponic system. 


\section{Materials and Methods}

\subsection{General}

Research was conducted at the West Virginia University Plant and Soil Sciences Greenhouses located at the Evansdale campus in the city of Morgantown, WV (U. S. A.). Three separate experiments called Experiment 1, Experiment 2, and Experiment 3, were carried out in two rooms (2B and 2C) of the greenhouse. Each of these experiments was conducted once during period spanning 2007 and 2008. Experiment 1 and Experiment 2 were located in room 2C. Experiment 1 was carried out first, followed by experiment 2 in 2007 and 2008. Experiment 3 was carried in room 2B in 2008. All experiments were designed to study a number of crops and their water use characteristics and drought tolerance. Both rooms were maintained at $20^{\circ} \mathrm{C}$, weather permitting, and a relative humidity of 60 to $80 \%$ with natural light conditions.

\subsection{Plant Material}

Four species of herbs and one ornamental crop were used to develop production protocols for high value horticultural crops. The crops we used throughout the study period were selected according to ease of production and marketing, and the climatic characteristics of central Mexico (light, temperature). Among the crops chosen were high and low water requiring plants to provide a range of water requirements to study. Plants considered high or low water requiring plants are species of plants that require high or low amounts of water to perform the physiological activities necessary to complete their life cycle (Muñoz and Castellanos, 2003) or,

in the case of our research until they were harvested to be sold. The following are the species of plants used in the three experiments of our research: 
- Mint (Mentha x piperita- Peppermint) (High water requirement)

- Basil (Ocimum basilicum) (var. Nufar ) (High water requirement)

- Thyme (Thymus vulgaris) (English Thyme) (Low water requirement)

- Rosemary (Rosmarinus officinalis) (var. Arp) (Low water requirement)

- Sunflower (Helianthus annuus) (var. Music box) (High water requirement)

Plugs and seeds of these plant species were purchased from a greenhouse supply company (Grimes) located in Concord, Ohio.

Although one of the objectives of this research was to use as little water as possible to cultivate a highly marketable product, species with a large water requirement were included because of their high commercial value.

All plants used have similar light requirements. Although some of the plants studied in this research (thyme and rosemary) are low water requiring plants they need to be watered regularly (depending on the weather) in order to grow and develop properly. This fact put all these plants into a group of plants with a "similar" range of water requirements. Therefore, the designation of low versus high water requiring should be viewed as a relative statement that only takes into consideration the plants we grew in our experiments. The plants can be cultivated in a place with the same water availability, although each one will have a different response depending on its own water requirement.

Rosemary, thyme, and mint arrived to the WVU greenhouse in plug trays containing a mix of peat moss and perlite as a growing media. Upon receipt plugs were put in one of the rooms of the greenhouse and watered using a 20-10-20 fertilizer at approximately $150 \mathrm{ppm} \mathrm{N}$ until research started and the plants were irrigated with Hoagland's solution (Nelson, 2003). At 
time of arrival the plants were very young and did not have a well-developed root system. We decided that to assure plant survival after transplanting into red lava rock we would grow the plugs in the same media until they adapted to the new management and environment in the WVU greenhouse and matured to ensure limited transplant shock. Plants of mint, rosemary and thyme used in Experiments 2 and 3 were obtained from cuttings of plants in Experiment 1 at the conclusion of this experiment.

Basil seeds were sown before starting each experiment (1-3) to establish a plant lasting until the end of the experiment. On the other hand, sunflowers were sown several times throughout each experiment to replace the plants after the cut flowers were harvested. Basil plants were transplanted into the red lava rock approximately two months after seeding or when plants had at least six true leaves. Sunflowers were transplanted from plug trays when the third set of true leaves was developing, approximately 8 weeks from seeding.

When all plants had a well-developed root system transplanting was initiated. Since plants were supposed to be grown in a hydroponic system using red lava rock (Tezontle) as a growing medium, roots had to be completely cleaned of the peat moss and perlite mix where they were previously growing. To achieve this, roots were completely rinsed using tap water. Roots were rinsed in different buckets containing water to take the peat moss and perlite mix completely out of the roots. It was decided to rinse the roots in containers with water instead under steady flow of water to avoid damaging the root system. Rinsing was alternated with transplanting to avoid the drying out of the roots from being exposed to the air for a long period of time. Thus, a lot of approximately ten to twenty plants (depending of the amount of soil retained by the roots and the number of them) was rinsed and transplanted every hour. After being transplanted plants were irrigated with the same fertilizer solution (20-10-20) that was 
used to establish the plants for approximately two weeks or until they were adapted to the new medium.

\subsection{Growing medium}

The medium used in the experiments was red lava rock or "Tezontle" (from its name in Náhuatl, one of the Mexican native languages, Tetzontli) (tetl, stone and tzontli, hair). This material was purchased from a local supplier in Morgantown, WV (Alcon, Buckhannon, WV). The red lava rock originally came from Santa Fe New Mexico where it is mined.

Tezontle can be an excellent substrate material because of the good aeration associated with its use. Tezontle can be used as a single size or a combination of particle sizes according to the amount of water that the medium needs to hold to maintain the desired moisture for the root system and the aeration requirements of the crops to be grown. Since the main objective in all experiments of this research was to determine the least amount of water possible to grow each species of plants, a medium was needed to be designed that held as much water as possible, while maintaining adequate aeration for the crops grown in the material. Therefore we used a mixture of different sizes of particle that took into account the range of aeration requirements of each of the plants used in the research.

The Tezontle that was available in Morgantown was large in size $\left(>5 \mathrm{~cm}^{3}\right)$, and was not useful as hydroponic medium because it did not retain any water, nor could it provide adequate anchorage for the plants. In order to obtain particles in a range useful for hydroponic production the material had to be crushed using a roller-vibrator machine (Smith Mauldin Manufacturer). First, a layer of Tezontle was spread on a concrete floor. Then, the vibrator was driven back and forth on the Tezontle several times. Since Tezontle is a hard rocky material it was necessary to 
drive the machine over the Tezontle for approximately one hour for each batch to be crushed. After the Tezontle was crushed, it was removed from the concrete floor, and sieved (Figure 2.1). research.

Figure 2.1. Process of crushing the red lava rock to make the medium used in this

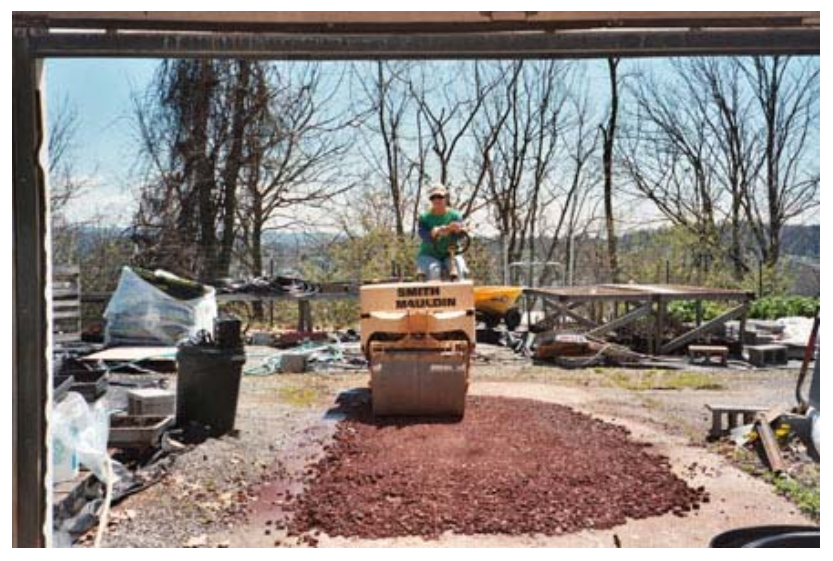

Particles bigger than $1 \mathrm{~cm}^{3}$ were rejected, and kept separately to get re-crushed later. At this point a mix of particles smaller than $1 \mathrm{~cm}^{3}$ including dust was ready to be used as a hydroponic medium. This medium was analyzed to determine some of its physical properties (Table 2.1). The same mix of particles, but excluding dust was also analyzed as a second choice of medium to be used in this research. Furthermore, a sample of the medium containing all particles sizes smaller than $1 \mathrm{~cm}^{3}$ including dust was sieved to obtain the different particle sizes that made up the mix. Each of these particle sizes was also analyzed for its physical properties (Table 2.1). During this analysis it was observed that dust particles upon drying showed salt deposits on top of the samples. Hence, dust particles generated during crushing were discarded to avoid elevated levels of salts in the final substrate. In order to achieve this, the Tezontle (particles smaller than $1 \mathrm{~cm}^{3}$ ) was passed through a mesh after the crushing process and subsequently rinsed to eliminate the dust and associated salts. Once the Tezontle was rinsed, it 
was spread on a plastic film on the ground in order to dry the material before use. This method was faster and easier than sifting all the material through different mesh sizes obtaining different particle sizes, and reconstituting a desired medium from those different particle sizes considering that only one person was assigned to this task. This method was also considered the safest since Tezontle dust contains small but sharp particles, which may cause injury to the lungs.

Given that the commonly used substrates are either natural or industrially processed materials originating from natural resources, the size of their particles vary within a wide range. The particle size distribution of a particular substrate is therefore commonly described as a fractional distribution of size ranges (Wallach et.al., 1992; Gizas et.al., 2007). We therefore used the above described protocol to obtain a medium that consisted of a mix of all particle sizes excluding dust and large particles $\left(>1 \mathrm{~cm}^{3}\right)$ thoroughly mixed it to uniformity.

In addition, this medium was also chosen based on the percent aeration obtained from the preliminary analysis (Table 2.1). The aeration of this medium at $35.26 \%$ was higher than an ideal peat-based greenhouse medium (10-20\%). However, removing the dust from the original medium with an aeration of $13.57 \%$ resulted in a much lower initial salt content (personal observation) as cited before. Furthermore, several of the crops chosen for this research, grow much better in well-aerated medium. Higher levels of aeration are also more desirable in hydroponic systems than peat-based growing medium (Nelson, 2003). 


\section{Table 2.1. Preliminary analysis of Tezontle}

Determination of Container capacity (CC), Bulk density at $\mathrm{CC}(\mathrm{gr} / \mathrm{L})$, and \% of aeration of different particle sizes of Tezontle; and for the two possible media (with and without dust) to be used in the experiments.

\begin{tabular}{|c||c|c|c||}
\hline \multicolumn{4}{|c|}{ Analysis of Tezontle } \\
\hline \hline Screen size & $\begin{array}{c}\text { Bulk density } \\
\text { at CC (gr/L) }\end{array}$ & $\begin{array}{c}\text { Container } \\
\text { capacity }\end{array}$ & \% aeration \\
\hline \hline 20 (dust) & 1504.55 & 0.45 & 6.76 \\
\hline \hline 10 & 1079.20 & 0.30 & 23.36 \\
\hline 6 & 904.10 & 0.20 & 35.51 \\
\hline \hline 4 & 802.25 & 0.20 & 40.84 \\
\hline \hline $23 / 2$ & 819.65 & 0.20 & 44.67 \\
\hline \hline Biggest (>1cm $\left.{ }^{3}\right)$ & 757.90 & 0.14 & 33.68 \\
\hline \hline Media: & & & \\
\hline \hline With dust & 985.80 & 0.16 & 13.57 \\
\hline Without dust & 848.50 & 0.11 & 35.26 \\
\hline \hline
\end{tabular}

\subsection{Containers}

All crops were grown in standard 6" $(15 \mathrm{~cm})$ pots in each of the three experiments.

\subsection{Hydroponic solution}

The hydroponic solution used for the three experiments was a modified Hoagland's AllNitrate Nutrient Solution (Nelson, 2003). Ten different stock solutions (10X) were used to make a fresh fertilizer solution for each watering. The stock solutions and their concentration to make the final modified Hoagland's solution used in this research appear in the following table (Table 2.2). 
Table 2.2. Chemical composition and concentration of the modified Hoagland's All - Nitrate Nutrient Solution.

\begin{tabular}{|c||c||}
\hline \multicolumn{1}{|c||}{ Chemical } & Final concentration \\
\hline \hline Potassium dihydrogen phosphate & $136 \mathrm{mg} / \mathrm{L}$ \\
\hline \hline Potassium nitrate & $505 \mathrm{mg} / \mathrm{L}$ \\
\hline \hline Calcium nitrate & $1,180 \mathrm{mg} / \mathrm{L}$ \\
\hline Magnesium sulfate & $492 \mathrm{mg} / \mathrm{L}$ \\
\hline Iron chelate & $5 \mathrm{mg} / \mathrm{L}$ \\
\hline Manganous chloride & $1.81 \mathrm{mg} / \mathrm{L}$ \\
\hline Boric acid & $2.86 \mathrm{mg} / \mathrm{L}$ \\
\hline Zinc sulfate & $0.022 \mathrm{mg} / \mathrm{L}$ \\
\hline Copper sulfate & $0.008 \mathrm{mg} / \mathrm{L}$ \\
\hline \hline Molybdic acid & $0.002 \mathrm{mg} / \mathrm{L}$ \\
\hline \hline
\end{tabular}

All these chemicals were granular compounds that were weighed and dissolved in tap water to make each of the stock solutions, except for the three last chemical solutions in the table. Stock solutions containing $2200 \mathrm{mg} / \mathrm{L}$ of Zinc sulfate, $800 \mathrm{mg} / \mathrm{L}$ of Copper sulfate, and $200 \mathrm{mg} / \mathrm{L}$ of Molybdic acid were made and diluted to a final concentration $0.022 \mathrm{mg} / \mathrm{L}, 0.008$ $\mathrm{mg} / \mathrm{L}$, and $0.002 \mathrm{mg} / \mathrm{L}$ respectively. To make 1 liter of Hoagland's solution $10 \mathrm{ml}$ of each of the ten stock solutions were mixed with $900 \mathrm{ml}$ of water. Buckets each with approximately 18 liters of Hoagland's solution were prepared for each watering.

In addition to nutrient concentration plant growth can be affected by $\mathrm{pH}$. Even though there is a broad range of optimal $\mathrm{pH}, 5.8$ is considered best for optimal nutrient availability in hydroponics (Bugbee, 2003; Kane et al., 2006). Islam et al. (1980) reported that a pH range of 
5.5 to 6.5 is optimal for the availability of nutrients from most nutrient solutions for most species. The availability of Magnesium (Mg), Calcium (Ca), Potassium (K), and Phosphorus (P) is slightly decreased at higher $\mathrm{pH}$, while the availability of Manganese $(\mathrm{Mn})$, Cupper $(\mathrm{Cu})$, Zinc (Zn), and especially Iron (Fe) is significantly reduced (Bugbee, 2003; Kane et.al., 2006). The nutrient solution in this research was therefore maintained in a pH range of 5.8 to 6.5 . To achieve this, the $\mathrm{pH}$ was measured immediately after making the nutrient solution using a $\mathrm{pH}$ meter (Ultrameter 6P, Myron L Company). Most of the time the $\mathrm{pH}$ of the solution was 6.5 or above. The $\mathrm{pH}$ was reduced to the range used (5.8 to 6.5) using a $1 \mathrm{~N}$ Sulfuric acid $\left(\mathrm{H}_{2} \mathrm{SO}_{4}\right)$ solution immediately before use of the solution.

\subsection{Experiment 1: Watering with $80,100 \& 120 \%$ of container capacity}

This experiment was conducted in room 2C of the WVU greenhouse from September 16 to December 15, 2007. The experiment consisted of the five plant species, cited above, grown under three different watering regimes: $80 \%, 100 \%$, and $120 \%$ of container capacity. Container capacity is defined as the maximum amount of water that the root substrate in a container can hold against gravity (Nelson, 2003). This measurement is usually taken using a completely dry medium. However, before starting the experiment an already established plant growing in Tezontle was present in each pot. The medium could therefore not be completely dry to estimate the amount of water necessary to reach container capacity. Container capacity could not be estimated using a pot with only dry Tezontle either, because the amount of medium in a pot (and consequently the water retained by it) depends of the volume of the root system of the plant. We therefore decided that the container capacity would be estimated by measuring the water that the medium could retain in one pot of each of the five species in the experiment. We repeated these 
measurements over a period of several days to obtain an average container capacity for all plants. Since the water requirements of the different crops were similar (at least at the beginning of the experiment) an average of the milliliters that each pot of each species retained was calculated. The amount of water at container capacity was based on the water the medium held without or with minimal leaching. The average amount of water (milliliters) the medium could hold at container capacity was calculated at $170 \mathrm{ml}$. Therefore, this amount of water was assigned to the $100 \%$ water treatment. The amount of water to be applied in the other two treatments, $80 \%$ and $120 \%$, was calculated based on the experimentally determined $100 \%$ container capacity. Thus, the $80 \%$ treatment received $136 \mathrm{ml}$, and the $120 \%$ treatment received $204 \mathrm{ml}$ at every watering throughout the experiment. For practical reasons the plants were watered with the average container capacity amount of water for all plant species instead using different watering amounts for each crop. The main reason for this approach was the fact that measuring and adjusting 3 levels of watering for five different crops would be very difficult and complex while trying to properly maintain the plants in the experiment.

Irrigation was applied when the $80 \%$ treatment in the least water requiring crop needed water. The initial idea behind this set up was that even if this caused drought stress in the other plant species, those species would potentially do better in treatments with higher water applications and therefore give us a measure of water requirements of each crop. Many of the most common herbs will tolerate low water levels, even if they will not thrive (Tucker and Debaggio, 2000). The watering schedule was determined empirically and adjusted according to weather conditions. In practical terms this meant that all plants in the experiment were irrigated, when thyme in the $80 \%$ treatment needed to be watered. All applications of hydroponic solution were recorded. Each application of modified Hoagland's solution was a measured application of 
fertilizer for each of the treatments and plant species. In addition, the amount of fertilizer solution leaching from the pots was measured in order to estimate evapotranspiration and help determine watering frequency. This practice also allowed better timing of the next watering. These measurements (together with the changes in fresh weight of the plants) could allow for an estimate of the water use efficiency throughout the development of the plants in the different treatments $(80 \%, 100 \%$, and $120 \%)$.

Every two weeks all plants in the experiment were flushed using plain water. This practice was initiated to avoid the accumulation of excessive salts in the medium, especially in treatments receiving low amounts of water at each watering. The amount of plain water used for this practice for all plants in the experiment was double the amount (approx. $400 \mathrm{ml}$ ) of the fertilizer solution in the treatment receiving most water $(120 \%$ treatment receiving $200 \mathrm{ml})$.

\subsubsection{Experimental design}

Experiment 1 was a randomized complete block design with three tables or blocks. Each table was divided in three split-plots, and the water treatments $(80 \%, 100 \%$ and $120 \%)$ assigned at random to each split-plot (Figure 2.2). Plant species (basil, mint, sunflowers, rosemary and thyme) were randomly assigned within each split-plot. Four pots of each plant species could be found in each split-plot. 


\section{Figure 2.2. Experiment 1.}

Three blocks/tables containing each one the three different watering treatments $(80 \%$, $100 \% \& 120 \%)$. Within each of the split-plots or watering treatment, 20 plants (5 plant species with 4 replications each) were randomly assigned. $\mathrm{S}=$ sunflower, $\mathrm{T}=$ Thyme, $\mathrm{R}=$ Rosemary, $\mathrm{B}=$ Basil and $\mathrm{M}=$ Mint.

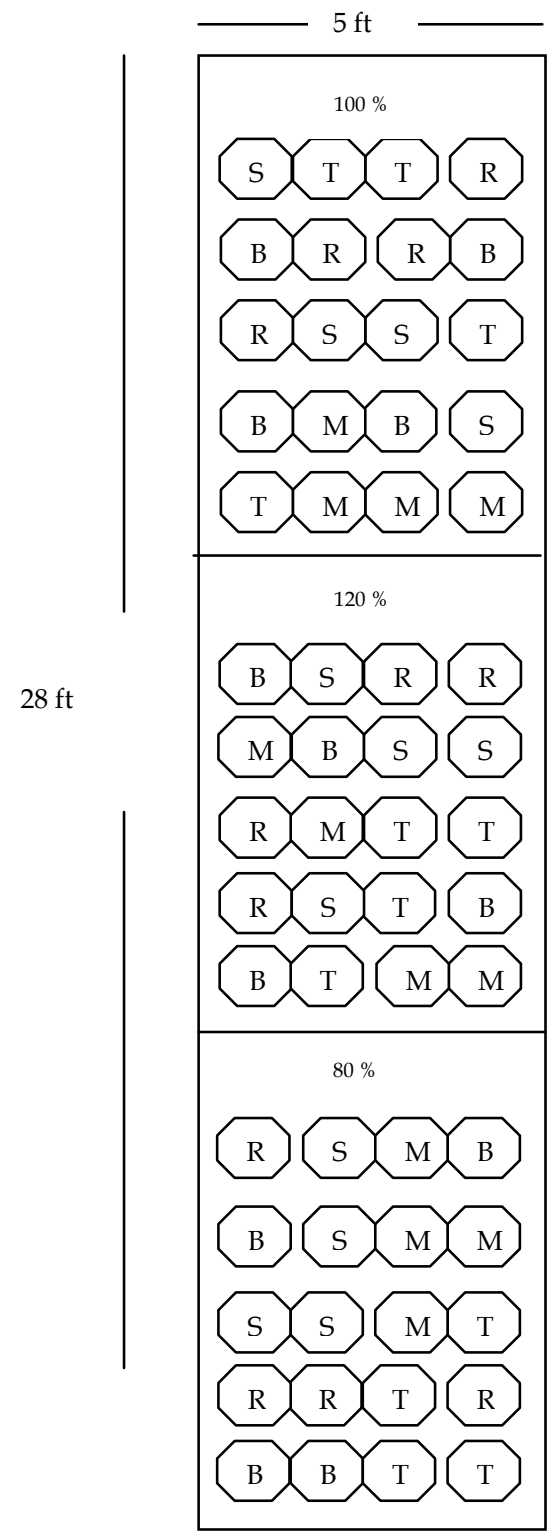

Table 1

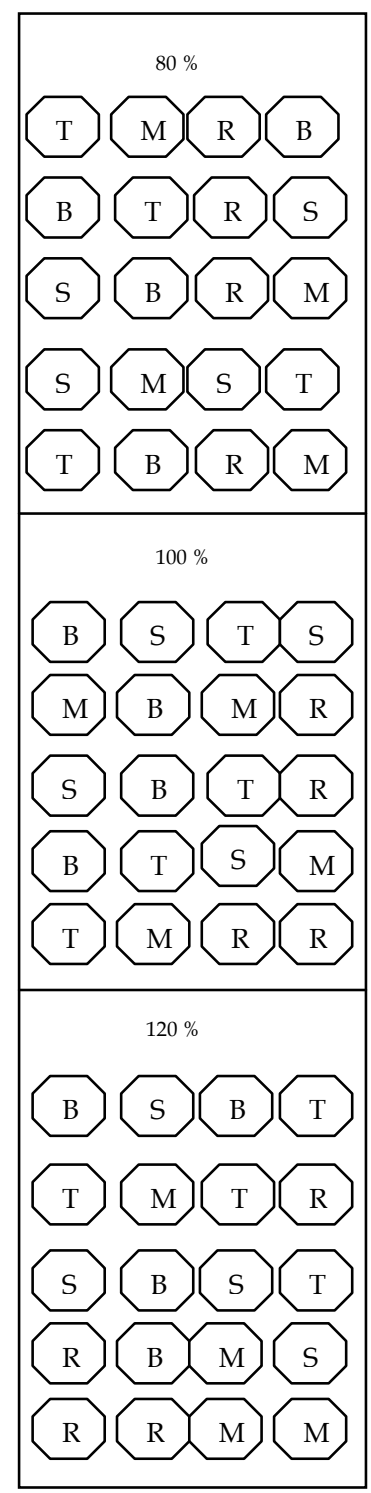

Table 2

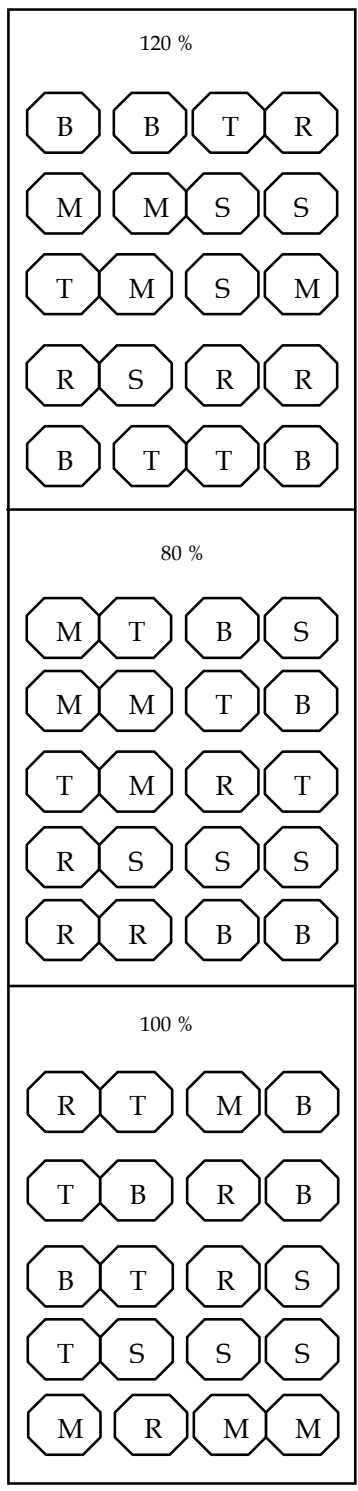

Table 3 


\subsection{Experiment 2}

This experiment was conducted in room 2C of the WVU greenhouse from April 30 to November 19, 2008. The experiment consisted of the five plant species described above but this time grown under five different watering treatments. These five different watering regimes were based on the frequency that plants received irrigation in a day. The water treatments were as follows:

* Treatment 3: irrigated three times a day

* Treatment 2: irrigated two times a day

* Treatment 1.5: irrigated two times a day alternated with one time the next day

* Treatment 1: irrigated once in a day

* Treatment 0.5 : irrigated every other day

The amount of fertilizer solution applied at each watering was the same for all treatments. The amount of solution to be applied in each watering was determined based on the treatment receiving the most water (120\%) in Experiment 1 . The medium in the $120 \%$ treatment looked well-watered. In other words the medium was completely wetted, allowing the medium to retain more water than any of the other treatments reducing wilting especially in the high water requiring plants. In addition, this treatment also showed the most water leaching from the pots in every watering reducing the accumulation of salts in the medium. Therefore, for Experiment 2 it was decided to apply to each pot approximately $200 \mathrm{ml}$ of modified Hoagland's solution at every watering. Irrigation was distributed in a period of time spanning twelve hours during the day starting around noon. At this time of the day the temperature increases considerably and it is when plants transpire more and their demand for water increases. The second and third waterings 
in the treatments with this schedule were applied in late afternoon (between 4 and 7 p.m.) and later in the evening (between 9 p.m. and 12 a.m.) with the exact time varying according to daily maintenance and data collection activities (harvesting, processing samples, making stock solutions, etc.) of the person in charge of the experiment resulting in irrigation approximately every 5 hours. Thus, treatment 3 in Experiment 2 received $200 \mathrm{ml}$ of modified Hoagland's solution 3 times a day $(600 \mathrm{ml})$ distributed over a period of 10 to 12 hours every day. The first watering started around noon $(200 \mathrm{ml})$, then the second watering late afternoon $(200 \mathrm{ml})$, and finally the third watering occurred in the evening $(200 \mathrm{ml})$. Treatment 2 received $200 \mathrm{ml}$ of modified Hoagland's solution 2 times a day $(400 \mathrm{ml})$, around noon and late afternoon. Treatment 1.5 received $200 \mathrm{ml}$ of modified Hoagland's solution 2 times a day $(400 \mathrm{ml})$, around noon and late afternoon and; $200 \mathrm{ml}$ of solution the next day around noon; followed by $200 \mathrm{ml}$ of solution 2 times a day $(400 \mathrm{ml})$ (noon and late afternoon) the day after and so on. Treatment 1 received $200 \mathrm{ml}$ of modified Hoagland's solution every day around noon. And Treatment 0.5 received 200 $\mathrm{ml}$ of modified Hoagland's solution every other day around noon. These watering regimens were followed throughout the experiment even on cloudy and cold days when watering may not have been necessary.

In Experiment 2 all plants were also flushed with plain water every two weeks to avoid the accumulation of excessive salts in the medium. The amount of plain water used for this practice was double (approx. $400 \mathrm{ml}$ ) the amount of the fertilizer solution. When plants were flushed they only received this treatment (plain water) for that day. Therefore, flushing was started early afternoon to assure plants were well irrigated before the highest temperature in the room with the experiment occurred. In addition, the flush was carried out when Treatment 0.5 (receiving water every other day) needed to be watered according to the set watering schedule. 


\subsubsection{Experimental design}

The design for Experiment 2 was a split-plot with two separate randomizations. The five watering frequency treatments were repeated six times (Figure 2.3). The first randomization in the experiment consisted of the water treatments with their replications. The 30 watering sections (5 watering frequency treatment levels X 6 replicates each) were set up randomly on the three tables having 10 watering sections each (Figure 2.3). The second randomization resulted from the division of each watering section into 5 sub-sections to each of which one of the five plant species was randomly assigned (Figure 2.3). 


\section{Figure 2.3. Experiment 2.}

"Split-plot design" having two randomizations. First randomization: The five different water treatments $(0.5,1,1.5,2$, and 3$)$ with six repetitions each were distributed among the three tables. Second randomization: Each watering section (10 per table) was divided into 5 sub-sections. Each of the five plant species (Basil (B); Rosemary (R); Thyme (T); Sunflowers (S); and Mint (M) was randomly assigned to each sub-section.

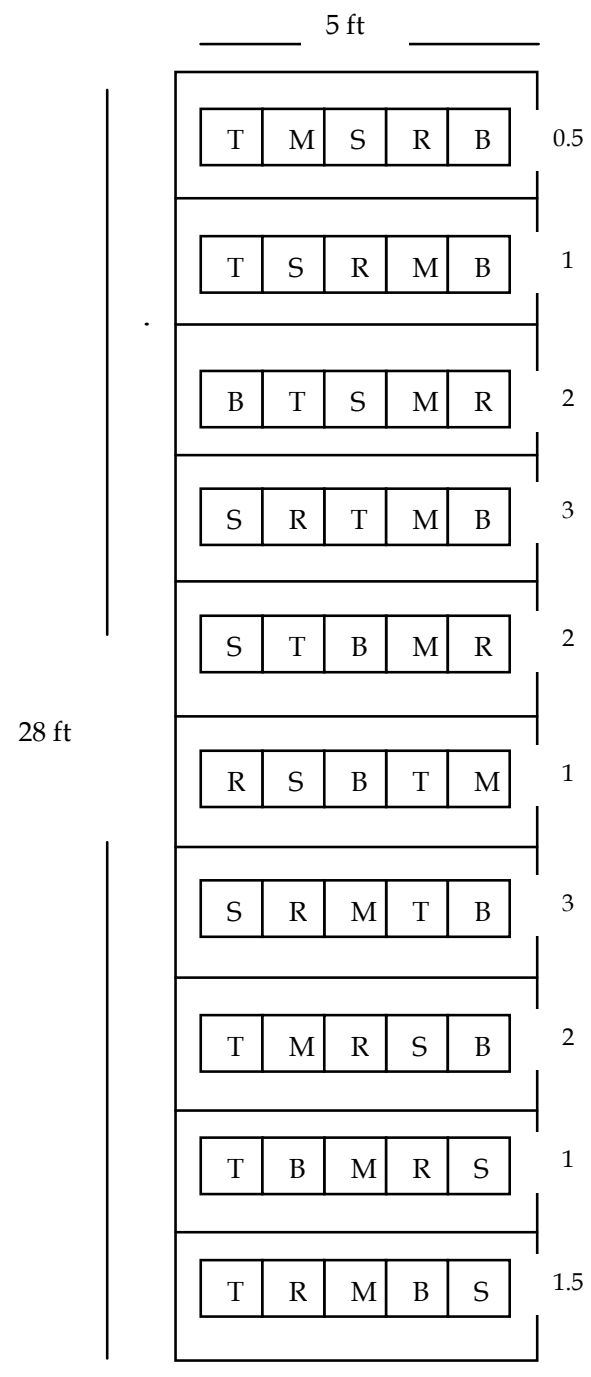

Table 1

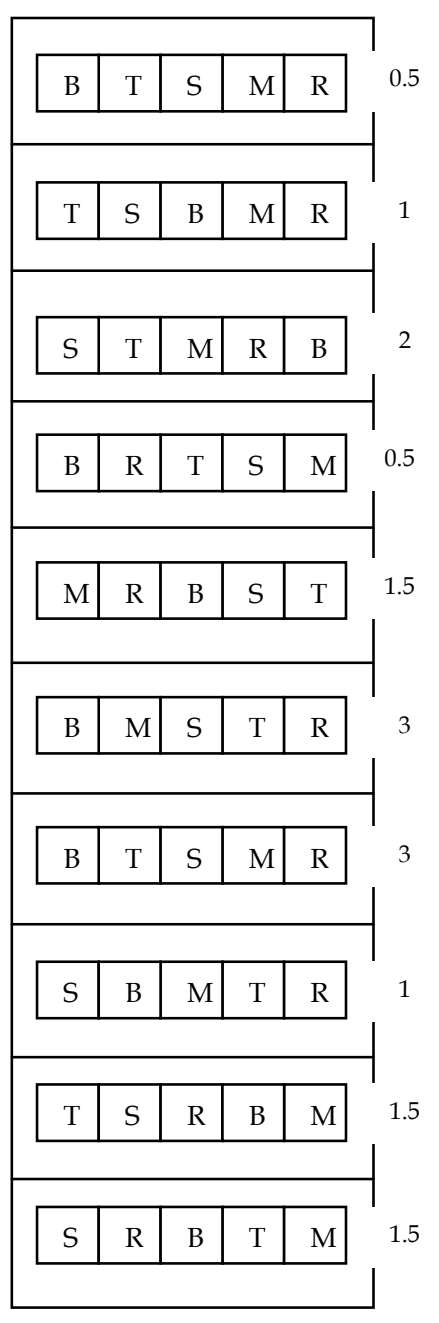

Table 2

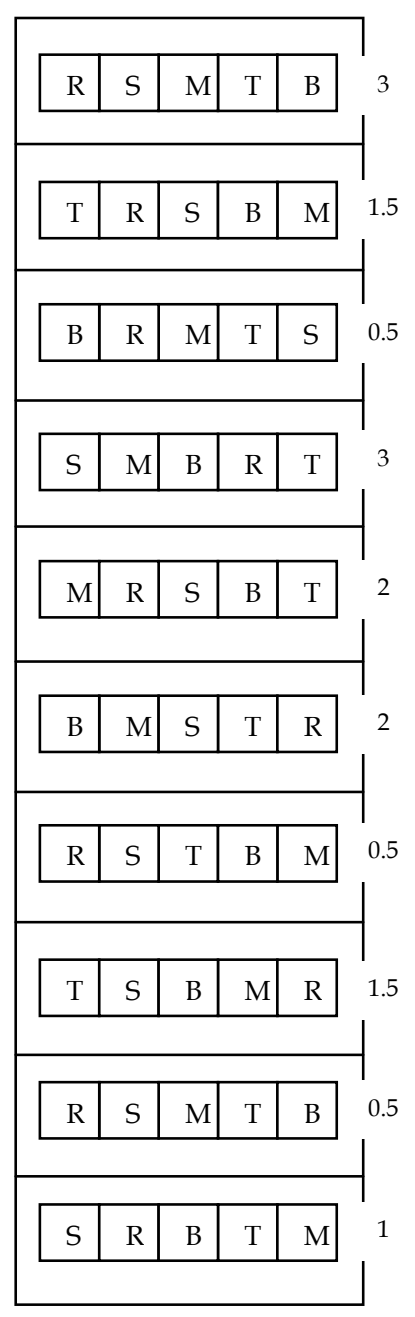

Table 3

The Tezontle medium used in Experiment 2 was disinfected using a 10\% bleach solution (6.0\% Sodium Hypochlorite original concentration). Approximately after 2 days from disinfection Tezontle was rinsed several times before the start of the experiment. 


\subsection{Experiment 3}

This experiment was conducted in room 2B from July 25 to December 18, 2008. Experiment 3 was an exact replica of Experiment 2 except for the fact that the medium in this experiment used a slightly different particle size of red lava rock. The medium used in experiment 3 excluded the smallest particle size used in the first two experiments. As Experiment 3 was being designed we observed that some plants (mainly thyme) in the previous experiments showed symptoms of overwatering (adventitious roots and changes in plant morphology).We postulated that the use of a medium with larger particle size could reduce these symptoms in low water requiring plants especially during periods of cloudy and cold days because bigger particles would result in higher aeration levels and lower water holding capacity. In order to design a medium with improved aeration, the available medium (similar in size to the medium used in Experiment 1 and at this time being used in Experiment 2) was sieved to establish the proportion of the particle sizes. For this task a Gilson shaker (Gilson Company, Inc.) (Figure 2.4) was used with three different sieve sizes: 1/2" (13 mm), 1/4" (6.8 mm), and $1 / 8$ " (3.3 mm) allowing the mechanically exclusion of the smallest particles ( $\left.\leq 1 / 8^{\prime \prime}\right)$.

Figure 2.4. Gilson shaker used to sieve the red lava rock for experiment 3.

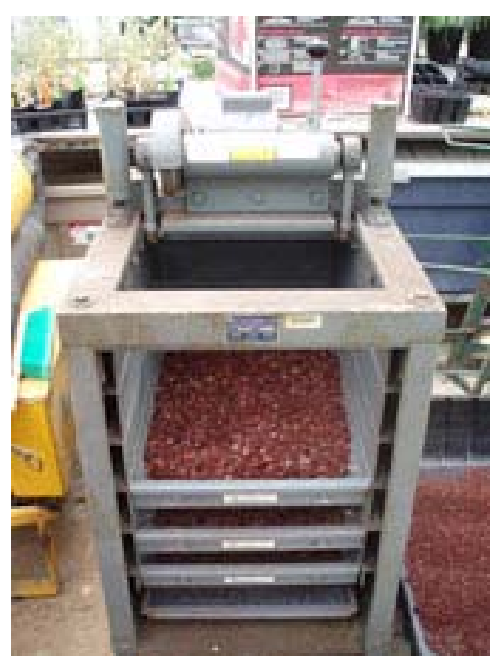


The medium that was retained by the $1 / 4$ ” $(6.8 \mathrm{~mm})$ sieve was manually sieved with a sieve of 1/6” (4.23 mm). This practice was performance because the $1 / 6$ ” $(4.23 \mathrm{~mm})$ particles had good qualities in terms of aeration to be the smallest particles in the medium for Experiment 3. This particle size was analyzed in the first analysis of Tezontle (Table 2.1) but its proportion into the original medium (used in experiments 1 and 2) was unknown. In order to reconstitute a medium with different particle sizes and at the same excluding the smallest particles $(<1 / 6$ ”'-4.23 $\mathrm{mm}$ ) used in the last two experiments to improve roots aeration, the proportion of each of the newly sieved particles (1/2”-13 mm, 1/4”-6.8 mm and 1/6”-4.23 mm) was calculated. The proportions of the particle sizes obtained were: $10.36 \%$ of particles of 1/2” (13 mm) of size, $78.35 \%$ of particles of $1 / 4$ ” $(6.8 \mathrm{~mm})$ of size, and $11.28 \%$ of particles of $1 / 6 ”(4.23 \mathrm{~mm})$ based on the volume they occupied. Since the proportion of the largest particles $(1 / 2$ "-13 mm of size not giving the adequate support to the plants nor water retention) and the smallest ones (1/6”$4.23 \mathrm{~mm}$ - not desired in this medium in a high proportion) was much lower than the proportion of the particles of $1 / 4$ ” (6.8 mm), it was decided to use this same proportion of particles to make the medium for this experiment. The analysis of this medium is in Table 2.3.

Table 2.3. Analysis of the Tezontle mix used as growing medium in Experiment 3. Determination of Container capacity (CC), Bulk density at CC (gr/L), and \% of aeration.

\begin{tabular}{|c|c|c|c||}
\hline \multicolumn{4}{|c||}{ Analysis of Tezontle } \\
\hline Medium & $\begin{array}{c}\text { Bulk density } \\
\text { at CC (gr/L) }\end{array}$ & $\begin{array}{c}\text { Container } \\
\text { capacity }\end{array}$ & \% aeration \\
\hline \hline Experiment 3 & 1341.65 & 0.16 & 36.5 \\
\hline
\end{tabular}




\subsection{Harvest and Measurements}

Before the start of each experiment all plants were pinched except sunflowers. Heights of all plants after the initial pinch were recorded, in order to establish a base line from which to measure new growth. The leaves and stems of the upper part of basil and rosemary plants were pinched leaving a plant with a height of approximately $15-16 \mathrm{~cm}$. Thyme and mint stems were cut leaving a plant of approximately $10 \mathrm{~cm}$ in height. The new growth was measured above these $15-16 \mathrm{~cm}$ and $10 \mathrm{~cm}$ bases.

Harvesting time was decided empirically. All plants except sunflowers were harvested when their canopy was not well-hydrated by the amount of water applied. Thus, harvesting was performed when plants usually not showing symptoms of drought stress (mainly in the treatments receiving the highest irrigation) looked wilted despite being irrigated. In some instances harvesting was initiated when plant size made it difficult to manage the experiment. Basil was harvested when, for a few days, its numerous leaves began to wilt during the highest temperature of the day despite being irrigated. Mint was harvested when its stems and rhizomes become entangled in the rolling table grates on which the plants were placed. Rosemary and thyme were the plant species having the slowest growth. Rosemary grows vertically and although it is considered to be a low water requiring plant it was harvested when it showed wilting symptoms when the amount of water supplied was not enough to maintain the extended canopy fully hydrated. Thyme grows very slowly, yet its stems presented wilt symptoms when they were very long. In addition, thyme stems grow close together and tend to tangle up resulting in decreased air and light penetration in some areas of the plant. In all the experiments of this research when basil, mint, rosemary or thyme was ready to be harvested all plants (of that particular plant species) were measured and cut the same day. Sunflowers were harvested when 
the flower on the central leader of each plant was fully open. Therefore, sunflowers were not harvested in the same day, but when each cut flower was ready to be harvested.

Before harvesting, the height of each plant was measured and recorded. The plant was then cut using clippers leaving the plant with a height equal to the established base line per species (basil and rosemary $15-16 \mathrm{~cm}$; and mint and thyme $10 \mathrm{~cm}$ ). The harvested leaves and/or stems of each plant were put in an individual labeled paper bag (sample). This task was usually performed in late afternoon or early evening, especially during summer, time to avoid that the samples would lose moisture between harvest and measurement leading to lower fresh weights. As a measurement of growth, the number of mature leaves was recorded for basil whereas for mint, rosemary and thyme the number of stems and/or rhizomes was recorded. Sunflowers were harvested by taking the complete plant (including roots) out of the pot. The length of each sunflower stem from root-stem interface to the base of the flower was recorded as the height of the plant. The roots of each plant were cut off and discarded and the cut flower was placed in an individual labeled paper bag (sample). The sunflowers samples were weighed after all flowers (ready to be harvested that day) were harvested and placed in paper bags. Fresh weight of plant material in each bag was recorded. After that, samples were placed in the oven at approximately $50^{\circ} \mathrm{C}$ for two days or until they were perfectly dry.

Dry weight was recorded for all samples at that time. Dry weight measurements allowed measuring new growth more accurately since the content of water in the samples (fresh weight) can vary depending on a number of factors including light, temperature, and relative humidity. 


\subsection{Statistical analysis}

\subsubsection{Experiment 1}

The amount of Leachate per plant species per split-plot per block and per experiment were used in our analysis.

Leachate, fresh and dry weight, height, number of stems and number of mature leaves of the unique harvest were analyzed as a split-plot using the GLM procedure of SAS ${ }^{\mathrm{TM}}$. The effect of water treatment was tested using the water treatment by block interaction (Error a).

The $100 \%$ treatment was contrasted with $80 \%$ treatment as well as $120 \%$ treatment to know the differences among them.

The sums of squares for the effect of water treatment were broken into two planned comparisons: $100 \%$ treatment vs. $80 \%$ treatment and, $100 \%$ treatment vs. $120 \%$ treatment.

\subsubsection{Experiments 2 and 3}

Average fresh and dry weights collected from individual plants over multiple harvests were used in our analysis. Since no differences were observed between means of the two experiments data were combined for further analysis. Means were transformed to a natural logarithm and analyzed using the PROC MIXED procedure of SAS ${ }^{\mathrm{TM}}$. Since the data was unbalanced (different number of observations per each plant species) back transformed least square means are reported with the exception of the comparisons between species, watering levels and the visual representation of the model generated from our data. 


\section{Results}

\subsection{Experiment 1}

\subsubsection{Leachate}

Leachate collected over the whole period of the experiment showed that the $80 \%$ treatment, on average, leached $22.53 \mathrm{ml}$, while the $100 \%$ and $120 \%$ treatments leached $47.14 \mathrm{ml}$ and $74.03 \mathrm{ml}$ in each watering, respectively. The statistical contrast between the $100 \%$ treatment (container capacity) and the $80 \%$ and $120 \%$ treatments showed P-values $<0.0001$, indicating that there was a significant difference in the amount of fertilizer that leached from the pots when comparing the $100 \%$ treatment with the two other treatments (Figure 3.1 ).

Figure 3.1. Leachate generated by the three water treatments in Experiment 1.

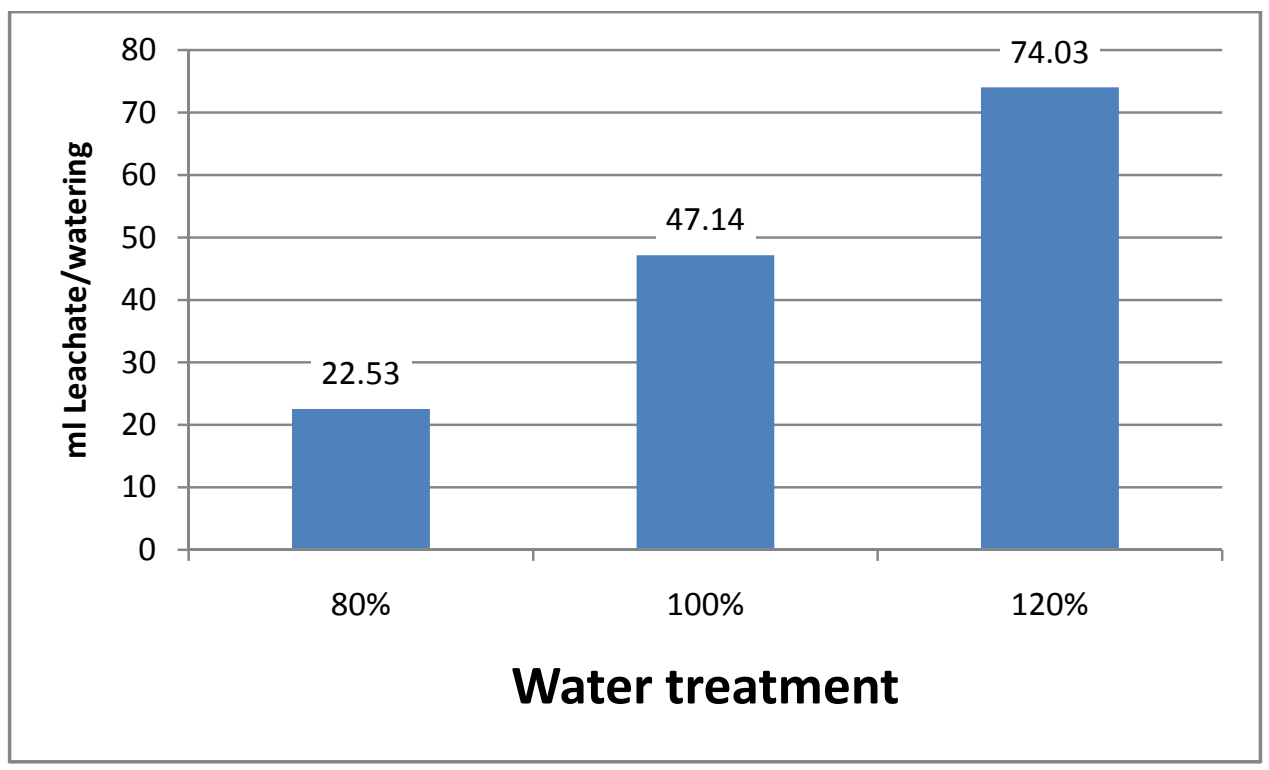


The amount of leachate collected was also very different depending on the species of plants used in the experiment (Figure 3.2). The contrast between the leachate of the high water requiring plants (mint, basil and sunflowers) and the low water requiring plants (thyme and rosemary) showed a P-value $<0.0001$ indicating a clear difference in the amount of leachate collected between the two groups of plants. In addition, it was also observed that the average amount of leachate collected over the whole period of the experiment was different between the species included in each group. Means for the high water requiring plants were $49.49 \mathrm{ml}, 36.55$ $\mathrm{ml}$, and $65.33 \mathrm{ml}$ for mint, basil, and sunflowers respectively. Means for the low water requiring plants were $45.80 \mathrm{ml}$ and $42.32 \mathrm{ml}$ for thyme and rosemary respectively (Figure 3.2).

Figure 3.2. Leachate mean per plant species in Experiment 1.

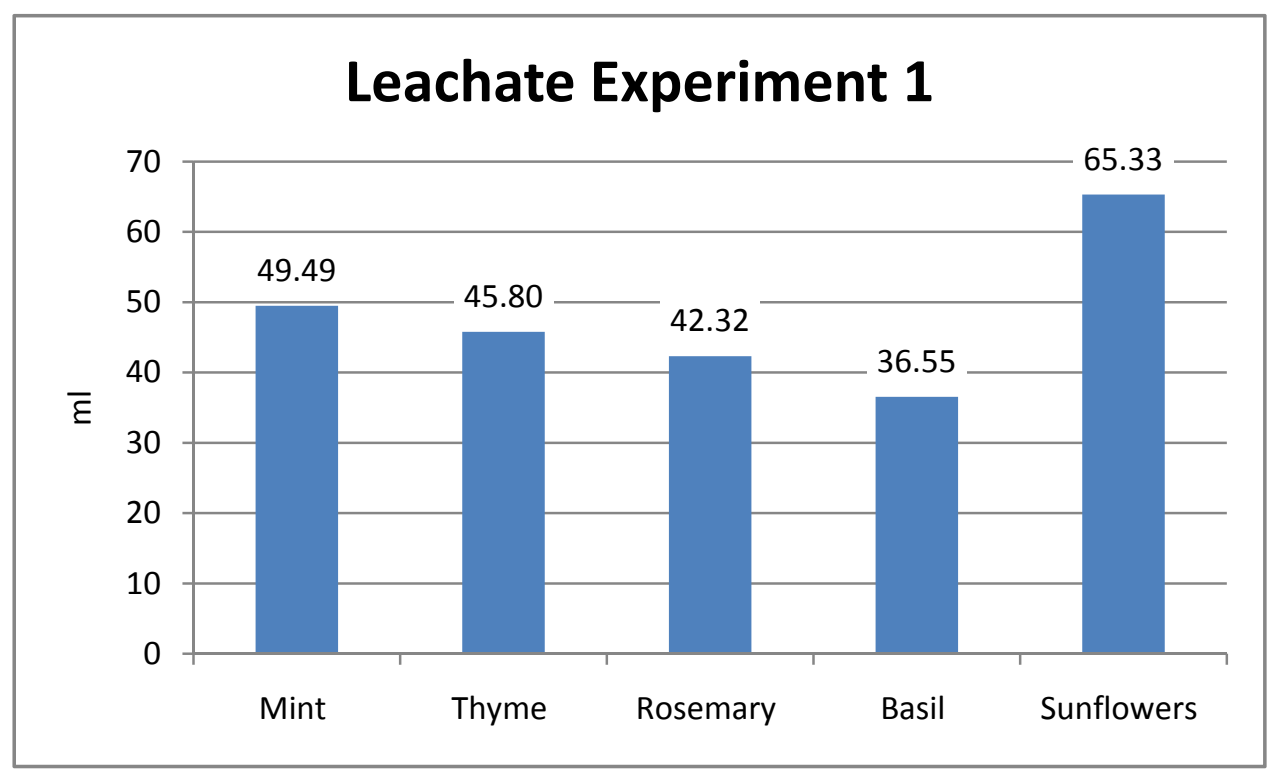




\subsubsection{Plant measurements}

\subsubsection{Fresh weight}

An interaction between treatment and species was observed. The data also showed differences in fresh weight between treatments and species. The $100 \%$ treatment showed the highest mean (23.13 grams) while the lowest mean (19.27 grams) was observed in the $80 \%$ treatment in total amount of fresh weight harvested $(\mathrm{P}<0.0001)$ in the experiment. No statistical significant differences were observed in fresh weight between the $100 \%$ treatment and $120 \%$ treatment (21.92 grams) (Figure 3.3).

Figure 3.3. Total fresh weight for the three water treatments $(80 \%, 100 \%$ and $120 \%$ ).

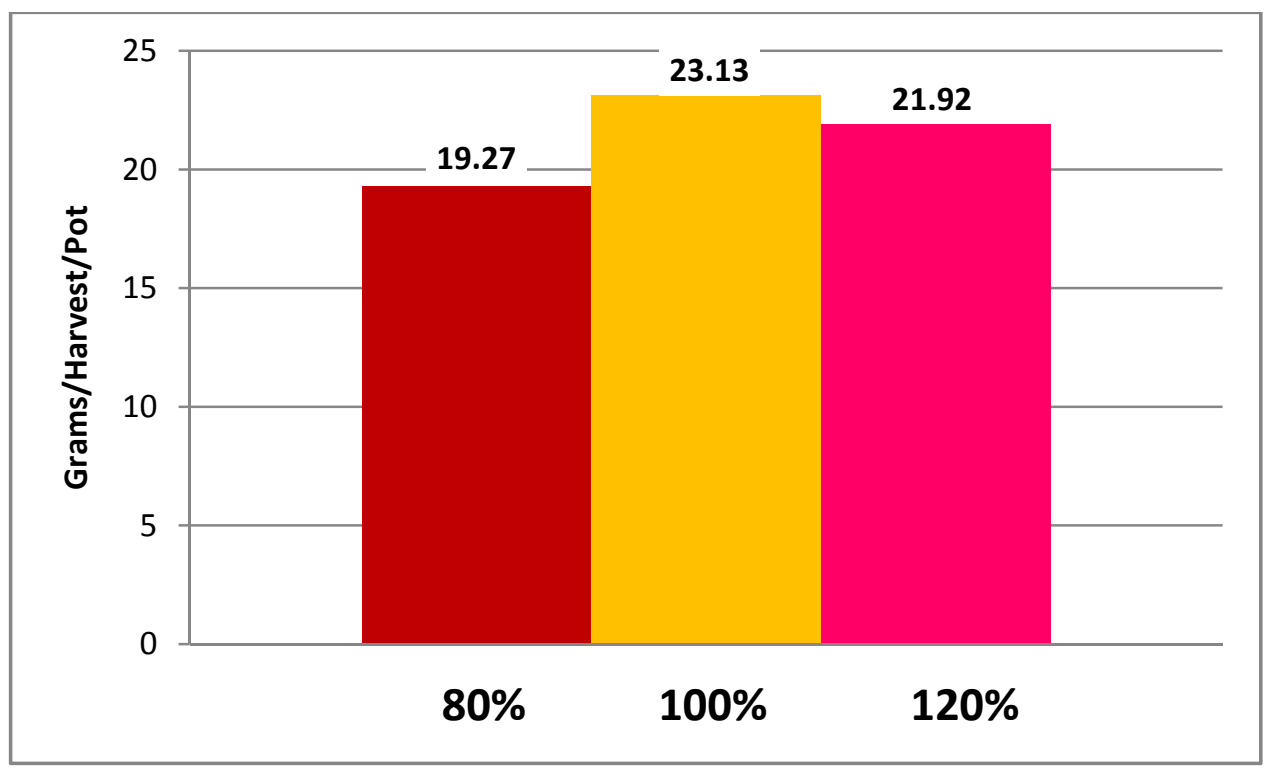

Basil showed the highest average weight, followed by thyme, sunflowers, rosemary, and mint with average weights of 47.39, 22.84, 14.39, 11.56 and 4.15 grams, respectively (Figure 3.4). A difference in fresh weight between the means of high and low water requiring plants also showed up in the statistical analysis of our data. The group of high water requiring plants showed 
a mean fresh weight of 20.05 grams, while the group with low water requirements showed a mean of 17.2 grams.

Figure 3.4. Fresh weight by treatment for the five plants species.

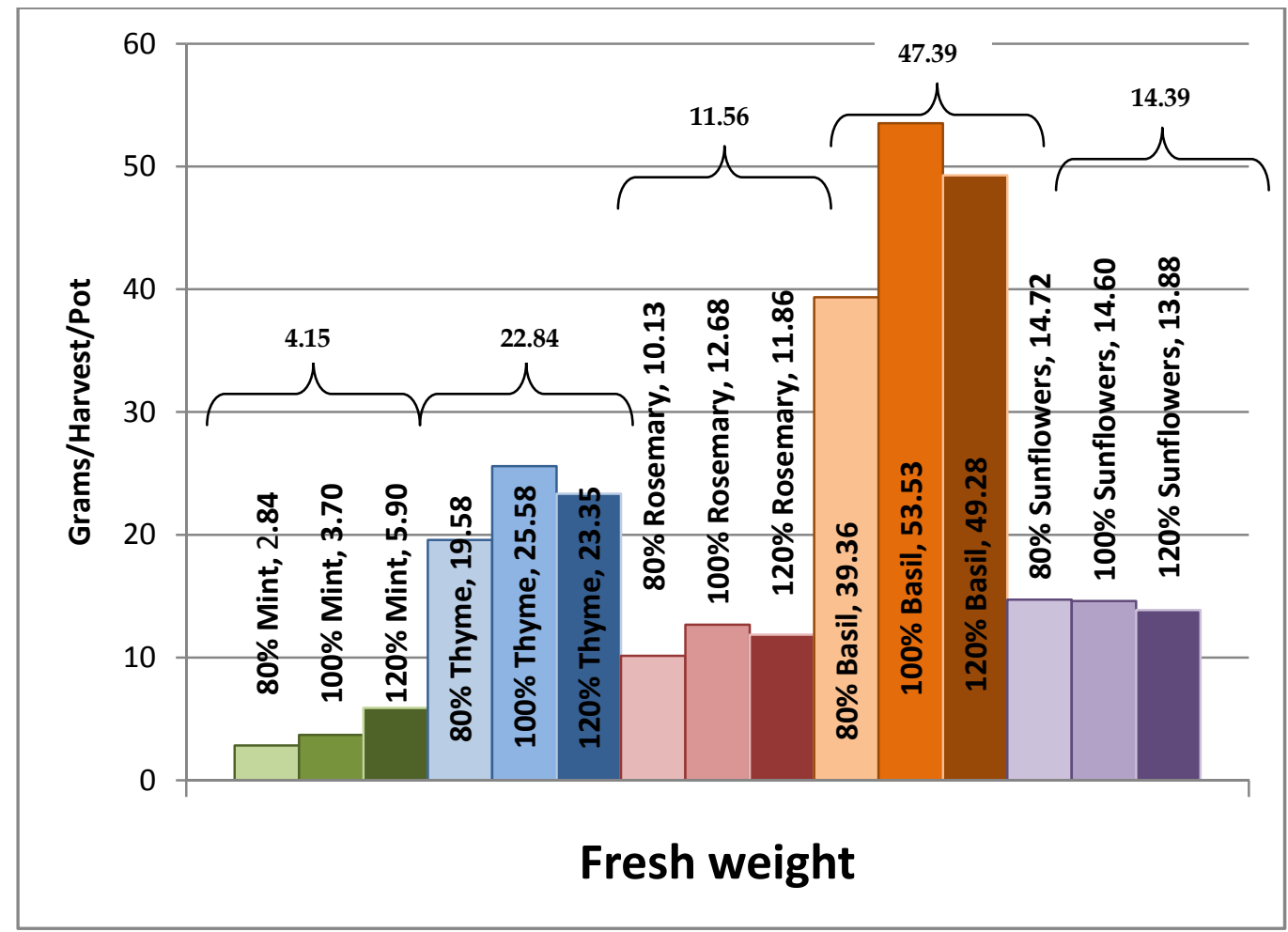

Basil obtained the highest fresh weight in the 100\% treatment (53.53 grams), followed by the $120 \%$ treatment, and $80 \%$ with a fresh weight of 49.28 and 39.36 grams, respectively (Figure 3.4). Thyme also obtained the highest fresh weight in the $100 \%$ treatment with a yield of 25.58 grams, followed by $120 \%$ treatment and $80 \%$ treatment showing 23.35 and 19.58 grams of fresh weight, respectively (Figure 3.4). Sunflower yield did not show significant differences among treatments (Figure 3.4). The highest fresh weight for rosemary was observed in $100 \%$ treatment with 12.68 grams. The next highest yield for this plant species was observed in $120 \%$ treatment with 11.86 grams while the $80 \%$ treatment showed a fresh weight of 10.13 grams (Figure 3.4). 
Mint obtained its highest and lowest yield in the treatment receiving the most and the least irrigation. The $120 \%$ treatment and $80 \%$ treatment yielded 5.90 and 2.84 grams of fresh weight respectively. The $100 \%$ treatment showed 3.70 grams of fresh weight in this unique harvest (Figure 3.4).

\subsubsection{Dry weight}

No interaction between treatment and species was observed. However, differences in dry weight between treatments as well as species were observed. A significant difference (P-value $<$ 0.0013) was observed between the means (all five plant species combined) when the $80 \%$ treatment (4.57 grams) was compared with the $100 \%$ treatment (5.33 grams). No differences were observed between the $100 \%$ and $120 \%$ (5.40 grams) treatments (Figure 3.5).

Figure 3.5. Total dry weight for the three water treatments $(80 \%, 100 \%$ and $120 \%)$.

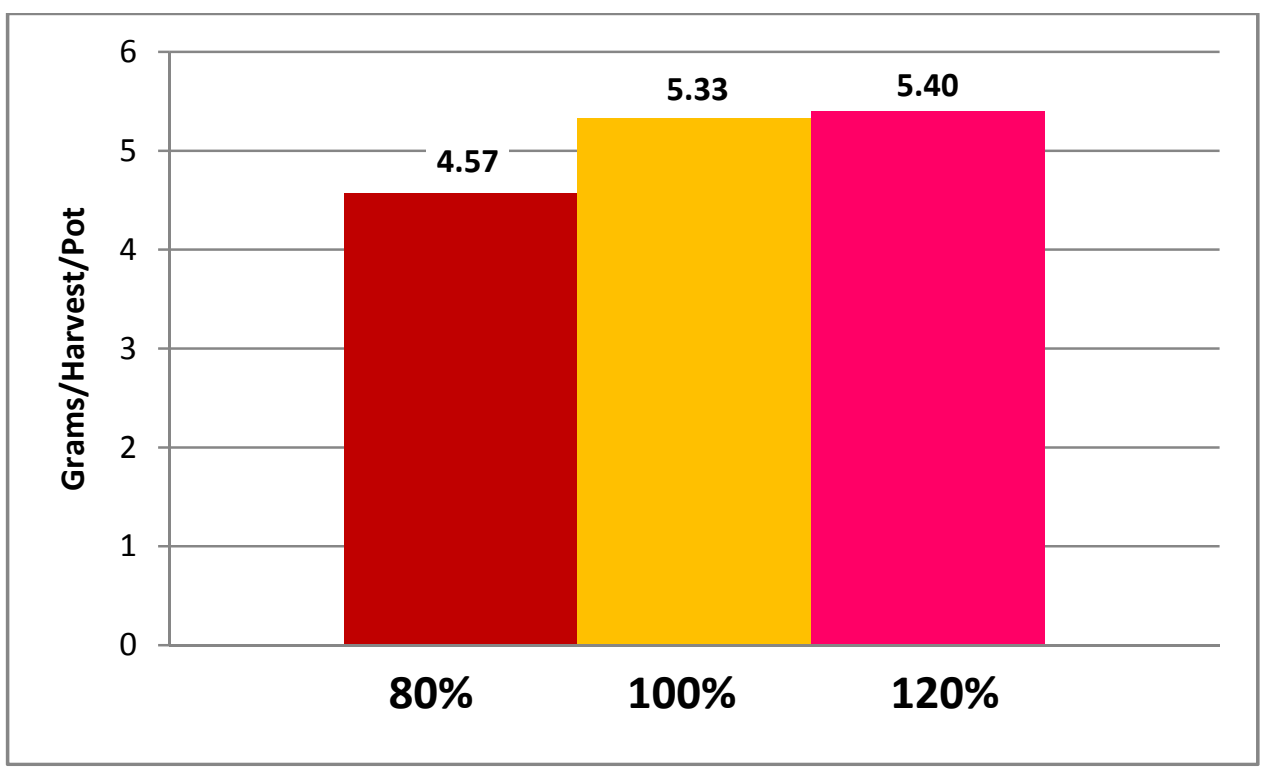


When analyzed separately the five different plants species, basil showed the highest average dry weight with 7.46 grams, followed by thyme, rosemary, mint, and sunflowers with an average weight of 5.47 grams, 4.56 grams, 2.80 grams, and 2.49 grams respectively (Figure 3.6).

Figure 3.6. Dry weight per treatment for the five plants species.

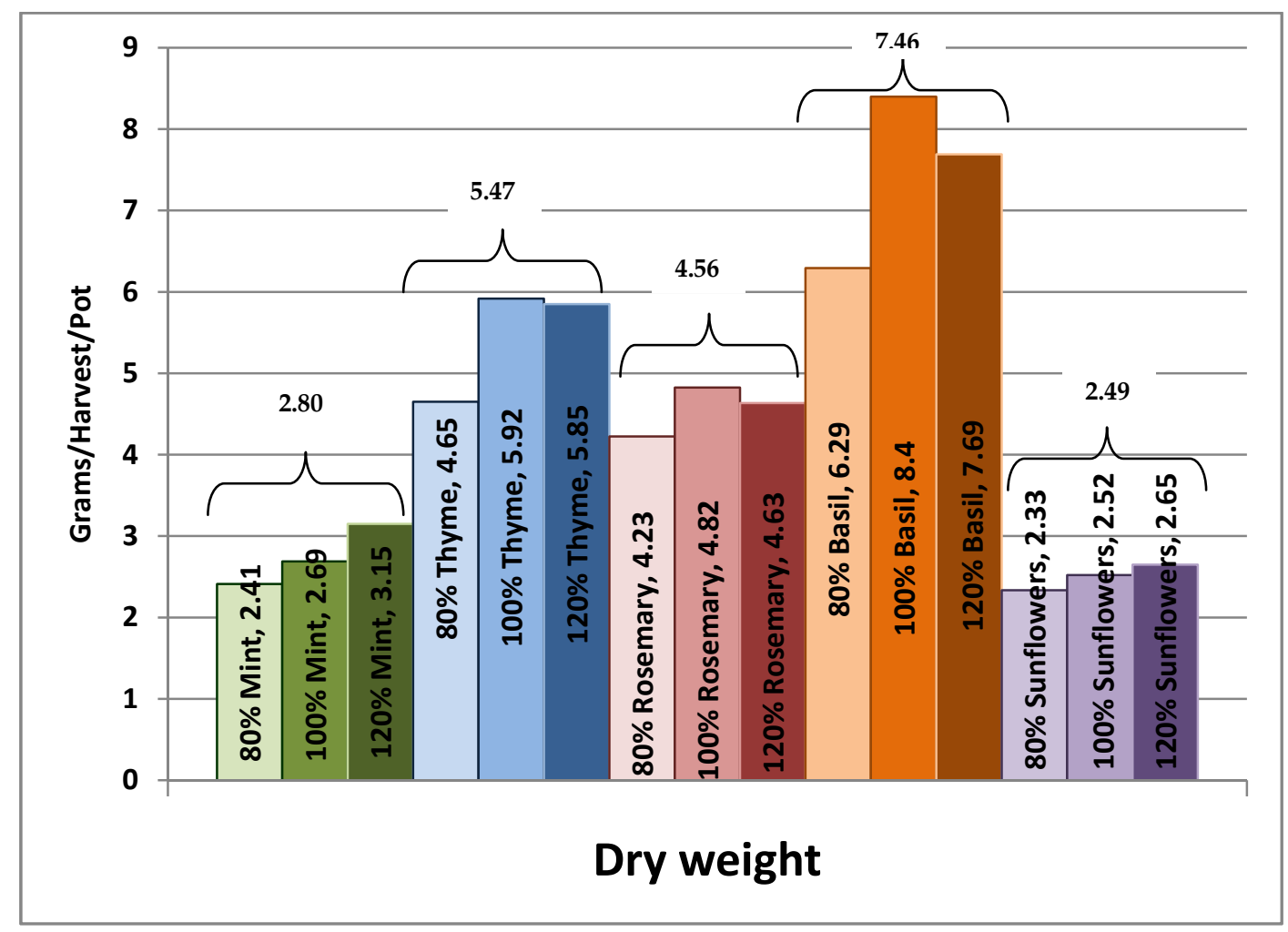

Basil showed its highest dry weight in the $100 \%$ treatment (8.4 grams) followed by $120 \%$ treatment and $80 \%$ treatment with dry weights of 7.69 and 6.29 grams, respectively (Figure 3.6). Thyme showed the highest dry weight in the $100 \%$ treatment (5.92 grams) followed very closely by the $120 \%$ treatment (5.85 grams). The $80 \%$ treatment obtained the lowest dry weight with a total mean of 4.65 grams (Figure 3.6). Rosemary showed values of dry weight very similar in the three treatments. However, the $100 \%$ treatment showed the highest value (4.82 grams) followed by $120 \%$ treatment and $80 \%$ treatment with 4.63 and 4.23 grams respectively (Figure 3.6). Mint 
obtained the highest dry weight in the $120 \%$ treatment ( 3.15 grams) followed by the $100 \%$ treatment and $80 \%$ treatment with averages of 2.69 and 2.41 grams, respectively (Figure 3.6). Sunflowers did not present a significant difference in dry weight among the three treatments. The $120 \%$ treatment showed the highest dry weight accumulation, followed by $100 \%$ treatment and $80 \%$ treatment with values of 2.65, 2.52 and 2.33 grams per harvest respectively (Figure 3.6).

\subsubsection{Height}

The five plant species in this experiment showed different heights. No differences were observed between treatments. In addition, no significant interaction between treatment and plant species was found in the data.

\subsubsection{Stems}

The number of stems was obtained only for three of the five species studied in this research: mint, thyme and rosemary. No significant differences between treatments were observed. The treatment having the highest number of stems (mean) was 120\% (60.76 stems) followed by the $100 \%$ (58.55 stems), and finally the $80 \%$ (49.34 stems) (Figure 3.7). 
Figure 3.7. Number of stems (means) per species and per treatment for each of the plants species.

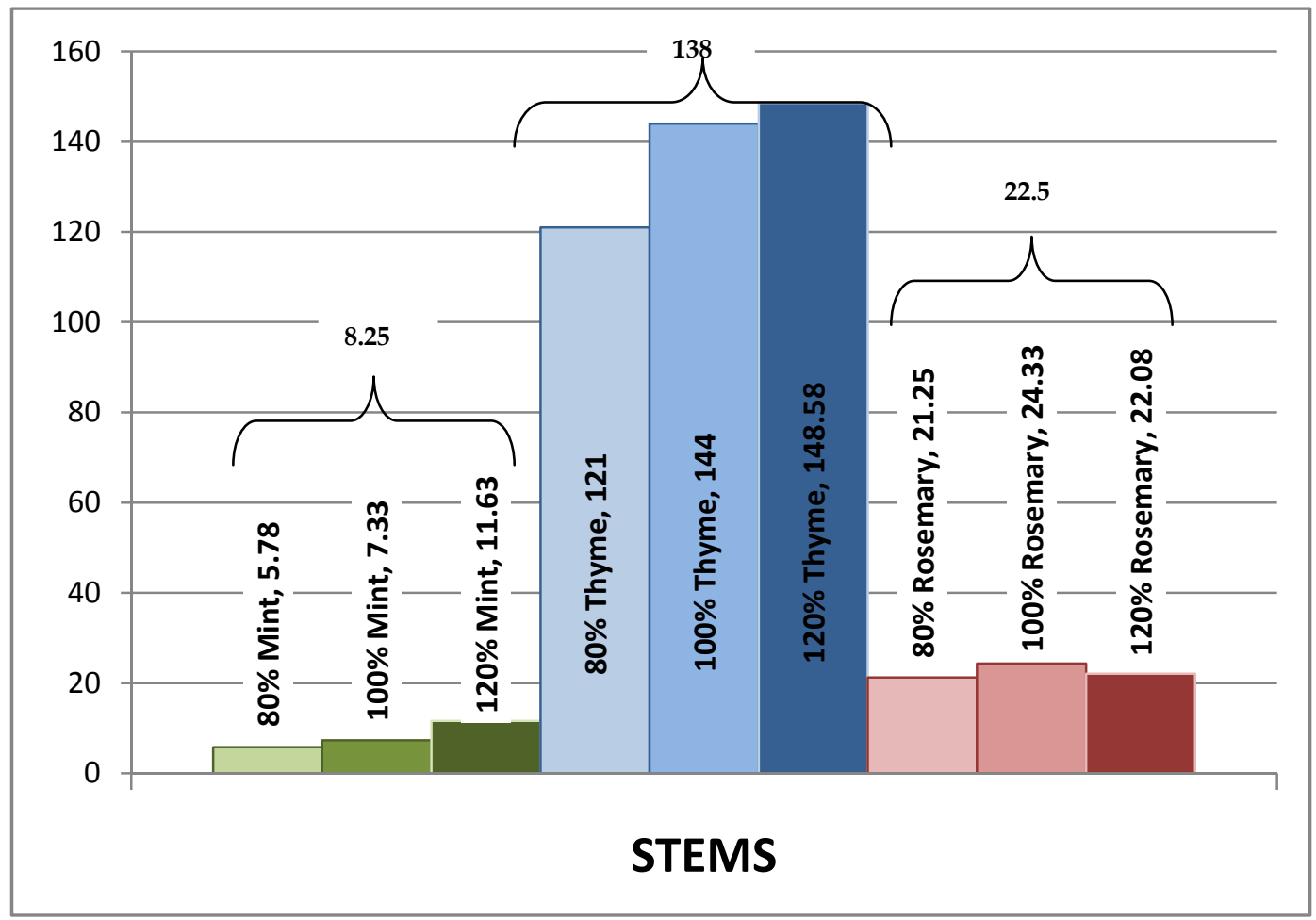

When the values (means) of the treatments $(80,100$, and $120 \%)$ were averaged for each plant species, thyme showed the highest mean number of stems followed by rosemary, and mint with 138, 22.5, and 8.25 stems, respectively (Figure 3.7).

\subsubsection{Unfolded (Mature) leaves}

Mature leaves were counted only in basil. The 100\% treatment showed the highest number of mature leaves (199) followed by the $120 \%$ treatment (160), and the $80 \%$ treatment (148). A significant difference $(\mathrm{P}=0.0293)$ in mature leaves at harvest was observed between the $100 \%$ and $80 \%$ treatments but not between the $100 \%$ and $120 \%$ treatments $(\mathrm{P}=0.0834)$ (Figure $3.8)$. 
Figure 3.8 Number of mature leaves per water treatment in Basil.

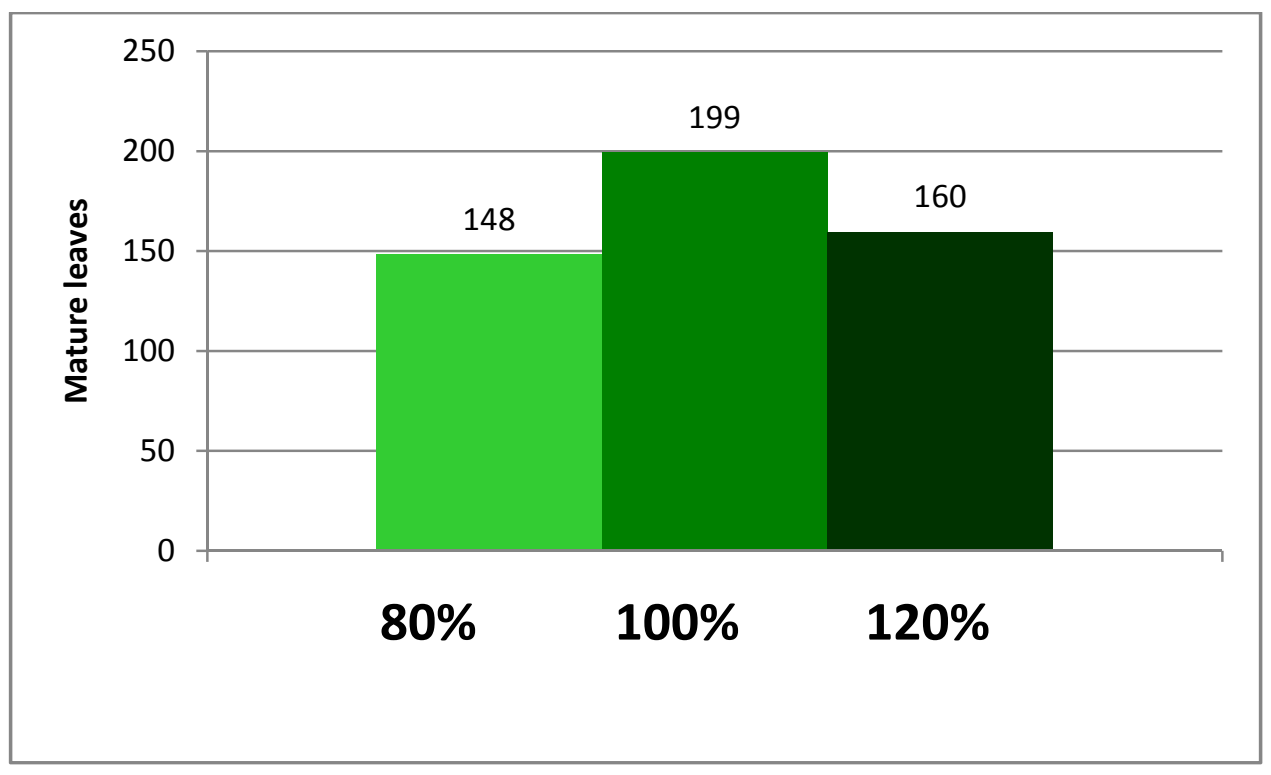




\subsection{Experiments 2 and 3}

\subsubsection{Fresh weight}

As stated previously since no significant differences were observed between the means of the two experiments data were combined to be analyzed. Data analysis was performed using natural logarithms of the calculated means (fresh weight/number of harvests) per each plant in the experiments. Since data was unbalanced (different number of observations per each plant species), least square means values were used to contrast treatments. Results were reported using transformed values $(\mathrm{e}=\mathrm{Inv} .+\mathrm{ln})$ of the least square means.

Differences were considered significant at $\alpha=0.002$. Based on the Least Square Means values (including all plant species) the yields decreased as water frequency decreased. Thus, the treatment showing the highest yield was Treatment 3 followed closely by Treatment 2 irrigated three and two times a day, respectively. Yields steadily decreased as watering frequency decreased in Treatment 1.5 (irrigated two times a day alternated with one time the next day), Treatment 1 (irrigated once in a day), and finally Treatment 0.5 (irrigated every other day) (Figure 3.9).

Figure 3.9. Comparison of the total fresh weight between the five different treatments.

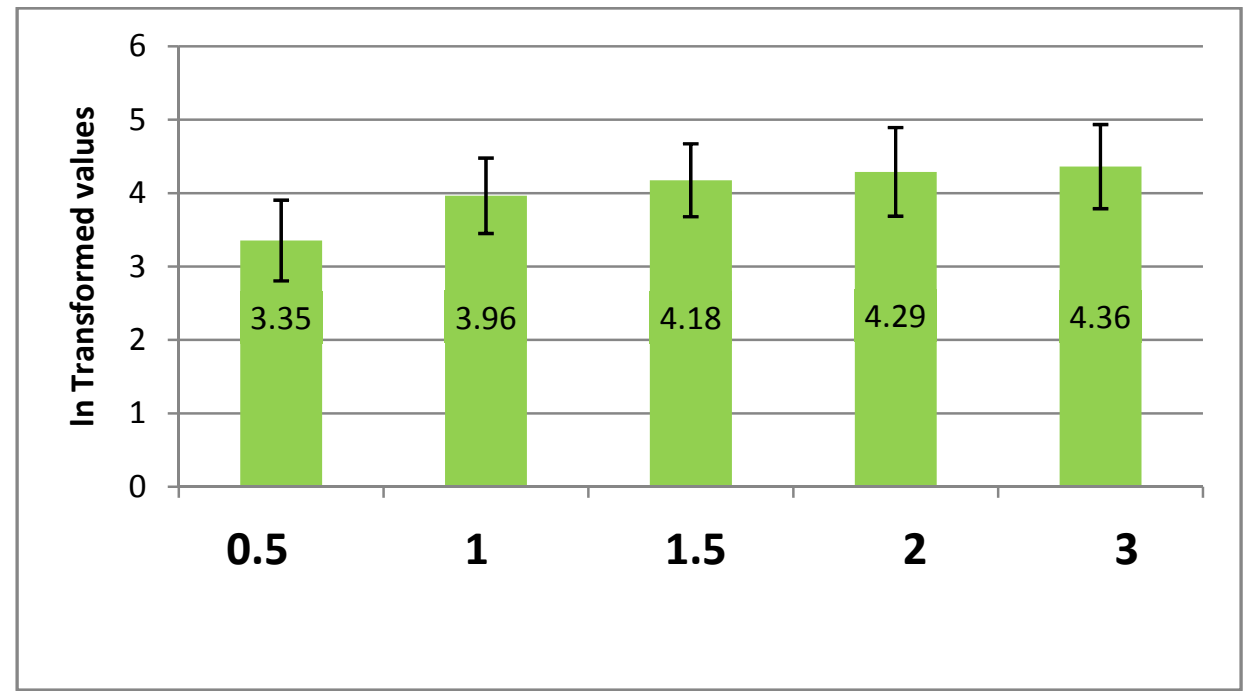


When analyzed separately the five plants species showed differences in fresh weight. Basil showed the highest average fresh weight (Least Square Means) followed by thyme, mint, sunflowers and rosemary (Figure 3.10). species.

Figure 3.10. Comparison of the total fresh weight between the five different plant

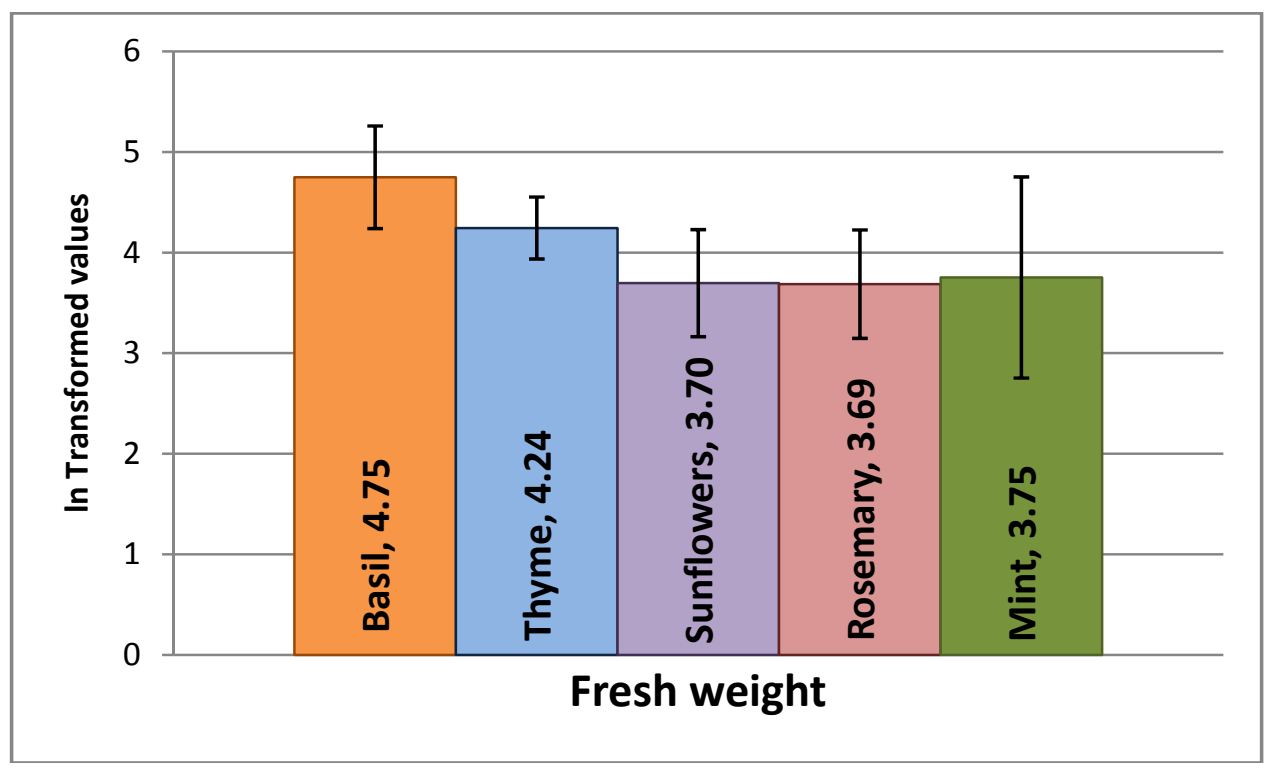

Figure 3.11 summarizes the fresh weight obtained per treatment and per plant species. It can be observed that most of the plant species obtained the highest fresh weight either in Treatment 3 (irrigated three times a day) or Treatment 2 (irrigated two times a day), except for thyme which showed the highest fresh weight in Treatment 1.5 (irrigated two times a day alternated with one time the next day). On the other hand, the figure also shows that Treatment 0.5 (irrigated every other day) obtained the lowest fresh weight in all plant species. 
Figure 3.11. Comparison of fresh weight between the five different plant species per watering treatment.

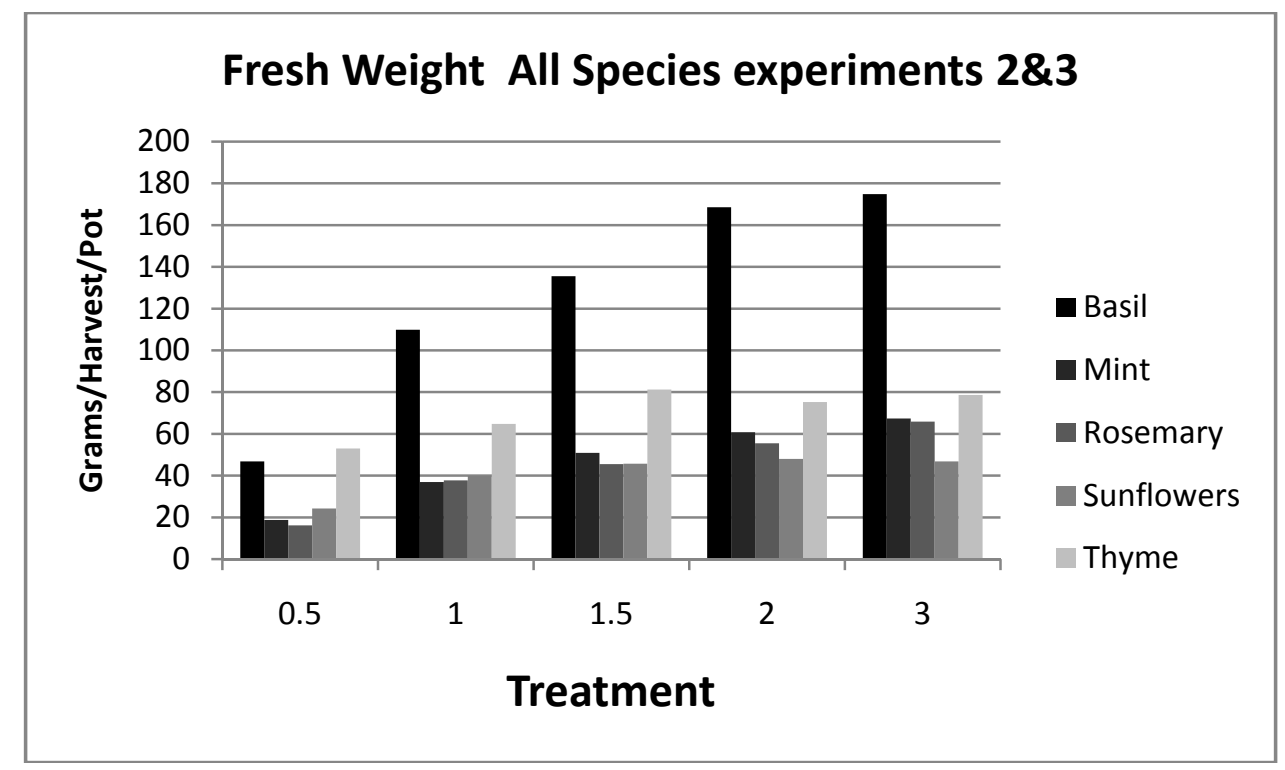

\subsubsection{Basil}

Treatment 0.5 (irrigated every other day) was significantly different $(\mathrm{P}$-value $<0.0001)$ from all the other treatments showing the lowest yield (46.77 grams) among them (Figure 3.12). Treatment 1 (irrigated once in a day) and Treatment 1.5 (irrigated two times a day alternated with one time the next day) were not statistically different (P-value=0.0964) (Figure 3.12), with yields of 109.87 and 135.53 grams respectively. However, Treatment 1.5 also showed similarities in yield to Treatment 2 (irrigated two times a day) $(\mathrm{P}$-value $=0.0844)$ and Treatment 3 (irrigated three times a day) $(\mathrm{P}$-value $=0.0437)$. Nevertheless, Treatment 1 was different than Treatment $2(\mathrm{P}$-value $=0.0008)$ and Treatment $3(\mathrm{P}$-value $=0.0003)$. Treatment 3 obtained the highest fresh weight (174.90 grams) followed very closely by Treatment 2 (168.53 grams) although the fresh weight was not statistically different (Figure 3.12). 
Figure 3.12. Comparison of fresh weight among the five different watering treatments in basil.

The same or different letters $(a, b, c)$ assigned to each treatment indicate respectively the similarity or difference between treatments.

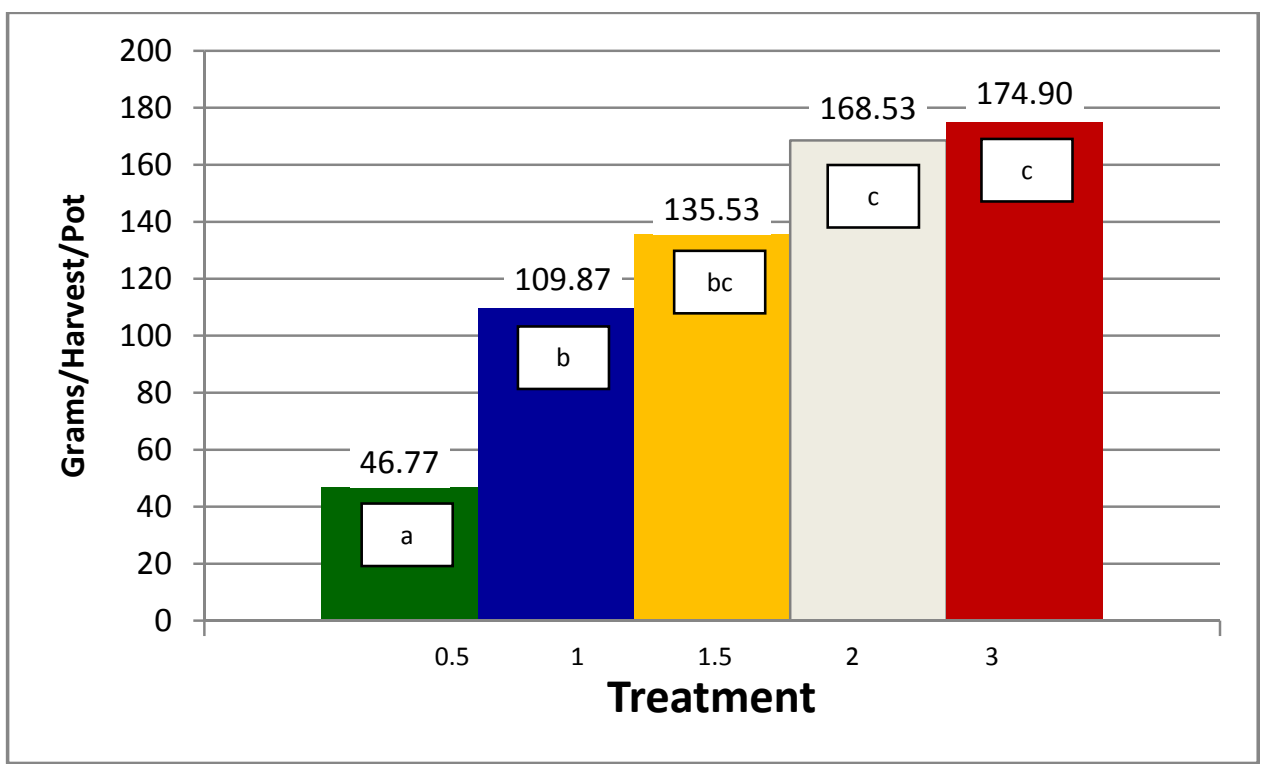

\subsubsection{Mint}

For mint Treatment 0.5 was different $(\mathrm{P}-\mathrm{value}<0.0001)$ from the other treatments and showed the lowest yield among them with an average fresh weight (Least Square Mean) of 18.77 grams (Figure 3.13). No significant differences were observed between Treatment 1 and Treatment $1.5(\mathrm{P}$-value $=0.0116)$. At the same time, Treatment 1.5 showed no significant differences to Treatment $2(\mathrm{P}$-value $=0.1708)$ and Treatment $3(\mathrm{P}$-value $=0.0308)$, yielding 50.91 and 60.75 grams respectively. However, Treatment 2 and Treatment 3 were different from Treatment 1 (P-values $=0.0001$ and $<0.0001$ respectively). Treatment 3 obtained the highest yield with a mean of 67.32 grams, although the fresh weight was not different from Treatment 1.5 and 2 (Figure 3.13). 
Figure 3.13. Comparison of fresh weight among the five different watering treatments in mint.

The same or different letters $(a, b, c)$ assigned to each treatment indicate respectively the similarity or difference between treatments.

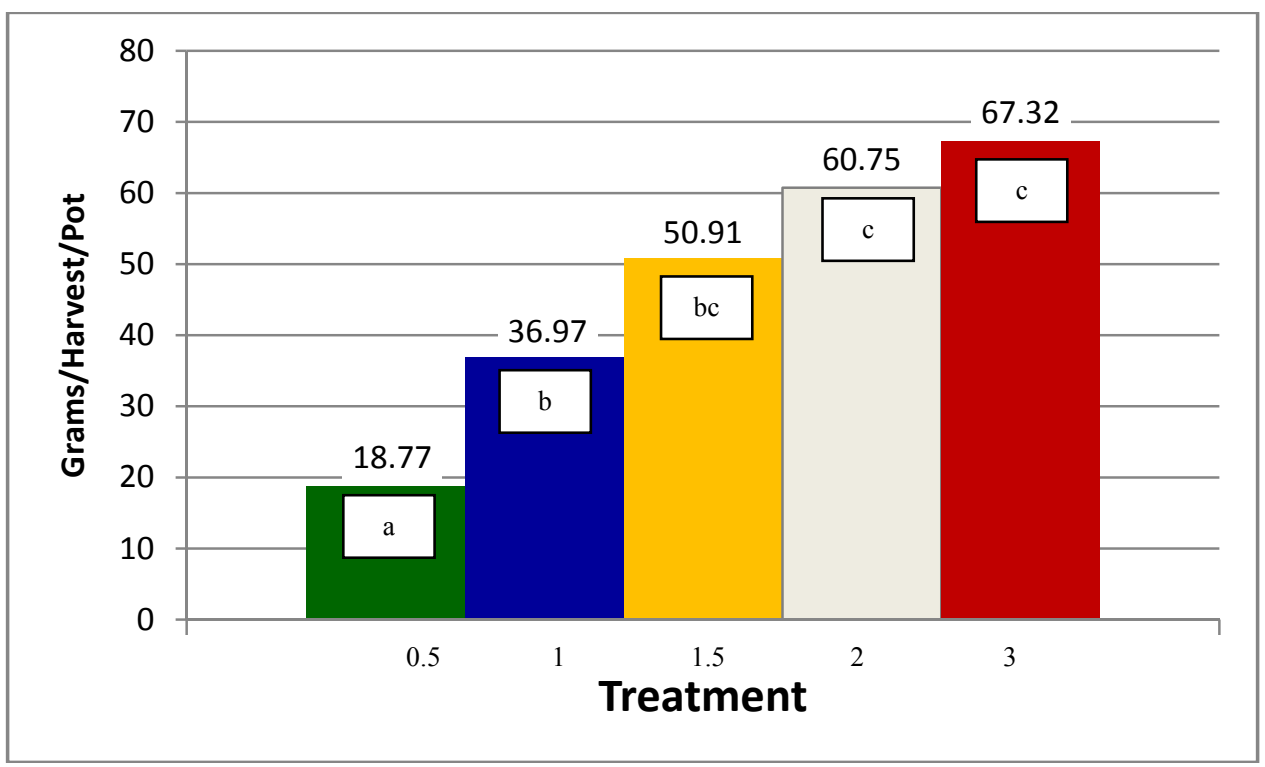

\subsubsection{Rosemary}

Treatment 0.5 obtained the lowest yield (16.19 grams) among the five treatments and was different $(\mathrm{P}$-value $<0.0001)$ from all the other treatments (Figure 3.14). Treatment 1 did not present differences to Treatment $1.5(\mathrm{P}$-value $=0.1342)$, and Treatment $2(\mathrm{P}$-value $=0.0024)$ obtaining means of $37.69,45.54$ and 55.45 grams respectively, but it was different from Treatment 3 (P-value $<0.0001)$ (Figure 3.14). Treatment 3 showed the highest fresh weight (65.90 grams) for rosemary. However, no significant differences between Treatment 1.5, Treatment 2 and Treatment 3 were observed (P-values $=0.1187,0.0036$ and 0.1709 respectively) (Figure 3.14). 
Figure 3.14. Comparison of fresh weight among the five different watering treatments in rosemary.

The same or different letters $(a, b, c)$ assigned to each treatment indicate respectively the similarity or difference between treatments.

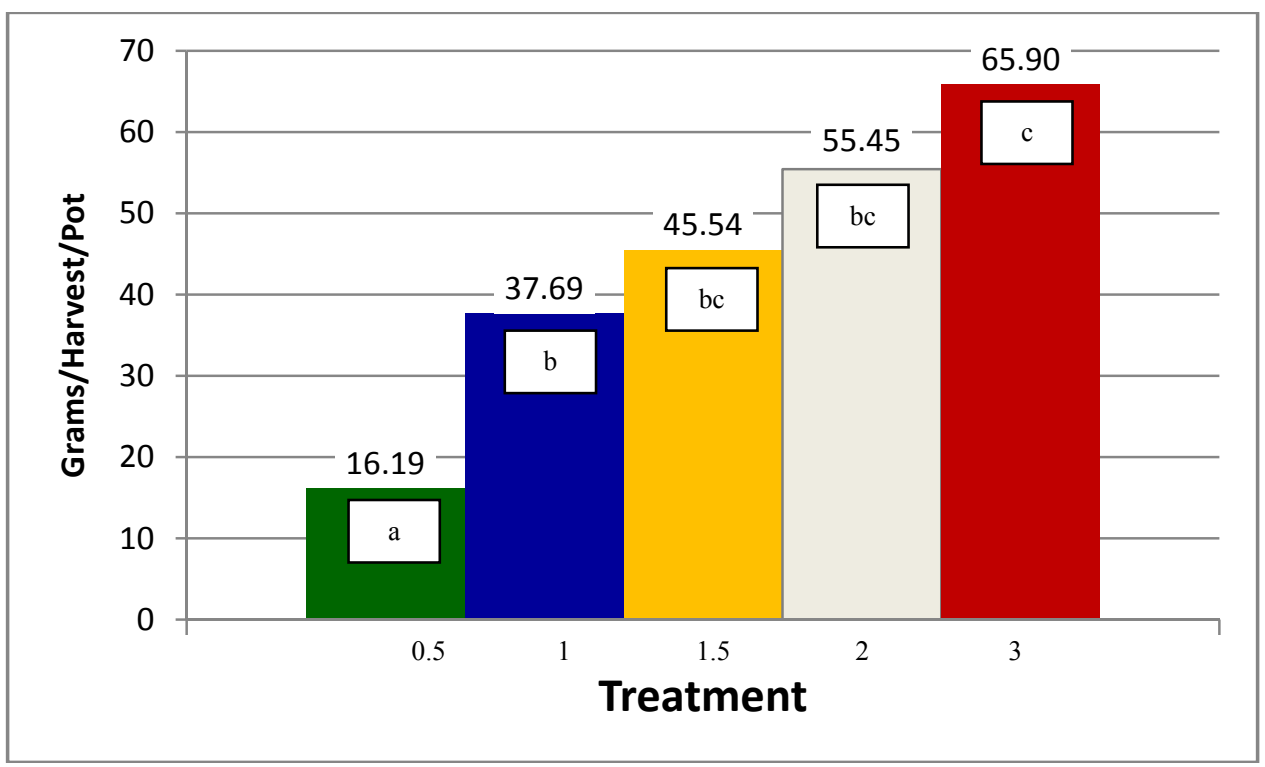

\subsubsection{Sunflowers}

Treatment 0.5 was different $(\mathrm{P}-\mathrm{value}<0.0001)$ from all the other treatments. This treatment also showed the lowest yield (24.23 grams) in fresh weight (Figure 3.15). Treatment 2 obtained the highest yield among the five treatments followed very closely by Treatment 3 and Treatment 1.5 showing means of 48.02 , 46.76, and 45.70 grams respectively. However, no significant differences between these three treatments and Treatment 1 (39.87 grams) were observed (Figure 3.15). 
Figure 3.15. Comparison of fresh weight among the five different watering treatments in sunflowers.

The same or different letters $(a, b, c)$ assigned to each treatment indicate respectively the similarity or difference between treatments.

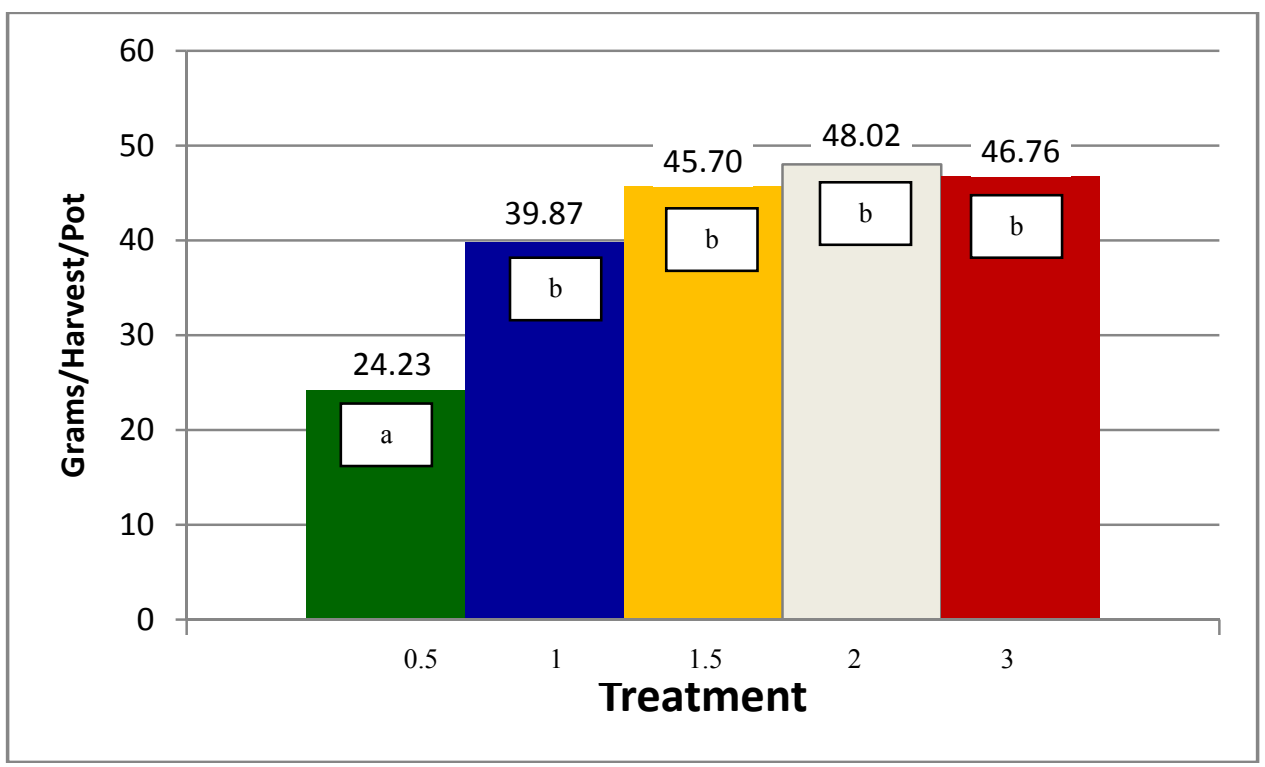

\subsubsection{Thyme}

No differences between Treatment 0.5, Treatment 1, Treatment 2, and Treatment 3 were observed (Figure 3.16). At the same time Treatment 1, Treatment 2 and Treatment 3 were statistically similar to Treatment 1.5 (Figure 3.16). However, Treatment 0.5 and Treatment 1.5 presented differences from each other $(\mathrm{P}-\mathrm{value}=0.0008)$ obtaining fresh weight means of 53.01 and 81.25 grams respectively (Figure 3.16). 
Figure 3.16. Comparison of fresh weight among the five different watering treatments in thyme.

The same or different letters $(a, b, c)$ assigned to each treatment indicate respectively the similarity or difference between treatments.

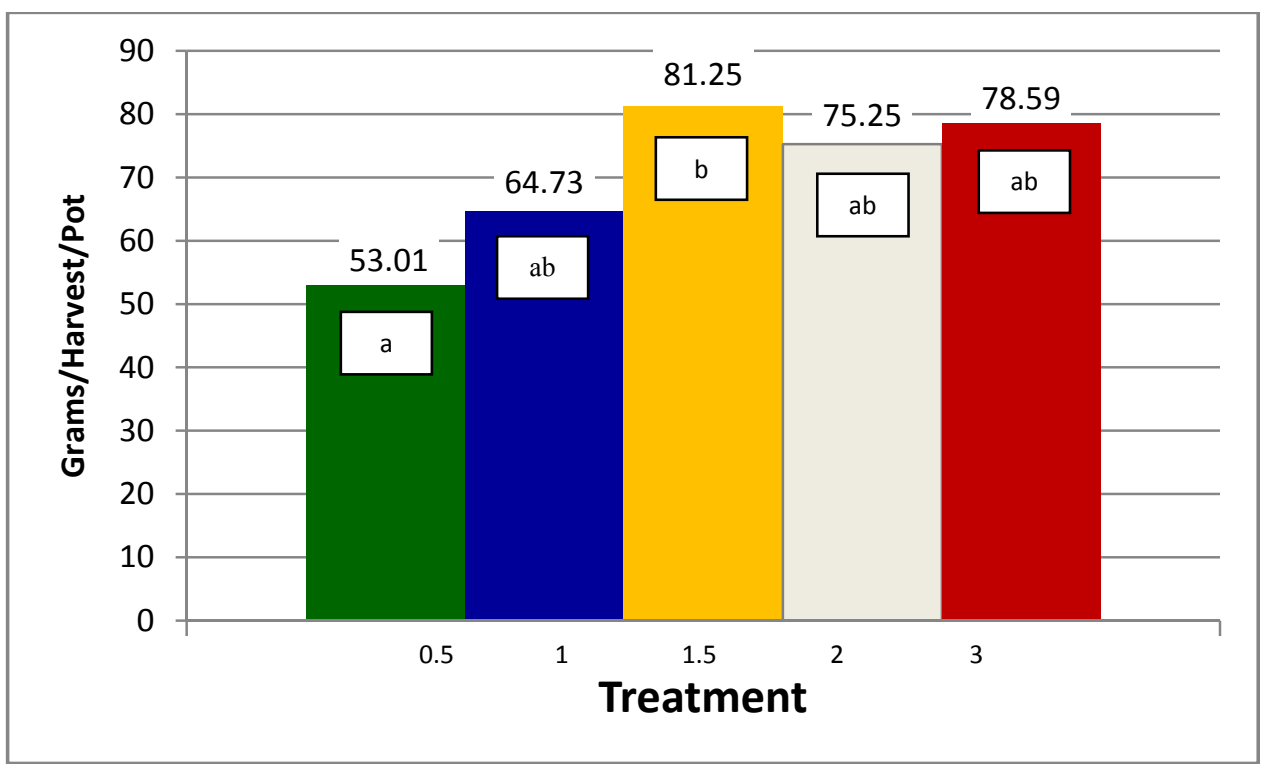

\subsubsection{Dry weight}

Differences in dry weight were observed (level of significance $\alpha=0.002$ ) between the five different treatments. Based on the Least Square Means values (including all plant species) dry weight decreased as the water frequency decreased. Treatment 3 and Treatment 2 obtained the highest yield (2.63 and 2.62 grams respectively) followed by Treatment 1.5 , Treatment 1 , and finally Treatment 0.5 (Figure 3.17). 
Figure 3.17. Comparison of the total dry weight between the five different treatments.

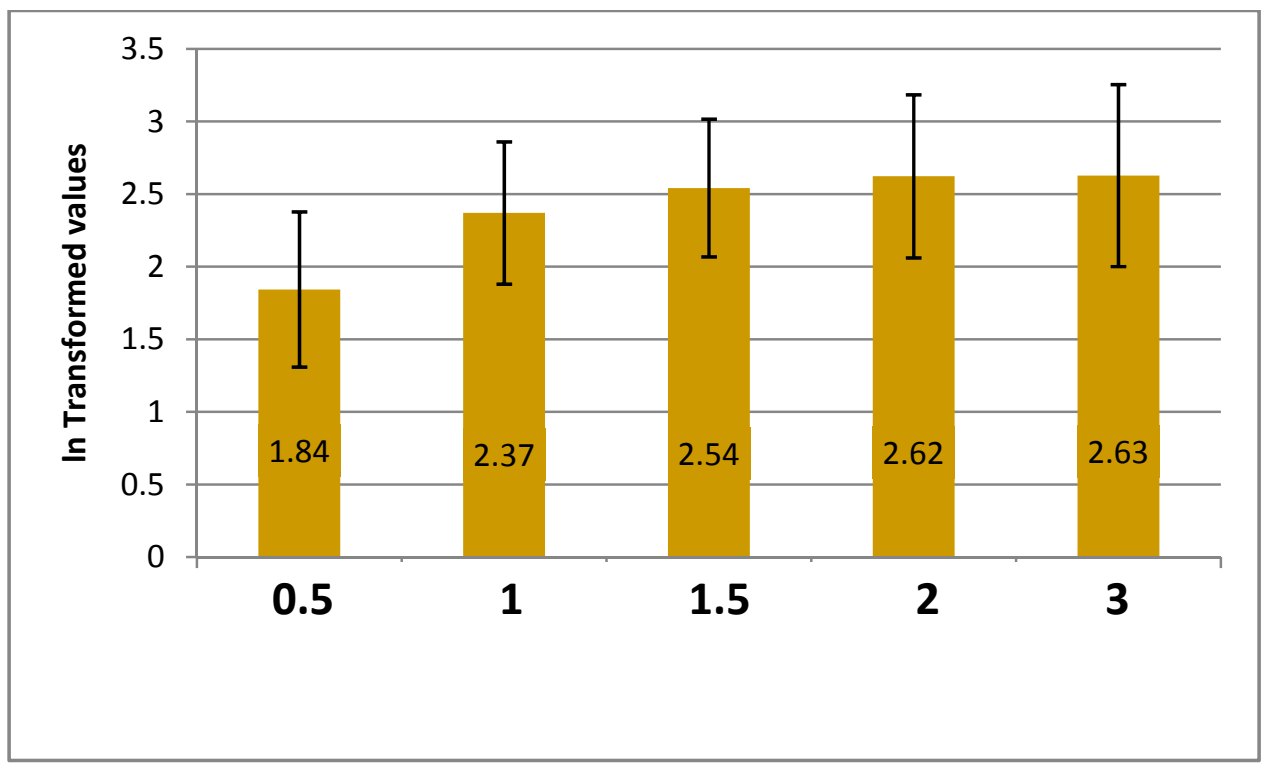

When the five plants species were analyzed separately differences in dry weight $(\mathrm{P}<0.0001)$ were observed. Thyme showed the highest average (Least Square Means) dry weight closely followed by basil, rosemary, mint and sunflowers (Figure 3.18).

Figure 3.18. Comparison of the total dry weight between the five different plant species.

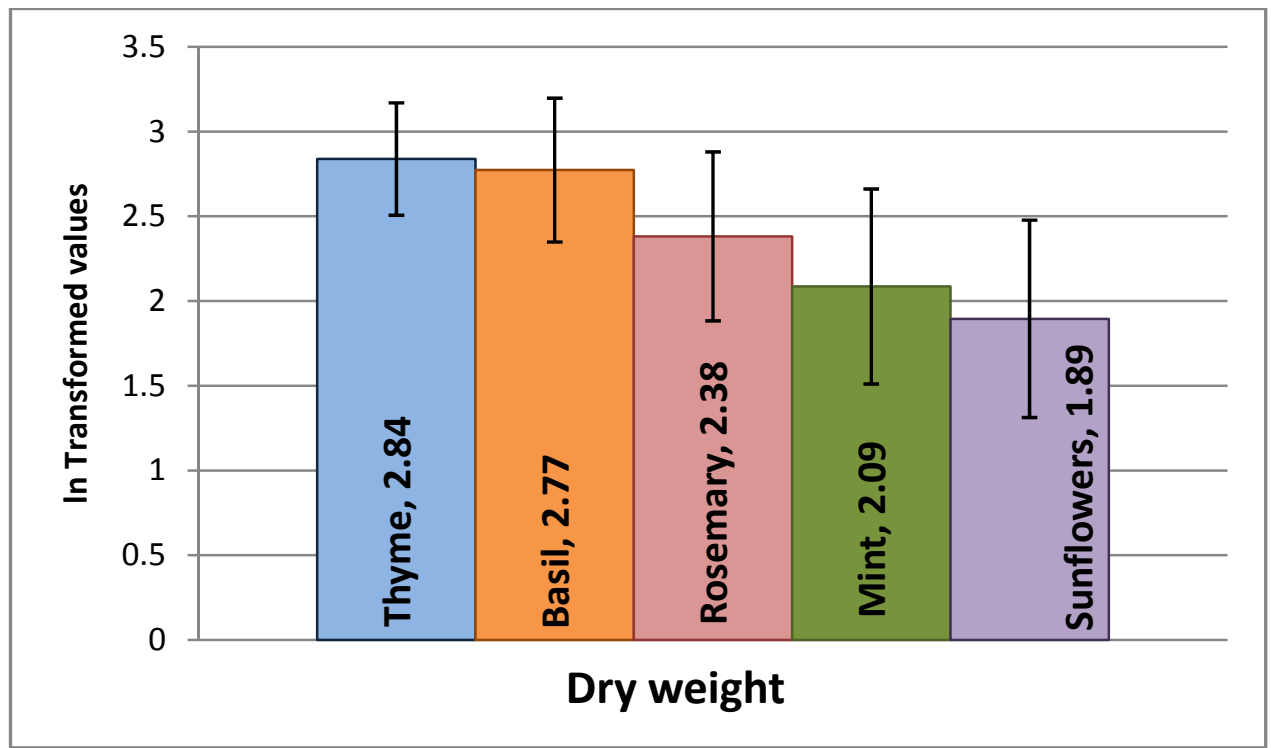


Figure 3.19 shows the total dry weight obtained per treatment and per plant species. Differences between water levels with respect to average dry weight varies by plant species $(\mathrm{P}<0.0001)$. Most of the plant species obtained the highest dry weight either in Treatment 3 or Treatment 2, except for thyme, for which the dry weight showed the highest values in Treatment 1.5. Treatment 0.5 yielded the lowest dry weight in all plant species. Sunflowers in Treatment 3 obtained a low yield, only slightly higher than the one obtained for Treatment 0.5 .

Figure 3.19. Comparison of dry weight between the five different plant species per watering treatment.

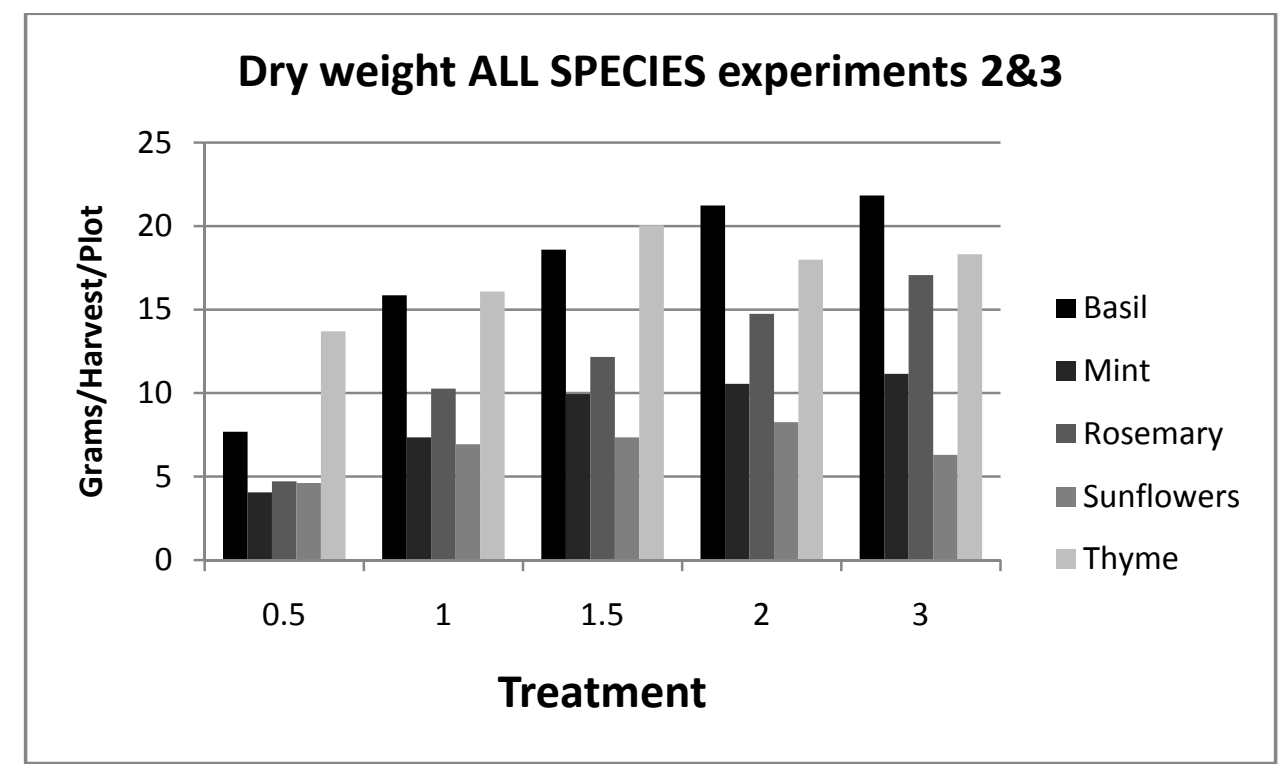

The performance of each plant species under the different watering regiments is included in the following sections. 


\subsubsection{Basil}

Treatment 0.5 was different $(\mathrm{P}$-value $<0.0001)$ from all of the other treatments. This treatment obtained the lowest dry weight (7.69 grams) (Figure 3.20). No statistical differences were observed between the other four treatments: Treatment 1, Treatment 1.5, Treatment 2 and Treatment 3 showing dry weights of 15.86, 18.59, 21.23, and 21.83 grams respectively (Figure $3.20)$.

Figure 3.20. Comparison of dry weight among the five different watering treatments in basil.

The same or different letters $(a, b, c)$ assigned to each treatment indicate respectively the similarity or difference between treatments.

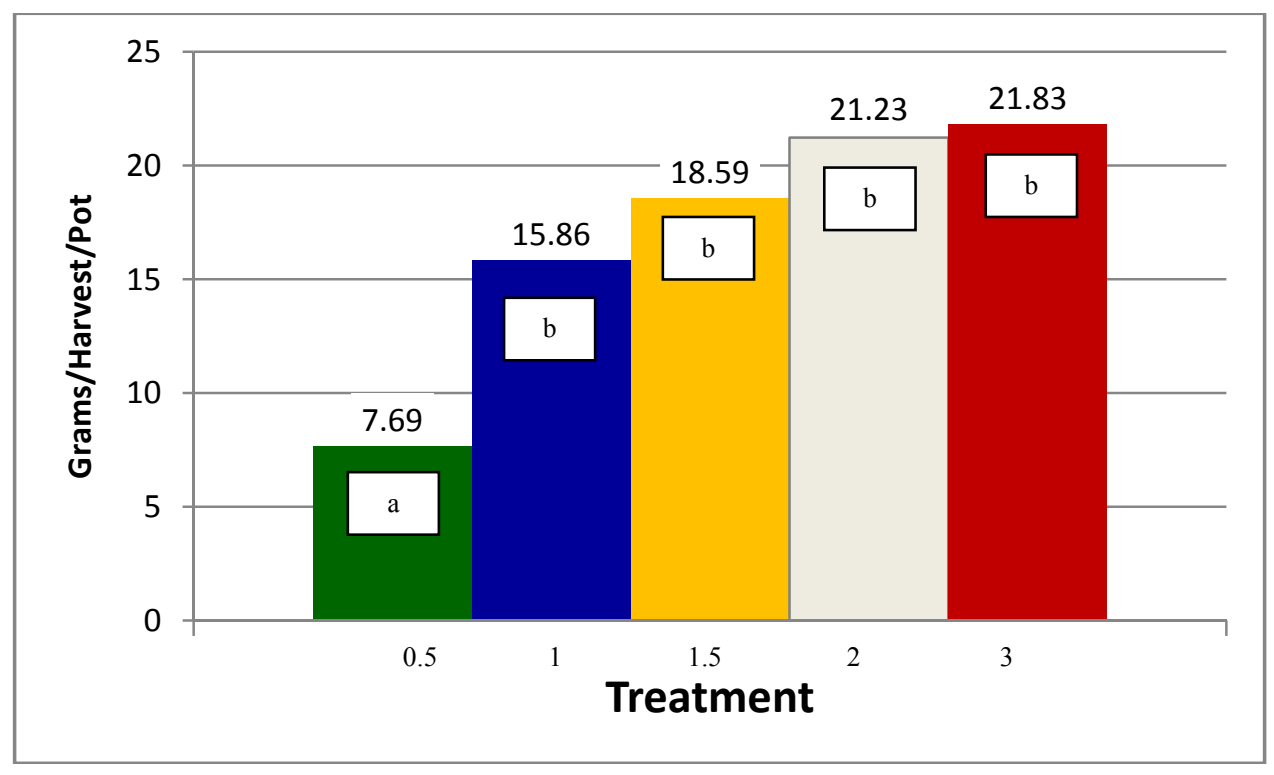




\subsubsection{Mint}

Statistical analysis showed Treatment 0.5 to be different $(\mathrm{P}$-value $<0.0001)$ from all the other treatments with a low dry weight of 4.06 grams (Figure 3.21). No differences in dry weight were observed between Treatment 1, Treatment 1.5, Treatment 2 and Treatment 3 which yielded $7.34,9.95,10.55$ and 11.15 respectively (Figure 3.21 ).

Figure 3.21. Comparison of dry weight among the five different watering treatments in mint.

The same or different letters (a, b, c) assigned to each treatment indicate respectively the similarity or difference between treatments.

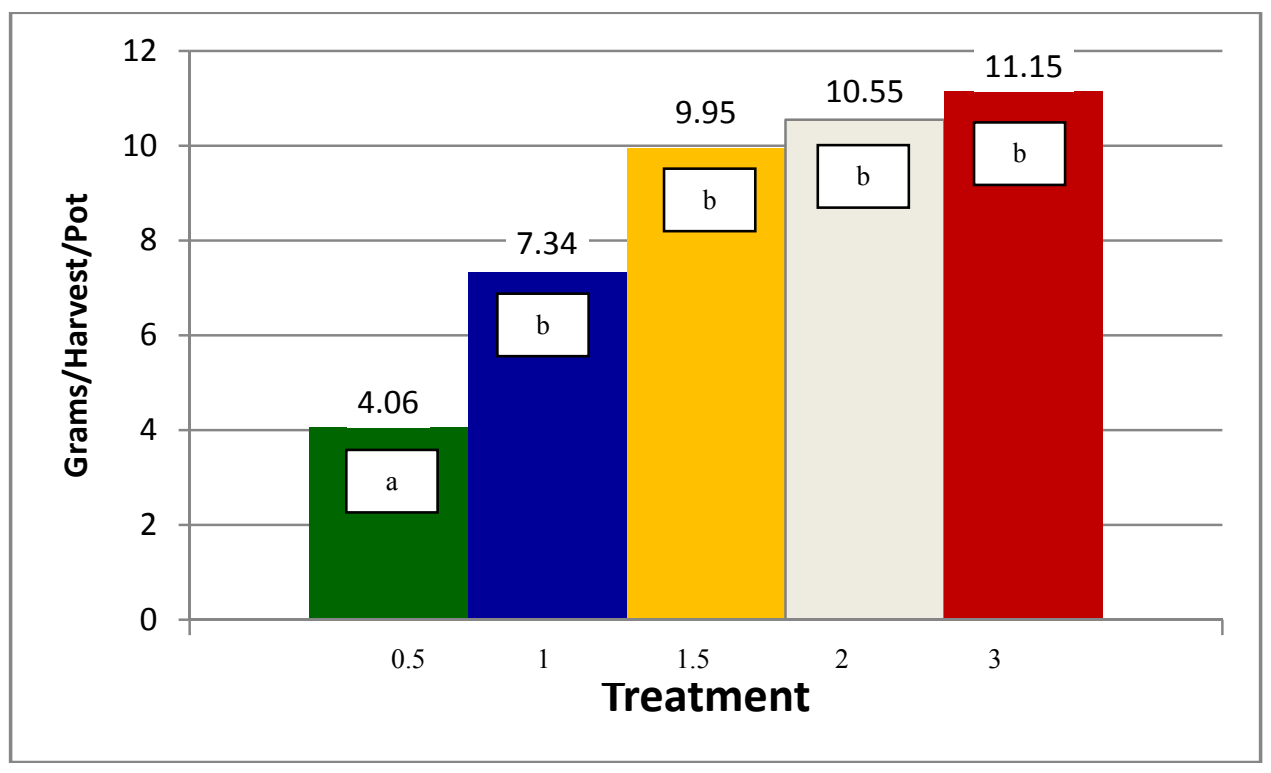




\subsubsection{Rosemary}

Treatment 0.5 showed a dry weight considerably lower (P-value $<0.0001)$ than the other treatments (Figure 3.22). Despite the fact that there was a trend toward increased dry weight as irrigation increased, no differences were observed between Treatment 1, Treatment 1.5 and Treatment 2 (Figure 3.22). At the same time Treatment 1.5 and Treatment 2 showed no differences with Treatment 3 (P-values $=0.0149$ and 0.2906 respectively). Nevertheless, Treatment 1 was different from Treatment $3(\mathrm{P}$-value= 0.0003). Treatment 3 showed the highest dry weight (17.06 grams) followed closely by Treatment 2 (14.74 grams) (Figure 3.22).

Figure 3.22. Comparison of dry weight among the five different watering treatments in rosemary.

The same or different letters $(a, b, c)$ assigned to each treatment indicate respectively the similarity or difference between treatments.

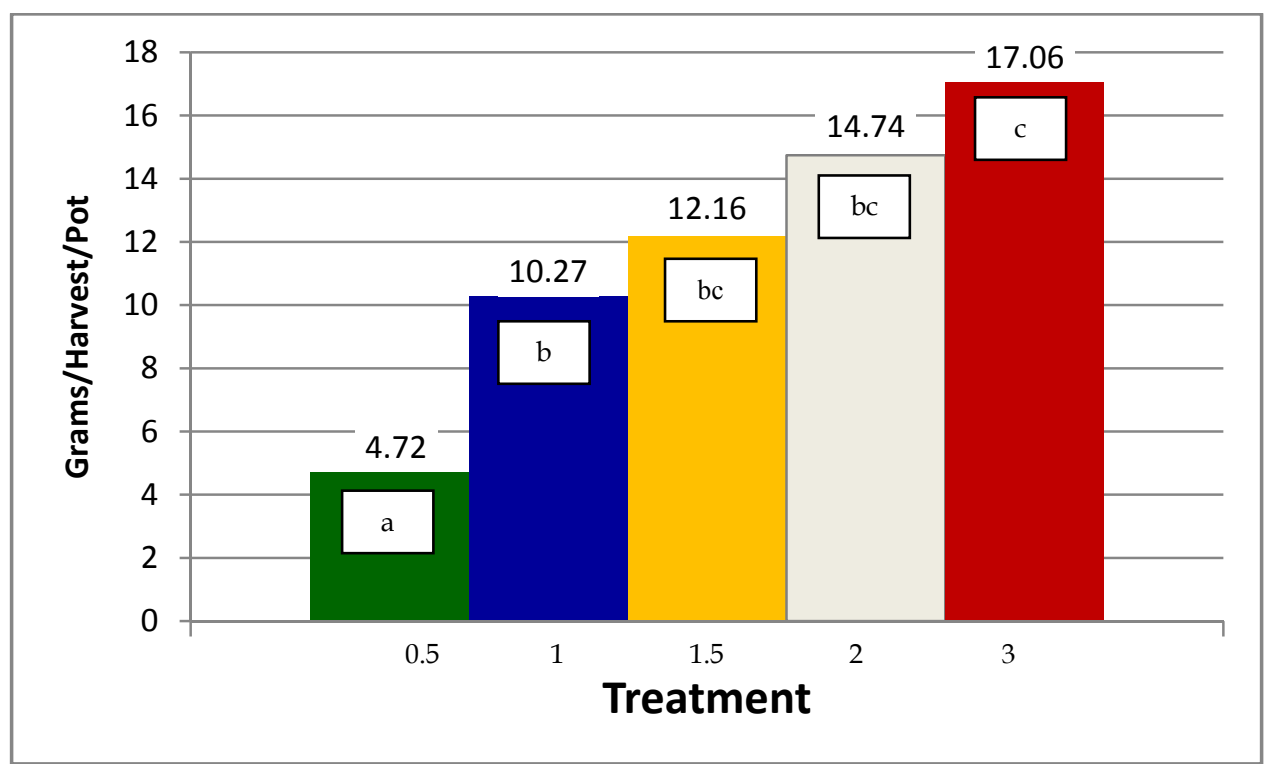




\subsubsection{Sunflowers}

No statistical differences were observed between Treatment 0.5 , Treatment 1 and Treatment 3. Among these three treatments, Treatment 0.5 obtained the lowest and Treatment 1 the highest dry weight at 4.61 and 6.94 grams, respectively. At the same time Treatment 1 and Treatment 3 showed similarities with Treatment 1.5 and Treatment 2 (Figure 3.23). However, Treatment 0.5 was different from Treatment $1.5(\mathrm{P}-\mathrm{value}=0.0015)$ and Treatment $2(\mathrm{P}-\mathrm{value}=$ $<0.0001)$. Despite of the similarities among treatments, Treatment 2 obtained the highest dry weight followed closely by Treatment 1.5 showing means of 8.25 and 7.35 grams respectively (Figure 3.23).

Figure 3.23. Comparison of dry weight among the five different watering treatments in sunflowers.

The same or different letters $(a, b, c)$ assigned to each treatment indicate respectively the similarity or difference between treatments.

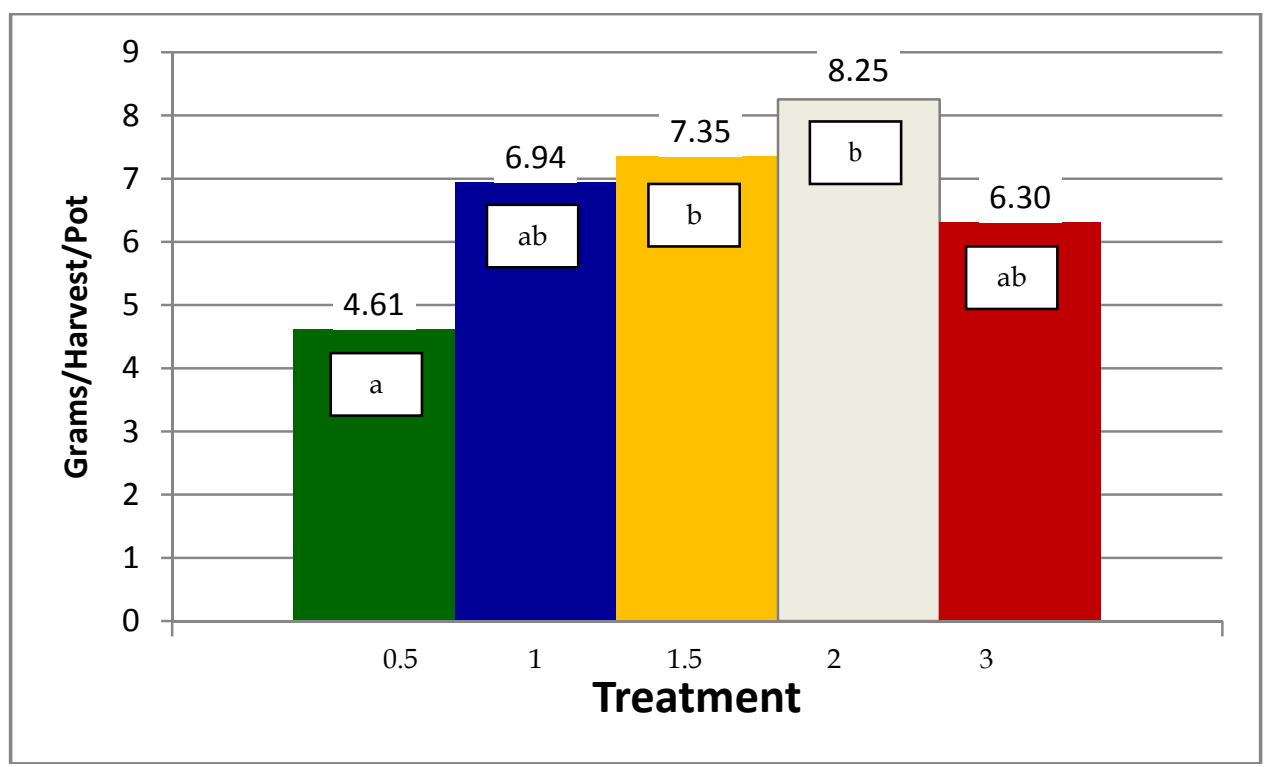




\subsubsection{Thyme}

No statistical differences in dry weight were observed among the five watering treatments (Figure 3.24). However, Treatment 0.5 obtained the lowest dry weight while Treatment 1.5 obtained the highest one showing means of 13.70 and 20.04 grams respectively. Treatment 3 and Treatment 2 showed means slightly lower than treatment 1.5 with 18.31 and 17.99 grams respectively (Figure 3.24).

Figure 3.24. Comparison of dry weight among the five different watering treatments in thyme.

The same or different letters $(a, b, c)$ assigned to each treatment indicate respectively the similarity or difference between treatments.

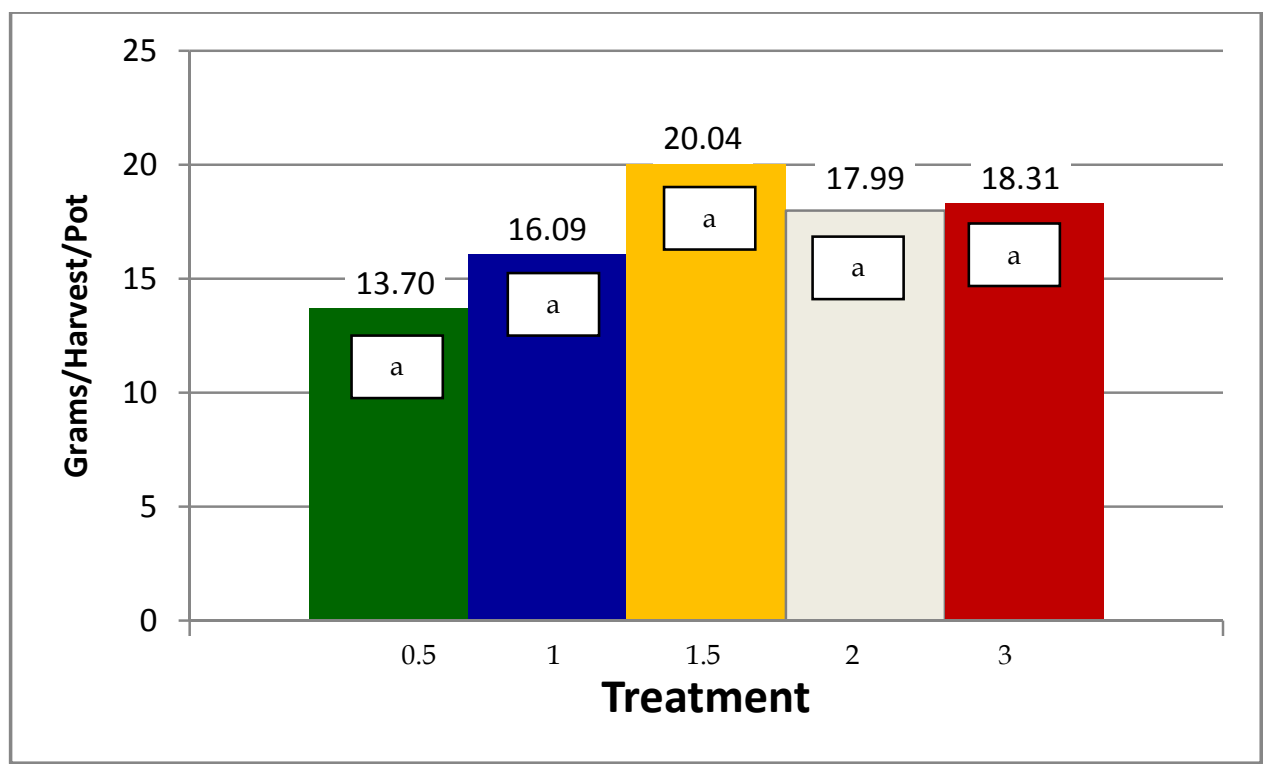




\section{Discussion}

\subsection{Experiment 1}

\subsubsection{Leachate}

The application of water, to a great extent, determines the growth rate of herbs. Stress from too little water will slow the growth and development of plants (Tucker and Debaggio, 2000). Many herbs have adapted to dry conditions, but the extent to which they can tolerate dry or relatively dry conditions is little known outside of the small circle of horticulturists and scientists who study the production requirements of these plants (Tucker and Debaggio, 2000).

This research was intended to study the water use of some herbs (mint, thyme, rosemary, and basil), and also one ornamental species (sunflowers). The experiment was designed to provide plants with water at $80 \%, 100 \%$, and $120 \%$ of container capacity. However, all the treatments in our experiment generated leachate. This phenomenon can be explained by the fact that the medium in each of the containers was never completely dry when water was applied. As mentioned before all plants were well-established into the medium before starting the experiment. Therefore, maintaining some level of moisture was essential for the growth and development of plants. As a consequence, the original measurements of container capacity were made based on the amount of water the medium (in a pot with an established plant growing in Tezontle) held without or with minimal leaching. In addition, the medium (Tezontle) used in this research was a very porous material. Despite the fact that different sizes of particles were well distributed in each pot when plants were established, after some time the smallest particles were located in the bottom of the container and the largest ones on the surface. This situation can be 
attributed to the fact that the particles were carried down in the medium profile by the water applied in the waterings and flushes. As a result the medium looked dry on the surface, while medium in the middle and bottom of the container most likely held plenty of moisture even in the $80 \%$ treatment (receiving the least amount of water). This phenomenon influenced the decision when watering was necessary. Hence, occurrence of leachate can be considered normal even in the $80 \%$ treatment.

The amount of the leachate among the treatments varied according to the amount of fertilizer solution applied to each of the water treatments. Thus, the $80 \%$ treatment receiving the least amount of water (approximately $136 \mathrm{ml})$ resulted in lowest amount of leachate $(22.53 \mathrm{ml})$. The $100 \%$ treatment receiving approximately $170 \mathrm{ml}$ of nutritive solution had a leachate mean of approximately $47.14 \mathrm{ml}$. And the $120 \%$ treatment receiving the most amount of water (approximately $204 \mathrm{ml}$ ) showed the highest amount of leaching $(74.03 \mathrm{ml})$.

Data also showed differences in the amount of leachate collected among plant species. Each plant has different morphological and physiological features and characteristics and the water and nutrients required to performance vital functions is therefore also different (Tucker and Debaggio, 2000). Among the species in this research were species having big and/or numerous leaves. These species (basil, mint, and sunflowers) will consume more water because of the presumably higher rate of transpiration. On the other hand, thyme and rosemary, the species in the group with low water requirements in this research, have smaller leaves and presumably show more conservative water use (lower transpiration). In addition rosemary leaves have a protective coat of trichomes and wax to avoid loss of water.

The root system of the plant species studied in this experiment looked very similar having numerous fibrous roots (Figure 4.1). In all species roots reached the bottom of the container and 
throughout the medium. However, roots occupied different number and size of voids in the medium, and their length depended on the size of the plant resulting in variable water holding capacity for each of the species. Basil and rosemary were the tallest permanently established plants in this research and showed the longest and most extensive root system (Figure 4.1).

\section{Figure 4.1. Root systems of four of the plants species studied.}

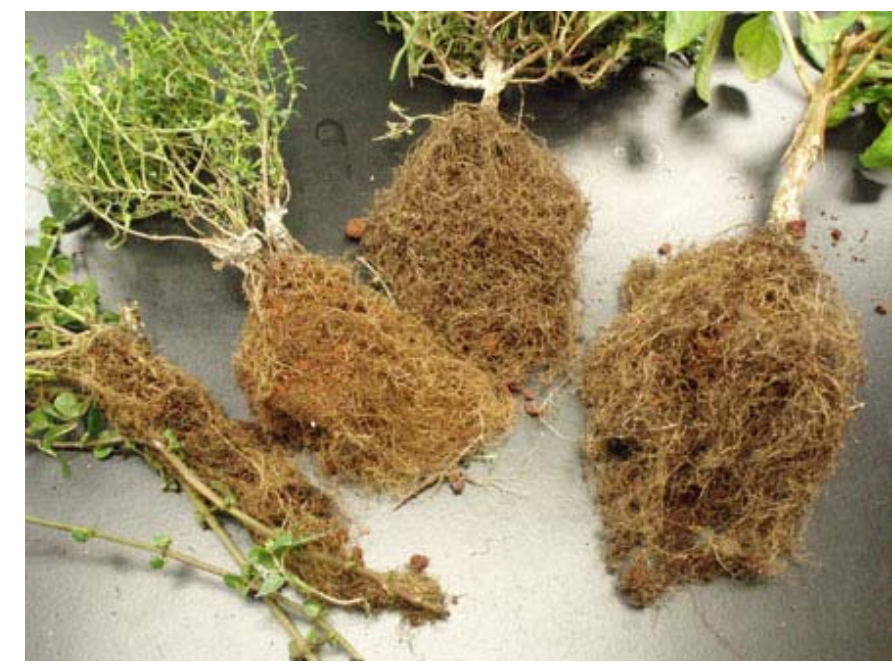

From left to right: mint, thyme, rosemary, and basil.

Leachate means for basil, plant species included in the high water requiring group, was the lowest (36.55 ml) indicating that most of the water applied was absorbed by the roots and/or retained by the medium in which these plants were growing (Figure 4.2). Although sunflowers were originally grouped with other species as high water requiring plants they did not show the same low amount of leaching $(65.33 \mathrm{ml})$ as basil. This observation may be directly related to the management of these plants. Sunflowers were established for cut flower production. Therefore, during the experiment the plants were at different stages of growth and development (starting when they were transplanted to when they were harvested) needing 
different amount of water in each stage of development. Sunflowers need very little water when first established compared to the water that they need when they are ready to be harvested. When sunflowers are newly established the plants have few and small leaves presenting a lower transpiration rate and in consequence a lower water loss than at harvest time. Moreover, plants in this juvenile stage have considerable fewer and shorter roots that do not extend throughout the medium. The fact that the leachate (average) of the sunflowers in this experiment was high (the highest in this experiment, even higher than the one of the plants with low water requirements) indicates that the overall water consumption of these particular plants (only one harvest was obtained and therefore evaluated for this experiment) was low. An explanation to these results is the fact that the sunflowers we grew in the unique harvest in this experiment (1) did not establish well in our production system and resulted in poor quality cut flowers. Consequently, the leachate that sunflowers showed in this experiment (unique harvest) is not a good indication of the performance (water uptake) of this plant species, and therefore it is not a reliable measure to consider sunflowers as a low water requiring plants. Unlike sunflowers, the low water requiring plants (thyme and rosemary) were well established into the medium before the experiment began. During the experiment they had an excellent development, and they maintained a slow-growing canopy all the time explaining their continuous and uniform water uptake (Figure 4.2). 
Figure 4.2. Leachate mean per plant species in Experiment 1.

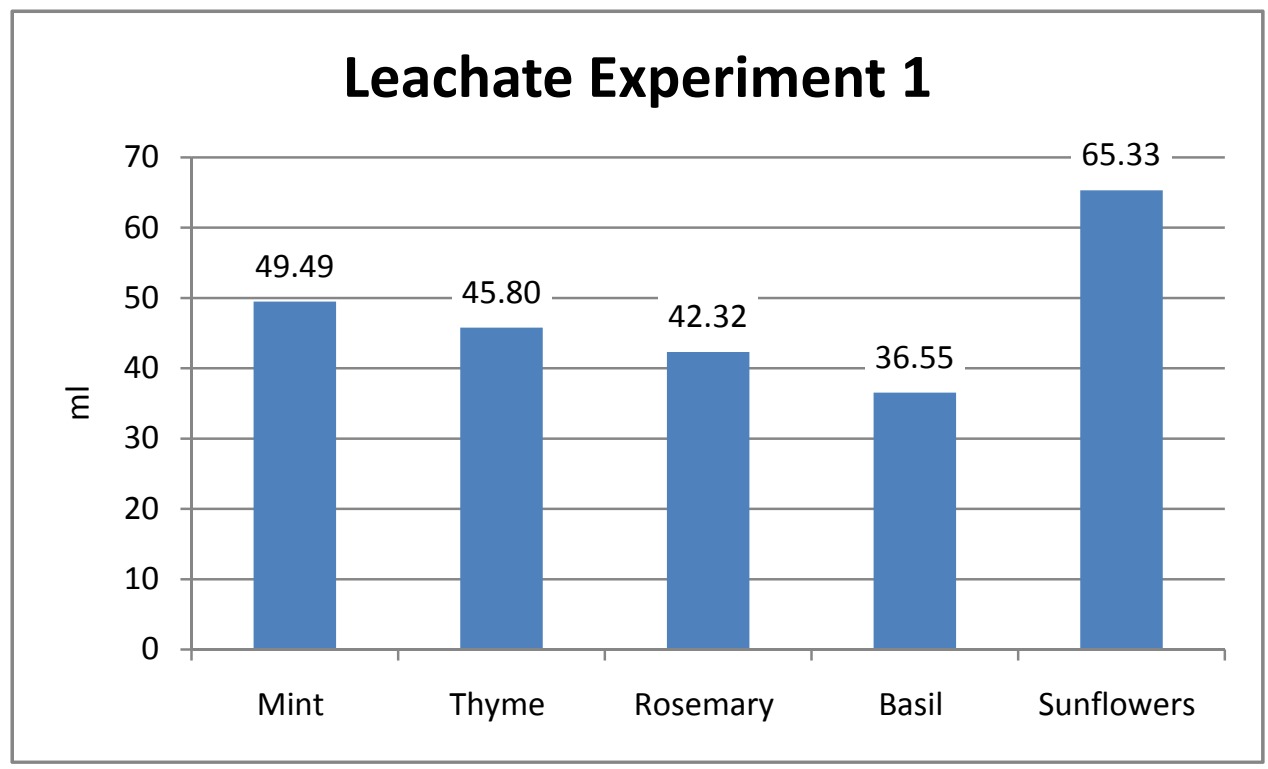

Thyme and rosemary leached on average $45.80 \mathrm{ml}$ and $42.32 \mathrm{ml}$, respectively (Figure 4.2). Although the means were very similar, thyme showed the lowest water requirement in this group. The response to the availability of water by plants varies (Tucker and Debaggio, 2000). The fact that both plant species developed and maintained physiological and morphological functions properly with slightly different amount of water sustains this statement.

Although mint is considered to be a high water requiring plant, this plant species showed a high leachate (49.49 $\mathrm{ml}$ ) (Figure 4.2) even higher than the low water requiring plants (thyme and rosemary). This phenomenon was most likely because of the multiple and severe pest infestations of spider mites (Tetranychus urticae) and aphids (Myzus spp.) that affected the canopy several times during the experiment diminishing the overall health of the plants. Also in the medium of this plant species the fungus Phythium $s p$ was found. This pathogen causes an impeded root functioning and could also have reduced the root mass of the plants. Therefore, the 
presence of these pathogens at the same time decreased in a high extent the water uptake of plants (Figure 4.3). urticae).

Figure 4.3. Mint plant with a severe infestation of spider mites (Tetranychus

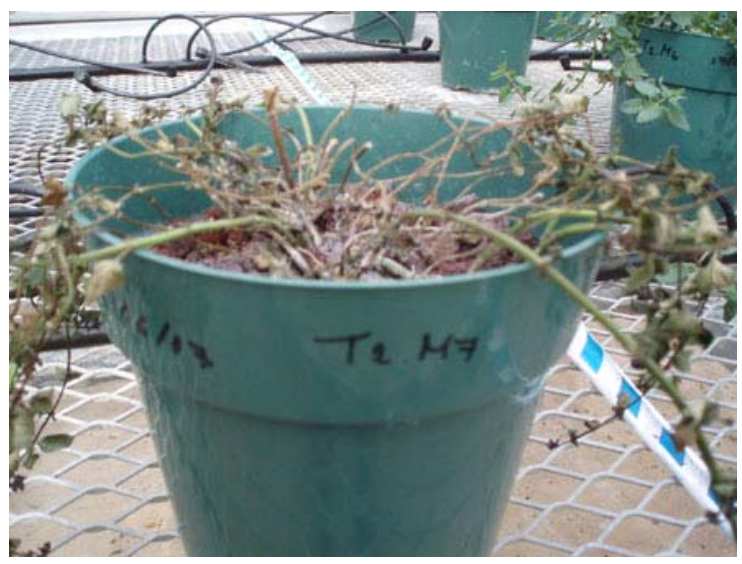

Observe the severe defoliation.

\subsubsection{Plant measurements}

Growth is accomplished through cell division, cell enlargement and differentiation, and involves genetic, physiological, ecological, and morphological processes and events and their complex interactions. The quality and quantity of plant growth depends on these processes and events and are in turn greatly affected by water availability and deficit. Growth is one of the most drought-sensitive physiological processes due to the reduction in turgor pressure (Taiz and Zeiger, 2006; Farooq et al., 2009). Cell elongation in higher plants is correlated with turgor pressure and under severe water deficiency cell elongation of higher plants can therefore be inhibited by interruption of water flow from the xylem to the surrounding elongating cells (Nonami, 1998; Farooq et al., 2009). Reduced water uptake also results in a decrease in tissue 
water content. Low water content induces the stomates to close. Drought stress therefore also reduces photosynthesis and the supply metabolites required for growth. As a consequence, less than optimum availability of water lead to impaired mitosis, cell elongation and expansion and therefore reduced growth (Farooq et al., 2009).

Most of the results of this study will be discussed with these basic facts in mind especially since one of our objectives was to test the performance of a number of crops in situations where water availability puts limits on crop production.

\subsubsection{Fresh weight}

The differences in fresh weight between the treatments (Figure 3.3) we observed were most likely related to morphological differences (number and size of leaves and/or stems) since we harvested tissue when plants did not show visual symptoms of drought stress. Drought stress has been shown to reduce leaf size, stem extension and root proliferation (Farooq et al, 2009). Therefore, as a group, well-irrigated treatments $(100 \%$ and $120 \%)$ obtained the highest means (23.13 grams and 21.92 grams respectively) while the treatment receiving the least amount of water (80\%) showed the lowest fresh weight (19.27 grams) (Figure 3.3).

Among the five plant species the highest fresh weights were recorded in basil (47.39 grams). Basil has large leaves attached to relatively wide stems and was the fastest growing plant among the plant species that were studied. The combination of these factors resulted in the high fresh weights observed for this species (Figure 3.4). Basil is one of the high water requiring plant in this study. The highest fresh weight for this crop although not significantly different from the other treatments was obtained in the $100 \%$ treatment (Figure 3.4). The small difference in yield between these treatments may be due to the fact that the amount of water that each one received 
was not very different (137ml-100\% treatment and $204 \mathrm{ml}-120 \%$ treatment), especially after taking into account the amount of water leaching from the medium. Furthermore, it needs to be considered that just one harvest was obtained and evaluated for this experiment.

Mint is another species that can show prolific growth, both in number of leaves and stems produced. However, in our experiment mint produced the lowest fresh weight among all the plant species that were studied (Figure 3.4). As cited before, mint plants suffered multiple severe infestations of spider mites (Tetranychus urticae) and aphids (Myzus spp.) throughout the experiment, diminishing their overall health. Under drought stress plants show increased susceptibility to diseases and insects (Witt et al., 1999). Nevertheless, in our experiment plants in all the treatments had to be treated to eliminate the insects, and in a couple of instances needed to be completely trimmed back to eliminate the damaged tissue. In addition to insect damage, an infestation of the root rot fungus Phythium sp. also reduced plant vigor. The combination of these pathogens caused all plants to grow slowly and some plants to die before they could be harvested. As a result, the data collected and averaged as fresh weight in the unique harvest of mint in this experiment included considerable fewer samples than the ones for the other species. The data collected for mint therefore does not properly reflect the performance or yield that this plant species could have in normal production circumstances. However, as a high water requiring plant, and despite all previously mentioned problems, mint showed higher yields as the amount of water increased (Figure 3.4).

Sunflowers were the third plant species considered as high water requiring plant in this study. Nevertheless, fresh weight was not considerably different between the three treatments for this plant species (Figure 3.4). A possible explanation may be the fact that the three treatments did not receive a different enough amount of water to cause a significant effect on the plants. 
Therefore, plants did not show big differences in their morphology and hence in their weight. In addition, and as mentioned before, this plant species did not show good plant establishment and development in this experiment, a condition that may have been exacerbated by the time of the year (fall and beginning of winter) when this experiment was performance. Consequently, the fresh weight reported in this unique harvest most likely does not reflect the yield that this plant species could obtain in optimal growing conditions.

The fresh weight of rosemary obtained in the three different treatments was very similar. However, the $100 \%$ treatment followed by $120 \%$ treatment obtained the highest yield (Figure 3.4). These results show that even rosemary, considered a low water requiring plant, needed to be irrigated with adequate amounts of water. The fact that the irrigation at container capacity $(100 \%$ treatment) obtained higher fresh weight than the $120 \%$ treatment in this harvest may be because this treatment presented better conditions for growth. One reason may have been the fact that the experiment was carried out during the fall and beginning of winter (September 16 to December 15). The temperature at that time of the year was not very high and consequently plants did not have high levels of transpiration or water use. In addition, plants received limited natural light. Hence, photosynthetic activity of rosemary plants was low and plants may have even entered into dormancy. Much of the applied water therefore remained in the medium and in the $120 \%$ treatment may have even resulted in flooding like conditions. Under flooded or overwatering conditions, plant roots are in state of hypoxia (low oxygen), their metabolic activity is inhibited and ATP production decreases (Saglio et al., 1980; Liao, 2001). The decreased ATP production restricts the supply of energy for root growth, thus reducing vegetative growth (Liao, 2001). Since evapotranspiration was not high during the time of the year when the experiment (unique harvest) took place, the aeration of the growing medium was most likely better in the 
pots in the $100 \%$ treatment allowing a higher oxygen uptake by the root system and therefore better water and nutrients flow into the plant.

Thyme like rosemary showed the highest fresh weight in the treatment irrigated at container capacity (CC) or 100\% treatment followed by the $120 \%$ treatment (Figure 3.4). Thyme plants in the $80 \%$ treatment showed the lowest fresh weights, an observation that could be visually corroborated by the fact that these plants suffered from drought stress throughout the experiment. These results also showed that even minimal drought stress has an influence on the growth of this plant species. Based on experience from this research, thyme production in Tezontle as hydroponic medium can use relatively small amounts of water preserving adequate aeration and at the same time maintaining reasonable yields. In addition, thyme responds differently to growing conditions (aeration of the medium and irrigation frequency). Therefore, this plant species showed different yield and even different morphology as the level of water increased. The fact that the $100 \%$ treatment obtained the highest yield may have the same explanation as what has already been mentioned for rosemary. Although thyme is considered a low water requiring plant, the $100 \%$ treatment presented the best growing conditions among the three treatments. Since plants were irrigated when the $80 \%$ treatment needed to be irrigated it is very probable that these plants continuously suffered drought stress (as well as the other four plant species growing in this treatment), and therefore affecting their yield. On the other hand, thyme plants growing in the $120 \%$ treatment most likely did not have adequate aeration for their root system, diminishing the oxygen uptake, and therefore affecting metabolic activities that translate in growth. 


\subsubsection{Dry weight}

Liu and Stutzel (2004) reported that drought stress significantly decreased plant total dry mass (Özenç et al., 2008). The treatment in this experiment with the least amount of water applied (80\%) therefore not surprisingly also showed the lowest dry weight (4.57 grams) (Figure 3.5). Transpiration rates decrease during soil drying (Nagakura et al., 2004; Özenç et al., 2008). Transpiration is directly related to whether stomata are open or closed. Transpiration is affected by several factors such as available water content, aeration capacity of soil, and humidity. As plants close their stomata under water stress conditions, the transpiration and photosynthesis rate is decreased resulting in decreased plant growth and dry matter production (Özenç et al., 2008). Besides a reduction in the rate of photosynthesis due to a lack of carbon dioxide assimilation, the closed stomata results in reduced transpiration that directly affects the transport of soluble nutrient elements (passive absorption) (Özenç et al., 2008). We could therefore surmise that stomata closure in plants in the $80 \%$ treatment was higher than in the plants in the other two treatments leading to a lower transpiration index and consequently decreased photosynthesis and less soluble nutrient elements available for proper cell formation and functioning. The effects of drought range from morphological to molecular levels and are evident at all stages of plant growth and development, whatever stage the water deficit takes place (Farooq et al., 2009). Therefore, we can assume that the difference in dry weight among the treatments was due to morphological, metabolic, and/or molecular changes in the cells of the plants submitted to less frequent watering.

In spite of Basil being considered a high water requiring plant this plant species obtained the highest dry weight in the treatment irrigated at container capacity (100\% treatment) (Figure 3.6). This indicates that plants in this treatment had a higher growth index using slightly less water than plants in the $120 \%$ treatment. Although the difference between these two treatments 
was not significant the results indicate that plants growing in the $100 \%$ treatment may have subjected to the most optimum conditions of growth, at least among the three treatments in this experiment. The effect of drought on yield and total growth is more detrimental in spring plantings than in autumn plantings. Steyn et al. (1998) stated that higher temperatures during spring trials may aggravate the effect of water stress (Mienie, 2008). According to this statement, since temperatures during the period of time when the experiment was performed (autumn and winter) were relatively low, basil was not subjected to a high transpiration index. Also, the hours of natural light were diminishing during the experiment most likely decreasing the evapotranpiration index. Therefore, plants did not need to replenish large amounts of water to maintain vital functions. Hence, it can be hypothesized that when plants were irrigated the medium already had some level of moisture due to the relative low water uptake by the plant. Despite the small difference in the amount of water applied between the $100 \%$ treatment and $120 \%$ treatment (137 and $204 \mathrm{ml}$ respectively), we think that the growing medium in the pots in the $100 \%$ treatment maintained more spaces or pores filled with air than water when compared to the $120 \%$ treatment. Therefore, the $100 \%$ treatment most likely maintained a better aerated root system.

Mint, despite some pest problems during the experiment, showed dry weights or actual growth increasing as irrigation increased (Figure 3.6). Mint as a high water requiring plant needs to be irrigated very frequently to maintain leaf turgor and performance of essential physiological functions. As cited previously lack of water has direct effects on stomatal opening and therefore has an influence on the vital physiological processes of transpiration and photosynthesis. A reduction in photosynthetic efficiency plays an important role in yield loss during water stress as it influences carbon assimilation (Ogren E., 1990; Mienie, 2008). Although mint plants in the 
three treatments lost a significant part of their canopy due to the infestations of spider mites (Tetranychus urticae) and aphids (Myzus spp.), plants receiving more irrigation were able to photosynthesize at a higher rate than plants receiving less water, in which the stress of the pests was exacerbated by drought.

Sunflowers are other high water requiring plant species that had significant production problems in this experiment. This plant species did not get established satisfactorily, and therefore plants showed slow rates of growth in all treatments (Figure 3.6). The inadequate performance of the plants may be attributable to the reduction of natural light while the experiment was being carried out (fall and winter). However, their poor development was also aggravated by the presence of the root rot fungus Phythium sp. into the growing medium. Hence, since sunflowers were stressed by biotic factors as well as drought their yield was predictably lower. However, the difference between treatments was minimal (Figure 3.6).

Rosemary, considered a low water requiring plant in this study showed the highest dry weight in the treatment irrigated at container capacity (100\% treatment) (Figure 3.6). Reports on its production indicate that rosemary grows well in pots, as long as they are in a sunny place and not over-watered (French, 1993). According our experience growing rosemary in Tezontle and despite some statements in the literature (Tucker et al., 2000; French, 1993) about its low water requirements, rosemary showed higher growth as irrigation increased, at least from $80 \%$ treatment to $100 \%$ treatment (container capacity). The fact that plants showed a higher dry weight in the $100 \%$ treatment instead in the $120 \%$ treatment in this experiment is probably rooted in the same morphological and physiological processes discussed to explain the higher yields of basil in the $100 \%$ treatment. 
Thyme, thought to be the lowest water requiring plant species among the five studied in this research, produced the highest dry weight in the $100 \%$ treatment (Figure 3.6). The explanation for this may be again the fact that the plants were watered when the $80 \%$ treatment (least irrigation) needed to be irrigated. Hence, plants in this treatment (80\%) suffered drought stress (by design) diminishing their growth and therefore resulting in the lowest dry weights. In contrast, the treatment receiving the most irrigation (120\% treatment) showed slightly lower dry weight than the $100 \%$ treatment (Figure 3.6). As stated before thyme is highly affected by the growing conditions into the medium (water and air proportion) showing different extent of growth and even different morphology (personal observation). A major constraint resulting from excess of water is an inadequate supply of oxygen to submerged tissues. Diffusion of oxygen through water is $10^{4}$-fold slower than in air (Armstrong et al., 2002; Jackson, 2005). Since plants were growing during the fall and winter their water consumption was very low. Therefore, the growing medium in the $120 \%$ treatment remained moist most of the time perhaps resulting in inadequate aeration of the root system as suggested before, and ultimately diminishing plant growth.

The trend in dry weights of the five plant species that were studied in this experiment corresponded well to the trend in fresh weight that was observed. In both measurements basil showed the highest means while mint showed the lowest fresh and dry weight of all species tested. The other species followed the same order in fresh weight and dry weight except for sunflowers and rosemary. Sunflowers occupied the third place in the sequence of fresh weight (from high to low) while rosemary occupied this place in the dry weight trend. Rosemary may have a higher amount of dry matter content than sunflowers because of the morphology of its stems and leaves which are woody, waxy, and thick. 
On the other hand, dry weight (average) for the group of plants with high and low water requirements was opposite to the one for fresh weight. The group of high water requiring plants (basil, mint and sunflowers) showed a mean (4.25 grams) of dry weight lower than the one shown by the low water requiring plants (thyme and rosemary; 5.01 grams). The ratio between dry matter produced and water consumed is termed water use efficiency at the whole-plant level (Monclus et al., 2005; Farooq, 2009). Although not calculated for our experiments, but according to this statement one could conclude that the low water requiring plants in this experiment were able to get a higher rate of growth (dry matter production) than the group of plants with high water requirements using the same amount of water and therefore a higher water use efficiency. However, it needs to be highlighted that the difference in dry weight between the two groups of plants could have been highly influenced by some other factors. Mint and sunflowers (high water requiring plants) suffered from other types of stress (pathogens) in addition to the drought stress. These combined stresses clearly diminished their vigor and growth.

\subsubsection{Height}

The five plant species in this experiment showed different heights (due to their own specific morphology and physiology). Increasing water deficits has been shown to result in a relatively lower yields and plant height (Kiziloglu et al., 2009). However, and despite the literature on the negative effect that scarcity of water has on growth and development of plants, none of the five plant species in this experiment (1) showed significant differences in height among treatments. As stated before, only one harvest was obtained for each of the plant species studied in this experiment. Hence, we were not able to compare the height response over prolonged periods of time. However, one way to explain the lack of differences in height in this 
experiment is the fact that the amount of water that plants received in each treatment was not very different ( $80 \%-136 \mathrm{ml}, 100 \%-170 \mathrm{ml}$ and 120\%-204 ml). On the other hand, as mentioned before differences in fresh weight and dry weight among treatments were observed. One of the theories that could explain this physiological phenomenon is that plants adapt to the amount of water they receive (Salisbury et al., 1992). Plants in the three treatments therefore would be able to present elongation at a similar rate despite of the amount of water that they receive. Another possible explanation for this phenomenon is that elongation is a response that is affected less by water availability than overall growth (estimated by fresh weight, dry weight, number of stems and number of leaves). For a number of species elongation takes place around sunrise. At this time of the day temperature is generally low resulting in relatively high turgor pressure. Therefore, plants in our experiment were most likely not heat or drought stressed during the time of the day when most elongation takes place. At sunrise and for a few hours plants thereafter may have had the stomata completely open because the rate of transpiration would be very low. At this point the photosynthetic rate of the plants was likely high (possibly the highest during the day) allowing the plants elongate and grow. High temperatures and drought stress later in the day, after most elongation took place would result in stomatal closing (Salisbury et al., 1992). At high temperature the transpiration rate increases and plants start losing water through the stomata. As a water conservation response against this situation plants close their stomata to reduce transpiration and as a result photosynthesis. Unlike elongation, growth does not occur at a pre-determined and limited time period of the day. Therefore, growth could be diminished or interrupted while elongation would not. 


\subsubsection{Stems}

Plants in this experiment were irrigated when thyme, the lowest water requiring plant species, needed water in the treatment receiving the least amount of water $(80 \%)$. At the beginning of the experiment watering was commonly done on a daily basis. However, since this experiment was performed from September 16 to December 15 as temperature and natural light hours were diminishing, thyme plants (and all plants in the experiment) showed reduced water uptake as the experiment went on. Therefore, watering was performed less frequently. During the first months of the experiments we observed that, at least for rosemary and mint, the amount of water that the $80 \%$ treatment received (and sometimes $100 \%$ treatment and even $120 \%$ treatment) was often not enough to maintain a well-hydrated canopy. This may have resulted in different levels of drought stress in plants in the different treatments. In addition, plants are affected by water stress differently depending on the developmental stage of the plant when subjected to drought (Özenç et al., 2003; Deproost et al., 2004; Font et al., 2005; Özenç, 2008). Plants were established in the growing medium during the months when they experienced most drought stress. Hence, it is very possible that plants experienced additional stressed because of being newly transplanted. A lack of water surely aggravated the drought stress and consequently caused a stronger long-term effect in the treatment receiving the least irrigation ( $80 \%$ treatment). Consequently, the three plant species (mint, thyme and rosemary) produced a lower number of stems in this treatment.

Mint most likely produced a reduced number of stems due to the severe pathogenic infestations of spider mites (Tetranychus urticae), aphids (Myzus spp.) and the root rot fungus Phythium sp. it encountered. However, and despite these problems mint as a high water requiring plant showed the highest number of stems as irrigation increased (Figure 3.7). This performance 
indicates that plants even heavily stressed by pathogens they were able to respond to application of water.

Thyme was the plant species having the largest number of stems due to its overall morphology (Figure 3.7). Despite the fact that this plant species showed the highest fresh weight or total yield in the treatment irrigated at container capacity (100\% treatment) (Figure 3.4), the highest number of stems was observed in the $120 \%$ treatment (Figure 3.7). One explanation for this observation could be a slightly different morphology of the stems. Although the stems in the three treatments were very similar at the first glance, stems in the $120 \%$ treatment could have been slightly thinner or have smaller leaves than the ones in the $100 \%$ treatment, something we observed in subsequent experiments (see below). Therefore, we postulate that stems in the $120 \%$ treatment albeit higher in number were lower in weight due to morphological changes. Based on our experience growing thyme hydroponically we know that its morphology and growth patterns are highly influenced by the amount of irrigation water applied and therefore, the aeration conditions in the growing medium. When thyme is over-watered the production of stems is higher without necessarily increases in fresh and dry weight (results in subsequent experiments in this research). Based on this observation, we may hypothesize that the medium in the $120 \%$ treatment did not have good aeration, especially during fall and winter. Plants were therefore starting to present symptoms of lack of oxygen which in the case of thyme presented itself as a higher number of thin shoots with a smaller leaves. Nevertheless, it is necessary to take into account that these results are just from one harvest, and that the difference in number of stems between these two treatments was very small.

For rosemary unlike thyme the highest fresh weight (Figure 3.4) and number of stems (Figure 3.7) was in the treatment irrigated at container capacity (100\% treatment). This indicates 
that this treatment presented the best growing conditions for this plant species. Since a large part of the experiment was performance under limited sunlight and relatively low temperatures rosemary did not experience high rates of transpiration. In addition, this plant species is considered a low water requiring plant. Therefore, rosemary plants most likely did not need the higher level of watering presented by the $120 \%$ treatment to stay hydrated, in turn causing this growing medium to possibly be waterlogged. Reduction of root respiration under over-watering stress has been shown to decrease stomatal conductance and therefore diminish the $\mathrm{CO}_{2}$ uptake necessary for photosynthesis (Liao, 2001). Hence, it can be theorized that rosemary plants in the $120 \%$ treatment showed a lower photosynthetic rate than plants in the $100 \%$ treatment translating into a lower rate of growth, and possibly a lower number of stems.

\subsubsection{Unfolded (Mature) leaves}

Mature leaves were counted only for basil. Leaves are the part of the plant showing the first effects of water deficit in this and other plant species (Farooq et al., 2009; Salisbury et al., 1992). We found it to be especially important to know the number of leaves (yield) for basil in each of the treatments because leaves are the most important part or marketable tissue for this species. Water stress, as mentioned before is one of major environmental constraints in plant growth and development. The main consequence of water stress is decreased growth and development caused by reductions of leaf area, dry matter production, decline in plant water status and transpiration (Gupta et al. 2001; Chaves et al. 2002; Bindi et al. 2005; Özenç et al., 2008). Raviv et al. (2004) reported that restricted water uptake results in low leaf water potential, leading to cessation of leaf and shoot expansive growth (Özenç et al., 2008). In the literature reviewed we did not find evidence for an effect of drought on the number of leaves. However, 
part of an overall strategy for a plant to deal with drought stress could be to decrease not only the size of leaves but also the number of leaves. The fact that the treatment receiving the least amount of water $(80 \%)$ in the experiment had the least number of mature leaves (148) supports this claim (Figure 3.8). Despite the fact that different numbers of leaves were observed in the three treatments of this experiment we did not observe changes in their morphology (shape and size) (personal observation) (Figure 4.4). Since the size of the leaves in the different treatments was similar, we conclude that plants in the $80 \%$ treatment may have adapted to limited water availability by reducing transpiration through producing fewer leaves.

Figure 4.4. Morphology of basil leaves.

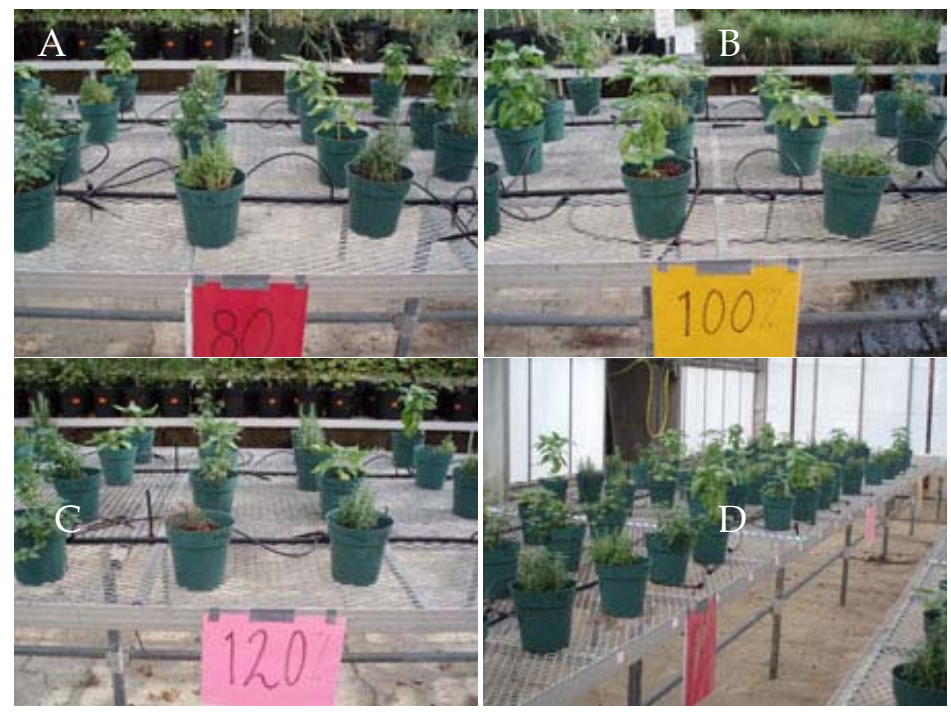

Pictures A, B and C show the similarity (shape and size) of basil leaves despite of the treatment which plants belong to. Picture D shows the homogeneity of plants among treatments $(80 \%$, $100 \%$ and $120 \%$ ). 


\subsection{Experiments 2 and 3}

No differences in yield (estimated by fresh weight, dry weight, height, number of stems and number of leaves) between Experiment 2 and Experiment 3 were observed. Therefore, data from both experiments were combined to analyze fresh and dry weight among the five different treatments.

Interactions between growing medium moisture and biomass production, as well as growth, are well established facts in the literature (Raviv and Blom 2001; Alsanius et al.; 2009). As a transport medium for nutrients and organic compounds, water plays an important role in photosynthesis and the maintenance of the turgor pressure both important factors in growth (Milburn 1979; Kramer and Boyer 1995; Raviv and Blom, 2001; Alsanius et al.; 2009). As can be expected it was observed that the treatments receiving a higher amount of water (same amount of water, but more times in a day) in general showed higher fresh weight (Figure 7.1 Fresh weight prediction model; Appendix B).

The differences in fresh weight among the five plants species studied in this research were due to the different physiology and morphology of the plants. However, each of these plant species needed different amounts of water to perform vital functions; hence they also deal with drought in different ways. The effects of water stress vary between plant species (Hasio and Xu 2000; Silvestre and Ferreira 2000; Özenç, 2008). Therefore, each of the five plant species reacted in a different way to the same amount of water in any given treatment. A clear example in this research of this difference in response to water is basil and thyme which showed opposite reactions in terms to the overall health (symptoms of drought stress) and marketable yields.

Dry weight presented the same overall trend as fresh weight. In general as water frequency decreased, so did dry weight. Transpiration is directly related to stomata being open or 
closed. As plants closed their stomata under water stress conditions, as was often observed, especially in the low irrigation frequency treatments, the transpiration rate was decreased resulting in decreased plant growth and dry matter production (Özenç, 2008). The differences in dry weight among the five plants species are due to the different morphology and physiology of each plant species. Each of the five plant species has specific water requirements to develop vital functions, and hence each of them was affected in a different way by drought stress.

\subsubsection{Basil}

\subsubsection{Fresh weight}

Increasing water deficits results, in general, in a relatively lower plant yields and height (Kiziloglu et al., 2009). Basil clearly demonstrated this response as the treatment receiving the least amount of water (Treatment 0.5 -irrigated every other day) also obtained the lowest yield (Figure 3.12). The first response of virtually all plants to acute water deficit is the closure of their stomata to prevent the transpirational water loss (Mansfield and Atkinson, 1990; Farooq, 2009). This may result in response to either a decrease in leaf turgor pressure and/or water potential (Ludlow and Muchow, 1990; Farooq, 2009). Closure of the stomata reduces photosynthesis and therefore results in a reduction of growth. The morphology and physiology of the plants of basil in Treatment 0.5 was markedly different from the plants in the other treatments. The space between internodes was considerable smaller than the one in the plants in the treatments receiving more water making the plants in this treatment the shortest in the experiments (Figure 4.5). 

regimens.

Figure 4.5. Comparison of basil plants between the five different watering

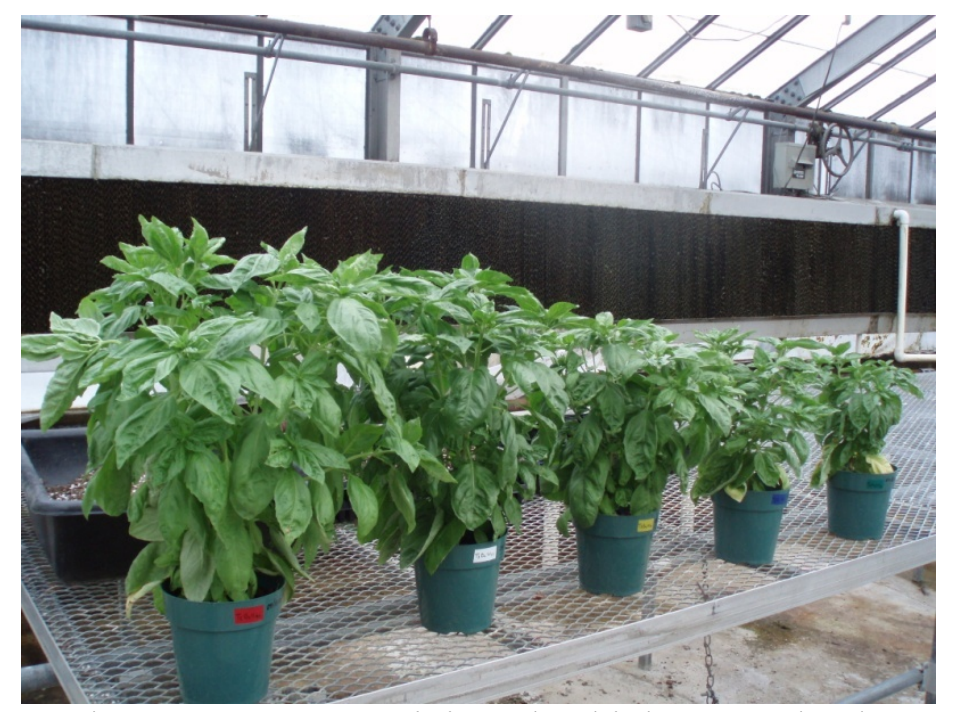

From left to right are the treatments receiving the highest to the lowest amount of water: Treatment 3, Treatment 2, Treatment 1.5, Treatment 1 and Treatment 0.5.

Changes in morphological characteristics caused by drought stress were aggravated slowly over time. Leaves although higher in number were much smaller in size. Plants generally limit the number and area of leaves in response to drought stress to cut down the water budget but at the cost of losses in yield (Schuppler et al., 1998; Farooq, 2009). Leaves were also curled and not turgid (Figure 4.6). These observations explain the fact that the tissue harvested (fresh weight) in Treatment 0.5 was considerable less than the one harvested in the other treatments. However, as an additional visual observation it is important to highlight that when temperatures were very high or plants had not been watered, plants in Treatment 0.5 did not or wilted less frequently than the plants in the treatments receiving more water. This observation became more and more obvious as plants adapted to the watering regimes over time. 
Figure 4.6. Comparison of the morphology of a basil plant before the first harvest and before the fourth harvest (Experiment 2).

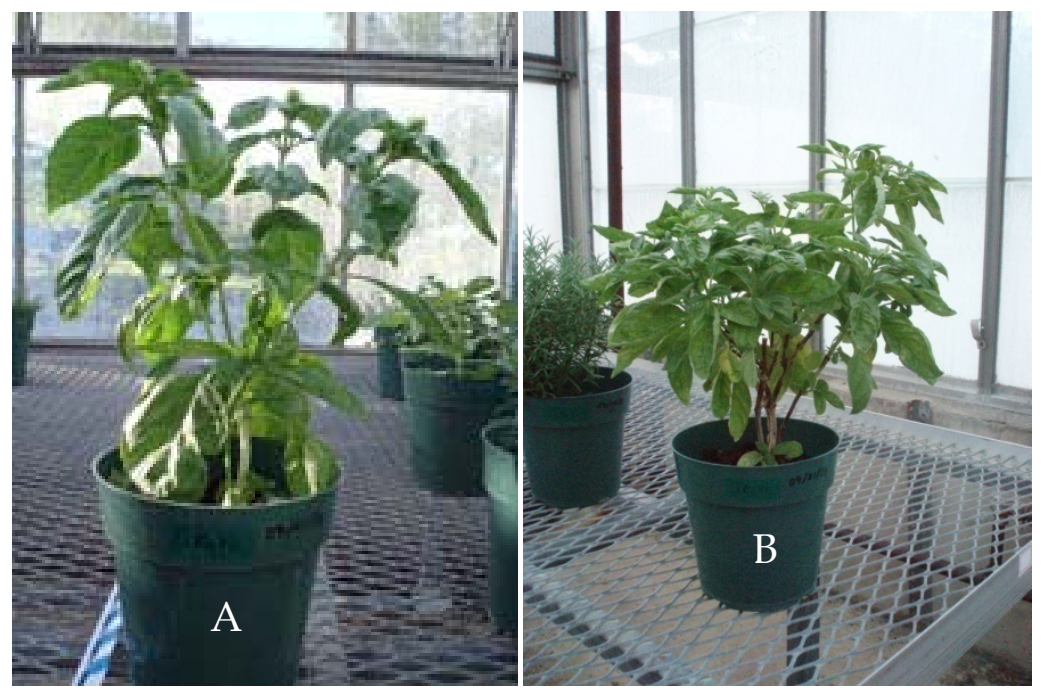

A) Basil plant (before the first harvest): Observe the short internodes, but lack of changes in the shape of the leaves. B) Same basil plant (before the fourth harvest): Observe the curled and higher number albeit smaller leaves.

The treatments obtaining the highest fresh weight were the ones receiving the most water (Figure 3.12). The highest yield was obtained in Treatment 3 followed very closely by Treatment 2. Nevertheless, Treatment 1.5 (irrigated two times a day alternated with one time the next day), Treatment 2 (irrigated two times a day) and Treatment 3 (irrigated three times a day) obtained similar fresh weight overall. Treatment 1 and 1.5 showed smaller leaves and shorter internodes with some curling of the leaves but at lower extent than the Treatment 0.5 . When taking into consideration the overall quality of the plants (shape and size of the leaves) (Figure 4.7), number of irrigations, and overall water use (labor, economics, environmental impact) we conclude that irrigation twice a day results in satisfactory performance of basil plants in a Tezontle hydroponic system. 
Figure 4.7. Basil plants from Treatment 2 and Treatment 3 before the third harvest (Experiment 2).

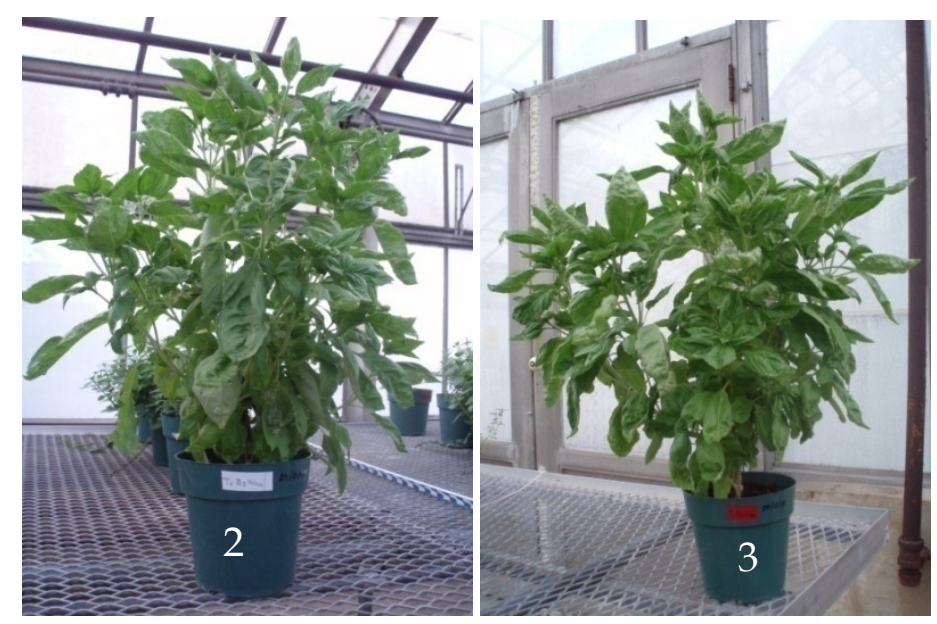

\subsubsection{Dry weight}

As a high water requiring plant, it was expected that basil showed the lowest dry weight in the treatment receiving the least irrigation (Treatment 0.5 ). Since these plants were constantly stressed by drought one of the mechanisms to conserve water was to decrease transpiration by closure of the stomata. Consequently, growth was reduced and the total dry matter content decreased. On the other hand, dry weight increased as plants received more irrigation. Kiziloglu et al. (2009) reported that in a two year study on silage maize Water Use Efficiency (WUE-ratio between dry matter produced and water consumed at the whole-plant level) increased by increasing irrigation which is an observation that was corroborated by dry weight measurements on basil in this study. Despite the fact that the treatment receiving the most frequent irrigation (Treatment 3-three times in a day) obtained the highest dry weight (a good estimation of the real growth) the difference with the other treatments (except Treatment 0.5) was not significant. Therefore, considerably less water than the applied in Treatment 3 could be used to obtain similar dry weight or tangible growth in basil, perhaps as little as one well timed irrigation per day. 


\subsubsection{Mint}

\subsubsection{Fresh weight}

Fresh weight obtained in Treatment 0.5 for mint was the lowest out of all treatments (Figure 3.13). Photosynthesis when soil water availability is reduced often limits plant growth (Huang and Fu, 2000; Farooq, 2009) and our observations clearly corroborate other studies. Plants in this treatment also developed the shortest stems and rhizomes while the size of the leaves was the smallest observed in all treatments. In addition to the physiological and morphological changes caused by drought stress, plants in this treatment were affected by the recurrent and severe infestations of spider mites (Tetranychus urticae) and aphids (Myzus spp.) throughout the experiments further diminishing their vigor. Despite the fact that water stress in peppermint can increase essential oil yields per leaf (probably because the leaf area became smaller but contained the same number of oil glands) (Tucker et al., 2000), we did not observe any benefit from the potentially higher concentrations of oils - thought to help plants defend against insects and diseases - in the leaves of the plants in our experiments. Drought stress most likely decreased overall fitness of plants, making them more susceptible to attack (Witt et al., 1999). Hence, insects attacked plants in Treatment 0.5 before plants in other treatments, and at first glance in higher numbers (Figure 4.8). 
Figure 4.8. Mint plant from Treatment 0.5 (Harvest 2 of Experiment 3) infested by spider mites (Tetranychus urticae).
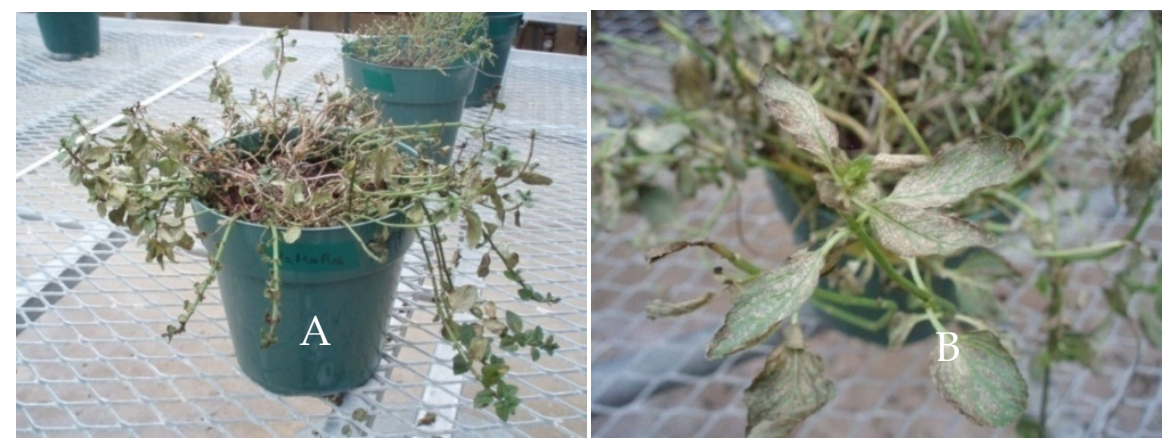

Close up of leaves reveals severe damage by spider mites (Tetranychus urticae). The discoloration (tiny white spots) on the surface of the leaves and the dry leaf margins of the leaves are the common signs of this pest.

Mint is one of the plants that normally require a steady supply of water to perform vital functions and produce a crop. Therefore, and not surprisingly, this plant species showed a trend toward increased yield or fresh weight as irrigation frequency increased. The best example to show this relationship is between Treatment 1 and Treatment 0.5 . Treatment 1 received twice the amount of irrigation water than Treatment 0.5 and its yield was the double of the one obtained by Treatment 0.5 . Nevertheless, after this point the increase in fresh weight was not as noticeable as this. Treatment 1 and Treatment 1.5 obtained similar fresh weight (Figure 4.9)

Figure 4.9. Comparison of the morphology of mint plants in Treatment 1 and Treatment 1.5 before the third harvest in experiment 2.

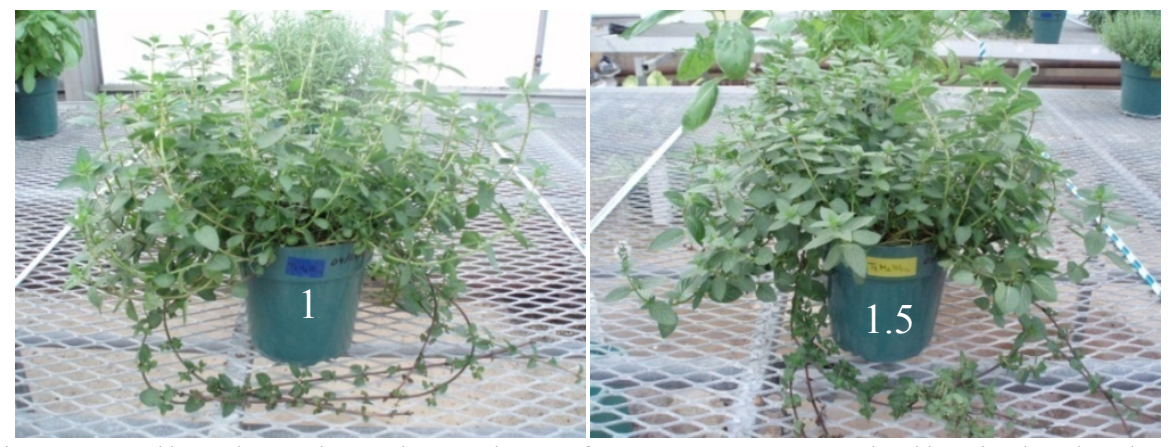

Leaf size as well as length and number of stems are very similar in both plants. 
At the same time, the yield in Treatment 1.5 was similar to yields observed in Treatment 2 and Treatment 3, although Treatment 3 obtained the highest fresh weight. It is important to highlight that the morphology of mint as well as the other plant species in this study was different in each of the five treatments. As water irrigation increased, the number and length of the stems and rhizomes increased as well as the size and number of the leaves (Figures 4.9 and 4.10). Given that these three treatments yielded statistically the same amount of fresh weight but used a different amount of water, in economical terms the treatment using the least water in this group would be the most desirable. However, as stated previously Treatment 1.5 also showed similarities in fresh weight with Treatment 1 which obtained one of the lowest yields. On the other hand, Treatment 2 used the next higher amount of water than Treatment 1.5, but its yield was very close than the one from Treatment 3 (Figure 4.10). Therefore, among the treatments tested, twice a day watering will likely result in the most favorable water to yield ratio. Nevertheless, if water is not a limitation into plant production and fresh weight (if the final marketable product will be commercialized in fresh) is of the interest, irrigation between Treatment 2 and 3 would be the best to obtain high yields and better uniformity in the production. Modeling yield (Figure 7.1 Fresh weight prediction model; Appendix B) shows that the highest fresh weights can be expected at an irrigation frequency of 2.5 (you can calculate this from the equations generated by the model that describe the response of each crop in terms of yield to water applications). 
Figure 4.10. Comparison of the morphology of mint plants in Treatment 2 and Treatment 3 before the third harvest in experiment 2.

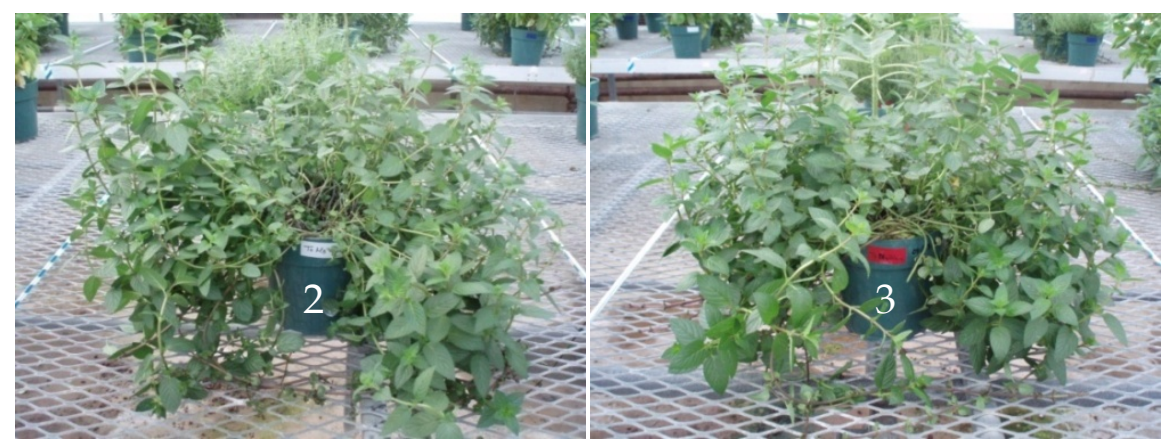

It can be observed that the morphology of the plants is very similar.

\subsubsection{Dry weight}

Dry weight in mint presented the same general trend as fresh weight showing an increase as irrigation increased. However, dry weight differences among some of the treatments were not important. The largest difference was again between Treatment 0.5 and treatment 1 , as the watering frequency increased from every other day to once a day, dry weight increased by 55.31\%. After this initial and notable increase the other four treatments (Treatment 1, 1.5, 2 and 3) did not show differences in dry weight. Plants in Treatment 0.5 were severely stressed by drought and pathogens and therefore unable to perform metabolic functions adequately which in turn was clearly reflected in diminished growth. On the other hand, results indicated that plants in Treatment 1 were stressed to a much lesser extent, being able to use water much more efficiently than any of the other treatments. A positive linear relationship between yield and water use has been recognized by various researches (Gencoglan and Yazar 1999; Istanbulluoglu et al. 2002; Kirnak et al. 2003; Oktem et al. 2003; Cakir 2004; Dagdelen et al. 2006; Payero et al. 2006; Kiziloglu, 2009). Mint plants watered once a day obtained the same dry weight or real growth using considerable less water than the plants in Treatments 1.5, 2 and 3. This indicates 
that if dry weight is of interest, irrigation once a day is enough to obtain the same yield than if much more water was used.

\subsubsection{Rosemary}

\subsubsection{Fresh weight}

Although rosemary was one of the plants defined as a low water requiring plant in this research, the plants presented symptoms and signs of drought stress in some treatments. Rosemary has a special morphology that helps the plant grow and develop with a relative low water uptake and loss. Glaucousness or waxy bloom on leaves helps with maintenance of high tissue water potential, and is therefore considered as a desirable trait for drought tolerance (Richards et al., 1986; Ludlow and Muchow, 1990; Farooq, 2009). Nevertheless there was a trend towards increased fresh weight as the number of irrigations per day increased (Figure 7.1 Fresh weight prediction model; Appendix B). Rosemary plants in the treatment receiving the least amount of water (Treatment 0.5 ) showed the lowest total fresh weight. These plants were the shortest in both experiments, and also presented the least number of stems in all of the harvests (Figure 4.11). These morphological characteristics and changes are clear symptoms of drought stress and adaptation to the amount of water they received. Similar to basil these plants presented signs of wilting less frequently than the plants in other treatments in hot days and/or before plants were watered, a clear sign of adaptative behavior of the plants. In recent years there have been reports that stomates will close even when leaves are not experiencing water stress, providing that the roots are being stressed. Stomates often close in response to dryness, suggesting that they are getting some kind of signal from the roots. Evidence is accumulating that this signal is abscisic acid (ABA) (Salisbury et al., 1992). This statement allows us to 
suppose that although rosemary leaves of plants in Treatment 0.5 did not show symptoms of wilt; plants closed their stomata in response to $\mathrm{ABA}$ to reduce water lost by transpiration. Consequently, leaves remained turgent, but plants grew significantly less than plants receiving higher irrigation.

Fresh weight in Treatment 1.5 was similar to the treatment receiving water once a day (Treatment 1) and twice a day (Treatment 2). Treatment 3 obtained the highest fresh weight but this yield was similar to treatment 1.5 and treatment 2 . Therefore, watering rosemary plants two times a day alternated with one time the next day (Treatment 1.5) on an alternating schedule would be the most convenient, economic, and environmentally sound treatment (Figure 4.11).

Figure 4.11. Comparison of the morphology of rosemary plants in the five different treatments (second harvest in experiment 2).
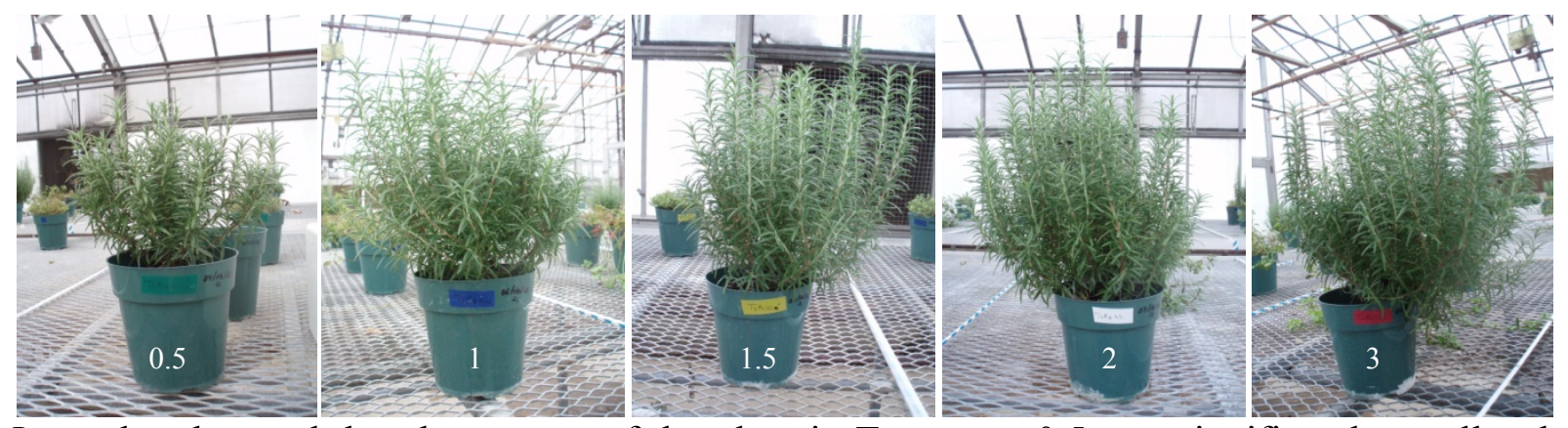

It can be observed that the canopy of the plant in Treatment 0.5 was significantly smaller than the one in Treatment 1, Treatment 1.5, Treatment 2 and Treatment 3.

\subsubsection{Dry weight}

Dry weight in rosemary increased as irrigation increased. This plant species therefore showed exactly the same pattern in dry weight as observed in changes in fresh weight. Despite the fact that rosemary is generally considered a low water requiring plant the results and observations of this study showed that this plant species produced more stems and leaves as more irrigation was applied. In addition to the morphology of this plant (waxy leaves) that help 
to conserve water in the tissues the results of this research allow us to speculate that rosemary also has a physiology adapted to conserve water. Proof of this is the fact that plants in all treatments developed vital functions properly adapting to the amount of water they received without changes in the overall appearance of the plants (color, size of leaves, and width of stems) despite some differences in height and number of stems (Figure 4.11). Stress from too little water slows the growth of a plant while in some species also affects the morphology of new growth (Tucker et al., 2000). In rosemary changes in fresh weight translated into real growth (dry weight) as a result of the completion of adequate physiological activity at all levels of watering.

\subsubsection{Sunflowers}

\subsubsection{Fresh weight}

Sunflowers were transplanted in the Tezontle medium at a juvenile stage of development. In despite of sunflowers were considered as one of the high water requiring crops in this research, at that time plants did not need a high amount of water to perform vital functions. And, even during cloudy days (depends of the temperature of the room) the every other day irrigation regimen provided adequate moisture for the plants. Hence, early on in the experiment plants showed similar morphology in all treatments (Figure 4.12).

Figure 4.12. Sunflowers being transplanted and newly transplanted.

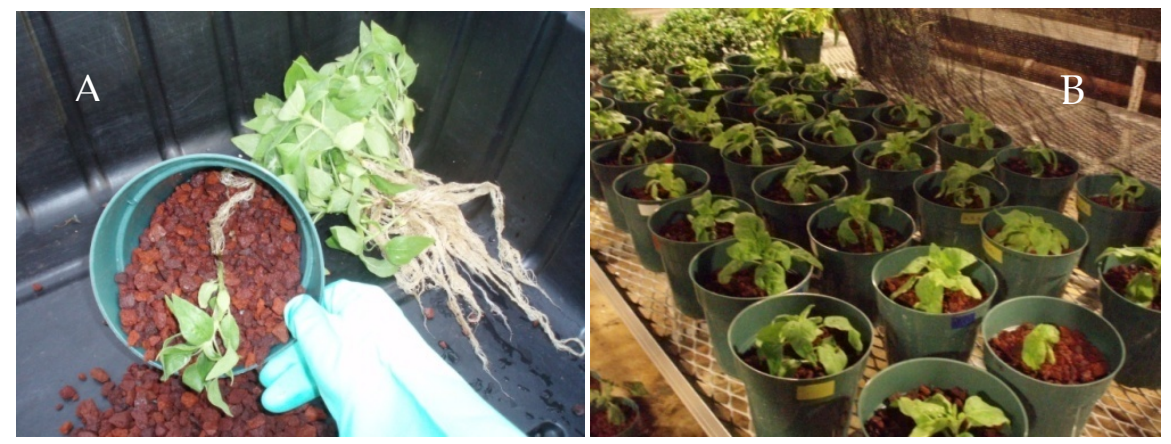

Observe the very similar morphology of the plants. 
However, water requirements of sunflowers significantly increased as plants were growing. Plants are affected differently by water stress according to their stage of development (Özenç and Özkan, 2003; Deproost et al., 2004; Font et al., 2005; Özenç, 2008). We observed that after relatively low water demands the water requirements of sunflowers increased at flower formation and opening. Plants in Treatment 0.5 showed the lowest height, and the size of their leaves and flower was the smallest among the five treatments. Also, plants in this treatment $(0.5)$ always bloomed considerably later than plants in the other treatments (Figure 4.13).

Figure 4.13. Comparison of the morphology of sunflowers in the five different treatments from the first harvest in experiment 2.

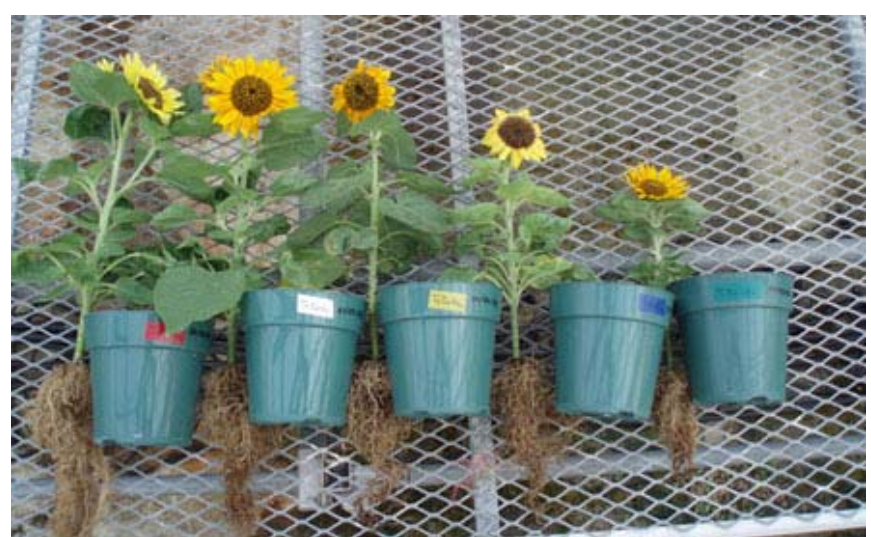

From left to right are the treatments receiving the most to the least irrigations (Treatments 3,2 , $1.5,1$, and 0.5$)$.

Despite some of the visual differences we observed (Figure 4.13) Treatment 1, 1.5, 2, and 3 did not show differences in the total fresh weight. The size and overall morphology of plants in these treatments was similar. However, in some of the harvests flowers in Treatment 1.5, Treatment 2 and Treatment 3 showed considerably higher stem length and width as well as a bigger flower than those observed in Treatment 1 (Figure 4.14). 
Figure 4.14. Comparison of the morphology of some of the sunflowers harvested in the first harvest of experiment 3 in the Treatments $3,2,1.5$, and 1.

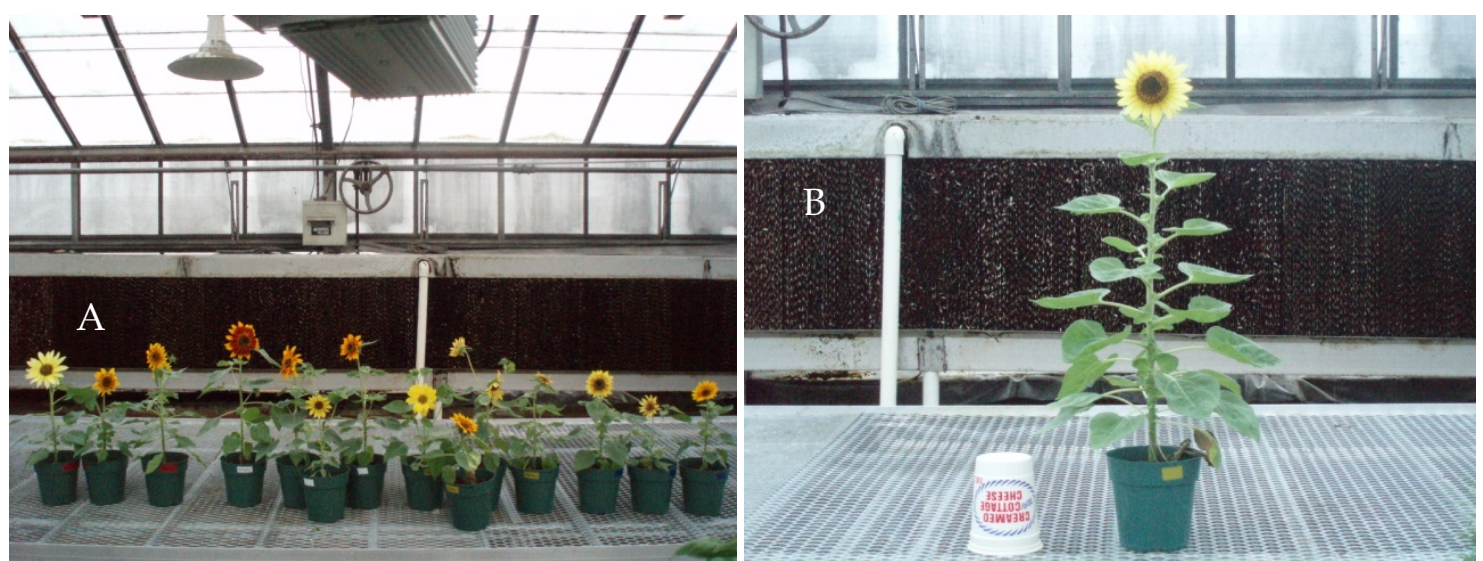

(A) From left to right are Treatment 3 (3 plants-red pot label), Treatment 2 (4 plants-white pot label), Treatment 1.5 (4 plants-yellow pot label), and Treatment 1 (3 plants-blue pot label). (B) The tallest (59 cm of height) sunflower in Experiments $2 \& 3$ was grown in Treatment 1.5 in the same harvest.

Nevertheless, the statistical uniformity among the 1 through 3 irrigation treatments indicates that irrigation using Treatment 1 (irrigated once in a day) is in economical terms and environmental soundness the best treatment since the total yield (fresh weight) obtained using one watering a day will result the same if more water was used for irrigation. However, it is important to highlight that plants in this treatment (1) continuously showed signs of wilt in hot days or before being irrigated. In light of this observation, Treatment 1.5 (irrigated two times a day alternated with one time the next day), or even 2 (irrigated two times in a day) could be recommended to water sunflowers in order to avoid any drought stress and assure more uniform plant growth and perhaps height, an important quality indicator of cut flower quality. 


\subsubsection{Dry weight}

Sunflowers are considered a high water requiring crop. This explains the fact that this plant species showed the lowest dry weight or real growth in the treatment receiving the least irrigation (Treatment 0.5). Sunflowers have many large leaves which causes that this plant species has a relatively high transpirational rate. When water deficiency increases, transpiration rate decreases. Therefore, plant growth slows down and total dry matter content decreases (Özenç, 2008). On the other hand, dry weight considerably increased as irrigation increased from Treatment 0.5 to Treatment 2. Dry weight decreased in Treatment 3 to just slightly above the treatment showing the lowest dry weight (Treatment 0.5). Although Treatment 3 received the highest irrigation dry weight as well fresh weight were lower than in Treatment 2. Nevertheless, dry weight showed a considerably larger difference with Treatment 2 than the one showed by fresh weight. This indicates that plants receiving a higher frequency of irrigation (Treatment 3 three times in a day) were not able to convert the extra water and nutrients into higher levels of photosynthesis or dry weight accumulation.

\subsubsection{Thyme}

\subsubsection{Fresh weight}

Thyme is considered as a low water requiring plant species and based on our data is the lowest water requiring plant among the five plant species in this study. Nevertheless, thyme showed an increase in fresh weight as the irrigation increased from once every other day to twice a day alternated by once a day watering. After this point fresh weight decreased as more water was supplied to the plants. This means that there were similarities in fresh weight among the treatments receiving the least (Treatment 0.5 and Treatment 1) and the most irrigation 
(Treatment 2, and Treatment 3). The most probable explanation of this phenomenon is that plants in these treatments were suffering stress due to under and over-watering in the treatments receiving the least and the most irrigation, respectively. Because of water, plants can experience feast or famine, flood or drought, air or suffocation (Witt et al., 1999). As cited previously drought stress causes a reduction in biomass production due to decline of the photosynthetic activity that translates in growth. However, it has also been shown that excess of water also causes a decline in the photosynthetic capacity in flooding-intolerant plants (Liao et al., 2001) and even their death (Witt et al., 1999). Reduction of root respiration is one of the earliest responses of plants under anoxia (total decrease in the level of oxygen) and/ or hypoxia (low oxygen), regardless of whether the plants are flooding-tolerant or intolerant. Root systems starved of oxygen are also poor providers of mineral nutrients for both themselves and the shoot systems (Liao et al., 2001). However, the effects of excess of water are not confined to the inundated parts of the plant. Stomatal closure and epinastic curvature take place in some roots and shoots (Jackson et al., 1993; Liao, 2001). Although fresh weight was similar in the treatments receiving low and high irrigation, the morphology of the plants was very different. Thyme in the treatments receiving less water produced fewer stems and leaves, but the stems were thicker and their leaves were larger (Figure 4.15). On the other hand, thyme produced a higher number of stems and leaves in the treatments receiving more water, but the stems were thinner and had smaller curled leaves that looked dehydrated (Figure 4.15). 
Figure 4.15. Comparison of the morphology of thyme in the treatment receiving the least amount of irrigation (Treatment 0.5-irrigated every other day), and the treatment receiving the highest number of irrigations per day (Treatment 3-irrigated three times in a day).

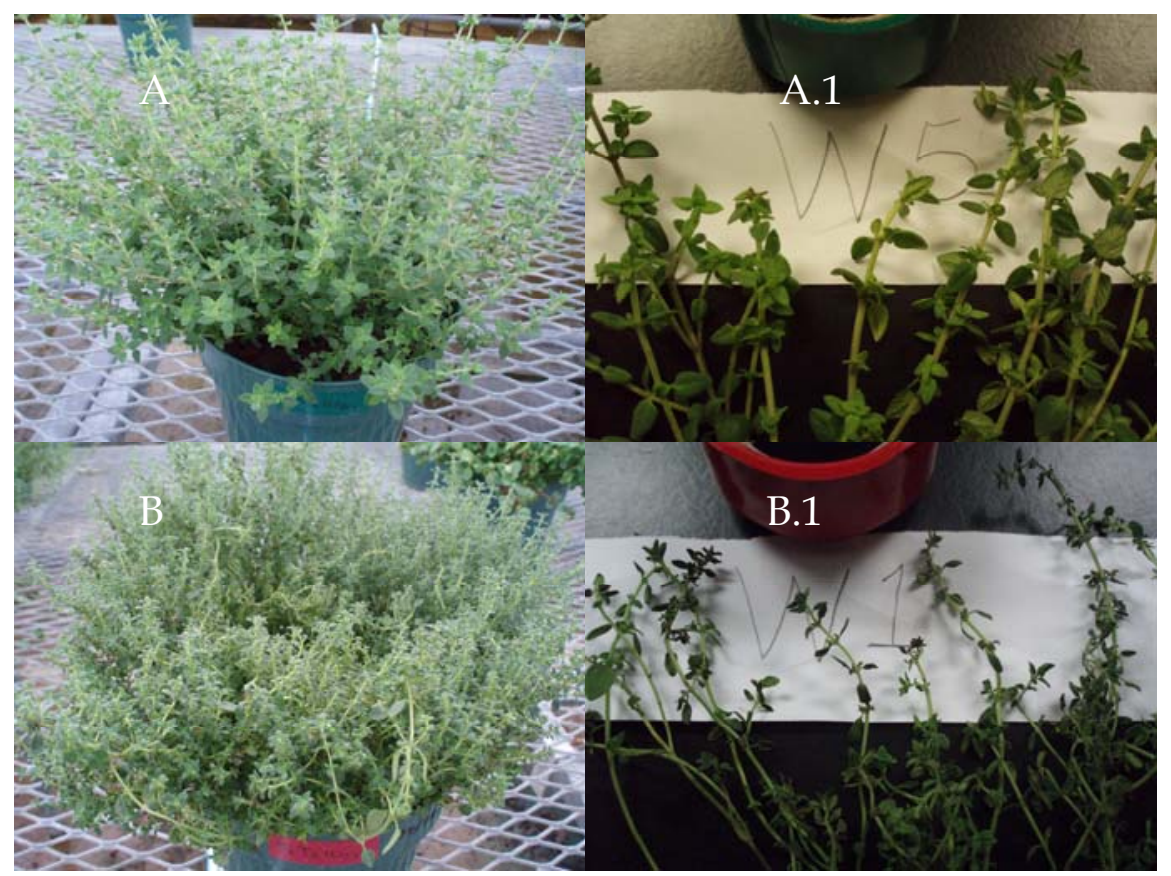

(A) The number of stems and leaves is lower in Treatment 0.5 than in Treatment 3. In picture A. 1 one can observe the larger size of leaves in Treatment 0.5 than the smaller and curled leaves in Treatment 3 (B.1).

The difference in the number of stems among treatments appeared itself from the start of the experiments. However, the difference in leaf morphology was a phenomenon that gradually presented itself. Plants did not show differences among treatments during the first months in both of the experiments. In fact, at the beginning of all the experiments (including Experiment 1) of this research thyme plants performed best in the treatments receiving more water. However, these plants soon after started showing morphological characteristics that may be tied to fitness or survival strategies. Thyme in the treatment receiving the least irrigation (Treatment 0.5) showed the best marketable stems and leaves (Figure 4.15), but their production was the lowest compared to the other treatments. Hence, it can be hypothesized that stomatal closure slowed 
transpiration rate preventing leaf dehydration (Bradford and Hsiao, 1982; Liao, 2001) while at the same time, this physiological response to drought stress diminished photosynthetic activity and consequently growth. On the other hand, plants in the treatments receiving the most irrigation (Treatment 3-irrigated three times a day and even Treatment 2-irrigated two times a day) also showed symptoms of stress. They presented the worst morphological characteristics in terms of marketing due to over-watering (Figure 4.15). Stress on plants imposed by episodic or permanently flooding or any excess of water has resulted in a wide range of biochemical, molecular and morphological adaptations that sanction growth and reproductive success (Jackson et al., 2005). These adaptations are attributed to the effect of phytohormones produced by the plant with ethylene and abscisic acid playing prominent roles (Jackson et al., 1993; Liao, 2001). Auxins and gibberellins are pre-requisites for ethylene action and play triggering rather than regulatory functions (Liao, 2001). The interaction of auxins and ethylene in turn is important for the induction of adventitious root formation (McNamara and Mitchell, 1989; Liao, 2001). Most of the plants in Treatment 3 and some in Treatment 2 developed adventitious roots on the surface of the Tezontle as an adaptation mechanism against the excess of water into the medium indicating that the plants suffered from flooding (Figure 4.16).

Figure 4.16. Adventitious roots in two thyme plants in Treatment 3 (irrigated three times a day).

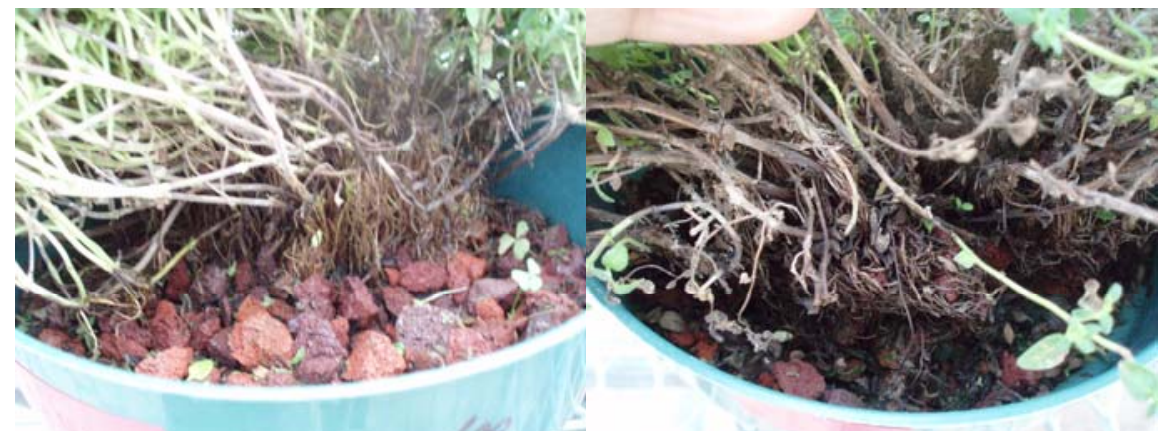

Observe the roots growing outside of the medium, and the necrotic nature of some of them (black coloration). 
Leaves of plants in these treatments were curled and also presented epinastic curvature (Figure 4.15-B.1). Liao et al. (2001) mention that epinastic curvature can be induced by ethylene and abscisic acid, and is one of the responses of plants caused by over-watering. Ethylene participates in physiological processes such as cell elongation, a process in turn influenced by the orientation of newly formed micro-fibrils in the cell wall. These micro-fibrils normally follow spiral pattern around the cell. However, when a plant is stressed, ethylene directs the microfibrils to grow in many directions resulting in a decrease of cell expansion and cell elongation and therefore growth. Studies showed that pea plants subjected to flooding increased their foliar abscisic acid content which was accompanied by closure of stomates (Jackson and Drew, 1984; Zhang and Davies, 1987; Liao, 2001). Similar results have been observed in tomato (Jackson, 1990a, 1990b; Liao, 2001). Stomatal conductance is correlated with $\mathrm{CER}\left(\mathrm{CO}_{2}\right.$ exchange rate $)$ (Liao and Lin, 1998; Smith and Ager, 1988; Vu and Yelenosky, 1991; Liao, 2001). This implies that stomatal aperture is a limiting factor for CER (Liao, 2001). A decrease of stomatal conductance coincided with a reduction of $\mathrm{CER}$, and lower $\mathrm{C}_{\mathrm{i}}$ (leaf internal $\mathrm{CO}_{2}$ concentration) (Liao, 2001). Another morphological characteristic of over-watered thyme plants in our experiments ( 2 and 3 ) was the production of a high number of stems and leaves. The literature we reviewed did not mention that these phenomena can be induced by phytohormones such as ethylene or abscisic acid. However, we think that these plants produced a higher number of stems and leaves as a mechanism of adaptation perhaps induced by phytohormones to increase their canopy size to overcome any transpirational and photosynthetic losses induced by flooding. Nevertheless, these mechanisms of adaptation were not enough to maintain the plants alive for a long time. Proving the statement of Jackson et al. (2005) saying that even seemingly poorly adapted species to the excess of water possess some short-term resilience, many of the over- 
watered thyme plants in our experiments $(2 \& 3)$ died before the experiments finished. Some other plants survived, but their overall appearance indicated that they were stressed and probably would die soon (Figure 4.17).

\section{Figure 4.17. Comparison of recently harvested thyme plants at the end of experiment 2.}

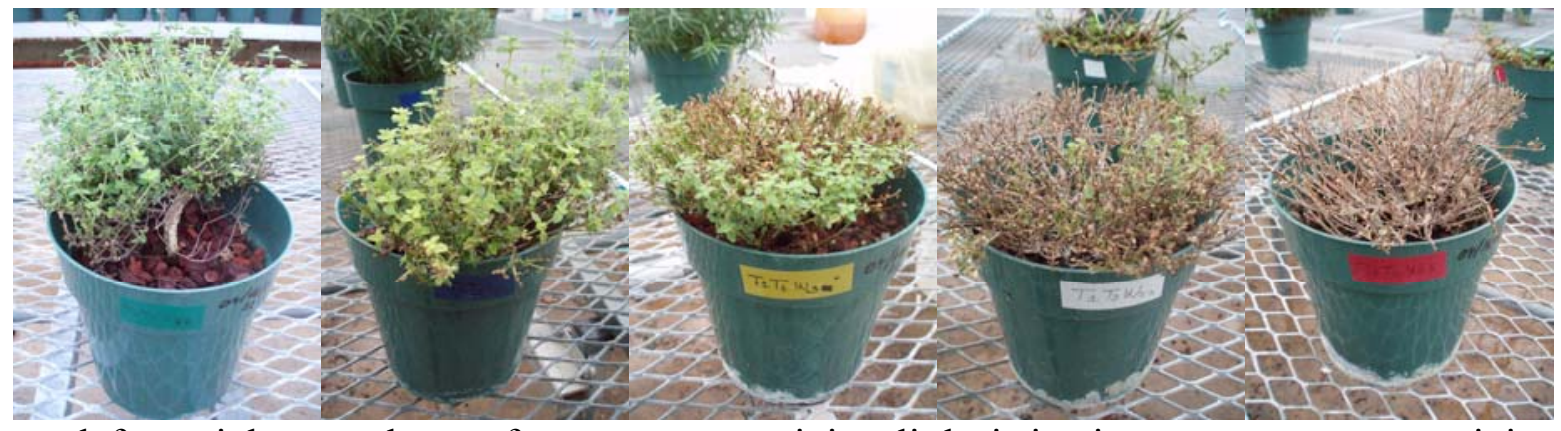

From left to right are plants of treatments receiving little irrigation to treatments receiving 3 waterings a day (Treatment 0.5 -irrigated every other day; Treatment 1-irrigated once in a day; treatment 1.5 irrigated two times a day alternated with one time the next day; Treatment 2irrigated two times in a day; and Treatment 3-irrigated three times in a day). Observe the overall health of the plants receiving less water that during the experiment preformed better than does receiving multiple watering a day.

The response in fresh weight to irrigation and the condition of the plants in our experiments lead us to conclude that Treatment 1.5 is optimal for thyme. This treatment showed the highest fresh weight (yield) and good marketable characteristics of stems and leaves in addition to an overall healthy appearance of the plants (Figure 4.18). 
Figure 4.18. Thyme plant grown under Treatment 1.5 conditions (irrigated two times a day alternated with one time the next day).

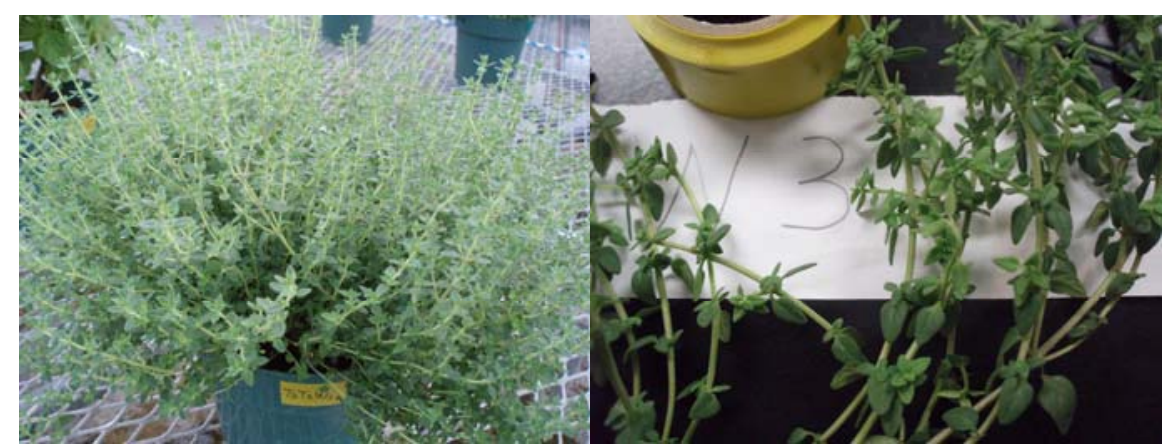

The plant has a high number of stems, and large high quality of leaves.

\subsubsection{Dry weight}

Dry weight in thyme followed exactly the same pattern as observed in the changes in fresh weight. Özenç (2008) cited that when the transpiration rate is decreased due to the stomata closure as a consequence of drought stress, dry matter production of plants is also decreased. This explains the fact that the treatment irrigated less frequently (Treatment 0.5 ) showed the lowest dry weight. Nevertheless, plants in the treatments receiving the most irrigation (Treatment 2 and Treatment 3) were also stressed showing a dry weight just slightly above that of Treatment 0.5. Flooding is a complex stress that imposes several often-concurrent challenges to normal plant functioning. Dominant is starvation of oxygen and carbon dioxide (Jackson et al., 2005). When plants suffer stress, either by drought or over-watering, their stomata close and both photosynthesis and transpiration rates are diminished. Consequently a reduction of growth is observed. Despite the fact that plants in these treatments (Treatment 2 and 3) showed signs of flooding stress, and the observation that Treatment 1.5 obtained the highest dry weight there were no important differences among the five treatments. This result indicates that even plants in Treatment 0.5 obtained the lowest yield (fresh weight) among the five treatments this treatment obtained statistically similar dry weight (or real growth) than treatments receiving more water. 
Therefore, if dry weight or growth is the measurement of interest, in economical terms (amount of water, watering periodicity, labor, etc.) Treatment 0.5 is the best among the five treatments. If fresh weight and dry weight are of importance treatment 1.5 could be considered optimal. 


\section{Conclusions}

Tezontle or Red lava rock can be successfully used as a growing medium to produce the herbs and one ornamental we tested for water use efficiency in this research. Results of this research demonstrated that in terms of quality and quantity the yield of basil, thyme, rosemary, mint, and sunflowers grown hydroponically in a Tezontle medium could be competitive when compared to other hydroponic systems, especially when provided with an adequate water supply. Tezontle with as one of its advantages that it can be crushed, sieved, and combined to make a medium with the best aeration characteristics for a given crop allowed us to create a medium high in aeration and with good water holding capacity. The combination of particle sizes (excluding dust and particles larger than $1 \mathrm{~cm}^{3}$ ) used in the Experiments 1 and 2 of this research retained adequate levels of water for most of the plant species studied. However, thyme showed symptoms of over-watering in some treatments. Adjustments in aeration and water holding capacity of Tezontle medium (Experiment 3) through the use of different size particles (excluding particles $\leq 1 / 8$ "-3.3 $\mathrm{mm}$ ) are necessary in order for thyme and other crops that require high levels of drainage and aeration.

Tezontle can be part of an effective strategy to reduce water use in a plant production. Plant species in this study were successfully cultivated using very low amounts of water. Even the treatment receiving the most irrigation (600 $\mathrm{ml}$ per day) received much less water than the amount that is commonly used in greenhouse production. In addition, all plant species studied in this research did better or showed similar yields with an irrigation regimen using even less water than $600 \mathrm{ml}$ per day. Despite the fact that increasing watering frequency leads to higher yields, the return in yield is often not proportional to the amount of water applied to the crop. This suggests that in cases where water availability is extremely limited that lowering the watering 
frequency does not have to lead to substantial yield losses (Figure 7.1 and 7.2 Fresh and dry weight prediction model; Appendix B).

Thyme is the plant species that performed best in low or very low water conditions. Despite the relatively low yields, this plant species showed the best morphology (quality) when it was watered $(200 \mathrm{ml})$ every other day. However, the highest yield was observed when thyme was watered two times a day $(400 \mathrm{ml})$ alternated with one time $(200 \mathrm{ml})$ the next day, while still showing good marketable characteristics. If dry weight is the most interest, plants watered (200 ml) every other day showed the same dry weight than plants irrigated more frequently. On the other hand, thyme showed a significant decrease in production and health when it was watered two $(400 \mathrm{ml})$ and three times $(600 \mathrm{ml})$ a day, treatments in which some plants died due to overwatering.

Although sunflowers are cataloged as high water requiring plant species, they can thrive and show acceptable marketable yields using low amounts of water. According to this study watering as little as once a day $(200 \mathrm{ml})$ can obtain similar yields than when watered more often. However, some sunflowers watered more frequently (up to two times in a day or $400 \mathrm{ml}$ ) showed the highest height with the biggest flowers, quality indicators that are more likely to influence crop management and watering frequency than fresh weight or even dry weight.

Water requirements of rosemary have been documented low. However, in this research this plant species showed significantly higher yields as irrigation increased. The best marketable characteristics (height and number of stems) were shown in the treatments receiving the most irrigation. Nevertheless, watering as little as two times a day $(400 \mathrm{ml})$ alternated with one time (200 $\mathrm{ml})$ the next day can be enough to obtain good yields of fresh weight and dry weight. 
Mint and basil are plant species that showed increased yields as irrigation increased. However, watering as little as two times a day $(400 \mathrm{ml})$ alternated with one time $(200 \mathrm{ml})$ the next day showed similar yields to plants irrigated more frequently. However, if dry weight is of interest irrigation as low as one time in a day $(200 \mathrm{ml})$ showed dry weight similar to plants irrigated more often.

In terms of plant production, all plants studied in this research showed a satisfactory performance and yields using Tezontle as a medium at all but the lowest amounts and frequency of watering. According to this study, basil, thyme, rosemary, sunflowers and mint can be grown successfully in a greenhouse Tezontle-based hydroponic system with a low input of water (ranging from 1 to 3 waterings per day). Although plants receiving the lowest irrigation showed low yields, they still showed acceptable marketable characteristics to be sold in fresh or dried. The economic and environmental cost of water in the end will determine what amounts of water should be used to obtain the quantity and quality of product demanded by the market. 


\section{References}

Alsanius Beatrix W., Löfkvist Klara, Kritz Göran, Ratkic Adrian (2009). "Reflection on reflection in action: a case study of growers conception of irrigation strategies in pot plant production". AI \& Soc 23:545-558.

Améndola Ricardo et. al. (2006). "Country/ Pasture /Forage Resourse Profiles". Country Pasture Profiles. Latin American \& the Caribbean- Mexico. Mexico.

Bassols Batalla Angel (1989). "Recursos Naturales de México". Teoría, conocimiento y uso. Editorial Nuestro tiempo, S. A. $2^{\text {nd }}$. Edición. México.

Catoira Ordoñez Morelia Noe (2004). "Gestión técnico-social del agua de los mantos freáticos de Celaya y de Irapuato-Valle de Santiago (México)".Tesis de fin de estudios. Universidad de las Antillas y de la Guyana.

Cestoni Frida, de Jovel Gilma, and Urquilla Alicia (2002). "Perfil de negocios del tomate para pasta o de cocina hacia el Mercado de los Estados Unidos". Ministerio de Economía de El Salvador C.A. El Salvador.

Comisión Estatal de Agua del Estado de Guanajuato (CEAG) (2004).”Cuarto informe de gobierno de Juan Carlos Romero Hicks. Programa Hidrológico de Guanajuato". Núcleo social: 54-60.

Comisión Nacional del Agua (CONAGUA) (2008). "Programa Nacional Hídrico 20072012”. Secretaría de Medio Ambiente y Recursos Naturales. México.

Dole John M. and Wilkins Harold F. (2005). "Floriculture”. Principles and Species. Pearson Prentice Hall. $2^{\text {nd }}$. Edition. U. S. A.

Farooq M.; Wahid A.; Kobayashi N.; Fujita D.; Basra S. M. A. (2009). "Plant drought stress: effects, mechanisms and management" Agron. Sustain. Dev. 29 pp.185-212.

Flores Francisco J., and Scott Christopher A. (2000). "Superficie Agrícola Estimada Mediante Análisis de Imágenes de Satélite en Guanajuato, México". IWMI, Serie Latinoamericana. México. 
French Jackie (1993). “Book of Rosemary”. Harper Collins Publishers. 1 Edition. Australia.

Gizas George and Savvas Dimitrios. Greece (2007). "Particle size and Hydraulic Properties of Pumice Affect growth and Yield of Greenhouse Crops in Soilless Culture". Amer. Soc. Hort. Sci. 42 (5): 1274-1280.

Horbath Corredor Jorge Enrique (2004). "Desarrollo regional y migración internacional en México: alternativa para enfrentar la pobreza rural". Economía y desarrollo. Vol. 3 No. 1: 737.

Instituto Nacional de Estadística Geografía e Informática (INEGI) (2005). "Mujeres y hombres en México 2005". Novena Edición. México.

Irizarry Otaño Eric A. (2006). "Hidroponía". Servicio de Extensión Agrícola. Recinto de Mayagüez. Colegio de Ciencias Agrícolas. Universidad de Puerto Rico.

Jackson M.B. and Colmer T. D. (2005). "Response and adaptation by plants to flooding stress". Annals of Botany 96: 501-505.

Jensen Merle H. U.S.A. (1997). "Hydroponics”. Amer. Soc. Hort. Sci. 32(6).

Kane Chad. D., Jasoni Richard L., Peffley Ellen P., Thompson Leslie D., Green Cary J., Pare Paul and Tissue David (2006). "Nutrient Solution and Solution pH Influences on Onion Growth and Mineral Content". Journal of Plant Nutrition, 29: 375-390.

Kiziloglu Fatih M., Sahin Ustun, Kuslu Yasemin, Tunc Talip (2009). "Determining wateryield relationship, water use efficiency, crop and pan coefficients for silage maize in semiarid region" Irrig Sci 27: 129-137.

Levine Gilbert (2007). "The Lerma-Chapala river basin: a case study of water transfer in a closed basin". Paddy Water Environ 5: 247-251.

Liao Chung-Ta and Lin Chin-Ho (2001). "Physiological adaptation of crop plants to flooding stress". Proc. Natl. Sci. Counc. ROC (B). Vol. 25, No. 3. Pp.148-157. 
López Villar Darío Antonio (2007). "Migración de mexicanos desde y hacia Estados Unidos de América": estadísticas, problemáticas y retos. Boletín de los Sistemas Nacionales Estadístico y de Informática Geográfica. Vol 1 No.2. INEGI. México.

López Villar Darío Antonio (2007). "Migración en México". Data from 1990 to 2000. INEGI. México.

Maranón-Pimentel, B. y Wester P. (2000). "Respuestas institucionales para el manejo de 1os acuíferos en la Cuenca Lerma-Chapala, México". IWMI, Serie Latinoamericana No. 17. México, D.F., México: Instituto Internacional del Manejo del Agua.

Martínez Pedro-Florián (2006). "El cultivo en sustrato". Curso INIA-AECI Horticultura Protegida y Semiprotegida. La Antigua, Guatemala, 20-24/03/2006.

Mestre Rodríguez José Eduardo (1997) “Case Study VIII* - Lerma-Chapala Basin, Mexico". Water Pollution Control - A Guide to the Use of Water Quality Management Principles. Published on behalf of the United Nations Environment Programme, the Water Supply \& Sanitation Collaborative Council and the World Health Organization by E. \& F. Spon.

Mienie A. and De Ronde J. A. (2008). "A comparison of drought stress and heat stress in the leaves and tubers of 12 potato cultivars" South African Journal of Science 104 pp.156-159.

Muñoz Ramos J.J. and Castellanos Javier Z. (2003). "Manual de producción hortícola en invernadero". INCAPA. Mexico.

Nelson Paul V. (2003) “Greenhouse operation and management”. Prentice Hall. 6th edition. United States of America.

Özenç Damla Bender (2008). "Growth and transpiration of tomato seedlings grown in hazelnut husk compost under water-deficit stress" Compost Science \& Utilization, Vol. 16, No. 2, 125-131.

Papail Jean (2003). "Migraciones internacionales y familias en áreas urbanas del Centro occidente de México". Universidad Autónoma del Estado de México. Papeles de población Abril/Junio No.036: 109-131. 
Rodríguez J.C., Cantliffe D.J.Shaw N.L. (2006). "Soilles Media and Containers for Greenhouse Production of "Galia" Type Muskmelon". Amer. Soc. Hort. Sci. 41(5): 12001205.

Salisbury Frank B. and Ross Cleon W. (1992). "Plant Physiology". Wadsworth Publishing Company. Fourth Edition. California, U.S. A.

Reyes Castañeda Pedro (1991). "Historia de la Agricultura". Información y síntesis. AGT Editor, S. A. 1era. Edición. México.

Tucker Arthur O. \& Debaggio Thomas (2000). "The big book of herbs" A comprehensive illustrated reference to herbs of flavor and fragance. Interweave Press, Inc. First printing. U.S.A.

Witt Mary L., Geneve Robert, Hartman John R., Wells Kenneth, and McNiel Robert E. (1999). "How Dry Seasons Affect Landscape Plants". Cooperative Extention Service. University of Kentucky. 


\section{Appendices}

\section{Appendix A: Statistical Analysis Experiment 1}

\section{The GLM Procedure}

Class Level Information

Class Levels Values

Table (tb) $\quad 3123$

Treatment (tmt) $\quad 3$ 1(80\%) 2(100\%) 3(120\%)

Species (sp) $\quad 5$ 1(mint) 2(thyme) 3(rosemary) 4(basil) 5(sunflowers)

Number of observations 45

Dependent Variable: Leachate

\begin{tabular}{|l|l|l|l|l|l|}
\hline Source & DF & $\begin{array}{l}\text { Sum of } \\
\text { Squares }\end{array}$ & Mean Square & F Value & Pr $>$ F \\
\hline Model & 20 & 24695.82924 & 1234.79146 & 61.03 & $<.0001$ \\
\hline Error & 24 & 485.57117 & 20.23213 & & \\
\hline $\begin{array}{l}\text { Corrected } \\
\text { Total }\end{array}$ & 44 & 25181.40041 & & & \\
\hline
\end{tabular}

\begin{tabular}{|l|l|l|l|}
\hline R-Square & Coeff Var & Root MSE & Leach Mean \\
\hline 0.980717 & 9.390639 & 4.498014 & 47.89892 \\
\hline
\end{tabular}

\begin{tabular}{|l|l|l|l|l|l|}
\hline Source & DF & Type III SS & Mean Square & F Value & Pr $>$ F \\
\hline tb & 2 & 164.34480 & 82.17240 & 4.06 & 0.0303 \\
\hline tmt & 2 & 19903.55468 & 9951.77734 & 491.88 & $<.0001$ \\
\hline tb*tmt & 4 & 92.57432 & 23.14358 & 1.14 & 0.3599 \\
\hline sp & 4 & 4235.33297 & 1058.83324 & 52.33 & $<.0001$ \\
\hline tmt*sp & 8 & 300.02247 & 37.50281 & 1.85 & 0.1158 \\
\hline
\end{tabular}

\begin{tabular}{|l|l|l|l|l|}
\hline Contrast & DF & Contrast SS & Mean Square & F Value \\
\hline 100 vs 80 & 1 & 4543.373063 & 4543.373063 & 224.56 \\
\hline 100 vs 120 & 1 & 5421.321467 & 5421.321467 & 267.96 \\
\hline high water req vs low water req & 1 & 442.381774 & 442.381774 & 21.87 \\
\hline
\end{tabular}




\begin{tabular}{|l|l|}
\hline Contrast & Pr $>$ F \\
\hline 100 vs 80 & $<.0001$ \\
\hline 100 vs 120 & $<.0001$ \\
\hline high water req vs low water req & $<.0001$ \\
\hline
\end{tabular}

Tests of Hypotheses Using the Type III MS for tb*tmt as an Error Term

\begin{tabular}{|l|l|l|l|l|l|}
\hline Source & DF & Type III SS & Mean Square & F Value & Pr $>$ F \\
\hline tmt & 2 & 19903.55468 & 9951.77734 & 430.00 & $<.0001$ \\
\hline
\end{tabular}

\begin{tabular}{|l|l|l|l|}
\hline Level of tb & $\mathrm{N}$ & Mean & Std Dev \\
\hline 1 & 15 & 49.3282599 & 24.6120546 \\
\hline 2 & 15 & 49.1706720 & 24.6340719 \\
\hline 3 & 15 & 45.1978176 & 23.9654296 \\
\hline
\end{tabular}

\begin{tabular}{|l|l|l|l|}
\hline Level of tmt & $\mathrm{N}$ & Mean & Std Dev \\
\hline 1 & 15 & 22.5285635 & 7.2399980 \\
\hline 2 & 15 & 47.1412244 & 12.4898706 \\
\hline 3 & 15 & 74.0269615 & 12.9836259 \\
\hline
\end{tabular}

\begin{tabular}{|l|l|l|l|}
\hline Level of sp & N & Mean & Std Dev \\
\hline 1 & 9 & 49.4929525 & 23.0658370 \\
\hline 2 & 9 & 45.8002961 & 21.6792845 \\
\hline 3 & 9 & 42.3174172 & 21.2962929 \\
\hline 4 & 9 & 36.5549145 & 20.8029849 \\
\hline 5 & 9 & 65.3290020 & 27.0173637 \\
\hline
\end{tabular}

\begin{tabular}{|l|l|l|l|l|}
\hline Level of tmt & Level of sp & N & Mean & Std Dev \\
\hline 1 & 1 & 3 & 23.4874044 & 3.30119586 \\
\hline 1 & 2 & 3 & 22.4944444 & 1.37465335 \\
\hline 1 & 3 & 3 & 17.8376068 & 0.56487903 \\
\hline 1 & 4 & 3 & 15.2307692 & 2.14712015 \\
\hline 1 & 5 & 3 & 33.5925926 & 7.16323848 \\
\hline 2 & 1 & 3 & 49.1880342 & 3.71612098 \\
\hline 2 & 2 & 3 & 42.8717949 & 3.61974641 \\
\hline 2 & 3 & 3 & 42.4413992 & 3.78427433 \\
\hline 2 & 4 & 3 & 33.8448718 & 9.25490284 \\
\hline 2 & 5 & 3 & 67.3600218 & 4.46588516 \\
\hline 3 & 1 & 3 & 75.8034188 & 7.10567984 \\
\hline 3 & 2 & 3 & 72.0346491 & 2.23675709 \\
\hline 3 & 3 & 3 & 66.6732456 & 3.28089205 \\
\hline 3 & 4 & 3 & 60.5891026 & 9.01303668 \\
\hline 3 & 5 & 3 & 95.0343915 & 2.80950513 \\
\hline
\end{tabular}


Class Level Information

Class Levels Values

Table (tb) $\quad 3 \quad 123$

Treatment (tmt) $3 \quad 1(80 \%)$ 2(100\%) 3(120\%)

Species (sp) 5 1(mint) 2(thyme) 3(rosemary) 4(basil) 5(sunflowers)

Number of observations 165

Dependent Variables with Equivalent Missing Value Patterns

\begin{tabular}{|l|l|l|}
\hline Pattern & Obs & Dependent Variables \\
\hline 1 & 93 & Height \\
\hline 2 & 165 & Fresh weight \\
\hline 3 & 140 & Dry weight \\
\hline 4 & 94 & Number of Stems \\
\hline 5 & 36 & Unfolded leaves (UFldLv) \\
\hline
\end{tabular}

NOTE: Variables in each group are consistent with respect to the presence or absence of missing values.

Dependent Variable: Height

\begin{tabular}{|l|l|l|l|l|l|}
\hline Source & DF & Sum of Squares & Mean Square & F Value & Pr > F \\
\hline Model & 14 & 416.736689 & 29.766906 & 2.95 & 0.0012 \\
\hline Error & 78 & 786.962236 & 10.089259 & & \\
\hline Corrected Total & 92 & 1203.698925 & & & \\
\hline
\end{tabular}

\begin{tabular}{|l|l|l|l|}
\hline R-Square & Coeff Var & Root MSE & Height Mean \\
\hline 0.346213 & 16.19082 & 3.176359 & 19.61828 \\
\hline
\end{tabular}

\begin{tabular}{|l|l|l|l|l|l|}
\hline Source & DF & Type III SS & Mean Square & F Value & Pr $>$ F \\
\hline tb & 2 & 86.0113005 & 43.0056503 & 4.26 & 0.0175 \\
\hline tmt & 2 & 21.0012222 & 10.5006111 & 1.04 & 0.3580 \\
\hline tb*tmt & 4 & 31.0309818 & 7.7577454 & 0.77 & 0.5487 \\
\hline sp & 2 & 206.7677822 & 103.3838911 & 10.25 & 0.0001 \\
\hline tmt* $^{*}$ sp & 4 & 58.9534697 & 14.7383674 & 1.46 & 0.2222 \\
\hline
\end{tabular}




\begin{tabular}{|l|l|l|l|l|l|}
\hline Contrast & DF & Contrast SS & Mean Square & F Value & Pr > F \\
\hline 100 vs 80 & 1 & 11.5231248 & 11.5231248 & 1.14 & 0.2885 \\
\hline 100 vs 120 & 1 & 1.4796097 & 1.4796097 & 0.15 & 0.7028 \\
\hline
\end{tabular}

Tests of Hypotheses Using the Type III MS for tb*tmt as an Error Term

\begin{tabular}{|l|l|l|l|l|l|}
\hline Source & DF & Type III SS & Mean Square & F Value & Pr > F \\
\hline tmt & 2 & 21.00122223 & 10.50061112 & 1.35 & 0.3557 \\
\hline
\end{tabular}

\begin{tabular}{|l|l|l|l|}
\hline Level of tb & N & Mean & Std Dev \\
\hline 1 & 29 & 21.1379310 & 3.85193957 \\
\hline 2 & 30 & 19.7166667 & 3.38781624 \\
\hline 3 & 34 & 18.2352941 & 3.12912829 \\
\hline
\end{tabular}

\begin{tabular}{|l|l|l|l|}
\hline Level of tmt & N & Mean & Std Dev \\
\hline 1 & 29 & 19.1206897 & 3.43473635 \\
\hline 2 & 32 & 19.7656250 & 4.38101545 \\
\hline 3 & 32 & 19.9218750 & 2.93782171 \\
\hline
\end{tabular}

\begin{tabular}{|l|l|l|l|}
\hline Level of sp & N & Mean & Std Dev \\
\hline 1 & 22 & 18.8181818 & 3.83761289 \\
\hline 2 & 36 & 21.4444444 & 2.50079352 \\
\hline 5 & 35 & 18.2428571 & 3.73845562 \\
\hline
\end{tabular}

\begin{tabular}{|l|l|l|l|l|}
\hline Level of tmt & Level of sp & $\mathrm{N}$ & Mean & Std Dev \\
\hline 1 & 1 & 5 & 15.8000000 & 3.76828874 \\
\hline 1 & 2 & 12 & 21.4166667 & 2.27469612 \\
\hline 1 & 5 & 12 & 18.2083333 & 2.83210758 \\
\hline 2 & 1 & 9 & 19.8888889 & 3.40750805 \\
\hline 2 & 2 & 12 & 22.0000000 & 3.24737656 \\
\hline 2 & 5 & 11 & 17.2272727 & 5.05155242 \\
\hline 3 & 1 & 8 & 19.5000000 & 3.77964473 \\
\hline 3 & 2 & 12 & 20.9166667 & 1.88092498 \\
\hline 3 & 5 & 12 & 19.2083333 & 3.15117823 \\
\hline
\end{tabular}


Dependent Variable: Fresh weight

\begin{tabular}{|l|l|l|l|l|l|}
\hline Source & DF & Sum of Squares & Mean Square & F Value & Pr $>$ F \\
\hline Model & 20 & 38274.29233 & 1913.71462 & 70.42 & $<.0001$ \\
\hline Error & 144 & 3913.23943 & 27.17527 & & \\
\hline Corrected Total & 164 & 42187.53176 & & & \\
\hline
\end{tabular}

\begin{tabular}{|l|l|l|l|}
\hline R-Square & Coeff Var & Root MSE & Fresh weight Mean \\
\hline 0.907242 & 24.26768 & 5.212991 & 21.48121 \\
\hline
\end{tabular}

\begin{tabular}{|l|l|l|l|l|l|}
\hline Source & DF & Type III SS & Mean Square & F Value & Pr $>$ F \\
\hline tb & 2 & 675.71412 & 337.85706 & 12.43 & $<.0001$ \\
\hline tmt & 2 & 477.28541 & 238.64270 & 8.78 & 0.0003 \\
\hline tb*tmt & 4 & 61.48507 & 15.37127 & 0.57 & 0.6880 \\
\hline sp & 4 & 34841.27504 & 8710.31876 & 320.52 & $<.0001$ \\
\hline tmt*sp & 8 & 897.63566 & 112.20446 & 4.13 & 0.0002 \\
\hline
\end{tabular}

\begin{tabular}{|l|l|l|l|l|}
\hline Contrast & DF & Contrast SS & Mean Square & F Value \\
\hline 100 vs 80 & 1 & 450.44505 & 450.44505 & 16.58 \\
\hline 100 vs 120 & 1 & 29.72463 & 29.72463 & 1.09 \\
\hline high water req vs low water req & 1 & 990.52661 & 990.52661 & 36.45 \\
\hline
\end{tabular}

\begin{tabular}{|l|l|}
\hline Contrast & Pr $>$ F \\
\hline 100 vs 80 & $<.0001$ \\
\hline 100 vs 120 & 0.2974 \\
\hline high water req vs low water req & $<.0001$ \\
\hline
\end{tabular}

Tests of Hypotheses Using the Type III MS for tb*tmt as an Error Term

\begin{tabular}{|l|l|l|l|l|l|}
\hline Source & DF & Type III SS & Mean Square & F Value & $\operatorname{Pr}>$ F \\
\hline tmt & 2 & 477.2854092 & 238.6427046 & 15.53 & 0.0130 \\
\hline
\end{tabular}

\begin{tabular}{|l|l|l|l|}
\hline Level of tb & N & Mean & Std Dev \\
\hline 1 & 53 & 25.1094340 & 17.4195874 \\
\hline 2 & 54 & 20.4962963 & 15.4275906 \\
\hline 3 & 58 & 19.0827586 & 14.9327515 \\
\hline
\end{tabular}

\begin{tabular}{|l|l|l|l|}
\hline Level of tmt & $\mathrm{N}$ & Mean & Std Dev \\
\hline 1 & 53 & 19.2698113 & 13.2696094 \\
\hline 2 & 56 & 23.1339286 & 18.2170377 \\
\hline 3 & 56 & 21.9214286 & 16.1560089 \\
\hline
\end{tabular}




\begin{tabular}{|l|l|l|l|}
\hline Level of sp & N & Mean & Std Dev \\
\hline 1 & 22 & 4.3818182 & 2.5325756 \\
\hline 2 & 36 & 22.8361111 & 5.7536648 \\
\hline 3 & 36 & 11.5583333 & 3.6694394 \\
\hline 4 & 36 & 47.3916667 & 10.7178723 \\
\hline 5 & 35 & 14.3914286 & 3.5607642 \\
\hline
\end{tabular}

\begin{tabular}{|l|l|l|l|l|}
\hline Level of tmt & Level of sp & $\mathrm{N}$ & Mean & Std Dev \\
\hline 1 & 1 & 5 & 3.1800000 & 2.1440616 \\
\hline 1 & 2 & 12 & 19.5750000 & 5.4057419 \\
\hline 1 & 3 & 12 & 10.1333333 & 3.3309385 \\
\hline 1 & 4 & 12 & 39.3583333 & 10.5518166 \\
\hline 1 & 5 & 12 & 14.7166667 & 2.7148860 \\
\hline 2 & 1 & 9 & 3.7000000 & 2.1077239 \\
\hline 2 & 2 & 12 & 25.5833333 & 5.8861677 \\
\hline 2 & 3 & 12 & 12.6833333 & 3.3220567 \\
\hline 2 & 4 & 12 & 53.5333333 & 9.1133602 \\
\hline 2 & 5 & 11 & 14.6000000 & 3.5835736 \\
\hline 3 & 1 & 8 & 5.9000000 & 2.6970884 \\
\hline 3 & 2 & 12 & 23.3500000 & 4.6196222 \\
\hline 3 & 3 & 12 & 11.8583333 & 4.1251905 \\
\hline 3 & 4 & 12 & 49.2833333 & 7.4602990 \\
\hline 3 & 5 & 12 & 13.8750000 & 4.4378793 \\
\hline
\end{tabular}

Dependent Variable: Dry weight

\begin{tabular}{|l|l|l|l|l|l|}
\hline Source & DF & Sum of Squares & Mean Square & F Value & $\operatorname{Pr}>$ F \\
\hline Model & 20 & 465.8278303 & 23.2913915 & 20.75 & $<.0001$ \\
\hline Error & 119 & 133.6043840 & 1.1227259 & & \\
\hline Corrected Total & 139 & 599.4322143 & & & \\
\hline
\end{tabular}

\begin{tabular}{|l|l|l|l|}
\hline R-Square & Coeff Var & Root MSE & Dry weight Mean \\
\hline 0.777115 & 20.70952 & 1.059588 & 5.116429 \\
\hline
\end{tabular}

\begin{tabular}{|l|l|l|l|l|l|}
\hline Source & DF & Type III SS & Mean Square & F Value & Pr $>$ F \\
\hline tb & 2 & 19.3983262 & 9.6991631 & 8.64 & 0.0003 \\
\hline tmt & 2 & 13.5917030 & 6.7958515 & 6.05 & 0.0031 \\
\hline tb*tmt & 4 & 1.3537689 & 0.3384422 & 0.30 & 0.8765 \\
\hline sp & 4 & 374.5598069 & 93.6399517 & 83.40 & $<.0001$ \\
\hline tmt*sp & 8 & 14.7095211 & 1.8386901 & 1.64 & 0.1212 \\
\hline
\end{tabular}




\begin{tabular}{|l|l|l|l|l|}
\hline Contrast & DF & Contrast SS & Mean Square & F Value \\
\hline 100 vs 80 & 1 & 12.2369093 & 12.2369093 & 10.90 \\
\hline 100 vs 120 & 1 & 0.1102208 & 0.1102208 & 0.10 \\
\hline high water req vs low water req & 1 & 16.5385391 & 16.5385391 & 14.73 \\
\hline
\end{tabular}

\begin{tabular}{|l|l|}
\hline Contrast & Pr $>$ F \\
\hline 100 vs 80 & 0.0013 \\
\hline 100 vs 120 & 0.7546 \\
\hline high water req vs low water req & 0.0002 \\
\hline
\end{tabular}

Tests of Hypotheses Using the Type III MS for tb*tmt as an Error Term

\begin{tabular}{|l|l|l|l|l|l|}
\hline Source & DF & Type III SS & Mean Square & F Value & Pr $>$ F \\
\hline tmt & 2 & 13.59170303 & 6.79585152 & 20.08 & 0.0082 \\
\hline
\end{tabular}

\begin{tabular}{|l|l|l|l|}
\hline Level of $\mathrm{tb}$ & $\mathrm{N}$ & Mean & Std Dev \\
\hline 1 & 45 & 5.74444444 & 2.20150316 \\
\hline 2 & 46 & 4.94782609 & 1.92996708 \\
\hline 3 & 49 & 4.69795918 & 1.99441823 \\
\hline
\end{tabular}

\begin{tabular}{|l|l|l|l|}
\hline Level of tmt & $\mathrm{N}$ & Mean & Std Dev \\
\hline 1 & 44 & 4.57272727 & 1.72577770 \\
\hline 2 & 50 & 5.33000000 & 2.37729481 \\
\hline 3 & 46 & 5.40434783 & 1.97393645 \\
\hline
\end{tabular}

\begin{tabular}{|l|l|l|l|}
\hline Level of sp & N & Mean & Std Dev \\
\hline 1 & 22 & 2.80000000 & 0.78921299 \\
\hline 2 & 36 & 5.47222222 & 1.31662146 \\
\hline 3 & 36 & 4.56111111 & 1.05160497 \\
\hline 4 & 36 & 7.46111111 & 1.54795308 \\
\hline 5 & 10 & 2.49000000 & 0.52799411 \\
\hline
\end{tabular}

\begin{tabular}{|l|l|l|l|l|}
\hline Level of tmt & Level of sp & $\mathrm{N}$ & Mean & Std Dev \\
\hline 1 & 1 & 5 & 2.44000000 & 0.84439327 \\
\hline 1 & 2 & 12 & 4.65000000 & 1.22363096 \\
\hline 1 & 3 & 12 & 4.22500000 & 0.92650369 \\
\hline 1 & 4 & 12 & 6.29166667 & 1.48352059 \\
\hline 1 & 5 & 3 & 2.33333333 & 0.40414519 \\
\hline 2 & 1 & 9 & 2.68888889 & 0.64700163 \\
\hline 2 & 2 & 12 & 5.91666667 & 1.29462759 \\
\hline 2 & 3 & 12 & 4.82500000 & 1.01455319 \\
\hline 2 & 4 & 12 & 8.40000000 & 1.32321921 \\
\hline
\end{tabular}




\begin{tabular}{|l|l|l|l|l|}
\hline 2 & 5 & 5 & 2.52000000 & 0.70851958 \\
\hline 3 & 1 & 8 & 3.15000000 & 0.85690473 \\
\hline 3 & 2 & 12 & 5.85000000 & 1.11069184 \\
\hline 3 & 3 & 12 & 4.63333333 & 1.19417779 \\
\hline 3 & 4 & 12 & 7.69166667 & 1.07741976 \\
\hline 3 & 5 & 2 & 2.65000000 & 0.21213203 \\
\hline
\end{tabular}

Dependent Variable: Stems

\begin{tabular}{|l|l|l|l|l|l|}
\hline Source & DF & Sum of Squares & Mean Square & F Value & Pr $>$ F \\
\hline Model & 14 & 335812.6229 & 23986.6159 & 49.58 & $<.0001$ \\
\hline Error & 79 & 38216.8665 & 483.7578 & & \\
\hline Corrected Total & 93 & 374029.4894 & & & \\
\hline
\end{tabular}

\begin{tabular}{|l|l|l|l|}
\hline R-Square & Coeff Var & Root MSE & Stems Mean \\
\hline 0.897824 & 34.63120 & 21.99449 & 63.51064 \\
\hline
\end{tabular}

\begin{tabular}{|l|l|l|l|l|l|}
\hline Source & DF & Type III SS & Mean Square & F Value & Pr $>$ F \\
\hline tb & 2 & 2181.7875 & 1090.8937 & 2.26 & 0.1116 \\
\hline tmt & 2 & 1688.0671 & 844.0336 & 1.74 & 0.1814 \\
\hline tb*tmt & 4 & 3385.2101 & 846.3025 & 1.75 & 0.1475 \\
\hline sp & 2 & 317171.5806 & 158585.7903 & 327.82 & $<.0001$ \\
\hline tmt*sp & 4 & 2706.5078 & 676.6269 & 1.40 & 0.2421 \\
\hline
\end{tabular}

\begin{tabular}{|l|l|l|l|l|l|}
\hline Contrast & DF & Contrast SS & Mean Square & F Value & Pr > F \\
\hline 100 vs 80 & 1 & 996.8298 & 996.8298 & 2.06 & 0.1551 \\
\hline 100 vs 120 & 1 & 89.6192 & 89.6192 & 0.19 & 0.6681 \\
\hline
\end{tabular}

Tests of Hypotheses Using the Type III MS for tb*tmt as an Error Term

\begin{tabular}{|l|l|l|l|l|l|}
\hline Source & DF & Type III SS & Mean Square & F Value & $\operatorname{Pr}>$ F \\
\hline tmt & 2 & 1688.067105 & 844.033552 & 1.00 & 0.4452 \\
\hline
\end{tabular}

\begin{tabular}{|l|l|l|l|}
\hline Level of tb & N & Mean & Std Dev \\
\hline 1 & 29 & 74.0000000 & 65.6979017 \\
\hline 2 & 31 & 58.7741935 & 57.4054061 \\
\hline 3 & 34 & 58.8823529 & 67.3524267 \\
\hline
\end{tabular}

\begin{tabular}{|l|l|l|l|}
\hline Level of tmt & N & Mean & Std Dev \\
\hline 1 & 29 & 60.1034483 & 56.6545578 \\
\hline 2 & 33 & 63.2121212 & 65.6095256 \\
\hline 3 & 32 & 66.9062500 & 68.5567151 \\
\hline
\end{tabular}




\begin{tabular}{|l|l|l|l|}
\hline Level of sp & $\mathrm{N}$ & Mean & Std Dev \\
\hline 1 & 22 & 8.863636 & 4.4432448 \\
\hline 2 & 36 & 137.861111 & 36.3484350 \\
\hline 3 & 36 & 22.555556 & 8.0762242 \\
\hline
\end{tabular}

\begin{tabular}{|l|l|l|l|l|}
\hline Level of tmt & Level of sp & N & Mean & Std Dev \\
\hline 1 & 1 & 5 & 7.200000 & 4.7644517 \\
\hline 1 & 2 & 12 & 121.000000 & 33.5152611 \\
\hline 1 & 3 & 12 & 21.250000 & 8.6142060 \\
\hline 2 & 1 & 9 & 7.333333 & 3.6055513 \\
\hline 2 & 2 & 12 & 144.000000 & 33.6371007 \\
\hline 2 & 3 & 12 & 24.333333 & 7.6078110 \\
\hline 3 & 1 & 8 & 11.625000 & 4.2067123 \\
\hline 3 & 2 & 12 & 148.583333 & 38.3724767 \\
\hline 3 & 3 & 12 & 22.083333 & 8.3607126 \\
\hline
\end{tabular}

Dependent Variable: Unfolded leaves (mature leaves) UFldLv

\begin{tabular}{|l|l|l|l|l|l|}
\hline Source & DF & Sum of Squares & Mean Square & F Value & Pr > F \\
\hline Model & 8 & 25981.3889 & 3247.6736 & 1.10 & 0.3922 \\
\hline Error & 27 & 79552.5000 & 2946.3889 & & \\
\hline Corrected Total & 35 & 105533.8889 & & & \\
\hline
\end{tabular}

\begin{tabular}{|l|l|l|l|}
\hline R-Square & Coeff Var & Root MSE & UFldLv Mean \\
\hline 0.246190 & 32.10817 & 54.28065 & 169.0556 \\
\hline
\end{tabular}

\begin{tabular}{|l|l|l|l|l|l|}
\hline Source & DF & Type III SS & Mean Square & F Value & Pr $>$ F \\
\hline $\mathrm{tb}$ & 2 & 2107.55556 & 1053.77778 & 0.36 & 0.7026 \\
\hline $\mathrm{tmt}$ & 2 & 17249.55556 & 8624.77778 & 2.93 & 0.0707 \\
\hline $\mathrm{tb} * \mathrm{tmt}$ & 4 & 6624.27778 & 1656.06944 & 0.56 & 0.6922 \\
\hline
\end{tabular}

\begin{tabular}{|l|l|l|l|l|l|}
\hline Contrast & DF & Contrast SS & Mean Square & F Value & Pr $>$ F \\
\hline 100 vs 80 & 1 & 15606.00000 & 15606.00000 & 5.30 & 0.0293 \\
\hline 100 vs 120 & 1 & 9520.16667 & 9520.16667 & 3.23 & 0.0834 \\
\hline
\end{tabular}

Tests of Hypotheses Using the Type III MS for tb*tmt as an Error Term

\begin{tabular}{|l|l|l|l|l|l|}
\hline Source & DF & Type III SS & Mean Square & F Value & $\operatorname{Pr}>$ F \\
\hline tmt & 2 & 17249.55556 & 8624.77778 & 5.21 & 0.0770 \\
\hline
\end{tabular}




\begin{tabular}{|l|l|l|l|}
\hline Level of tb & $\mathrm{N}$ & Mean & Std Dev \\
\hline 1 & 12 & 179.833333 & 71.3593127 \\
\hline 2 & 12 & 164.500000 & 33.6681668 \\
\hline 3 & 12 & 162.833333 & 56.3621945 \\
\hline
\end{tabular}

\begin{tabular}{|l|l|l|l|}
\hline Level of tmt & N & Mean & Std Dev \\
\hline 1 & 12 & 148.333333 & 28.7949911 \\
\hline 2 & 12 & 199.333333 & 70.6455086 \\
\hline 3 & 12 & 159.500000 & 46.9671065 \\
\hline
\end{tabular}

\begin{tabular}{|l|l|l|l|}
\hline Level of sp & $\mathrm{N}$ & Mean & Std Dev \\
\hline 4 & 36 & 169.055556 & 54.9113282 \\
\hline
\end{tabular}

\begin{tabular}{|l|l|l|l|l|}
\hline Level of tmt & Level of sp & N & Mean & Std Dev \\
\hline 1 & 4 & 12 & 148.333333 & 28.7949911 \\
\hline 2 & 4 & 12 & 199.333333 & 70.6455086 \\
\hline 3 & 4 & 12 & 159.500000 & 46.9671065 \\
\hline
\end{tabular}




\section{Appendix B: Statistical Analysis Experiments 2 and 3}

Fresh weight

The MEANS Procedure

\begin{tabular}{|r|r|l|l|l|l|l|}
\hline \multicolumn{7}{|c|}{ Analysis Variable : fresh } \\
\hline water & N Obs & N & Mean & Std Dev & Minimum & Maximum \\
\hline 0.5 & 57 & 57 & 3.3546875 & 0.5501869 & 2.3608540 & 4.2710951 \\
\hline 1 & 59 & 59 & 3.9648265 & 0.5138878 & 2.5726122 & 4.9196159 \\
\hline 1.5 & 60 & 60 & 4.1755156 & 0.4971680 & 3.2228678 & 5.0689042 \\
\hline 2 & 59 & 59 & 4.2895883 & 0.6044451 & 2.4595888 & 5.3147811 \\
\hline 3 & 58 & 58 & 4.3619986 & 0.5734555 & 2.7212954 & 5.5577157 \\
\hline
\end{tabular}

\begin{tabular}{|l|r|l|l|l|l|l|}
\hline \multicolumn{7}{|c|}{ Analysis Variable : fresh } \\
\hline herb & $\begin{array}{r}\text { N } \\
\text { Obs }\end{array}$ & N & Mean & Std Dev & Minimum & Maximum \\
\hline Basil & 60 & 60 & 4.7490157 & 0.5100569 & 3.6674004 & 5.5577157 \\
\hline Mint & 57 & 57 & 3.7529166 & 0.5903132 & 2.5136561 & 4.9919960 \\
\hline Rose & 60 & 60 & 3.6868595 & 0.5388549 & 2.3608540 & 4.5522967 \\
\hline Sun & 56 & 56 & 3.6965352 & 0.5329378 & 2.4423470 & 4.8759604 \\
\hline Thyme & 60 & 60 & 4.2446631 & 0.3081620 & 3.5351454 & 4.9533592 \\
\hline
\end{tabular}

\begin{tabular}{|c|c|c|c|c|c|c|c|}
\hline \multicolumn{8}{|c|}{ Analysis Variable : fresh } \\
\hline herb & water & $\begin{array}{c}\mathbf{N} \\
\text { Obs }\end{array}$ & $\mathbf{N}$ & Mean & Std Dev & Minimum & Maximum \\
\hline \multirow[t]{5}{*}{ Basil } & 0.5 & 12 & 12 & 3.8452809 & 0.1326087 & 3.6674004 & 4.0368920 \\
\hline & 1 & 12 & 12 & 4.6993054 & 0.1690174 & 4.4510862 & 4.9196159 \\
\hline & 1.5 & 12 & 12 & 4.9092063 & 0.1001680 & 4.7564310 & 5.0689042 \\
\hline & 2 & 12 & 12 & 5.1271178 & 0.1249730 & 4.8899731 & 5.3147811 \\
\hline & 3 & 12 & 12 & 5.1641679 & 0.2407009 & 4.7953772 & 5.5577157 \\
\hline \multirow[t]{5}{*}{ Mint } & 0.5 & 11 & 11 & 2.9229809 & 0.1862940 & 2.5136561 & 3.1945831 \\
\hline & 1 & 12 & 12 & 3.6102146 & 0.3052826 & 3.1966302 & 4.0276704 \\
\hline & 1.5 & 12 & 12 & 3.9301252 & 0.2594979 & 3.5145261 & 4.3350660 \\
\hline & 2 & 11 & 11 & 4.0968128 & 0.5395401 & 3.0864866 & 4.7034759 \\
\hline & 3 & 11 & 11 & 4.2013126 & 0.5272402 & 3.4873751 & 4.9919960 \\
\hline \multirow[t]{5}{*}{ Rose } & 0.5 & 12 & 12 & 2.7844780 & 0.3202654 & 2.3608540 & 3.4111477 \\
\hline & 1 & 12 & 12 & 3.6276695 & 0.1523310 & 3.3534067 & 3.8066625 \\
\hline & 1.5 & 12 & 12 & 3.8185555 & 0.1509997 & 3.5380566 & 4.0741419 \\
\hline & 2 & 12 & 12 & 4.0154381 & 0.2244339 & 3.5292974 & 4.2738845 \\
\hline & 3 & 12 & 12 & 4.1881565 & 0.2355410 & 3.6609943 & 4.5522967 \\
\hline \multirow[t]{5}{*}{ Sun } & 0.5 & 10 & 10 & 3.1861503 & 0.3797804 & 2.4423470 & 3.6203329 \\
\hline & 1 & 11 & 11 & 3.6941595 & 0.4553340 & 2.5726122 & 4.1510399 \\
\hline & 1.5 & 12 & 12 & 3.8221885 & 0.4217699 & 3.2228678 & 4.8759604 \\
\hline & 2 & 12 & 12 & 3.8717049 & 0.6259964 & 2.4595888 & 4.6185799 \\
\hline & 3 & 11 & 11 & 3.8347266 & 0.5108574 & 2.7212954 & 4.5352841 \\
\hline \multirow[t]{5}{*}{ Thyme } & 0.5 & 12 & 12 & 3.9704823 & 0.1679407 & 3.6609943 & 4.2710951 \\
\hline & 1 & 12 & 12 & 4.1702280 & 0.2999966 & 3.5351454 & 4.6885918 \\
\hline & 1.5 & 12 & 12 & 4.3975026 & 0.2565508 & 3.8712010 & 4.7621739 \\
\hline & 2 & 12 & 12 & 4.3208032 & 0.3577281 & 3.8220983 & 4.9533592 \\
\hline & 3 & 12 & 12 & 4.3642996 & 0.2487693 & 3.9740584 & 4.8846941 \\
\hline
\end{tabular}




\begin{tabular}{|l|l|}
\hline Model Information \\
\hline Data Set & WORK.VICTORIA01 \\
\hline Dependent Variable & fresh \\
\hline Covariance Structure & Variance Components \\
\hline Estimation Method & REML \\
\hline Residual Variance Method & Profile \\
\hline Fixed Effects SE Method & Kenward-Roger \\
\hline Degrees of Freedom Method & Kenward-Roger \\
\hline
\end{tabular}

\begin{tabular}{|c|c|c|}
\hline \multicolumn{3}{|r|}{ Class Level Information } \\
\hline Class & Levels & Values \\
\hline block & 2 & 12 \\
\hline water & 5 & 0.511 .523 \\
\hline herb & 5 & Basil Mint Rose Sun Thyme \\
\hline bench & 60 & $\begin{array}{l}12345678910111213141516171819202122 \\
23242526272829303132333435363738394041 \\
42434445464748495051525354555657585960\end{array}$ \\
\hline
\end{tabular}

\begin{tabular}{|l|r|}
\hline Dimensions \\
\hline Covariance Parameters & 3 \\
\hline Columns in X & 36 \\
\hline Columns in Z & 62 \\
\hline Subjects & 1 \\
\hline Max Obs Per Subject & 293 \\
\hline
\end{tabular}

\begin{tabular}{|l|r|}
\hline Number of Observations \\
\hline Number of Observations Read & 293 \\
\hline Number of Observations Used & 293 \\
\hline Number of Observations Not Used & 0 \\
\hline
\end{tabular}

\begin{tabular}{|r|r|r|l|}
\hline \multicolumn{4}{|c|}{ Iteration History } \\
\hline $\begin{array}{r}\text { Iterati } \\
\text { on }\end{array}$ & $\begin{array}{r}\text { Evaluati } \\
\text { ons }\end{array}$ & $\begin{array}{r}\text {-2 Res Log } \\
\text { Like }\end{array}$ & Criterion \\
\hline $\mathbf{0}$ & 1 & 220.4172743 & \\
8 & \\
\hline $\mathbf{1}$ & 2 & 194.0461862 & 0.00000000 \\
\hline
\end{tabular}

\section{Convergence criteria}

\begin{tabular}{|l|l|c|r|r|}
\hline \multicolumn{6}{|l|}{ Covariance Parameter Estimates } \\
\hline Cov Parm & Estimate & $\begin{array}{c}\text { Standard } \\
\text { Error }\end{array}$ & $\begin{array}{r}\mathbf{Z} \\
\text { Value }\end{array}$ & $\mathbf{P r}>\mathbf{Z}$ \\
\hline block & 0.02014 & 0.02949 & 0.68 & 0.2474 \\
\hline bench(block*water) & 0.002568 & 0.004522 & 0.57 & 0.2851 \\
\hline Residual & 0.09237 & 0.008944 & 10.33 & $<.0001$ \\
\hline
\end{tabular}

\begin{tabular}{|l|l|}
\hline \multicolumn{2}{|l|}{ Fit Statistics } \\
\hline -2 Res Log Likelihood & 194.0 \\
\hline AIC (smaller is better) & 200.0 \\
\hline AICC (smaller is better) & 200.1 \\
\hline BIC (smaller is better) & 196.1 \\
\hline
\end{tabular}




\begin{tabular}{|l|l|l|r|r|r|r|r|}
\hline \multicolumn{7}{|c|}{ Solution for Fixed Effects } \\
\hline Effect & herb & water & Estimate & $\begin{array}{r}\text { Standard } \\
\text { Error }\end{array}$ & DF & $\begin{array}{r}\mathbf{t} \\
\text { Value }\end{array}$ & $\begin{array}{r}\text { Pr }> \\
|\mathbf{t}|\end{array}$ \\
\hline Intercept & & & 4.3643 & 0.1341 & 2.97 & 32.55 & $<.0001$ \\
\hline water & & 0.5 & -0.3938 & 0.1258 & 266 & -3.13 & 0.0019 \\
\hline water & & 1 & -0.1941 & 0.1258 & 266 & -1.54 & 0.1241 \\
\hline water & & 1.5 & 0.03320 & 0.1258 & 266 & 0.26 & 0.7920 \\
\hline water & & 2 & -0.04350 & 0.1258 & 266 & -0.35 & 0.7298 \\
\hline water & & 3 & 0 &. &. &. &. \\
\hline herb & Basil & & 0.7999 & 0.1241 & 213 & 6.45 & $<.0001$ \\
\hline herb & Mint & & -0.1549 & 0.1270 & 217 & -1.22 & 0.2239 \\
\hline herb & Rose & & -0.1761 & 0.1241 & 213 & -1.42 & 0.1572 \\
\hline herb & Sun & & -0.5192 & 0.1270 & 217 & -4.09 & $<.0001$ \\
\hline herb & Thyme & & 0 & &. &. &. \\
\hline water*herb & Basil & 0.5 & -0.9251 & 0.1755 & 213 & -5.27 & $<.0001$ \\
\hline water*herb & Mint & 0.5 & -0.8834 & 0.1796 & 217 & -4.92 & $<.0001$ \\
\hline water*herb & Rose & 0.5 & -1.0099 & 0.1755 & 213 & -5.76 & $<.0001$ \\
\hline water*herb & Sun & 0.5 & -0.2636 & 0.1820 & 219 & -1.45 & 0.1490 \\
\hline water*herb & Thyme & 0.5 & 0 & &. &. &. \\
\hline
\end{tabular}

\begin{tabular}{|l|l|l|r|r|r|r|c|}
\hline \multicolumn{7}{|c|}{ Solution for Fixed Effects } \\
\hline Effect & herb & water & Estimate & $\begin{array}{r}\text { Standard } \\
\text { Error }\end{array}$ & $\begin{array}{r}\text { DF } \\
\text { Value }\end{array}$ & $\begin{array}{r}\text { Pr }> \\
|\mathbf{t}|\end{array}$ \\
\hline water*herb & Basil & 1 & -0.2708 & 0.1755 & 213 & -1.54 & 0.1243 \\
\hline water*herb & Mint & 1 & -0.4051 & 0.1775 & 215 & -2.28 & 0.0235 \\
\hline water*herb & Rose & 1 & -0.3648 & 0.1756 & 216 & -2.08 & 0.0390 \\
\hline water*herb & Sun & 1 & 0.03470 & 0.1796 & 217 & 0.19 & 0.8470 \\
\hline water*herb & Thyme & 1 & 0 &. &. &. &. \\
\hline water*herb & Basil & 1.5 & -0.2882 & 0.1755 & 213 & -1.64 & 0.1020 \\
\hline water*herb & Mint & 1.5 & -0.3125 & 0.1775 & 215 & -1.76 & 0.0798 \\
\hline water*herb & Rose & 1.5 & -0.4028 & 0.1755 & 213 & -2.30 & 0.0227 \\
\hline water*herb & Sun & 1.5 & -0.05610 & 0.1775 & 215 & -0.32 & 0.7523 \\
\hline water*herb & Thyme & 1.5 & 0 &. &. &. &. \\
\hline water*herb & Basil & 2 & 0.006446 & 0.1755 & 213 & 0.04 & 0.9707 \\
\hline water*herb & Mint & 2 & -0.05908 & 0.1796 & 217 & -0.33 & 0.7425 \\
\hline water*herb & Rose & 2 & -0.1292 & 0.1755 & 213 & -0.74 & 0.4623 \\
\hline water*herb & Sun & 2 & 0.07011 & 0.1775 & 215 & 0.39 & 0.6933 \\
\hline water*herb & Thyme & 2 & 0 & &. &. &. \\
\hline water*herb & Basil & 3 & 0 &. &. &. &. \\
\hline water*herb & Mint & 3 & 0 &. &. &. &. \\
\hline water*herb & Rose & 3 & 0 &. &. &. &. \\
\hline water*herb & Sun & 3 & 0 &. &. &. &. \\
\hline water*herb & Thyme & 3 & 0 & &. &. &. \\
\hline
\end{tabular}




\begin{tabular}{|l|l|l|l|l|c|r|r|r|}
\hline \multicolumn{9}{|c|}{ Solution for Random Effects } \\
\hline Effect & block & water & bench & Estimate & $\begin{array}{c}\text { Std Err } \\
\text { Pred }\end{array}$ & $\begin{array}{r}\mathbf{t} \\
\text { DF }\end{array}$ & $\begin{array}{c}\text { Pr }> \\
\text { Value }\end{array}$ \\
\hline block & 1 & & & 0.09860 & 0.1023 & 1 & 0.96 & 0.5117 \\
\hline block & 2 & & & -0.09860 & 0.1023 & 1 & -0.96 & 0.5117 \\
\hline bench(block*water) & 1 & 0.5 & 10 & -0.00204 & 0.06079 & 1 & -0.03 & 0.9787 \\
\hline bench(block*water) & 1 & 0.5 & 17 & -0.02343 & 0.06079 & 1 & -0.39 & 0.7658 \\
\hline bench(block*water) & 1 & 0.5 & 20 & 0.002887 & 0.05961 & 1 & 0.05 & 0.9692 \\
\hline bench(block*water) & 1 & 0.5 & 22 & -0.01859 & 0.06079 & 1 & -0.31 & 0.8111 \\
\hline bench(block*water) & 1 & 0.5 & 24 & -0.01035 & 0.06079 & 1 & -0.17 & 0.8927 \\
\hline bench(block*water) & 1 & 0.5 & 28 & -0.01431 & 0.05962 & 1 & -0.24 & 0.8500 \\
\hline
\end{tabular}

\begin{tabular}{|c|c|c|c|c|c|c|c|c|}
\hline \multicolumn{9}{|c|}{ Solution for Random Effects } \\
\hline Effect & block & water & bench & Estimate & $\begin{array}{c}\text { Std Err } \\
\text { Pred } \\
\end{array}$ & DF & $\begin{array}{r}\text { t } \\
\text { Value } \\
\end{array}$ & $\begin{array}{c}\operatorname{Pr}> \\
|t| \\
\end{array}$ \\
\hline bench(block*water) & 1 & 1 & 2 & -0.01192 & 0.06081 & 1 & -0.20 & 0.8767 \\
\hline bench(block*water) & 1 & 1 & 5 & 0.006235 & 0.06081 & 1 & 0.10 & 0.9350 \\
\hline bench(block*water) & 1 & 1 & 9 & 0.009730 & 0.05963 & 1 & 0.16 & 0.8970 \\
\hline bench(block*water) & 1 & 1 & 13 & 0.008411 & 0.06081 & 1 & 0.14 & 0.9125 \\
\hline bench(block*water) & 1 & 1 & 19 & -0.00965 & 0.06159 & 1 & -0.16 & 0.9011 \\
\hline bench(block*water) & 1 & 1 & 21 & 0.000727 & 0.06081 & 1 & 0.01 & 0.9924 \\
\hline bench(block*water) & 1 & 1.5 & 1 & -0.02856 & 0.06082 & 1 & -0.47 & 0.7205 \\
\hline bench(block*water) & 1 & 1.5 & 11 & -0.01762 & 0.06082 & 1 & -0.29 & 0.8205 \\
\hline bench(block*water) & 1 & 1.5 & 12 & 0.001224 & 0.06082 & 1 & 0.02 & 0.9872 \\
\hline bench(block*water) & 1 & 1.5 & 16 & 0.002340 & 0.06082 & 1 & 0.04 & 0.9755 \\
\hline bench(block*water) & 1 & 1.5 & 23 & -0.00329 & 0.06082 & 1 & -0.05 & 0.9656 \\
\hline bench(block*water) & 1 & 1.5 & 29 & -0.00395 & 0.06082 & 1 & -0.06 & 0.9587 \\
\hline bench(block*water) & 1 & 2 & 3 & -0.00309 & 0.06081 & 1 & -0.05 & 0.9677 \\
\hline bench(block*water) & 1 & 2 & 6 & -0.00865 & 0.06081 & 1 & -0.14 & 0.9100 \\
\hline bench(block*water) & 1 & 2 & 8 & 0.01521 & 0.06081 & 1 & 0.25 & 0.8440 \\
\hline bench(block*water) & 1 & 2 & 18 & 0.03087 & 0.06081 & 1 & 0.51 & 0.7009 \\
\hline bench(block*water) & 1 & 2 & 25 & 0.01166 & 0.05964 & 1 & 0.20 & 0.8771 \\
\hline bench(block*water) & 1 & 2 & 26 & 0.03162 & 0.06081 & 1 & 0.52 & 0.6947 \\
\hline bench(block*water) & 1 & 3 & 4 & 0.02188 & 0.06080 & 1 & 0.36 & 0.7801 \\
\hline bench(block*water) & 1 & 3 & 7 & -0.00122 & 0.06080 & 1 & -0.02 & 0.9872 \\
\hline bench(block*water) & 1 & 3 & 14 & 0.01915 & 0.06080 & 1 & 0.31 & 0.8058 \\
\hline bench(block*water) & 1 & 3 & 15 & 0.001406 & 0.06080 & 1 & 0.02 & 0.9853 \\
\hline bench(block*water) & 1 & 3 & 27 & 0.01539 & 0.05962 & 1 & 0.26 & 0.8392 \\
\hline bench(block*water) & 1 & 3 & 30 & -0.00949 & 0.05962 & 1 & -0.16 & 0.8995 \\
\hline bench(block*water) & 2 & 0.5 & 40 & -0.02972 & 0.06080 & 1 & -0.49 & 0.7105 \\
\hline bench(block*water) & 2 & 0.5 & 47 & 0.01698 & 0.06080 & 1 & 0.28 & 0.8267 \\
\hline bench(block*water) & 2 & 0.5 & 50 & 0.02084 & 0.06080 & 1 & 0.34 & 0.7898 \\
\hline bench(block*water) & 2 & 0.5 & 52 & 0.02991 & 0.05963 & 1 & 0.50 & 0.7040 \\
\hline bench(block*water) & 2 & 0.5 & 54 & 0.004531 & 0.06080 & 1 & 0.07 & 0.9526 \\
\hline bench(block*water) & 2 & 0.5 & 58 & 0.02329 & 0.06080 & 1 & 0.38 & 0.7671 \\
\hline bench(block*water) & 2 & 1 & 32 & -0.03447 & 0.06081 & 1 & -0.57 & 0.6717 \\
\hline
\end{tabular}




\begin{tabular}{|c|c|c|c|c|c|c|c|c|}
\hline \multicolumn{9}{|c|}{ Solution for Random Effects } \\
\hline Effect & block & water & bench & Estimate & $\begin{array}{c}\text { Std Err } \\
\text { Pred }\end{array}$ & DF & Value & $\begin{array}{c}\operatorname{Pr}> \\
|\mathbf{t}|\end{array}$ \\
\hline bench(block*water) & 2 & 1 & 35 & 0.008515 & 0.06081 & 1 & 0.14 & 0.9114 \\
\hline bench(block*water) & 2 & 1 & 39 & 0.004211 & 0.06081 & 1 & 0.07 & 0.9560 \\
\hline bench(block*water) & 2 & 1 & 43 & 0.001745 & 0.06081 & 1 & 0.03 & 0.9817 \\
\hline bench(block*water) & 2 & 1 & 49 & 0.01071 & 0.06081 & 1 & 0.18 & 0.8890 \\
\hline bench(block*water) & 2 & 1 & 51 & 0.005755 & 0.05964 & 1 & 0.10 & 0.9388 \\
\hline bench(block* water) & 2 & 1.5 & 31 & 0.01028 & 0.06082 & 1 & 0.17 & 0.8934 \\
\hline bench(block*water) & 2 & 1.5 & 41 & -0.00328 & 0.06082 & 1 & -0.05 & 0.9657 \\
\hline bench(block*water) & 2 & 1.5 & 42 & 0.02977 & 0.06082 & 1 & 0.49 & 0.7102 \\
\hline bench(block*water) & 2 & 1.5 & 46 & 0.009996 & 0.06082 & 1 & 0.16 & 0.8963 \\
\hline bench(block* water) & 2 & 1.5 & 53 & -0.00220 & 0.06082 & 1 & -0.04 & 0.9770 \\
\hline bench(block*water) & 2 & 1.5 & 59 & 0.005301 & 0.06082 & 1 & 0.09 & 0.9447 \\
\hline bench(block*water) & 2 & 2 & 33 & -0.01870 & 0.06082 & 1 & -0.31 & 0.8101 \\
\hline bench(block*water) & 2 & 2 & 36 & -0.00435 & 0.06082 & 1 & -0.07 & 0.9546 \\
\hline bench(block*water) & 2 & 2 & 38 & 0.004561 & 0.06082 & 1 & 0.08 & 0.9523 \\
\hline bench(block* water) & 2 & 2 & 48 & -0.02550 & 0.06082 & 1 & -0.42 & 0.7473 \\
\hline bench(block*water) & 2 & 2 & 55 & -0.02444 & 0.06082 & 1 & -0.40 & 0.7567 \\
\hline bench(block* water) & 2 & 2 & 56 & -0.00919 & 0.06082 & 1 & -0.15 & 0.9045 \\
\hline bench(block*water) & 2 & 3 & 34 & -0.02562 & 0.06081 & 1 & -0.42 & 0.7462 \\
\hline bench(block*water) & 2 & 3 & 37 & -0.01589 & 0.06081 & 1 & -0.26 & 0.8373 \\
\hline bench(block* water) & 2 & 3 & 44 & -0.00918 & 0.06081 & 1 & -0.15 & 0.9046 \\
\hline bench(block*water) & 2 & 3 & 45 & -0.03331 & 0.06081 & 1 & -0.55 & 0.6810 \\
\hline bench(block*water) & 2 & 3 & 57 & 0.01936 & 0.06081 & 1 & 0.32 & 0.8038 \\
\hline bench(block*water) & 2 & 3 & 60 & 0.01753 & 0.06081 & 1 & 0.29 & 0.8213 \\
\hline
\end{tabular}

\begin{tabular}{|l|r|c|r|l|}
\hline \multicolumn{7}{|l|}{ Type 3 Tests of Fixed Effects } \\
\hline Effect & $\begin{array}{r}\text { Num } \\
\text { DF }\end{array}$ & $\begin{array}{r}\text { Den } \\
\text { DF }\end{array}$ & $\begin{array}{r}\text { F } \\
\text { Value }\end{array}$ & Pr > F \\
\hline water & 4 & 53.7 & 91.31 & $<.0001$ \\
\hline herb & 4 & 216 & 140.05 & $<.0001$ \\
\hline water*herb & 16 & 216 & 4.13 & $<.0001$ \\
\hline
\end{tabular}




\begin{tabular}{|c|c|c|c|c|c|c|c|}
\hline & & Least & res Means & & & & \\
\hline Effect & herb & water & Estimate & Standard Error & DF & t Value & $\operatorname{Pr}>\mid \mathbf{t}$ \\
\hline water*herb & Basil & 0.5 & 3.8453 & 0.1341 & 2.97 & 28.68 & 0.0001 \\
\hline water*herb & Mint & 0.5 & 2.9322 & 0.1368 & 3.21 & 21.44 & 0.0001 \\
\hline water*herb & Rose & 0.5 & 2.7845 & 0.1341 & 2.97 & 20.77 & 0.0003 \\
\hline water*herb & Sun & 0.5 & 3.1877 & 0.1399 & 3.51 & 22.78 & $<.0001$ \\
\hline water*herb & Thyme & 0.5 & 3.9705 & 0.1341 & 2.97 & 29.61 & $<.0001$ \\
\hline water*herb & Basil & 1 & 4.6993 & 0.1341 & 2.97 & 35.05 & $<.0001$ \\
\hline water*herb & Mint & 1 & 3.6102 & 0.1341 & 2.97 & 26.92 & 0.0001 \\
\hline water*herb & Rose & 1 & 3.6293 & 0.1343 & 2.98 & 27.03 & 0.0001 \\
\hline water*herb & Sun & 1 & 3.6857 & 0.1368 & 3.21 & 26.95 & $<.0001$ \\
\hline water*herb & Thyme & 1 & 4.1702 & 0.1341 & 2.97 & 31.10 & $<.0001$ \\
\hline water*herb & Basil & 1.5 & 4.9092 & 0.1341 & 2.97 & 36.61 & $<.0001$ \\
\hline water*herb & Mint & 1.5 & 3.9301 & 0.1341 & 2.97 & 29.31 & $<.0001$ \\
\hline water*herb & Rose & 1.5 & 3.8186 & 0.1341 & 2.97 & 28.48 & 0.0001 \\
\hline water*herb & Sun & 1.5 & 3.8222 & 0.1341 & 2.97 & 28.51 & 0.0001 \\
\hline water*herb & Thyme & 1.5 & 4.3975 & 0.1341 & 2.97 & 32.80 & $<.0001$ \\
\hline water*herb & Basil & 2 & 5.1271 & 0.1341 & 2.97 & 38.24 & $<.0001$ \\
\hline water*herb & Mint & 2 & 4.1068 & 0.1368 & 3.21 & 30.02 & $<.0001$ \\
\hline water*herb & Rose & 2 & 4.0154 & 0.1341 & 2.97 & 29.95 & $<.0001$ \\
\hline water*herb & Sun & 2 & 3.8717 & 0.1341 & 2.97 & 28.87 & $<.0001$ \\
\hline water*herb & Thyme & 2 & 4.3208 & 0.1341 & 2.97 & 32.22 & $<.0001$ \\
\hline water*herb & Basil & 3 & 5.1642 & 0.1341 & 2.97 & 38.51 & $<.0001$ \\
\hline water*herb & Mint & 3 & 4.2094 & 0.1368 & 3.21 & 30.77 & $<.0001$ \\
\hline water*herb & Rose & 3 & 4.1882 & 0.1341 & 2.97 & 31.23 & $<.0001$ \\
\hline water*herb & Sun & 3 & 3.8451 & 0.1368 & 3.21 & 28.11 & $<.0001$ \\
\hline water*herb & Thyme & 3 & 4.3643 & 0.1341 & 2.97 & 32.55 & $<.0001$ \\
\hline
\end{tabular}




\begin{tabular}{|c|c|c|c|c|c|c|c|c|c|}
\hline \multicolumn{10}{|c|}{ Differences of Least Squares Means } \\
\hline Effect & herb & water & herb & water & Estimate & Standard Error & DF & t Value & $\operatorname{Pr}>|t|$ \\
\hline water*herb & Basil & 0.5 & Mint & 0.5 & 0.9131 & 0.1270 & 217 & 7.19 & $<.0001$ \\
\hline water*herb & Basil & 0.5 & Rose & 0.5 & 1.0608 & 0.1241 & 213 & 8.55 & $<.0001$ \\
\hline water*herb & Basil & 0.5 & Sun & 0.5 & 0.6576 & 0.1304 & 221 & 5.04 & $<.0001$ \\
\hline water*herb & Basil & 0.5 & Thyme & 0.5 & -0.1252 & 0.1241 & 213 & -1.01 & 0.3141 \\
\hline water*herb & Basil & 0.5 & Basil & 1 & -0.8540 & 0.1258 & 266 & -6.79 & $<.0001$ \\
\hline water*herb & Basil & 0.5 & Mint & 1 & 0.2351 & 0.1258 & 266 & 1.87 & 0.0628 \\
\hline water*herb & Basil & 0.5 & Rose & 1 & 0.2160 & 0.1260 & 265 & 1.71 & 0.0876 \\
\hline water*herb & Basil & 0.5 & Sun & 1 & 0.1596 & 0.1287 & 266 & 1.24 & 0.2160 \\
\hline water*herb & Basil & 0.5 & Thyme & 1 & -0.3249 & 0.1258 & 266 & -2.58 & 0.0103 \\
\hline water*herb & Basil & 0.5 & Basil & 1.5 & -1.0639 & 0.1258 & 266 & -8.46 & $<.0001$ \\
\hline water*herb & Basil & 0.5 & Mint & 1.5 & -0.08484 & 0.1258 & 266 & -0.67 & 0.5006 \\
\hline water*herb & Basil & 0.5 & Rose & 1.5 & 0.02673 & 0.1258 & 266 & 0.21 & 0.8319 \\
\hline water*herb & Basil & 0.5 & Sun & 1.5 & 0.02309 & 0.1258 & 266 & 0.18 & 0.8545 \\
\hline water*herb & Basil & 0.5 & Thyme & 1.5 & -0.5522 & 0.1258 & 266 & -4.39 & $<.0001$ \\
\hline water*herb & Basil & 0.5 & Basil & 2 & -1.2818 & 0.1258 & 266 & -10.19 & $<.0001$ \\
\hline water*herb & Basil & 0.5 & Mint & 2 & -0.2616 & 0.1287 & 266 & -2.03 & 0.0431 \\
\hline water*herb & Basil & 0.5 & Rose & 2 & -0.1702 & 0.1258 & 266 & -1.35 & 0.1773 \\
\hline water*herb & Basil & 0.5 & Sun & 2 & -0.02642 & 0.1258 & 266 & -0.21 & 0.8338 \\
\hline water*herb & Basil & 0.5 & Thyme & 2 & -0.4755 & 0.1258 & 266 & -3.78 & 0.0002 \\
\hline water*herb & Basil & 0.5 & Basil & 3 & -1.3189 & 0.1258 & 266 & -10.48 & $<.0001$ \\
\hline water*herb & Basil & 0.5 & Mint & 3 & -0.3641 & 0.1287 & 266 & -2.83 & 0.0050 \\
\hline water*herb & Basil & 0.5 & Rose & 3 & -0.3429 & 0.1258 & 266 & -2.73 & 0.0068 \\
\hline water*herb & Basil & 0.5 & Sun & 3 & 0.000192 & 0.1287 & 266 & 0.00 & 0.9988 \\
\hline water*herb & Basil & 0.5 & Thyme & 3 & -0.5190 & 0.1258 & 266 & -4.13 & $<.0001$ \\
\hline water*herb & Mint & 0.5 & Rose & 0.5 & 0.1477 & 0.1270 & 217 & 1.16 & 0.2460 \\
\hline water*herb & Mint & 0.5 & Sun & 0.5 & -0.2555 & 0.1332 & 225 & -1.92 & 0.0563 \\
\hline water*herb & Mint & 0.5 & Thyme & 0.5 & -1.0383 & 0.1270 & 217 & -8.18 & $<.0001$ \\
\hline water*herb & Mint & 0.5 & Basil & 1 & -1.7671 & 0.1287 & 266 & -13.73 & $<.0001$ \\
\hline water*herb & Mint & 0.5 & Mint & 1 & -0.6780 & 0.1287 & 266 & -5.27 & $<.0001$ \\
\hline water*herb & Mint & 0.5 & Rose & 1 & -0.6971 & 0.1289 & 265 & -5.41 & $<.0001$ \\
\hline water*herb & Mint & 0.5 & Sun & 1 & -0.7535 & 0.1315 & 266 & -5.73 & $<.0001$ \\
\hline
\end{tabular}




\begin{tabular}{|c|c|c|c|c|c|c|c|c|c|}
\hline \multicolumn{10}{|c|}{ Differences of Least Squares Means } \\
\hline Effect & herb & water & herb & water & Estimate & Standard Error & DF & t Value & $\operatorname{Pr}>|\mathbf{t}|$ \\
\hline water*herb & Mint & 0.5 & Thyme & 1 & -1.2380 & 0.1287 & 266 & -9.62 & $<.0001$ \\
\hline water*herb & Mint & 0.5 & Basil & 1.5 & -1.9770 & 0.1287 & 266 & -15.37 & $<.0001$ \\
\hline water*herb & Mint & 0.5 & Mint & 1.5 & -0.9979 & 0.1287 & 266 & -7.76 & $<.0001$ \\
\hline water*herb & Mint & 0.5 & Rose & 1.5 & -0.8863 & 0.1287 & 266 & -6.89 & $<.0001$ \\
\hline water*herb & Mint & 0.5 & Sun & 1.5 & -0.8900 & 0.1287 & 266 & -6.92 & $<.0001$ \\
\hline water*herb & Mint & 0.5 & Thyme & 1.5 & -1.4653 & 0.1287 & 266 & -11.39 & $<.0001$ \\
\hline water*herb & Mint & 0.5 & Basil & 2 & -2.1949 & 0.1287 & 266 & -17.06 & $<.0001$ \\
\hline water*herb & Mint & 0.5 & Mint & 2 & -1.1746 & 0.1314 & 266 & -8.94 & $<.0001$ \\
\hline water*herb & Mint & 0.5 & Rose & 2 & -1.0832 & 0.1287 & 266 & -8.42 & $<.0001$ \\
\hline water*herb & Mint & 0.5 & Sun & 2 & -0.9395 & 0.1287 & 266 & -7.30 & $<.0001$ \\
\hline water*herb & Mint & 0.5 & Thyme & 2 & -1.3886 & 0.1287 & 266 & -10.79 & $<.0001$ \\
\hline water*herb & Mint & 0.5 & Basil & 3 & -2.2320 & 0.1287 & 266 & -17.35 & $<.0001$ \\
\hline water*herb & Mint & 0.5 & Mint & 3 & -1.2772 & 0.1314 & 266 & -9.72 & $<.0001$ \\
\hline water*herb & Mint & 0.5 & Rose & 3 & -1.2559 & 0.1287 & 266 & -9.76 & $<.0001$ \\
\hline water*herb & Mint & 0.5 & Sun & 3 & -0.9129 & 0.1314 & 266 & -6.94 & $<.0001$ \\
\hline water*herb & Mint & 0.5 & Thyme & 3 & -1.4321 & 0.1287 & 266 & -11.13 & $<.0001$ \\
\hline water*herb & Rose & 0.5 & Sun & 0.5 & -0.4032 & 0.1304 & 221 & -3.09 & 0.0022 \\
\hline water*herb & Rose & 0.5 & Thyme & 0.5 & -1.1860 & 0.1241 & 213 & -9.56 & $<.0001$ \\
\hline water*herb & Rose & 0.5 & Basil & 1 & -1.9148 & 0.1258 & 266 & -15.22 & $<.0001$ \\
\hline water*herb & Rose & 0.5 & Mint & 1 & -0.8257 & 0.1258 & 266 & -6.56 & $<.0001$ \\
\hline water*herb & Rose & 0.5 & Rose & 1 & -0.8448 & 0.1260 & 265 & -6.70 & $<.0001$ \\
\hline water*herb & Rose & 0.5 & Sun & 1 & -0.9012 & 0.1287 & 266 & -7.00 & $<.0001$ \\
\hline water*herb & Rose & 0.5 & Thyme & 1 & -1.3857 & 0.1258 & 266 & -11.02 & $<.0001$ \\
\hline water*herb & Rose & 0.5 & Basil & 1.5 & -2.1247 & 0.1258 & 266 & -16.89 & $<.0001$ \\
\hline water*herb & Rose & 0.5 & Mint & 1.5 & -1.1456 & 0.1258 & 266 & -9.11 & $<.0001$ \\
\hline water*herb & Rose & 0.5 & Rose & 1.5 & -1.0341 & 0.1258 & 266 & -8.22 & $<.0001$ \\
\hline water*herb & Rose & 0.5 & Sun & 1.5 & -1.0377 & 0.1258 & 266 & -8.25 & $<.0001$ \\
\hline water*herb & Rose & 0.5 & Thyme & 1.5 & -1.6130 & 0.1258 & 266 & -12.82 & $<.0001$ \\
\hline water*herb & Rose & 0.5 & Basil & 2 & -2.3426 & 0.1258 & 266 & -18.62 & $<.0001$ \\
\hline water*herb & Rose & 0.5 & Mint & 2 & -1.3224 & 0.1287 & 266 & -10.28 & $<.0001$ \\
\hline water*herb & Rose & 0.5 & Rose & 2 & -1.2310 & 0.1258 & 266 & -9.79 & $<.0001$ \\
\hline
\end{tabular}




\begin{tabular}{|c|c|c|c|c|c|c|c|c|c|}
\hline \multicolumn{10}{|c|}{ Differences of Least Squares Means } \\
\hline Effect & herb & water & herb & water & Estimate & Standard Error & DF & t Value & $\operatorname{Pr}>|\mathbf{t}|$ \\
\hline water*herb & Rose & 0.5 & Sun & 2 & -1.0872 & 0.1258 & 266 & -8.64 & $<.0001$ \\
\hline water*herb & Rose & 0.5 & Thyme & 2 & -1.5363 & 0.1258 & 266 & -12.21 & $<.0001$ \\
\hline water*herb & Rose & 0.5 & Basil & 3 & -2.3797 & 0.1258 & 266 & -18.92 & $<.0001$ \\
\hline water*herb & Rose & 0.5 & Mint & 3 & -1.4249 & 0.1287 & 266 & -11.08 & $<.0001$ \\
\hline water*herb & Rose & 0.5 & Rose & 3 & -1.4037 & 0.1258 & 266 & -11.16 & $<.0001$ \\
\hline water*herb & Rose & 0.5 & Sun & 3 & -1.0606 & 0.1287 & 266 & -8.24 & $<.0001$ \\
\hline water*herb & Rose & 0.5 & Thyme & 3 & -1.5798 & 0.1258 & 266 & -12.56 & $<.0001$ \\
\hline water*herb & Sun & 0.5 & Thyme & 0.5 & -0.7828 & 0.1304 & 221 & -6.00 & $<.0001$ \\
\hline water*herb & Sun & 0.5 & Basil & 1 & -1.5116 & 0.1320 & 266 & -11.45 & $<.0001$ \\
\hline water*herb & Sun & 0.5 & Mint & 1 & -0.4225 & 0.1320 & 266 & -3.20 & 0.0015 \\
\hline water*herb & Sun & 0.5 & Rose & 1 & -0.4416 & 0.1322 & 265 & -3.34 & 0.0010 \\
\hline water*herb & Sun & 0.5 & Sun & 1 & -0.4980 & 0.1347 & 266 & -3.70 & 0.0003 \\
\hline water*herb & Sun & 0.5 & Thyme & 1 & -0.9825 & 0.1320 & 266 & -7.44 & $<.0001$ \\
\hline water*herb & Sun & 0.5 & Basil & 1.5 & -1.7215 & 0.1320 & 266 & -13.04 & $<.0001$ \\
\hline water*herb & Sun & 0.5 & Mint & 1.5 & -0.7424 & 0.1320 & 266 & -5.62 & $<.0001$ \\
\hline water*herb & Sun & 0.5 & Rose & 1.5 & -0.6308 & 0.1320 & 266 & -4.78 & $<.0001$ \\
\hline water*herb & Sun & 0.5 & Sun & 1.5 & -0.6345 & 0.1320 & 266 & -4.81 & $<.0001$ \\
\hline water*herb & Sun & 0.5 & Thyme & 1.5 & -1.2098 & 0.1320 & 266 & -9.17 & $<.0001$ \\
\hline water*herb & Sun & 0.5 & Basil & 2 & -1.9394 & 0.1320 & 266 & -14.69 & $<.0001$ \\
\hline water*herb & Sun & 0.5 & Mint & 2 & -0.9191 & 0.1347 & 266 & -6.82 & $<.0001$ \\
\hline water*herb & Sun & 0.5 & Rose & 2 & -0.8277 & 0.1320 & 266 & -6.27 & $<.0001$ \\
\hline water*herb & Sun & 0.5 & Sun & 2 & -0.6840 & 0.1320 & 266 & -5.18 & $<.0001$ \\
\hline water*herb & Sun & 0.5 & Thyme & 2 & -1.1331 & 0.1320 & 266 & -8.58 & $<.0001$ \\
\hline water*herb & Sun & 0.5 & Basil & 3 & -1.9765 & 0.1320 & 266 & -14.97 & $<.0001$ \\
\hline water*herb & Sun & 0.5 & Mint & 3 & -1.0217 & 0.1347 & 266 & -7.58 & $<.0001$ \\
\hline water*herb & Sun & 0.5 & Rose & 3 & -1.0004 & 0.1320 & 266 & -7.58 & $<.0001$ \\
\hline water*herb & Sun & 0.5 & Sun & 3 & -0.6574 & 0.1347 & 266 & -4.88 & $<.0001$ \\
\hline water*herb & Sun & 0.5 & Thyme & 3 & -1.1766 & 0.1320 & 266 & -8.91 & $<.0001$ \\
\hline water*herb & Thyme & 0.5 & Basil & 1 & -0.7288 & 0.1258 & 266 & -5.79 & $<.0001$ \\
\hline water*herb & Thyme & 0.5 & Mint & 1 & 0.3603 & 0.1258 & 266 & 2.86 & 0.0045 \\
\hline water*herb & Thyme & 0.5 & Rose & 1 & 0.3412 & 0.1260 & 265 & 2.71 & 0.0072 \\
\hline
\end{tabular}




\begin{tabular}{|c|c|c|c|c|c|c|c|c|c|}
\hline \multicolumn{10}{|c|}{ Differences of Least Squares Means } \\
\hline Effect & herb & water & herb & water & Estimate & Standard Error & DF & t Value & $\operatorname{Pr}>\mid \mathbf{t}$ \\
\hline water*herb & Thyme & 0.5 & Sun & 1 & 0.2848 & 0.1287 & 266 & 2.21 & 0.0277 \\
\hline water*herb & Thyme & 0.5 & Thyme & 1 & -0.1997 & 0.1258 & 266 & -1.59 & 0.1135 \\
\hline water*herb & Thyme & 0.5 & Basil & 1.5 & -0.9387 & 0.1258 & 266 & -7.46 & $<.0001$ \\
\hline water*herb & Thyme & 0.5 & Mint & 1.5 & 0.04036 & 0.1258 & 266 & 0.32 & 0.7486 \\
\hline water*herb & Thyme & 0.5 & Rose & 1.5 & 0.1519 & 0.1258 & 266 & 1.21 & 0.2282 \\
\hline water*herb & Thyme & 0.5 & Sun & 1.5 & 0.1483 & 0.1258 & 266 & 1.18 & 0.2395 \\
\hline water*herb & Thyme & 0.5 & Thyme & 1.5 & -0.4270 & 0.1258 & 266 & -3.39 & 0.0008 \\
\hline water*herb & Thyme & 0.5 & Basil & 2 & -1.1566 & 0.1258 & 266 & -9.19 & $<.0001$ \\
\hline water*herb & Thyme & 0.5 & Mint & 2 & -0.1364 & 0.1287 & 266 & -1.06 & 0.2902 \\
\hline water*herb & Thyme & 0.5 & Rose & 2 & -0.04496 & 0.1258 & 266 & -0.36 & 0.7211 \\
\hline water*herb & Thyme & 0.5 & Sun & 2 & 0.09878 & 0.1258 & 266 & 0.79 & 0.4330 \\
\hline water*herb & Thyme & 0.5 & Thyme & 2 & -0.3503 & 0.1258 & 266 & -2.78 & 0.0057 \\
\hline water*herb & Thyme & 0.5 & Basil & 3 & -1.1937 & 0.1258 & 266 & -9.49 & $<.0001$ \\
\hline water*herb & Thyme & 0.5 & Mint & 3 & -0.2389 & 0.1287 & 266 & -1.86 & 0.0644 \\
\hline water*herb & Thyme & 0.5 & Rose & 3 & -0.2177 & 0.1258 & 266 & -1.73 & 0.0847 \\
\hline water*herb & Thyme & 0.5 & Sun & 3 & 0.1254 & 0.1287 & 266 & 0.97 & 0.3306 \\
\hline water*herb & Thyme & 0.5 & Thyme & 3 & -0.3938 & 0.1258 & 266 & -3.13 & 0.0019 \\
\hline water*herb & Basil & 1 & Mint & 1 & 1.0891 & 0.1241 & 213 & 8.78 & $<.0001$ \\
\hline water*herb & Basil & 1 & Rose & 1 & 1.0700 & 0.1243 & 220 & 8.61 & $<.0001$ \\
\hline water*herb & Basil & 1 & Sun & 1 & 1.0136 & 0.1270 & 217 & 7.98 & $<.0001$ \\
\hline water*herb & Basil & 1 & Thyme & 1 & 0.5291 & 0.1241 & 213 & 4.26 & $<.0001$ \\
\hline water*herb & Basil & 1 & Basil & 1.5 & -0.2099 & 0.1258 & 266 & -1.67 & 0.0964 \\
\hline water*herb & Basil & 1 & Mint & 1.5 & 0.7692 & 0.1258 & 266 & 6.11 & $<.0001$ \\
\hline water*herb & Basil & 1 & Rose & 1.5 & 0.8807 & 0.1258 & 266 & 7.00 & $<.0001$ \\
\hline water*herb & Basil & 1 & Sun & 1.5 & 0.8771 & 0.1258 & 266 & 6.97 & $<.0001$ \\
\hline water*herb & Basil & 1 & Thyme & 1.5 & 0.3018 & 0.1258 & 266 & 2.40 & 0.0171 \\
\hline water*herb & Basil & 1 & Basil & 2 & -0.4278 & 0.1258 & 266 & -3.40 & 0.0008 \\
\hline water*herb & Basil & 1 & Mint & 2 & 0.5925 & 0.1287 & 266 & 4.60 & $<.0001$ \\
\hline water*herb & Basil & 1 & Rose & 2 & 0.6839 & 0.1258 & 266 & 5.44 & $<.0001$ \\
\hline water*herb & Basil & 1 & Sun & 2 & 0.8276 & 0.1258 & 266 & 6.58 & $<.0001$ \\
\hline water*herb & Basil & 1 & Thyme & 2 & 0.3785 & 0.1258 & 266 & 3.01 & 0.0029 \\
\hline
\end{tabular}




\begin{tabular}{|c|c|c|c|c|c|c|c|c|c|}
\hline \multicolumn{10}{|c|}{ Differences of Least Squares Means } \\
\hline Effect & herb & water & herb & water & Estimate & Standard Error & DF & t Value & $\operatorname{Pr}>|\mathbf{t}|$ \\
\hline water*herb & Basil & 1 & Basil & 3 & -0.4649 & 0.1258 & 266 & -3.70 & 0.0003 \\
\hline water*herb & Basil & 1 & Mint & 3 & 0.4899 & 0.1287 & 266 & 3.81 & 0.0002 \\
\hline water*herb & Basil & 1 & Rose & 3 & 0.5111 & 0.1258 & 266 & 4.06 & $<.0001$ \\
\hline water*herb & Basil & 1 & Sun & 3 & 0.8542 & 0.1287 & 266 & 6.64 & $<.0001$ \\
\hline water*herb & Basil & 1 & Thyme & 3 & 0.3350 & 0.1258 & 266 & 2.66 & 0.0082 \\
\hline water*herb & Mint & 1 & Rose & 1 & -0.01907 & 0.1243 & 220 & -0.15 & 0.8782 \\
\hline water*herb & Mint & 1 & Sun & 1 & -0.07550 & 0.1270 & 217 & -0.59 & 0.5527 \\
\hline water*herb & Mint & 1 & Thyme & 1 & -0.5600 & 0.1241 & 213 & -4.51 & $<.0001$ \\
\hline water*herb & Mint & 1 & Basil & 1.5 & -1.2990 & 0.1258 & 266 & -10.33 & $<.0001$ \\
\hline water*herb & Mint & 1 & Mint & 1.5 & -0.3199 & 0.1258 & 266 & -2.54 & 0.0116 \\
\hline water*herb & Mint & 1 & Rose & 1.5 & -0.2083 & 0.1258 & 266 & -1.66 & 0.0988 \\
\hline water*herb & Mint & 1 & Sun & 1.5 & -0.2120 & 0.1258 & 266 & -1.69 & 0.0931 \\
\hline water*herb & Mint & 1 & Thyme & 1.5 & -0.7873 & 0.1258 & 266 & -6.26 & $<.0001$ \\
\hline water*herb & Mint & 1 & Basil & 2 & -1.5169 & 0.1258 & 266 & -12.06 & $<.0001$ \\
\hline water*herb & Mint & 1 & Mint & 2 & -0.4966 & 0.1287 & 266 & -3.86 & 0.0001 \\
\hline water*herb & Mint & 1 & Rose & 2 & -0.4052 & 0.1258 & 266 & -3.22 & 0.0014 \\
\hline water*herb & Mint & 1 & Sun & 2 & -0.2615 & 0.1258 & 266 & -2.08 & 0.0386 \\
\hline water*herb & Mint & 1 & Thyme & 2 & -0.7106 & 0.1258 & 266 & -5.65 & $<.0001$ \\
\hline water*herb & Mint & 1 & Basil & 3 & -1.5540 & 0.1258 & 266 & -12.35 & $<.0001$ \\
\hline water*herb & Mint & 1 & Mint & 3 & -0.5992 & 0.1287 & 266 & -4.66 & $<.0001$ \\
\hline water*herb & Mint & 1 & Rose & 3 & -0.5779 & 0.1258 & 266 & -4.59 & $<.0001$ \\
\hline water*herb & Mint & 1 & Sun & 3 & -0.2349 & 0.1287 & 266 & -1.83 & 0.0690 \\
\hline water*herb & Mint & 1 & Thyme & 3 & -0.7541 & 0.1258 & 266 & -5.99 & $<.0001$ \\
\hline water*herb & Rose & 1 & Sun & 1 & -0.05644 & 0.1272 & 223 & -0.44 & 0.6577 \\
\hline water*herb & Rose & 1 & Thyme & 1 & -0.5409 & 0.1243 & 220 & -4.35 & $<.0001$ \\
\hline water*herb & Rose & 1 & Basil & 1.5 & -1.2799 & 0.1260 & 265 & -10.16 & $<.0001$ \\
\hline water*herb & Rose & 1 & Mint & 1.5 & -0.3008 & 0.1260 & 265 & -2.39 & 0.0177 \\
\hline water*herb & Rose & 1 & Rose & 1.5 & -0.1893 & 0.1260 & 265 & -1.50 & 0.1342 \\
\hline water*herb & Rose & 1 & Sun & 1.5 & -0.1929 & 0.1260 & 265 & -1.53 & 0.1270 \\
\hline water*herb & Rose & 1 & Thyme & 1.5 & -0.7682 & 0.1260 & 265 & -6.10 & $<.0001$ \\
\hline water*herb & Rose & 1 & Basil & 2 & -1.4978 & 0.1260 & 265 & -11.89 & $<.0001$ \\
\hline
\end{tabular}




\begin{tabular}{|c|c|c|c|c|c|c|c|c|c|}
\hline \multicolumn{10}{|c|}{ Differences of Least Squares Means } \\
\hline Effect & herb & water & herb & water & Estimate & Standard Error & DF & t Value & $\operatorname{Pr}>|t|$ \\
\hline water*herb & Rose & 1 & Mint & 2 & -0.4776 & 0.1289 & 265 & -3.71 & 0.0003 \\
\hline water*herb & Rose & 1 & Rose & 2 & -0.3862 & 0.1260 & 265 & -3.06 & 0.0024 \\
\hline water*herb & Rose & 1 & Sun & 2 & -0.2424 & 0.1260 & 265 & -1.92 & 0.0554 \\
\hline water*herb & Rose & 1 & Thyme & 2 & -0.6915 & 0.1260 & 265 & -5.49 & $<.0001$ \\
\hline water*herb & Rose & 1 & Basil & 3 & -1.5349 & 0.1260 & 265 & -12.18 & $<.0001$ \\
\hline water*herb & Rose & 1 & Mint & 3 & -0.5801 & 0.1289 & 265 & -4.50 & $<.0001$ \\
\hline water*herb & Rose & 1 & Rose & 3 & -0.5589 & 0.1260 & 265 & -4.44 & $<.0001$ \\
\hline water*herb & Rose & 1 & Sun & 3 & -0.2158 & 0.1289 & 265 & -1.67 & 0.0952 \\
\hline water*herb & Rose & 1 & Thyme & 3 & -0.7350 & 0.1260 & 265 & -5.83 & $<.0001$ \\
\hline water*herb & Sun & 1 & Thyme & 1 & -0.4845 & 0.1270 & 217 & -3.82 & 0.0002 \\
\hline water*herb & Sun & 1 & Basil & 1.5 & -1.2235 & 0.1287 & 266 & -9.51 & $<.0001$ \\
\hline water*herb & Sun & 1 & Mint & 1.5 & -0.2444 & 0.1287 & 266 & -1.90 & 0.0586 \\
\hline water*herb & Sun & 1 & Rose & 1.5 & -0.1328 & 0.1287 & 266 & -1.03 & 0.3028 \\
\hline water*herb & Sun & 1 & Sun & 1.5 & -0.1365 & 0.1287 & 266 & -1.06 & 0.2898 \\
\hline water*herb & Sun & 1 & Thyme & 1.5 & -0.7118 & 0.1287 & 266 & -5.53 & $<.0001$ \\
\hline water*herb & Sun & 1 & Basil & 2 & -1.4414 & 0.1287 & 266 & -11.20 & $<.0001$ \\
\hline water*herb & Sun & 1 & Mint & 2 & -0.4211 & 0.1315 & 266 & -3.20 & 0.0015 \\
\hline water*herb & Sun & 1 & Rose & 2 & -0.3297 & 0.1287 & 266 & -2.56 & 0.0109 \\
\hline water*herb & Sun & 1 & Sun & 2 & -0.1860 & 0.1287 & 266 & -1.45 & 0.1495 \\
\hline water*herb & Sun & 1 & Thyme & 2 & -0.6351 & 0.1287 & 266 & -4.94 & $<.0001$ \\
\hline water*herb & Sun & 1 & Basil & 3 & -1.4784 & 0.1287 & 266 & -11.49 & $<.0001$ \\
\hline water*herb & Sun & 1 & Mint & 3 & -0.5237 & 0.1315 & 266 & -3.98 & $<.0001$ \\
\hline water*herb & Sun & 1 & Rose & 3 & -0.5024 & 0.1287 & 266 & -3.91 & 0.0001 \\
\hline water*herb & Sun & 1 & Sun & 3 & -0.1594 & 0.1315 & 266 & -1.21 & 0.2266 \\
\hline water*herb & Sun & 1 & Thyme & 3 & -0.6786 & 0.1287 & 266 & -5.27 & $<.0001$ \\
\hline water*herb & Thyme & 1 & Basil & 1.5 & -0.7390 & 0.1258 & 266 & -5.87 & $<.0001$ \\
\hline water*herb & Thyme & 1 & Mint & 1.5 & 0.2401 & 0.1258 & 266 & 1.91 & 0.0574 \\
\hline water*herb & Thyme & 1 & Rose & 1.5 & 0.3517 & 0.1258 & 266 & 2.80 & 0.0056 \\
\hline water*herb & Thyme & 1 & Sun & 1.5 & 0.3480 & 0.1258 & 266 & 2.77 & 0.0061 \\
\hline water*herb & Thyme & 1 & Thyme & 1.5 & -0.2273 & 0.1258 & 266 & -1.81 & 0.0719 \\
\hline water*herb & Thyme & 1 & Basil & 2 & -0.9569 & 0.1258 & 266 & -7.61 & $<.0001$ \\
\hline
\end{tabular}




\begin{tabular}{|c|c|c|c|c|c|c|c|c|c|}
\hline \multicolumn{10}{|c|}{ Differences of Least Squares Means } \\
\hline Effect & herb & water & herb & water & Estimate & $\begin{array}{r}\text { Standard } \\
\text { Error }\end{array}$ & DF & $\begin{array}{r}\text { t } \\
\text { Value }\end{array}$ & $\operatorname{Pr}>|\mathbf{t}|$ \\
\hline water*herb & Thyme & 1 & Mint & 2 & 0.06339 & 0.1287 & 266 & 0.49 & 0.6226 \\
\hline water*herb & Thyme & 1 & Rose & 2 & 0.1548 & 0.1258 & 266 & 1.23 & 0.2196 \\
\hline water*herb & Thyme & 1 & Sun & 2 & 0.2985 & 0.1258 & 266 & 2.37 & 0.0183 \\
\hline water*herb & Thyme & 1 & Thyme & 2 & -0.1506 & 0.1258 & 266 & -1.20 & 0.2324 \\
\hline water*herb & Thyme & 1 & Basil & 3 & -0.9939 & 0.1258 & 266 & -7.90 & $<.0001$ \\
\hline water*herb & Thyme & 1 & Mint & 3 & -0.03919 & 0.1287 & 266 & -0.30 & 0.7609 \\
\hline water*herb & Thyme & 1 & Rose & 3 & -0.01793 & 0.1258 & 266 & -0.14 & 0.8868 \\
\hline water*herb & Thyme & 1 & Sun & 3 & 0.3251 & 0.1287 & 266 & 2.53 & 0.0121 \\
\hline water*herb & Thyme & 1 & Thyme & 3 & -0.1941 & 0.1258 & 266 & -1.54 & 0.1241 \\
\hline water*herb & Basil & 1.5 & Mint & 1.5 & 0.9791 & 0.1241 & 213 & 7.89 & $<.0001$ \\
\hline water*herb & Basil & 1.5 & Rose & 1.5 & 1.0907 & 0.1241 & 213 & 8.79 & $<.0001$ \\
\hline water*herb & Basil & 1.5 & Sun & 1.5 & 1.0870 & 0.1241 & 213 & 8.76 & $<.0001$ \\
\hline water*herb & Basil & 1.5 & Thyme & 1.5 & 0.5117 & 0.1241 & 213 & 4.12 & $<.0001$ \\
\hline water*herb & Basil & 1.5 & Basil & 2 & -0.2179 & 0.1258 & 266 & -1.73 & 0.0844 \\
\hline water*herb & Basil & 1.5 & Mint & 2 & 0.8024 & 0.1287 & 266 & 6.24 & $<.0001$ \\
\hline water*herb & Basil & 1.5 & Rose & 2 & 0.8938 & 0.1258 & 266 & 7.11 & $<.0001$ \\
\hline water*herb & Basil & 1.5 & Sun & 2 & 1.0375 & 0.1258 & 266 & 8.25 & $<.0001$ \\
\hline water*herb & Basil & 1.5 & Thyme & 2 & 0.5884 & 0.1258 & 266 & 4.68 & $<.0001$ \\
\hline water*herb & Basil & 1.5 & Basil & 3 & -0.2550 & 0.1258 & 266 & -2.03 & 0.0437 \\
\hline water*herb & Basil & 1.5 & Mint & 3 & 0.6998 & 0.1287 & 266 & 5.44 & $<.0001$ \\
\hline water*herb & Basil & 1.5 & Rose & 3 & 0.7210 & 0.1258 & 266 & 5.73 & $<.0001$ \\
\hline water*herb & Basil & 1.5 & Sun & 3 & 1.0641 & 0.1287 & 266 & 8.27 & $<.0001$ \\
\hline water*herb & Basil & 1.5 & Thyme & 3 & 0.5449 & 0.1258 & 266 & 4.33 & $<.0001$ \\
\hline water*herb & Mint & 1.5 & Rose & 1.5 & 0.1116 & 0.1241 & 213 & 0.90 & 0.3696 \\
\hline water*herb & Mint & 1.5 & Sun & 1.5 & 0.1079 & 0.1241 & 213 & 0.87 & 0.3853 \\
\hline water*herb & Mint & 1.5 & Thyme & 1.5 & -0.4674 & 0.1241 & 213 & -3.77 & 0.0002 \\
\hline water*herb & Mint & 1.5 & Basil & 2 & -1.1970 & 0.1258 & 266 & -9.52 & $<.0001$ \\
\hline water*herb & Mint & 1.5 & Mint & 2 & -0.1767 & 0.1287 & 266 & -1.37 & 0.1708 \\
\hline water*herb & Mint & 1.5 & Rose & 2 & -0.08531 & 0.1258 & 266 & -0.68 & 0.4982 \\
\hline water*herb & Mint & 1.5 & Sun & 2 & 0.05842 & 0.1258 & 266 & 0.46 & 0.6427 \\
\hline water*herb & Mint & 1.5 & Thyme & 2 & -0.3907 & 0.1258 & 266 & -3.11 & 0.0021 \\
\hline
\end{tabular}




\begin{tabular}{|c|c|c|c|c|c|c|c|c|c|}
\hline \multicolumn{10}{|c|}{ Differences of Least Squares Means } \\
\hline Effect & herb & water & herb & water & Estimate & $\begin{array}{r}\text { Standard } \\
\text { Error }\end{array}$ & DF & $\begin{array}{r}\text { t } \\
\text { Value } \\
\end{array}$ & $\begin{array}{c}\operatorname{Pr}> \\
|\mathbf{t}|\end{array}$ \\
\hline water*herb & Mint & 1.5 & Basil & 3 & -1.2340 & 0.1258 & 266 & -9.81 & $<.0001$ \\
\hline water*herb & Mint & 1.5 & Mint & 3 & -0.2793 & 0.1287 & 266 & -2.17 & 0.0308 \\
\hline water*herb & Mint & 1.5 & Rose & 3 & -0.2580 & 0.1258 & 266 & -2.05 & 0.0412 \\
\hline water*herb & Mint & 1.5 & Sun & 3 & 0.08504 & 0.1287 & 266 & 0.66 & 0.5092 \\
\hline water*herb & Mint & 1.5 & Thyme & 3 & -0.4342 & 0.1258 & 266 & -3.45 & 0.0006 \\
\hline water*herb & Rose & 1.5 & Sun & 1.5 & -0.00363 & 0.1241 & 213 & -0.03 & 0.9767 \\
\hline water*herb & Rose & 1.5 & Thyme & 1.5 & -0.5789 & 0.1241 & 213 & -4.67 & $<.0001$ \\
\hline water*herb & Rose & 1.5 & Basil & 2 & -1.3086 & 0.1258 & 266 & -10.40 & $<.0001$ \\
\hline water*herb & Rose & 1.5 & Mint & 2 & -0.2883 & 0.1287 & 266 & -2.24 & 0.0259 \\
\hline water*herb & Rose & 1.5 & Rose & 2 & -0.1969 & 0.1258 & 266 & -1.57 & 0.1187 \\
\hline water*herb & Rose & 1.5 & Sun & 2 & -0.05315 & 0.1258 & 266 & -0.42 & 0.6730 \\
\hline water*herb & Rose & 1.5 & Thyme & 2 & -0.5022 & 0.1258 & 266 & -3.99 & $<.0001$ \\
\hline water*herb & Rose & 1.5 & Basil & 3 & -1.3456 & 0.1258 & 266 & -10.70 & $<.0001$ \\
\hline water*herb & Rose & 1.5 & Mint & 3 & -0.3909 & 0.1287 & 266 & -3.04 & 0.0026 \\
\hline water*herb & Rose & 1.5 & Rose & 3 & -0.3696 & 0.1258 & 266 & -2.94 & 0.0036 \\
\hline water*herb & Rose & 1.5 & Sun & 3 & -0.02653 & 0.1287 & 266 & -0.21 & 0.8368 \\
\hline water*herb & Rose & 1.5 & Thyme & 3 & -0.5457 & 0.1258 & 266 & -4.34 & $<.0001$ \\
\hline water*herb & Sun & 1.5 & Thyme & 1.5 & -0.5753 & 0.1241 & 213 & -4.64 & $<.0001$ \\
\hline water*herb & Sun & 1.5 & Basil & 2 & -1.3049 & 0.1258 & 266 & -10.37 & $<.0001$ \\
\hline water*herb & Sun & 1.5 & Mint & 2 & -0.2846 & 0.1287 & 266 & -2.21 & 0.0278 \\
\hline water*herb & Sun & 1.5 & Rose & 2 & -0.1932 & 0.1258 & 266 & -1.54 & 0.1257 \\
\hline water*herb & Sun & 1.5 & Sun & 2 & -0.04952 & 0.1258 & 266 & -0.39 & 0.6942 \\
\hline water*herb & Sun & 1.5 & Thyme & 2 & -0.4986 & 0.1258 & 266 & -3.96 & $<.0001$ \\
\hline water*herb & Sun & 1.5 & Basil & 3 & -1.3420 & 0.1258 & 266 & -10.67 & $<.0001$ \\
\hline water*herb & Sun & 1.5 & Mint & 3 & -0.3872 & 0.1287 & 266 & -3.01 & 0.0029 \\
\hline water*herb & Sun & 1.5 & Rose & 3 & -0.3660 & 0.1258 & 266 & -2.91 & 0.0039 \\
\hline water*herb & Sun & 1.5 & Sun & 3 & -0.02290 & 0.1287 & 266 & -0.18 & 0.8589 \\
\hline water*herb & Sun & 1.5 & Thyme & 3 & -0.5421 & 0.1258 & 266 & -4.31 & $<.0001$ \\
\hline water*herb & Thyme & 1.5 & Basil & 2 & -0.7296 & 0.1258 & 266 & -5.80 & $<.0001$ \\
\hline water*herb & Thyme & 1.5 & Mint & 2 & 0.2907 & 0.1287 & 266 & 2.26 & 0.0247 \\
\hline water*herb & Thyme & 1.5 & Rose & 2 & 0.3821 & 0.1258 & 266 & 3.04 & 0.0026 \\
\hline
\end{tabular}




\begin{tabular}{|c|c|c|c|c|c|c|c|c|c|}
\hline \multicolumn{10}{|c|}{ Differences of Least Squares Means } \\
\hline Effect & herb & water & herb & water & Estimate & $\begin{array}{r}\text { Standard } \\
\text { Error }\end{array}$ & DF & $\begin{array}{r}\text { t } \\
\text { Value } \\
\end{array}$ & $\begin{array}{c}\operatorname{Pr}> \\
|t| \\
\end{array}$ \\
\hline water*herb & Thyme & 1.5 & Sun & 2 & 0.5258 & 0.1258 & 266 & 4.18 & $<.0001$ \\
\hline water*herb & Thyme & 1.5 & Thyme & 2 & 0.07670 & 0.1258 & 266 & 0.61 & 0.5426 \\
\hline water*herb & Thyme & 1.5 & Basil & 3 & -0.7667 & 0.1258 & 266 & -6.09 & $<.0001$ \\
\hline water*herb & Thyme & 1.5 & Mint & 3 & 0.1881 & 0.1287 & 266 & 1.46 & 0.1449 \\
\hline water*herb & Thyme & 1.5 & Rose & 3 & 0.2093 & 0.1258 & 266 & 1.66 & 0.0972 \\
\hline water*herb & Thyme & 1.5 & Sun & 3 & 0.5524 & 0.1287 & 266 & 4.29 & $<.0001$ \\
\hline water*herb & Thyme & 1.5 & Thyme & 3 & 0.03320 & 0.1258 & 266 & 0.26 & 0.7920 \\
\hline water*herb & Basil & 2 & Mint & 2 & 1.0203 & 0.1270 & 217 & 8.03 & $<.0001$ \\
\hline water*herb & Basil & 2 & Rose & 2 & 1.1117 & 0.1241 & 213 & 8.96 & $<.0001$ \\
\hline water*herb & Basil & 2 & Sun & 2 & 1.2554 & 0.1241 & 213 & 10.12 & $<.0001$ \\
\hline water*herb & Basil & 2 & Thyme & 2 & 0.8063 & 0.1241 & 213 & 6.50 & $<.0001$ \\
\hline water*herb & Basil & 2 & Basil & 3 & -0.03705 & 0.1258 & 266 & -0.29 & 0.7686 \\
\hline water*herb & Basil & 2 & Mint & 3 & 0.9177 & 0.1287 & 266 & 7.13 & $<.0001$ \\
\hline water*herb & Basil & 2 & Rose & 3 & 0.9390 & 0.1258 & 266 & 7.46 & $<.0001$ \\
\hline water*herb & Basil & 2 & Sun & 3 & 1.2820 & 0.1287 & 266 & 9.96 & $<.0001$ \\
\hline water*herb & Basil & 2 & Thyme & 3 & 0.7628 & 0.1258 & 266 & 6.06 & $<.0001$ \\
\hline water*herb & Mint & 2 & Rose & 2 & 0.09140 & 0.1270 & 217 & 0.72 & 0.4725 \\
\hline water*herb & Mint & 2 & Sun & 2 & 0.2351 & 0.1270 & 217 & 1.85 & 0.0654 \\
\hline water*herb & Mint & 2 & Thyme & 2 & -0.2140 & 0.1270 & 217 & -1.68 & 0.0934 \\
\hline water*herb & Mint & 2 & Basil & 3 & -1.0573 & 0.1287 & 266 & -8.22 & $<.0001$ \\
\hline water*herb & Mint & 2 & Mint & 3 & -0.1026 & 0.1314 & 266 & -0.78 & 0.4359 \\
\hline water*herb & Mint & 2 & Rose & 3 & -0.08132 & 0.1287 & 266 & -0.63 & 0.5279 \\
\hline water*herb & Mint & 2 & Sun & 3 & 0.2617 & 0.1314 & 266 & 1.99 & 0.0475 \\
\hline water*herb & Mint & 2 & Thyme & 3 & -0.2575 & 0.1287 & 266 & -2.00 & 0.0464 \\
\hline water*herb & Rose & 2 & Sun & 2 & 0.1437 & 0.1241 & 213 & 1.16 & 0.2480 \\
\hline water*herb & Rose & 2 & Thyme & 2 & -0.3054 & 0.1241 & 213 & -2.46 & 0.0146 \\
\hline water*herb & Rose & 2 & Basil & 3 & -1.1487 & 0.1258 & 266 & -9.13 & $<.0001$ \\
\hline water*herb & Rose & 2 & Mint & 3 & -0.1940 & 0.1287 & 266 & -1.51 & 0.1328 \\
\hline water*herb & Rose & 2 & Rose & 3 & -0.1727 & 0.1258 & 266 & -1.37 & 0.1709 \\
\hline water*herb & Rose & 2 & Sun & 3 & 0.1703 & 0.1287 & 266 & 1.32 & 0.1866 \\
\hline water*herb & Rose & 2 & Thyme & 3 & -0.3489 & 0.1258 & 266 & -2.77 & 0.0059 \\
\hline
\end{tabular}




\begin{tabular}{|c|c|c|c|c|c|c|c|c|c|}
\hline \multicolumn{10}{|c|}{ Differences of Least Squares Means } \\
\hline Effect & herb & water & herb & water & Estimate & Standard Error & DF & t Value & $\operatorname{Pr}>|\mathbf{t}|$ \\
\hline water*herb & Sun & 2 & Thyme & 2 & -0.4491 & 0.1241 & 213 & -3.62 & 0.0004 \\
\hline water*herb & Sun & 2 & Basil & 3 & -1.2925 & 0.1258 & 266 & -10.27 & $<.0001$ \\
\hline water*herb & Sun & 2 & Mint & 3 & -0.3377 & 0.1287 & 266 & -2.62 & 0.0092 \\
\hline water*herb & Sun & 2 & Rose & 3 & -0.3165 & 0.1258 & 266 & -2.52 & 0.0125 \\
\hline water*herb & Sun & 2 & Sun & 3 & 0.02662 & 0.1287 & 266 & 0.21 & 0.8363 \\
\hline water*herb & Sun & 2 & Thyme & 3 & -0.4926 & 0.1258 & 266 & -3.92 & 0.0001 \\
\hline water*herb & Thyme & 2 & Basil & 3 & -0.8434 & 0.1258 & 266 & -6.70 & $<.0001$ \\
\hline water*herb & Thyme & 2 & Mint & 3 & 0.1114 & 0.1287 & 266 & 0.87 & 0.3874 \\
\hline water*herb & Thyme & 2 & Rose & 3 & 0.1326 & 0.1258 & 266 & 1.05 & 0.2926 \\
\hline water*herb & Thyme & 2 & Sun & 3 & 0.4757 & 0.1287 & 266 & 3.70 & 0.0003 \\
\hline water*herb & Thyme & 2 & Thyme & 3 & -0.04350 & 0.1258 & 266 & -0.35 & 0.7298 \\
\hline water*herb & Basil & 3 & Mint & 3 & 0.9548 & 0.1270 & 217 & 7.52 & $<.0001$ \\
\hline water*herb & Basil & 3 & Rose & 3 & 0.9760 & 0.1241 & 213 & 7.87 & $<.0001$ \\
\hline water*herb & Basil & 3 & Sun & 3 & 1.3191 & 0.1270 & 217 & 10.39 & $<.0001$ \\
\hline water*herb & Basil & 3 & Thyme & 3 & 0.7999 & 0.1241 & 213 & 6.45 & $<.0001$ \\
\hline water*herb & Mint & 3 & Rose & 3 & 0.02126 & 0.1270 & 217 & 0.17 & 0.8672 \\
\hline water*herb & Mint & 3 & Sun & 3 & 0.3643 & 0.1298 & 221 & 2.81 & 0.0055 \\
\hline water*herb & Mint & 3 & Thyme & 3 & -0.1549 & 0.1270 & 217 & -1.22 & 0.2239 \\
\hline water*herb & Rose & 3 & Sun & 3 & 0.3431 & 0.1270 & 217 & 2.70 & 0.0074 \\
\hline water*herb & Rose & 3 & Thyme & 3 & -0.1761 & 0.1241 & 213 & -1.42 & 0.1572 \\
\hline water*herb & Sun & 3 & Thyme & 3 & -0.5192 & 0.1270 & 217 & -4.09 & $<.0001$ \\
\hline
\end{tabular}




\begin{tabular}{|r|l|r|l|r|c|c|r|l|}
\hline Obs & Effect & water & herb & Estimate & StdErr & DF & tValue & Probt \\
\hline $\mathbf{1}$ & water*herb & 0.5 & Basil & 3.8453 & 0.1341 & 2.97 & 28.68 & 0.0001 \\
\hline $\mathbf{2}$ & water*herb & 0.5 & Mint & 2.9322 & 0.1368 & 3.21 & 21.44 & 0.0001 \\
\hline $\mathbf{3}$ & water*herb & 0.5 & Rose & 2.7845 & 0.1341 & 2.97 & 20.77 & 0.0003 \\
\hline $\mathbf{4}$ & water*herb & 0.5 & Sun & 3.1877 & 0.1399 & 3.51 & 22.78 & $<.0001$ \\
\hline $\mathbf{5}$ & water*herb & 0.5 & Thyme & 3.9705 & 0.1341 & 2.97 & 29.61 & $<.0001$ \\
\hline $\mathbf{6}$ & water*herb & 1 & Basil & 4.6993 & 0.1341 & 2.97 & 35.05 & $<.0001$ \\
\hline $\mathbf{7}$ & water*herb & 1 & Mint & 3.6102 & 0.1341 & 2.97 & 26.92 & 0.0001 \\
\hline $\mathbf{8}$ & water*herb & 1 & Rose & 3.6293 & 0.1343 & 2.98 & 27.03 & 0.0001 \\
\hline $\mathbf{9}$ & water*herb & 1 & Sun & 3.6857 & 0.1368 & 3.21 & 26.95 & $<.0001$ \\
\hline $\mathbf{1 0}$ & water*herb & 1 & Thyme & 4.1702 & 0.1341 & 2.97 & 31.10 & $<.0001$ \\
\hline $\mathbf{1 1}$ & water*herb & 1.5 & Basil & 4.9092 & 0.1341 & 2.97 & 36.61 & $<.0001$ \\
\hline $\mathbf{1 2}$ & water*herb & 1.5 & Mint & 3.9301 & 0.1341 & 2.97 & 29.31 & $<.0001$ \\
\hline $\mathbf{1 3}$ & water*herb & 1.5 & Rose & 3.8186 & 0.1341 & 2.97 & 28.48 & 0.0001 \\
\hline $\mathbf{1 4}$ & water*herb & 1.5 & Sun & 3.8222 & 0.1341 & 2.97 & 28.51 & 0.0001 \\
\hline $\mathbf{1 5}$ & water*herb & 1.5 & Thyme & 4.3975 & 0.1341 & 2.97 & 32.80 & $<.0001$ \\
\hline $\mathbf{1 6}$ & water*herb & 2 & Basil & 5.1271 & 0.1341 & 2.97 & 38.24 & $<.0001$ \\
\hline $\mathbf{1 7}$ & water*herb & 2 & Mint & 4.1068 & 0.1368 & 3.21 & 30.02 & $<.0001$ \\
\hline $\mathbf{1 8}$ & water*herb & 2 & Rose & 4.0154 & 0.1341 & 2.97 & 29.95 & $<.0001$ \\
\hline $\mathbf{1 9}$ & water*herb & 2 & Sun & 3.8717 & 0.1341 & 2.97 & 28.87 & $<.0001$ \\
\hline $\mathbf{2 0}$ & water*herb & 2 & Thyme & 4.3208 & 0.1341 & 2.97 & 32.22 & $<.0001$ \\
\hline $\mathbf{2 1}$ & water*herb & 3 & Basil & 5.1642 & 0.1341 & 2.97 & 38.51 & $<.0001$ \\
\hline $\mathbf{2 2}$ & water*herb & 3 & Mint & 4.2094 & 0.1368 & 3.21 & 30.77 & $<.0001$ \\
\hline $\mathbf{2 3}$ & water*herb & 3 & Rose & 4.1882 & 0.1341 & 2.97 & 31.23 & $<.0001$ \\
\hline $\mathbf{2 4}$ & water*herb & 3 & Sun & 3.8451 & 0.1368 & 3.21 & 28.11 & $<.0001$ \\
\hline $\mathbf{2 5}$ & water*herb & 3 & Thyme & 4.3643 & 0.1341 & 2.97 & 32.55 & $<.0001$ \\
\hline
\end{tabular}

\begin{tabular}{|l|l|l|l|}
\hline \multicolumn{4}{|c|}{ Moments } \\
\hline N & 293 & Sum Weights & 293 \\
\hline Mean & 0.00002833 & Sum Observations & 0.00829977 \\
\hline Std Deviation & 1.01115316 & Variance & 1.02243071 \\
\hline Skewness & -0.539014 & Kurtosis & 2.38086614 \\
\hline Uncorrected SS & 298.549768 & Corrected SS & 298.549768 \\
\hline Coeff Variation & 3569590.63 & Std Error Mean & 0.0590722 \\
\hline
\end{tabular}

\begin{tabular}{|l|r|l|l|}
\hline \multicolumn{3}{|l|}{ Basic Statistical Measures } \\
\hline Location & \multicolumn{2}{|c|}{ Variability } \\
\hline Mean & 0.00003 & Std Deviation & 1.01115 \\
\hline Median & -0.00250 & Variance & 1.02243 \\
\hline Mode &. & Range & 8.47954 \\
\hline & & Interquartile Range & 1.21287 \\
\hline
\end{tabular}




\begin{tabular}{|c|c|c|c|c|}
\hline \multicolumn{5}{|c|}{ Tests for Location: $\mathrm{Mu} 0=0$} \\
\hline Test & \multicolumn{3}{|c|}{ Statistic } & p Value \\
\hline Student's t & $\mathbf{t}$ & 0.00048 & $\operatorname{Pr}>|\mathbf{t}|$ & 0.9996 \\
\hline Sign & $\bar{M}$ & -0.5 & $\overline{\operatorname{Pr}>=|\mathbf{M}|}$ & 1.0000 \\
\hline Signed Rank & $\mathbf{S}$ & 880.5 & $\operatorname{Pr}>=|\mathbf{S}|$ & 0.5450 \\
\hline
\end{tabular}

\begin{tabular}{|c|c|c|c|c|}
\hline \multicolumn{5}{|l|}{ Tests for Normality } \\
\hline \multirow{2}{*}{$\begin{array}{l}\text { Test } \\
\text { Shapiro-Wilk }\end{array}$} & \multicolumn{2}{|c|}{ Statistic } & \multicolumn{2}{|l|}{ p Value } \\
\hline & $\mathbf{W}$ & 0.966555 & $\operatorname{Pr}<W$ & $<0.0001$ \\
\hline Kolmogorov-Smirnov & D & 0.069809 & $\operatorname{Pr}>D$ & $<0.0100$ \\
\hline Cramer-von Mises & W-Sq & 0.220218 & Pr $>$ W-Sq & $<0.0050$ \\
\hline Anderson-Darling & $\mathrm{A}-\mathrm{Sq}$ & 1.69423 & Pr $>$ A-Sq & $<0.0050$ \\
\hline
\end{tabular}

The UNIVARIATE Procedure

Variable: StudentResid (Studentized Residual)

\begin{tabular}{|l|c|}
\hline \multicolumn{2}{|l|}{ Quantiles (Definition } \\
5) \\
\hline Quantile & Estimate \\
\hline $\begin{array}{l}\mathbf{1 0 0 \%} \\
\text { Max }\end{array}$ & 3.9470767 \\
\hline $\mathbf{9 9 \%}$ & 2.3383846 \\
\hline $\mathbf{9 5 \%}$ & 1.4275734 \\
\hline $\mathbf{9 0 \%}$ & 1.1924921 \\
\hline $\mathbf{7 5 \%}$ Q3 & 0.6996238 \\
\hline $\mathbf{5 0 \%}$ & - \\
Median & 0.0024972 \\
\hline $\mathbf{2 5 \%}$ Q1 & - \\
\hline $\mathbf{1 0 \%}$ & -5132493 \\
\hline $\mathbf{5 \%}$ & - \\
& - \\
$\mathbf{1 \%}$ & - \\
\hline $\mathbf{0 \%}$ Min & - \\
\hline
\end{tabular}

\begin{tabular}{|l|l|l|c|}
\hline \multicolumn{4}{|l|}{ Extreme Observations } \\
\hline Lowest & \multicolumn{1}{l|}{ Highest } \\
\hline Value & Obs & Value & Obs \\
\hline- & 256 & 2.02175 & 137 \\
\hline 4.53246 & 257 \\
\hline- & 285 & 2.22583 & 108 \\
\hline 3.50102 & 280 \\
\hline 3.46134 & 193 & 2.33838 & 124 \\
\hline- & 243 & 2.46816 & 163 \\
\hline 3.16344 & 246 \\
\hline 2.66600 & 257 & 3.94708 & 224 \\
\hline
\end{tabular}


The UNIVARIATE Procedure

Fitted Normal Distribution for StudentResid

\begin{tabular}{|l|l|l|}
\hline \multicolumn{3}{|l|}{ Parameters for Normal Distribution } \\
\hline Parameter & Symbol & Estimate \\
\hline Mean & $\mathrm{Mu}$ & 0.000028 \\
\hline Std Dev & Sigma & 1.011153 \\
\hline
\end{tabular}

\begin{tabular}{|l|l|l|l|l|l|}
\hline Goodness-of-Fit Tests for Normal Distribution \\
\hline Test & \multicolumn{2}{|l|}{ Statistic } & \multicolumn{2}{|c|}{ p Value } \\
\hline Kolmogorov-Smirnov & D & 0.06980937 & Pr $>$ D & $<0.010$ \\
\hline Cramer-von Mises & W-Sq & 0.22021792 & Pr $>$ W-Sq & $<0.005$ \\
\hline Anderson-Darling & A-Sq & 1.69423030 & Pr $>$ A-Sq & $<0.005$ \\
\hline
\end{tabular}

\begin{tabular}{|r|r|r|}
\hline \multicolumn{3}{|c|}{ Quantiles for Normal Distribution } \\
\hline & & Quantile \\
\hline Percent & Observed & Estimated \\
\hline $\mathbf{1 . 0}$ & -3.46134 & -2.35227 \\
\hline $\mathbf{5 . 0}$ & -1.79560 & -1.66317 \\
\hline $\mathbf{1 0 . 0}$ & -1.13741 & -1.29582 \\
\hline $\mathbf{2 5 . 0}$ & -0.51325 & -0.68198 \\
\hline $\mathbf{5 0 . 0}$ & -0.00250 & 0.00003 \\
\hline $\mathbf{7 5 . 0}$ & 0.69962 & 0.68204 \\
\hline $\mathbf{9 0 . 0}$ & 1.19249 & 1.29587 \\
\hline $\mathbf{9 5 . 0}$ & 1.42757 & 1.66323 \\
\hline $\mathbf{9 9 . 0}$ & 2.33838 & 2.35232 \\
\hline
\end{tabular}

The UNIVARIATE Procedure

Variable: Estimate

Effect=bench (block*water)

\begin{tabular}{|l|r|l|l|}
\hline \multicolumn{4}{|c|}{ Moments } \\
\hline $\mathbf{N}$ & 60 & Sum Weights & 60 \\
\hline Mean & 0 & Sum Observations & 0 \\
\hline Std Deviation & 0.01674007 & Variance & 0.00028023 \\
\hline Skewness & -0.129829 & Kurtosis & -0.5402503 \\
\hline Uncorrected SS & 0.01653357 & Corrected SS & 0.01653357 \\
\hline Coeff Variation & & Std Error Mean & 0.00216113 \\
\hline
\end{tabular}

\begin{tabular}{|l|l|l|r|}
\hline \multicolumn{4}{|l|}{ Basic Statistical Measures } \\
\hline Location & & Variability & \\
\hline Mean & 0.000000 & Std Deviation & 0.01674 \\
\hline Median & 0.001315 & Variance & 0.0002802 \\
\hline Mode &. & Range & 0.06610 \\
\hline & & Interquartile Range & 0.02049 \\
\hline
\end{tabular}

\begin{tabular}{|c|c|c|c|c|}
\hline \multicolumn{5}{|c|}{ Tests for Location: $\mathrm{Mu} 0=0$} \\
\hline \multirow{2}{*}{$\begin{array}{l}\text { Test } \\
\text { Student's t }\end{array}$} & \multicolumn{2}{|c|}{ Statistic } & & \multirow{2}{*}{$\frac{\text { p Value }}{1.0000}$} \\
\hline & t & 0 & $\operatorname{Pr}>|\mathbf{t}|$ & \\
\hline Sign & $\mathbf{M}$ & 2 & $\operatorname{Pr}>=|\mathbf{M}|$ & 0.6989 \\
\hline Signed Rank & $\mathbf{S}$ & 22 & $\mathbf{P r}>=|\mathbf{S}|$ & 0.8729 \\
\hline
\end{tabular}




\begin{tabular}{|c|c|c|c|c|}
\hline \multicolumn{5}{|l|}{ Tests for Normality } \\
\hline Test & \multicolumn{2}{|c|}{ Statistic } & \multicolumn{2}{|c|}{ p Value } \\
\hline Shapiro-Wilk & $\mathbf{W}$ & 0.981268 & $\operatorname{Pr}<W$ & 0.4845 \\
\hline Kolmogorov-Smirnov & $\mathbf{D}$ & 0.064184 & $\operatorname{Pr}>D$ & $>0.1500$ \\
\hline Cramer-von Mises & W-Sq & 0.029424 & Pr $>W-S q$ & $>0.2500$ \\
\hline Anderson-Darling & $\mathrm{A}-\mathrm{Sq}$ & 0.22867 & $\operatorname{Pr}>\mathbf{A}-\mathrm{Sq}$ & $>0.2500$ \\
\hline
\end{tabular}

The UNIVARIATE Procedure

Variable:Estimate

Effect=bench (block ${ }^{*}$ water)

\begin{tabular}{|l|l|}
\hline Quantiles (Definition 5) \\
\hline Quantile & Estimate \\
\hline $\mathbf{1 0 0 \%}$ Max & 0.03162451 \\
\hline $\mathbf{9 9 \%}$ & 0.03162451 \\
\hline $\mathbf{9 5 \%}$ & 0.02984264 \\
\hline $\mathbf{9 0 \%}$ & 0.02136052 \\
\hline $\mathbf{7 5 \%}$ Q3 & 0.01049468 \\
\hline $\mathbf{5 0 \%}$ Median & 0.00131513 \\
\hline $\mathbf{2 5 \%}$ Q1 & -0.00999711 \\
\hline $\mathbf{1 0 \%}$ & -0.02497052 \\
\hline $\mathbf{5 \%}$ & -0.02914204 \\
\hline $\mathbf{1 \%}$ & -0.03447136 \\
\hline $\mathbf{0 \%}$ Min & -0.03447136 \\
\hline
\end{tabular}

\begin{tabular}{|l|r|l|r|}
\hline \multicolumn{4}{|l|}{ Extreme Observations } \\
\hline Lowest & \multicolumn{1}{|l|}{ Obs } & \multicolumn{1}{|l|}{ Value } & Obs \\
\hline Value & 39 & 0.0232855 & 38 \\
\hline-0.0344714 & 60 & 0.0297703 & 47 \\
\hline-0.0333106 & 33 & 0.0299150 & 36 \\
\hline-0.0297204 & 15 & 0.0308703 & 24 \\
\hline-0.0285637 & 57 & 0.0316245 & 26 \\
\hline-0.0256187 &
\end{tabular}

The UNIVARIATE Procedure

Variable:Estimate

Effect $=$ block

\begin{tabular}{|l|r|l|l|}
\hline \multicolumn{3}{|c|}{ Moments } \\
\hline $\mathbf{N}$ & 2 & Sum Weights & 2 \\
\hline Mean & 0 & Sum Observations & 0 \\
\hline Std Deviation & 0.13943767 & Variance & 0.01944286 \\
\hline Skewness &. & Kurtosis &. \\
\hline Uncorrected SS & 0.01944286 & Corrected SS & 0.01944286 \\
\hline Coeff Variation & $\cdot$ & Std Error Mean & 0.09859732 \\
\hline
\end{tabular}

\begin{tabular}{|l|r|l|l|}
\hline \multicolumn{3}{|l|}{ Basic Statistical Measures } \\
\hline Location & & \multicolumn{2}{|c|}{ Variability } \\
\hline Mean & 0 & Std Deviation & 0.13944 \\
\hline Median & $1 \mathrm{E}-13$ & Variance & 0.01944 \\
\hline Mode & $\cdot$ & Range & 0.19719 \\
\hline & & Interquartile Range & 0.19719 \\
\hline
\end{tabular}




\begin{tabular}{|l|l|r|l|l|l|}
\hline Tests for Location: $\mathbf{M u} 0=\mathbf{0}$ \\
\hline Test & \multicolumn{1}{|l|}{ Statistic } & \multicolumn{1}{|c|}{ p Value } \\
\hline Student's t & t & 0 & $\operatorname{Pr}>|\mathbf{t}|$ & 1.0000 \\
\hline Sign & M & 0 & $\operatorname{Pr}>=|\mathbf{M}|$ & 1.0000 \\
\hline Signed Rank & S & 0.5 & $\operatorname{Pr}>=|\mathbf{S}|$ & 1.0000 \\
\hline
\end{tabular}

\begin{tabular}{|l|l|l|l|l|}
\hline Tests for Normality & \multicolumn{4}{|l|}{ p Value } \\
\hline Test & \multicolumn{2}{|l|}{ Statistic } & Pr $<$ W & 1.0000 \\
\hline Shapiro-Wilk & W & 1 & Pr $>$ D & $>0.1500$ \\
\hline Kolmogorov-Smirnov & D & 0.26025 & Pr $>$ W-Sq & $>0.2500$ \\
\hline Cramer-von Mises & W-Sq & 0.041877 & Pr $>$ A-Sq & 0.2332 \\
\hline Anderson-Darling & A-Sq & 0.250482 & & \\
\hline
\end{tabular}

The UNIVARIATE Procedure

Variable: Estimate

Effect $=$ block

\begin{tabular}{l|r}
\hline \multicolumn{2}{|l|}{ Quantiles (Definition 5) } \\
\hline Quantile & Estimate \\
\hline $\mathbf{1 0 0 \%}$ Max & 0.0985973 \\
\hline $\mathbf{9 9 \%}$ & 0.0985973 \\
\hline $\mathbf{9 5 \%}$ & 0.0985973 \\
\hline $\mathbf{9 0 \%}$ & 0.0985973 \\
\hline $\mathbf{7 5 \%}$ Q3 & 0.0985973 \\
\hline $\mathbf{5 0 \%}$ Median & 0.0000000 \\
\hline $\mathbf{2 5 \%}$ Q1 & -0.0985973 \\
\hline $\mathbf{1 0 \%}$ & -0.0985973 \\
\hline $\mathbf{5 \%}$ & -0.0985973 \\
\hline $\mathbf{1 \%}$ & -0.0985973 \\
\hline $\mathbf{0 \%}$ Min & -0.0985973 \\
\hline
\end{tabular}

\begin{tabular}{|c|c|c|c|}
\hline \multicolumn{4}{|c|}{ Extreme Observations } \\
\hline \multicolumn{3}{|l|}{ Lowest } & \multirow{2}{*}{$\frac{\text { Highest }}{\text { Obs }}$} \\
\hline Value & Obs & Value & \\
\hline-0.0985973 & 2 & -0.0985973 & 2 \\
\hline 0.0985973 & 1 & 0.0985973 & 1 \\
\hline
\end{tabular}

\begin{tabular}{l|l}
\hline Model Information & \\
\hline Data Set & WORK.ABSR \\
\hline Dependent Variable & absr \\
\hline Covariance Structure & Diagonal \\
\hline Estimation Method & REML \\
\hline Residual Variance Method & Profile \\
\hline Fixed Effects SE Method & Model-Based \\
\hline Degrees of Freedom Method & Residual \\
\hline
\end{tabular}




\begin{tabular}{l|r|l}
\hline \multicolumn{3}{|c}{ Class Level Information } \\
\hline Class & Levels & Values \\
\hline block & 2 & 12 \\
\hline water & 5 & 0.511 .523 \\
\hline herb & 5 & Basil Mint Rose Sun Thyme \\
\hline bench & 60 & 12345678910111213141516171819202122232425262728 \\
& 293031323334353637383940414243444546474849505152 \\
& 5354555657585960 \\
\hline
\end{tabular}

\begin{tabular}{l|r}
\hline \multicolumn{2}{l|}{ Dimensions } \\
\hline Covariance Parameters & 1 \\
\hline Columns in X & 98 \\
\hline Columns in Z & 0 \\
\hline Subjects & 1 \\
\hline Max Obs Per Subject & 293 \\
\hline
\end{tabular}

\begin{tabular}{l|r}
\hline Number of Observations \\
\hline Number of Observations Read & 293 \\
\hline Number of Observations Used & 293 \\
\hline Number of Observations Not Used & 0 \\
\hline
\end{tabular}

\begin{tabular}{|l|l|}
\hline \multicolumn{2}{|l|}{ Covariance Parameter Estimates } \\
\hline Cov Parm & Estimate \\
\hline Residual & 0.03090 \\
\hline
\end{tabular}

\begin{tabular}{|l|r|}
\hline \multicolumn{2}{|l|}{ Fit Statistics } \\
\hline -2 Res Log Likelihood & -0.2 \\
\hline AIC (smaller is better) & 1.8 \\
\hline AICC (smaller is better) & 1.9 \\
\hline BIC (smaller is better) & 5.2 \\
\hline
\end{tabular}

\begin{tabular}{|l|r|c|r|c|}
\hline Type 3 Tests of Fixed Effects \\
\hline Effect & Num DF & Den DF & F Value & Pr > F \\
\hline water & 4 & 213 & 2.20 & 0.0704 \\
\hline herb & 4 & 213 & 5.74 & 0.0002 \\
\hline water*herb & 16 & 213 & 1.89 & 0.0226 \\
\hline block & 1 & 213 & 3.80 & 0.0525 \\
\hline bench(block*water) & 54 & 213 & 1.10 & 0.3136 \\
\hline
\end{tabular}

\begin{tabular}{|l|l|}
\hline Model Information \\
\hline Data Set & WORK.VICTORIA01 \\
\hline Dependent Variable & fresh \\
\hline Covariance Structure & Variance Components \\
\hline Estimation Method & REML \\
\hline Residual Variance Method & Profile \\
\hline Fixed Effects SE Method & Kenward-Roger \\
\hline Degrees of Freedom Method & Kenward-Roger \\
\hline
\end{tabular}

\begin{tabular}{|l|r|l|}
\hline \multicolumn{3}{|c|}{ Class Level Information } \\
\hline Class & Levels & Values \\
\hline block & 2 & 12 \\
\hline water & 5 & 0.511 .523 \\
\hline herb & 5 & Basil Mint Rose Sun Thyme \\
\hline bench & 60 & $\begin{array}{l}123456789101112131415161718192021222324252627 \\
2829303132333435363738394041424344454647484950 \\
\end{array}$ \\
& 51525354555657585960 \\
\hline
\end{tabular}




\begin{tabular}{|l|r|}
\hline Dimensions \\
\hline Covariance Parameters & 3 \\
\hline Columns in X & 18 \\
\hline Columns in Z & 62 \\
\hline Subjects & 1 \\
\hline Max Obs Per Subject & 293 \\
\hline
\end{tabular}

\begin{tabular}{|l|r|}
\hline Number of Observations \\
\hline Number of Observations Read & 293 \\
\hline Number of Observations Used & 293 \\
\hline Number of Observations Not Used & 0 \\
\hline
\end{tabular}

\begin{tabular}{|r|r|r|l|}
\hline \multicolumn{5}{|c|}{ Iteration History } \\
\hline Iteration & Evaluations & $\mathbf{- 2}$ Res Log Like & Criterion \\
\hline $\mathbf{0}$ & 1 & 226.09970343 & \\
\hline $\mathbf{1}$ & 2 & 198.50008600 & 0.00000001 \\
\hline $\mathbf{2}$ & 1 & 198.50008416 & 0.00000000 \\
\hline
\end{tabular}

\section{Convergence criteria}

\begin{tabular}{|l|l|c|r|r|}
\hline \multicolumn{6}{|l|}{ Covariance Parameter Estimates } \\
\hline Cov Parm & Estimate & $\begin{array}{c}\text { Standard } \\
\text { Error }\end{array}$ & $\begin{array}{r}\mathbf{Z} \\
\text { Value }\end{array}$ & Pr $>$ Z \\
\hline block & 0.02015 & 0.02968 & 0.68 & 0.2485 \\
\hline bench(block*water) & 0.006170 & 0.005028 & 1.23 & 0.1099 \\
\hline Residual & 0.09129 & 0.008681 & 10.52 & $<.0001$ \\
\hline
\end{tabular}

\begin{tabular}{|l|l|}
\hline \multicolumn{2}{|l|}{ Fit Statistics } \\
\hline -2 Res Log Likelihood & 198.5 \\
\hline AIC (smaller is better) & 204.5 \\
\hline AICC (smaller is better) & 204.6 \\
\hline BIC (smaller is better) & 200.6 \\
\hline
\end{tabular}

\begin{tabular}{|l|l|r|r|r|r|c|}
\hline \multicolumn{7}{|c|}{ Solution for Fixed Effects } \\
\hline Effect & herb & Estimate & $\begin{array}{r}\text { Standard } \\
\text { Error }\end{array}$ & DF & $\begin{array}{r}\mathbf{t} \\
\text { Value }\end{array}$ & $\begin{array}{c}\text { Pr }> \\
|\mathbf{t}|\end{array}$ \\
\hline Intercept & & 3.7165 & 0.1927 & 12.2 & 19.29 & $<.0001$ \\
\hline herb & Basil & -0.5740 & 0.2251 & 221 & -2.55 & 0.0115 \\
\hline herb & Mint & -1.4430 & 0.2300 & 224 & -6.27 & $<.0001$ \\
\hline herb & Rose & -1.5563 & 0.2251 & 221 & -6.91 & $<.0001$ \\
\hline herb & Sun & -0.9278 & 0.2337 & 226 & -3.97 & $<.0001$ \\
\hline herb & Thyme & 0 & &. & &. \\
\hline qwater & & 0.5913 & 0.2158 & 272 & 2.74 & 0.0066 \\
\hline qwater*herb & Basil & 1.1575 & 0.2954 & 221 & 3.92 & 0.0001 \\
\hline qwater*herb & Mint & 0.9738 & 0.3011 & 224 & 3.23 & 0.0014 \\
\hline qwater*herb & Rose & 0.9983 & 0.2954 & 221 & 3.38 & 0.0009 \\
\hline
\end{tabular}




\begin{tabular}{|l|l|r|r|r|r|c|}
\hline \multicolumn{7}{|c|}{ Solution for Fixed Effects } \\
\hline Effect & herb & Estimate & Standard Error & DF & t Value & Pr $>|\mathbf{t}|$ \\
\hline qwater*herb & Sun & 0.4367 & 0.3029 & 225 & 1.44 & 0.1508 \\
\hline qwater*herb & Thyme & 0 &. &. &. &. \\
\hline qwater*qwater & & -0.1266 & 0.05950 & 272 & -2.13 & 0.0342 \\
\hline qwater*qwater*herb & Basil & -0.2344 & 0.08144 & 221 & -2.88 & 0.0044 \\
\hline qwater*qwater*herb & Mint & -0.1821 & 0.08294 & 224 & -2.20 & 0.0292 \\
\hline qwater*qwater*herb & Rose & -0.1814 & 0.08145 & 221 & -2.23 & 0.0270 \\
\hline qwater*qwater*herb & Sun & -0.1007 & 0.08323 & 224 & -1.21 & 0.2276 \\
\hline qwater*qwater*herb & Thyme & 0 & &. & &. \\
\hline
\end{tabular}

\begin{tabular}{|l|r|c|r|l|}
\hline \multicolumn{7}{|l|}{ Type 1 Tests of Fixed Effects } \\
\hline Effect & Num DF & Den DF & F Value & Pr > F \\
\hline herb & 4 & 223 & 140.10 & $<.0001$ \\
\hline qwater & 1 & 56.7 & 231.02 & $<.0001$ \\
\hline qwater*herb & 4 & 224 & 13.09 & $<.0001$ \\
\hline qwater*qwater & 1 & 56.1 & 78.15 & $<.0001$ \\
\hline qwater*qwater*herb & 4 & 223 & 2.51 & 0.0428 \\
\hline
\end{tabular}

\begin{tabular}{|l|r|r|r|r|r|}
\hline \multicolumn{7}{|c|}{ Estimates } \\
\hline Label & Estimate & Standard Error & DF & t Value & Pr $>|\mathbf{t}|$ \\
\hline Int for Basil & 3.1425 & 0.1927 & 12.2 & 16.31 & $<.0001$ \\
\hline B_Lin for Basil & 1.7488 & 0.2158 & 272 & 8.10 & $<.0001$ \\
\hline B_quad for Basil & -0.3611 & 0.05950 & 272 & -6.07 & $<.0001$ \\
\hline Int for Mint & 2.2735 & 0.1983 & 13.7 & 11.46 & $<.0001$ \\
\hline B_Lin for Mint & 1.5651 & 0.2235 & 273 & 7.00 & $<.0001$ \\
\hline B_quad for Mint & -0.3087 & 0.06154 & 273 & -5.02 & $<.0001$ \\
\hline Int for Rose & 2.1602 & 0.1927 & 12.2 & 11.21 & $<.0001$ \\
\hline B_Lin for Rose & 1.5896 & 0.2158 & 272 & 7.37 & $<.0001$ \\
\hline B_quad for Rose & -0.3080 & 0.05951 & 272 & -5.18 & $<.0001$ \\
\hline Int for Sun & 2.7887 & 0.2027 & 14.8 & 13.76 & $<.0001$ \\
\hline B_Lin for Sun & 1.0279 & 0.2260 & 274 & 4.55 & $<.0001$ \\
\hline
\end{tabular}

\begin{tabular}{|l|r|r|r|r|r|}
\hline \multicolumn{7}{|c|}{ Estimates } \\
\hline Label & Estimate & Standard Error & DF & t Value & Pr $>|\mathbf{t}|$ \\
\hline B_quad for Sun & -0.2273 & 0.06193 & 273 & -3.67 & 0.0003 \\
\hline Int for Thyme & 3.7165 & 0.1927 & 12.2 & 19.29 & $<.0001$ \\
\hline B_Lin for Thyme & 0.5913 & 0.2158 & 272 & 2.74 & 0.0066 \\
\hline B_quad for Thyme & -0.1266 & 0.05950 & 272 & -2.13 & 0.0342 \\
\hline
\end{tabular}




\begin{tabular}{|l|l|}
\hline Model Information \\
\hline Data Set & WORK.VICTORIA01 \\
\hline Dependent Variable & fresh \\
\hline Covariance Structure & Variance Components \\
\hline Estimation Method & REML \\
\hline Residual Variance Method & Profile \\
\hline Fixed Effects SE Method & Kenward-Roger \\
\hline Degrees of Freedom Method & Kenward-Roger \\
\hline
\end{tabular}

\begin{tabular}{|l|r|l|}
\hline \multicolumn{3}{|c|}{ Class Level Information } \\
\hline Class & Levels & Values \\
\hline block & 2 & 12 \\
\hline water & 5 & 0.511 .523 \\
\hline herb & 5 & Basil Mint Rose Sun Thyme \\
\hline bench & 60 & $\begin{array}{l}123456789101112131415161718192021222324252627282930 \\
\end{array}$ \\
& & $\begin{array}{l}3132333435363738394041424344454647484950515253545556 \\
\end{array}$ \\
\hline
\end{tabular}

\begin{tabular}{|l|r|}
\hline Dimensions \\
\hline Covariance Parameters & 3 \\
\hline Columns in X & 11 \\
\hline Columns in Z & 62 \\
\hline Subjects & 1 \\
\hline Max Obs Per Subject & 293 \\
\hline
\end{tabular}

\begin{tabular}{|l|r|}
\hline Number of Observations \\
\hline Number of Observations Read & 293 \\
\hline Number of Observations Used & 293 \\
\hline Number of Observations Not Used & 0 \\
\hline
\end{tabular}

\begin{tabular}{|r|r|r|l|}
\hline \multicolumn{5}{|c|}{ Iteration History } \\
\hline Iteration & Evaluations & $\mathbf{- 2}$ Res Log Like & Criterion \\
\hline $\mathbf{0}$ & 1 & 221.43355728 & \\
\hline $\mathbf{1}$ & 2 & 194.70620426 & 0.00000001 \\
\hline $\mathbf{2}$ & 1 & 194.70620223 & 0.00000000 \\
\hline
\end{tabular}

Convergence criteria met.

\begin{tabular}{|l|l|c|r|r|}
\hline \multicolumn{6}{|l|}{ Covariance Parameter Estimates } \\
\hline Cov Parm & Estimate & $\begin{array}{c}\text { Standard } \\
\text { Error }\end{array}$ & $\begin{array}{r}\mathbf{Z} \\
\text { Value }\end{array}$ & $\mathbf{P r}>\mathbf{Z}$ \\
\hline block & 0.02017 & 0.02970 & 0.68 & 0.2485 \\
\hline bench(block*water) & 0.005577 & 0.005021 & 1.11 & 0.1334 \\
\hline Residual & 0.09381 & 0.008840 & 10.61 & $<.0001$ \\
\hline
\end{tabular}

\begin{tabular}{|l|l|}
\hline \multicolumn{2}{|l|}{ Fit Statistics } \\
\hline -2 Res Log Likelihood & 194.7 \\
\hline AIC (smaller is better) & 200.7 \\
\hline AICC (smaller is better) & 200.8 \\
\hline BIC (smaller is better) & 196.8 \\
\hline
\end{tabular}

\begin{tabular}{|l|l|r|r|r|r|r|}
\hline \multicolumn{7}{|c|}{ Solution for Fixed Effects } \\
\hline Effect & herb & Estimate & $\begin{array}{r}\text { Standard } \\
\text { Error }\end{array}$ & DF & $\begin{array}{r}\mathbf{t} \\
\text { Value }\end{array}$ & Pr $>|\mathbf{t}|$ \\
\hline herb & Basil & 3.3664 & 0.1501 & 4.57 & 22.42 & $<.0001$ \\
\hline herb & Mint & 2.3744 & 0.1519 & 4.79 & 15.63 & $<.0001$ \\
\hline herb & Rose & 2.2584 & 0.1502 & 4.57 & 15.04 & $<.0001$ \\
\hline herb & Sun & 2.6933 & 0.1543 & 5.09 & 17.46 & $<.0001$ \\
\hline herb & Thyme & 3.3859 & 0.1501 & 4.57 & 22.55 & $<.0001$ \\
\hline qwater(herb) & Basil & 1.4136 & 0.1166 & 72.8 & 12.13 & $<.0001$ \\
\hline qwater(herb) & Mint & 1.4152 & 0.1174 & 74.4 & 12.05 & $<.0001$ \\
\hline qwater(herb) & Rose & 1.4424 & 0.1166 & 72.7 & 12.37 & $<.0001$ \\
\hline qwater(herb) & Sun & 1.1670 & 0.1181 & 75.8 & 9.88 & $<.0001$ \\
\hline
\end{tabular}




\begin{tabular}{|l|l|r|r|r|r|c|}
\hline \multicolumn{7}{|c|}{ Solution for Fixed Effects } \\
\hline Effect & herb & Estimate & $\begin{array}{r}\text { Standard } \\
\text { Error }\end{array}$ & DF & $\begin{array}{r}\mathbf{t} \\
\text { Value }\end{array}$ & $\begin{array}{c}\text { Pr }> \\
|\mathbf{t}|\end{array}$ \\
\hline qwater(herb) & Thyme & 1.0861 & 0.1166 & 72.8 & 9.32 & $<.0001$ \\
\hline qwater*qwater & & -0.2664 & 0.03009 & 56.2 & -8.85 & $<.0001$ \\
\hline
\end{tabular}

\begin{tabular}{|l|r|c|r|r|}
\hline \multicolumn{6}{|l|}{ Type 3 Tests of Fixed Effects } \\
\hline Effect & Num DF & Den DF & F Value & Pr $>$ F \\
\hline herb & 5 & 25 & 115.39 & $<.0001$ \\
\hline qwater(herb) & 5 & 218 & 38.60 & $<.0001$ \\
\hline qwater*qwater & 1 & 56.2 & 78.40 & $<.0001$ \\
\hline
\end{tabular}




\section{Dry weight}

\section{The MEANS Procedure}

\begin{tabular}{|c|c|c|c|c|c|c|c|}
\hline \multicolumn{8}{|c|}{ Analysis Variable : dry } \\
\hline water & N Obs & $\mathbf{N}$ & Mean & Std Dev & \multicolumn{2}{|c|}{ Minimum } & Maximum \\
\hline 0.5 & 57 & 57 & 1.8430716 & 0.5346802 & \multicolumn{2}{|c|}{0.6151856} & 2.9806186 \\
\hline 1 & 59 & 59 & 2.3700575 & 0.4900350 & \multicolumn{2}{|c|}{0.7884574} & 3.3843903 \\
\hline 1.5 & 60 & 60 & 2.5421263 & 0.4746789 & \multicolumn{2}{|c|}{1.3862944} & 3.4177267 \\
\hline 2 & 59 & 59 & 2.6225753 & 0.5615976 & \multicolumn{2}{|c|}{0.7419373} & 3.5793436 \\
\hline 3 & 58 & 58 & 2.6279157 & 0.6269324 & \multicolumn{2}{|c|}{0.3364722} & 3.5624655 \\
\hline \multicolumn{8}{|c|}{ Analysis Variable : dry } \\
\hline herb & $\begin{array}{r}\mathbf{N} \\
\text { Obs } \\
\end{array}$ & $\mathbf{N}$ & Mean & Std Dev & Minimum & & ximum \\
\hline Basil & 60 & 60 & 2.7729537 & 0.4245351 & 1.9139771 & & 624655 \\
\hline Mint & 57 & 57 & 2.0858803 & 0.5757159 & 0.6151856 & & 108437 \\
\hline Rose & 60 & 60 & 2.3814942 & 0.4987403 & 1.2237754 & & 027464 \\
\hline Sun & 56 & 56 & 1.8949774 & 0.5825058 & 0.3364722 & & 654750 \\
\hline Thyme & 60 & 60 & 2.8381054 & 0.3315491 & 1.9459101 & & 793436 \\
\hline
\end{tabular}

\begin{tabular}{|c|c|c|c|c|c|c|c|}
\hline \multicolumn{8}{|c|}{ Analysis Variable : dry } \\
\hline herb & water & N Obs & $\mathbf{N}$ & Mean & Std Dev & Minimum & Maximum \\
\hline \multirow[t]{5}{*}{ Basil } & 0.5 & 12 & 12 & 2.0392606 & 0.1062228 & 1.9139771 & 2.1860513 \\
\hline & 1 & 12 & 12 & 2.7638754 & 0.2286337 & 2.4510051 & 3.1441523 \\
\hline & 1.5 & 12 & 12 & 2.9227747 & 0.1055499 & 2.7663191 & 3.0796138 \\
\hline & 2 & 12 & 12 & 3.0554024 & 0.1363882 & 2.8564702 & 3.2260500 \\
\hline & 3 & 12 & 12 & 3.0834553 & 0.2633714 & 2.6741486 & 3.5624655 \\
\hline \multirow[t]{5}{*}{ Mint } & 0.5 & 11 & 11 & 1.3872006 & 0.3047868 & 0.6151856 & 1.6486586 \\
\hline & 1 & 12 & 12 & 1.9936086 & 0.3857054 & 1.4586150 & 2.4765384 \\
\hline & 1.5 & 12 & 12 & 2.2972149 & 0.3260922 & 1.8000583 & 2.7343675 \\
\hline & 2 & 11 & 11 & 2.3430280 & 0.6030737 & 1.2527630 & 3.0286834 \\
\hline & 3 & 11 & 11 & 2.3975255 & 0.5818525 & 1.6193882 & 3.2108437 \\
\hline \multirow[t]{5}{*}{ Rose } & 0.5 & 12 & 12 & 1.5517893 & 0.3089857 & 1.2237754 & 2.1860513 \\
\hline & 1 & 12 & 12 & 2.3295386 & 0.1287149 & 2.0980179 & 2.5095993 \\
\hline & 1.5 & 12 & 12 & 2.4984479 & 0.1511158 & 2.2300144 & 2.7725887 \\
\hline & 2 & 12 & 12 & 2.6907169 & 0.2250370 & 2.2192035 & 2.9704145 \\
\hline & 3 & 12 & 12 & 2.8369783 & 0.2216906 & 2.3749058 & 3.2027464 \\
\hline \multirow[t]{5}{*}{ Sun } & 0.5 & 10 & 10 & 1.5292410 & 0.3885261 & 0.9162907 & 2.1804175 \\
\hline & 1 & 11 & 11 & 1.9503457 & 0.4981375 & 0.7884574 & 2.5095993 \\
\hline & 1.5 & 12 & 12 & 1.9942743 & 0.4490218 & 1.3862944 & 3.1654750 \\
\hline & 2 & 12 & 12 & 2.1108083 & 0.6842223 & 0.7419373 & 3.0228609 \\
\hline & 3 & 11 & 11 & 1.8283206 & 0.7319222 & 0.3364722 & 2.8478121 \\
\hline \multirow[t]{5}{*}{ Thyme } & 0.5 & 12 & 12 & 2.6175723 & 0.2332518 & 2.2512918 & 2.9806186 \\
\hline & 1 & 12 & 12 & 2.7779430 & 0.3738152 & 1.9459101 & 3.3843903 \\
\hline & 1.5 & 12 & 12 & 2.9979197 & 0.2948879 & 2.4510051 & 3.4177267 \\
\hline & 2 & 12 & 12 & 2.8896252 & 0.3792640 & 2.3513753 & 3.5793436 \\
\hline & 3 & 12 & 12 & 2.9074670 & 0.2676586 & 2.4723279 & 3.4919517 \\
\hline
\end{tabular}




\begin{tabular}{|l|l|}
\hline Model Information & \\
\hline Data Set & WORK.VICTORIA01 \\
\hline Dependent Variable & dry \\
\hline Covariance Structure & Variance Components \\
\hline Estimation Method & REML \\
\hline Residual Variance Method & Profile \\
\hline Fixed Effects SE Method & Kenward-Roger \\
\hline Degrees of Freedom Method & Kenward-Roger \\
\hline
\end{tabular}

\begin{tabular}{|l|r|l|}
\hline \multicolumn{3}{|c|}{ Class Level Information } \\
\hline Class & Levels & Values \\
\hline block & 2 & 12 \\
\hline water & 5 & 0.511 .523 \\
\hline herb & 5 & Basil Mint Rose Sun Thyme \\
\hline bench & 60 & $\begin{array}{l}123456789101112131415161718192021222324252627282930 \\
\end{array}$ \\
& & $\begin{array}{l}3132333435363738394041424344454647484950515253545556 \\
57585960\end{array}$ \\
\hline
\end{tabular}

\begin{tabular}{|l|r|}
\hline Dimensions \\
\hline Covariance Parameters & 3 \\
\hline Columns in X & 36 \\
\hline Columns in Z & 62 \\
\hline Subjects & 1 \\
\hline Max Obs Per Subject & 293 \\
\hline
\end{tabular}

\begin{tabular}{|l|r|}
\hline Number of Observations \\
\hline Number of Observations Read & 293 \\
\hline Number of Observations Used & 293 \\
\hline Number of Observations Not Used & 0 \\
\hline
\end{tabular}

\begin{tabular}{|r|r|r|l|}
\hline \multicolumn{5}{|c|}{ Iteration History } \\
\hline Iteration & Evaluations & -2 Res Log Like & Criterion \\
\hline $\mathbf{0}$ & 1 & 292.52050928 & \\
\hline $\mathbf{1}$ & 2 & 245.16775965 & 0.00000000 \\
\hline
\end{tabular}

\section{Convergence criteria met.}

\begin{tabular}{|l|r|r|r|l|}
\hline Covariance Parameter Estimates \\
\hline Cov Parm & Estimate & Standard Error & Z Value & $\operatorname{Pr}$ Z \\
\hline block & 0.04432 & 0.06374 & 0.70 & 0.4868 \\
\hline bench(block*water) & -0.00126 & 0.004847 & -0.26 & 0.7941 \\
\hline Residual & 0.1157 & 0.01119 & 10.34 & $<.0001$ \\
\hline
\end{tabular}

\begin{tabular}{|l|l|l|}
\hline \multicolumn{3}{|c|}{ Null Model Likelihood Ratio Test } \\
\hline DF & Chi-Square & Pr $>$ ChiSq \\
\hline 2 & 47.35 & $<.0001$ \\
\hline
\end{tabular}

\begin{tabular}{|l|l|}
\hline \multicolumn{2}{|l|}{ Fit Statistics } \\
\hline -2 Res Log Likelihood & 245.2 \\
\hline AIC (smaller is better) & 251.2 \\
\hline AICC (smaller is better) & 251.3 \\
\hline BIC (smaller is better) & 247.2 \\
\hline
\end{tabular}




\begin{tabular}{|l|l|l|r|r|r|r|r|}
\hline \multicolumn{7}{|c|}{ Solution for Fixed Effects } \\
\hline Effect & herb & water & Estimate & $\begin{array}{r}\text { Standard } \\
\text { Error }\end{array}$ & DF & $\begin{array}{r}\mathbf{t} \\
\text { Value }\end{array}$ & $\begin{array}{c}\text { Pr }> \\
|\mathbf{t}|\end{array}$ \\
\hline Intercept & & & 2.9075 & 0.1780 & 1.98 & 16.33 & 0.0039 \\
\hline water & & 0.5 & -0.2899 & 0.1381 & 267 & -2.10 & 0.0368 \\
\hline water & & 1 & -0.1295 & 0.1381 & 267 & -0.94 & 0.3492 \\
\hline water & & 1.5 & 0.09045 & 0.1381 & 267 & 0.65 & 0.5131 \\
\hline water & & 2 & -0.01784 & 0.1381 & 267 & -0.13 & 0.8973 \\
\hline water & & 3 & 0 &. &. & &. \\
\hline herb & Basil & & 0.1760 & 0.1389 & 214 & 1.27 & 0.2064 \\
\hline herb & Mint & & -0.4963 & 0.1420 & 218 & -3.49 & 0.0006 \\
\hline herb & Rose & & -0.07049 & 0.1389 & 214 & -0.51 & 0.6123 \\
\hline herb & Sun & & -1.0664 & 0.1420 & 218 & -7.51 & $<.0001$ \\
\hline herb & Thyme & & 0 & &. & &. \\
\hline
\end{tabular}

\begin{tabular}{|l|l|l|r|r|r|r|c|}
\hline \multicolumn{7}{|c|}{ Solution for Fixed Effects } \\
\hline Effect & herb & water & Estimate & $\begin{array}{r}\text { Standard } \\
\text { Error }\end{array}$ & $\begin{array}{r}\text { DF } \\
\text { Value }\end{array}$ & $\begin{array}{c}\text { Pr }> \\
|\mathbf{t}|\end{array}$ \\
\hline water*herb & Basil & 0.5 & -0.7543 & 0.1964 & 214 & -3.84 & 0.0002 \\
\hline water*herb & Mint & 0.5 & -0.7207 & 0.2008 & 218 & -3.59 & 0.0004 \\
\hline water*herb & Rose & 0.5 & -0.9953 & 0.1964 & 214 & -5.07 & $<.0001$ \\
\hline water*herb & Sun & 0.5 & -0.02235 & 0.2034 & 220 & -0.11 & 0.9126 \\
\hline water*herb & Thyme & 0.5 & 0 &. &. &. &. \\
\hline water*herb & Basil & 1 & -0.1901 & 0.1964 & 214 & -0.97 & 0.3343 \\
\hline water*herb & Mint & 1 & -0.2881 & 0.1986 & 216 & -1.45 & 0.1485 \\
\hline water*herb & Rose & 1 & -0.3787 & 0.1964 & 218 & -1.93 & 0.0552 \\
\hline water*herb & Sun & 1 & 0.2252 & 0.2009 & 218 & 1.12 & 0.2635 \\
\hline water*herb & Thyme & 1 & 0 &. &. &. &. \\
\hline water*herb & Basil & 1.5 & -0.2511 & 0.1964 & 214 & -1.28 & 0.2024 \\
\hline water*herb & Mint & 1.5 & -0.2044 & 0.1986 & 216 & -1.03 & 0.3046 \\
\hline water*herb & Rose & 1.5 & -0.4290 & 0.1964 & 214 & -2.18 & 0.0300 \\
\hline water*herb & Sun & 1.5 & 0.06276 & 0.1986 & 216 & 0.32 & 0.7523 \\
\hline water*herb & Thyme & 1.5 & 0 &. &. &. &. \\
\hline water*herb & Basil & 2 & -0.01021 & 0.1964 & 214 & -0.05 & 0.9586 \\
\hline water*herb & Mint & 2 & -0.03738 & 0.2008 & 218 & -0.19 & 0.8525 \\
\hline water*herb & Rose & 2 & -0.1284 & 0.1964 & 214 & -0.65 & 0.5139 \\
\hline water*herb & Sun & 2 & 0.2876 & 0.1986 & 216 & 1.45 & 0.1491 \\
\hline water*herb & Thyme & 2 & 0 &. &. &. &. \\
\hline water*herb & Basil & 3 & 0 &. &. &. &. \\
\hline water*herb & Mint & 3 & 0 &. &. &. \\
\hline water*herb & Rose & 3 & 0 &. &. &. &. \\
\hline water*herb & Sun & 3 & 0 &. &. &. \\
\hline water*herb & Thyme & 3 & 0 &. &. &. \\
\hline
\end{tabular}




\begin{tabular}{|c|c|c|c|c|c|c|c|c|}
\hline \multicolumn{9}{|c|}{ Solution for Random Effects } \\
\hline Effect & block & water & bench & Estimate & $\begin{array}{r}\text { Std } \\
\text { Err } \\
\text { Pred } \\
\end{array}$ & DF & $\begin{array}{r}\text { t } \\
\text { Value } \\
\end{array}$ & $\begin{array}{c}\operatorname{Pr}> \\
|\mathbf{t}| \\
\end{array}$ \\
\hline block & 1 & & & 0.1476 & 0.1501 & 1.07 & 0.98 & 0.4967 \\
\hline block & 2 & & & -0.1476 & 0.1501 & 1.07 & -0.98 & 0.4968 \\
\hline bench(block*water) & 1 & 0.5 & 10 & -0.00172 & 0 & 268 & -Infty & $<.0001$ \\
\hline bench(block*water) & 1 & 0.5 & 17 & 0.01062 & 0 & 268 & Infty & $<.0001$ \\
\hline bench(block*water) & 1 & 0.5 & 20 & -0.00038 & 0 & 268 & -Infty & $<.0001$ \\
\hline bench(block*water) & 1 & 0.5 & 22 & 0.01037 & 0 & 268 & Infty & $<.0001$ \\
\hline bench(block*water) & 1 & 0.5 & 24 & 0.004582 & 0 & 268 & Infty & $<.0001$ \\
\hline bench(block*water) & 1 & 0.5 & 28 & 0.007191 & 0 & 268 & Infty & $<.0001$ \\
\hline bench(block*water) & 1 & 1 & 2 & 0.005113 & 0 & 268 & Infty & $<.0001$ \\
\hline bench(block*water) & 1 & 1 & 5 & -0.00298 & 0 & 268 & -Infty & $<.0001$ \\
\hline bench(block*water) & 1 & 1 & 9 & -0.00377 & 0 & 268 & -Infty & $<.0001$ \\
\hline bench(block*water) & 1 & 1 & 13 & -0.00525 & 0 & 268 & -Infty & $<.0001$ \\
\hline bench(block*water) & 1 & 1 & 19 & 0.005624 & 0 & 268 & Infty & $<.0001$ \\
\hline bench(block*water) & 1 & 1 & 21 & -0.00139 & 0 & 268 & -Infty & $<.0001$ \\
\hline bench(block*water) & 1 & 1.5 & 1 & 0.01334 & 0 & 268 & Infty & $<.0001$ \\
\hline bench(block*water) & 1 & 1.5 & 11 & 0.007352 & 0 & 268 & Infty & $<.0001$ \\
\hline bench(block*water) & 1 & 1.5 & 12 & 0.000106 & 0 & 268 & Infty & $<.0001$ \\
\hline bench(block*water) & 1 & 1.5 & 16 & 0.001039 & 0 & 268 & Infty & $<.0001$ \\
\hline bench(block*water) & 1 & 1.5 & 23 & 0.002934 & 0 & 268 & Infty & $<.0001$ \\
\hline bench(block*water) & 1 & 1.5 & 29 & 0.002194 & 0 & 268 & Infty & $<.0001$ \\
\hline bench(block*water) & 1 & 2 & 3 & 0.003936 & 0 & 268 & Infty & $<.0001$ \\
\hline bench(block*water) & 1 & 2 & 6 & 0.006427 & 0 & 268 & Infty & $<.0001$ \\
\hline bench(block*water) & 1 & 2 & 8 & -0.00664 & 0 & 268 & -Infty & $<.0001$ \\
\hline bench(block*water) & 1 & 2 & 18 & -0.01628 & 0 & 268 & -Infty & $<.0001$ \\
\hline bench(block*water) & 1 & 2 & 25 & -0.00531 & 0 & 268 & -Infty & $<.0001$ \\
\hline bench(block*water) & 1 & 2 & 26 & -0.01580 & 0 & 268 & -Infty & $<.0001$ \\
\hline bench(block*water) & 1 & 3 & 4 & -0.00982 & 0 & 268 & -Infty & $<.0001$ \\
\hline bench(block*water) & 1 & 3 & 7 & 0.002027 & 0 & 268 & Infty & $<.0001$ \\
\hline bench(block*water) & 1 & 3 & 14 & -0.01267 & 0 & 268 & -Infty & $<.0001$ \\
\hline bench(block*water) & 1 & 3 & 15 & -0.00026 & 0 & 268 & -Infty & $<.0001$ \\
\hline bench(block*water) & 1 & 3 & 27 & -0.00748 & 0 & 268 & -Infty & $<.0001$ \\
\hline
\end{tabular}




\begin{tabular}{|c|c|c|c|c|c|c|c|c|}
\hline \multicolumn{9}{|c|}{ Solution for Random Effects } \\
\hline Effect & block & water & bench & Estimate & $\begin{array}{r}\text { Std } \\
\text { Err } \\
\text { Pred } \\
\end{array}$ & DF & $\begin{array}{r}\text { t } \\
\text { Value } \\
\end{array}$ & $\begin{array}{c}\operatorname{Pr}> \\
|\mathbf{t}| \\
\end{array}$ \\
\hline bench(block*water) & 1 & 3 & 30 & 0.002680 & 0 & 268 & Infty & $<.0001$ \\
\hline bench(block*water) & 2 & 0.5 & 40 & 0.01648 & 0 & 268 & Infty & $<.0001$ \\
\hline bench(block*water) & 2 & 0.5 & 47 & -0.00858 & 0 & 268 & -Infty & $<.0001$ \\
\hline bench(block*water) & 2 & 0.5 & 50 & -0.01060 & 0 & 268 & -Infty & $<.0001$ \\
\hline bench(block*water) & 2 & 0.5 & 52 & -0.01141 & 0 & 268 & -Infty & $<.0001$ \\
\hline bench(block*water) & 2 & 0.5 & 54 & -0.00302 & 0 & 268 & -Infty & $<.0001$ \\
\hline bench(block*water) & 2 & 0.5 & 58 & -0.01354 & 0 & 268 & -Infty & $<.0001$ \\
\hline bench(block*water) & 2 & 1 & 32 & 0.01577 & 0 & 268 & Infty & $<.0001$ \\
\hline bench(block*water) & 2 & 1 & 35 & -0.00118 & 0 & 268 & -Infty & $<.0001$ \\
\hline bench(block* water) & 2 & 1 & 39 & -0.00057 & 0 & 268 & -Infty & $<.0001$ \\
\hline bench(block*water) & 2 & 1 & 43 & -0.00169 & 0 & 268 & -Infty & $<.0001$ \\
\hline bench(block*water) & 2 & 1 & 49 & -0.00732 & 0 & 268 & -Infty & $<.0001$ \\
\hline bench(block* water) & 2 & 1 & 51 & -0.00235 & 0 & 268 & -Infty & $<.0001$ \\
\hline bench(block*water) & 2 & 1.5 & 31 & -0.00179 & 0 & 268 & -Infty & $<.0001$ \\
\hline bench(block*water) & 2 & 1.5 & 41 & 0.000611 & 0 & 268 & Infty & $<.0001$ \\
\hline bench(block* water) & 2 & 1.5 & 42 & -0.01654 & 0 & 268 & -Infty & $<.0001$ \\
\hline bench(block* water) & 2 & 1.5 & 46 & -0.00557 & 0 & 268 & -Infty & $<.0001$ \\
\hline bench(block* water) & 2 & 1.5 & 53 & 0.000641 & 0 & 268 & Infty & $<.0001$ \\
\hline bench(block* water) & 2 & 1.5 & 59 & -0.00431 & 0 & 268 & -Infty & $<.0001$ \\
\hline bench(block* water) & 2 & 2 & 33 & 0.008715 & 0 & 268 & Infty & $<.0001$ \\
\hline bench(block* water) & 2 & 2 & 36 & 0.002470 & 0 & 268 & Infty & $<.0001$ \\
\hline bench(block* water) & 2 & 2 & 38 & 0.001026 & 0 & 268 & Infty & $<.0001$ \\
\hline bench(block* water) & 2 & 2 & 48 & 0.01073 & 0 & 268 & Infty & $<.0001$ \\
\hline bench(block*water) & 2 & 2 & 55 & 0.007225 & 0 & 268 & Infty & $<.0001$ \\
\hline bench(block* water) & 2 & 2 & 56 & 0.003496 & 0 & 268 & Infty & $<.0001$ \\
\hline bench(block* water) & 2 & 3 & 34 & 0.01292 & 0 & 268 & Infty & $<.0001$ \\
\hline bench(block* water) & 2 & 3 & 37 & 0.005362 & 0 & 268 & Infty & $<.0001$ \\
\hline bench(block*water) & 2 & 3 & 44 & 0.000711 & 0 & 268 & Infty & $<.0001$ \\
\hline bench(block*water) & 2 & 3 & 45 & 0.01230 & 0 & 268 & Infty & $<.0001$ \\
\hline bench(block* water) & 2 & 3 & 57 & 0.006429 & 0 & 268 & Infty & $<.0001$ \\
\hline bench(block*water) & 2 & 3 & 60 & -0.01220 & 0 & 268 & -Infty & $<.0001$ \\
\hline
\end{tabular}




\begin{tabular}{|l|r|c|r|r|}
\hline \multicolumn{6}{|l|}{ Type 3 Tests of Fixed Effects } \\
\hline Effect & Num DF & Den DF & F Value & Pr > F \\
\hline water & 4 & 54.2 & 57.99 & $<.0001$ \\
\hline herb & 4 & 217 & 86.88 & $<.0001$ \\
\hline water*herb & 16 & 217 & 3.16 & $<.0001$ \\
\hline
\end{tabular}

\begin{tabular}{|l|l|l|r|r|r|r|r|}
\hline \multicolumn{7}{|c|}{ Least Squares Means } \\
\hline Effect & herb & water & Estimate & $\begin{array}{r}\text { Standard } \\
\text { Error }\end{array}$ & $\begin{array}{r}\text { DF } \\
\text { Value }\end{array}$ & $\begin{array}{c}\text { Pr }> \\
\mathbf{t} \mid\end{array}$ \\
\hline water*herb & Basil & 0.5 & 2.0393 & 0.1780 & 1.98 & 11.45 & 0.0078 \\
\hline water*herb & Mint & 0.5 & 1.4006 & 0.1805 & 2.09 & 7.76 & 0.0143 \\
\hline water*herb & Rose & 0.5 & 1.5518 & 0.1780 & 1.98 & 8.72 & 0.0134 \\
\hline water*herb & Sun & 0.5 & 1.5288 & 0.1834 & 2.22 & 8.34 & 0.0102 \\
\hline water*herb & Thyme & 0.5 & 2.6176 & 0.1780 & 1.98 & 14.70 & 0.0048 \\
\hline water*herb & Basil & 1 & 2.7639 & 0.1780 & 1.98 & 15.52 & 0.0043 \\
\hline water*herb & Mint & 1 & 1.9936 & 0.1780 & 1.98 & 11.20 & 0.0082 \\
\hline water*herb & Rose & 1 & 2.3288 & 0.1781 & 1.98 & 13.08 & 0.0061 \\
\hline water*herb & Sun & 1 & 1.9367 & 0.1805 & 2.09 & 10.73 & 0.0074 \\
\hline water*herb & Thyme & 1 & 2.7779 & 0.1780 & 1.98 & 15.60 & 0.0043 \\
\hline water*herb & Basil & 1.5 & 2.9228 & 0.1780 & 1.98 & 16.42 & 0.0039 \\
\hline water*herb & Mint & 1.5 & 2.2972 & 0.1780 & 1.98 & 12.90 & 0.0062 \\
\hline water*herb & Rose & 1.5 & 2.4984 & 0.1780 & 1.98 & 14.03 & 0.0053 \\
\hline water*herb & Sun & 1.5 & 1.9943 & 0.1780 & 1.98 & 11.20 & 0.0082 \\
\hline water*herb & Thyme & 1.5 & 2.9979 & 0.1780 & 1.98 & 16.84 & 0.0037 \\
\hline water*herb & Basil & 2 & 3.0554 & 0.1780 & 1.98 & 17.16 & 0.0036 \\
\hline water*herb & Mint & 2 & 2.3560 & 0.1805 & 2.09 & 13.05 & 0.0049 \\
\hline water*herb & Rose & 2 & 2.6907 & 0.1780 & 1.98 & 15.11 & 0.0046 \\
\hline water*herb & Sun & 2 & 2.1108 & 0.1780 & 1.98 & 11.86 & 0.0073 \\
\hline water*herb & Thyme & 2 & 2.8896 & 0.1780 & 1.98 & 16.23 & 0.0040 \\
\hline water*herb & Basil & 3 & 3.0835 & 0.1780 & 1.98 & 17.32 & 0.0035 \\
\hline water*herb & Mint & 3 & 2.4112 & 0.1805 & 2.09 & 13.36 & 0.0047 \\
\hline water*herb & Rose & 3 & 2.8370 & 0.1780 & 1.98 & 15.93 & 0.0041 \\
\hline
\end{tabular}

\begin{tabular}{|l|l|l|r|r|r|r|c|}
\hline \multicolumn{10}{|c|}{ Least Squares Means } \\
\hline Effect & herb & water & Estimate & $\begin{array}{r}\text { Standard } \\
\text { Error }\end{array}$ & DF & $\begin{array}{r}\mathbf{t} \\
\text { Value }\end{array}$ & $\begin{array}{c}\text { Pr }> \\
|\mathbf{t}|\end{array}$ \\
\hline water*herb & Sun & 3 & 1.8411 & 0.1805 & 2.09 & 10.20 & 0.0082 \\
\hline water*herb & Thyme & 3 & 2.9075 & 0.1780 & 1.98 & 16.33 & 0.0039 \\
\hline
\end{tabular}




\begin{tabular}{|c|c|c|c|c|c|c|c|c|c|}
\hline \multicolumn{10}{|c|}{ Differences of Least Squares Means } \\
\hline Effect & herb & water & herb & water & Estimate & $\begin{array}{r}\text { Standard } \\
\text { Error }\end{array}$ & DF & $\begin{array}{r}\text { t } \\
\text { Value } \\
\end{array}$ & $\begin{array}{c}\operatorname{Pr}> \\
|\mathbf{t}| \\
\end{array}$ \\
\hline water*herb & Basil & 0.5 & Mint & 0.5 & 0.6387 & 0.1420 & 218 & 4.50 & $<.0001$ \\
\hline water*herb & Basil & 0.5 & Rose & 0.5 & 0.4875 & 0.1389 & 214 & 3.51 & 0.0005 \\
\hline water*herb & Basil & 0.5 & Sun & 0.5 & 0.5104 & 0.1457 & 222 & 3.50 & 0.0006 \\
\hline water*herb & Basil & 0.5 & Thyme & 0.5 & -0.5783 & 0.1389 & 214 & -4.16 & $<.0001$ \\
\hline water*herb & Basil & 0.5 & Basil & 1 & -0.7246 & 0.1381 & 267 & -5.25 & $<.0001$ \\
\hline water*herb & Basil & 0.5 & Mint & 1 & 0.04565 & 0.1381 & 267 & 0.33 & 0.7412 \\
\hline water*herb & Basil & 0.5 & Rose & 1 & -0.2895 & 0.1382 & 267 & -2.10 & 0.0371 \\
\hline water*herb & Basil & 0.5 & Sun & 1 & 0.1025 & 0.1413 & 267 & 0.73 & 0.4685 \\
\hline water*herb & Basil & 0.5 & Thyme & 1 & -0.7387 & 0.1381 & 267 & -5.35 & $<.0001$ \\
\hline water*herb & Basil & 0.5 & Basil & 1.5 & -0.8835 & 0.1381 & 267 & -6.40 & $<.0001$ \\
\hline water*herb & Basil & 0.5 & Mint & 1.5 & -0.2580 & 0.1381 & 267 & -1.87 & 0.0629 \\
\hline water*herb & Basil & 0.5 & Rose & 1.5 & -0.4592 & 0.1381 & 267 & -3.32 & 0.0010 \\
\hline water*herb & Basil & 0.5 & Sun & 1.5 & 0.04499 & 0.1381 & 267 & 0.33 & 0.7449 \\
\hline water*herb & Basil & 0.5 & Thyme & 1.5 & -0.9587 & 0.1381 & 267 & -6.94 & $<.0001$ \\
\hline water*herb & Basil & 0.5 & Basil & 2 & -1.0161 & 0.1381 & 267 & -7.36 & $<.0001$ \\
\hline water*herb & Basil & 0.5 & Mint & 2 & -0.3167 & 0.1413 & 267 & -2.24 & 0.0258 \\
\hline water*herb & Basil & 0.5 & Rose & 2 & -0.6515 & 0.1381 & 267 & -4.72 & $<.0001$ \\
\hline water*herb & Basil & 0.5 & Sun & 2 & -0.07155 & 0.1381 & 267 & -0.52 & 0.6049 \\
\hline water*herb & Basil & 0.5 & Thyme & 2 & -0.8504 & 0.1381 & 267 & -6.16 & $<.0001$ \\
\hline water*herb & Basil & 0.5 & Basil & 3 & -1.0442 & 0.1381 & 267 & -7.56 & $<.0001$ \\
\hline water*herb & Basil & 0.5 & Mint & 3 & -0.3719 & 0.1413 & 267 & -2.63 & 0.0090 \\
\hline water*herb & Basil & 0.5 & Rose & 3 & -0.7977 & 0.1381 & 267 & -5.78 & $<.0001$ \\
\hline water*herb & Basil & 0.5 & Sun & 3 & 0.1982 & 0.1413 & 267 & 1.40 & 0.1618 \\
\hline water*herb & Basil & 0.5 & Thyme & 3 & -0.8682 & 0.1381 & 267 & -6.29 & $<.0001$ \\
\hline water*herb & Mint & 0.5 & Rose & 0.5 & -0.1512 & 0.1420 & 218 & -1.06 & 0.2882 \\
\hline water*herb & Mint & 0.5 & Sun & 0.5 & -0.1282 & 0.1487 & 226 & -0.86 & 0.3893 \\
\hline water*herb & Mint & 0.5 & Thyme & 0.5 & -1.2170 & 0.1420 & 218 & -8.57 & $<.0001$ \\
\hline water*herb & Mint & 0.5 & Basil & 1 & -1.3633 & 0.1413 & 267 & -9.65 & $<.0001$ \\
\hline water*herb & Mint & 0.5 & Mint & 1 & -0.5930 & 0.1413 & 267 & -4.20 & $<.0001$ \\
\hline water*herb & Mint & 0.5 & Rose & 1 & -0.9282 & 0.1413 & 267 & -6.57 & $<.0001$ \\
\hline water*herb & Mint & 0.5 & Sun & 1 & -0.5361 & 0.1444 & 267 & -3.71 & 0.0002 \\
\hline
\end{tabular}




\begin{tabular}{|c|c|c|c|c|c|c|c|c|c|}
\hline \multicolumn{10}{|c|}{ Differences of Least Squares Means } \\
\hline Effect & herb & water & herb & water & Estimate & Standard Error & DF & t Value & $\operatorname{Pr}>|\mathbf{t}|$ \\
\hline water*herb & Mint & 0.5 & Thyme & 1 & -1.3774 & 0.1413 & 267 & -9.75 & $<.0001$ \\
\hline water*herb & Mint & 0.5 & Basil & 1.5 & -1.5222 & 0.1413 & 267 & -10.77 & $<.0001$ \\
\hline water*herb & Mint & 0.5 & Mint & 1.5 & -0.8966 & 0.1413 & 267 & -6.35 & $<.0001$ \\
\hline water*herb & Mint & 0.5 & Rose & 1.5 & -1.0979 & 0.1413 & 267 & -7.77 & $<.0001$ \\
\hline water*herb & Mint & 0.5 & Sun & 1.5 & -0.5937 & 0.1413 & 267 & -4.20 & $<.0001$ \\
\hline water*herb & Mint & 0.5 & Thyme & 1.5 & -1.5973 & 0.1413 & 267 & -11.31 & $<.0001$ \\
\hline water*herb & Mint & 0.5 & Basil & 2 & -1.6548 & 0.1413 & 267 & -11.71 & $<.0001$ \\
\hline water*herb & Mint & 0.5 & Mint & 2 & -0.9554 & 0.1443 & 267 & -6.62 & $<.0001$ \\
\hline water*herb & Mint & 0.5 & Rose & 2 & -1.2901 & 0.1413 & 267 & -9.13 & $<.0001$ \\
\hline water*herb & Mint & 0.5 & Sun & 2 & -0.7102 & 0.1413 & 267 & -5.03 & $<.0001$ \\
\hline water*herb & Mint & 0.5 & Thyme & 2 & -1.4890 & 0.1413 & 267 & -10.54 & $<.0001$ \\
\hline water*herb & Mint & 0.5 & Basil & 3 & -1.6829 & 0.1413 & 267 & -11.91 & $<.0001$ \\
\hline water*herb & Mint & 0.5 & Mint & 3 & -1.0106 & 0.1443 & 267 & -7.00 & $<.0001$ \\
\hline water*herb & Mint & 0.5 & Rose & 3 & -1.4364 & 0.1413 & 267 & -10.17 & $<.0001$ \\
\hline water*herb & Mint & 0.5 & Sun & 3 & -0.4405 & 0.1443 & 267 & -3.05 & 0.0025 \\
\hline water*herb & Mint & 0.5 & Thyme & 3 & -1.5069 & 0.1413 & 267 & -10.67 & $<.0001$ \\
\hline water*herb & Rose & 0.5 & Sun & 0.5 & 0.02297 & 0.1457 & 222 & 0.16 & 0.8749 \\
\hline water*herb & Rose & 0.5 & Thyme & 0.5 & -1.0658 & 0.1389 & 214 & -7.67 & $<.0001$ \\
\hline water*herb & Rose & 0.5 & Basil & 1 & -1.2121 & 0.1381 & 267 & -8.78 & $<.0001$ \\
\hline water*herb & Rose & 0.5 & Mint & 1 & -0.4418 & 0.1381 & 267 & -3.20 & 0.0015 \\
\hline water*herb & Rose & 0.5 & Rose & 1 & -0.7770 & 0.1382 & 267 & -5.62 & $<.0001$ \\
\hline water*herb & Rose & 0.5 & Sun & 1 & -0.3849 & 0.1413 & 267 & -2.72 & 0.0069 \\
\hline water*herb & Rose & 0.5 & Thyme & 1 & -1.2262 & 0.1381 & 267 & -8.88 & $<.0001$ \\
\hline water*herb & Rose & 0.5 & Basil & 1.5 & -1.3710 & 0.1381 & 267 & -9.93 & $<.0001$ \\
\hline water*herb & Rose & 0.5 & Mint & 1.5 & -0.7454 & 0.1381 & 267 & -5.40 & $<.0001$ \\
\hline water*herb & Rose & 0.5 & Rose & 1.5 & -0.9467 & 0.1381 & 267 & -6.85 & $<.0001$ \\
\hline water*herb & Rose & 0.5 & Sun & 1.5 & -0.4425 & 0.1381 & 267 & -3.20 & 0.0015 \\
\hline water*herb & Rose & 0.5 & Thyme & 1.5 & -1.4461 & 0.1381 & 267 & -10.47 & $<.0001$ \\
\hline water*herb & Rose & 0.5 & Basil & 2 & -1.5036 & 0.1381 & 267 & -10.89 & $<.0001$ \\
\hline water*herb & Rose & 0.5 & Mint & 2 & -0.8042 & 0.1413 & 267 & -5.69 & $<.0001$ \\
\hline water*herb & Rose & 0.5 & Rose & 2 & -1.1389 & 0.1381 & 267 & -8.25 & $<.0001$ \\
\hline
\end{tabular}




\begin{tabular}{|c|c|c|c|c|c|c|c|c|c|}
\hline \multicolumn{10}{|c|}{ Differences of Least Squares Means } \\
\hline Effect & herb & water & herb & water & Estimate & $\begin{array}{r}\text { Standard } \\
\text { Error }\end{array}$ & DF & $\begin{array}{r}\text { t } \\
\text { Value } \\
\end{array}$ & $\begin{array}{c}\operatorname{Pr}> \\
|t| \\
\end{array}$ \\
\hline water*herb & Rose & 0.5 & Sun & 2 & -0.5590 & 0.1381 & 267 & -4.05 & $<.0001$ \\
\hline water*herb & Rose & 0.5 & Thyme & 2 & -1.3378 & 0.1381 & 267 & -9.69 & $<.0001$ \\
\hline water*herb & Rose & 0.5 & Basil & 3 & -1.5317 & 0.1381 & 267 & 11.09 & $<.0001$ \\
\hline water*herb & Rose & 0.5 & Mint & 3 & -0.8594 & 0.1413 & 267 & -6.08 & $<.0001$ \\
\hline water*herb & Rose & 0.5 & Rose & 3 & -1.2852 & 0.1381 & 267 & -9.31 & $<.0001$ \\
\hline water*herb & Rose & 0.5 & Sun & 3 & -0.2893 & 0.1413 & 267 & -2.05 & 0.0416 \\
\hline water*herb & Rose & 0.5 & Thyme & 3 & -1.3557 & 0.1381 & 267 & -9.82 & $<.0001$ \\
\hline water*herb & Sun & 0.5 & Thyme & 0.5 & -1.0888 & 0.1457 & 222 & -7.47 & $<.0001$ \\
\hline water*herb & Sun & 0.5 & Basil & 1 & -1.2351 & 0.1450 & 267 & -8.52 & $<.0001$ \\
\hline water*herb & Sun & 0.5 & Mint & 1 & -0.4648 & 0.1450 & 267 & -3.21 & 0.0015 \\
\hline water*herb & Sun & 0.5 & Rose & 1 & -0.7999 & 0.1450 & 267 & -5.52 & $<.0001$ \\
\hline water*herb & Sun & 0.5 & Sun & 1 & -0.4079 & 0.1480 & 267 & -2.76 & 0.0062 \\
\hline water*herb & Sun & 0.5 & Thyme & 1 & -1.2491 & 0.1450 & 267 & -8.62 & $<.0001$ \\
\hline water*herb & Sun & 0.5 & Basil & 1.5 & -1.3940 & 0.1450 & 267 & -9.62 & $<.0001$ \\
\hline water*herb & Sun & 0.5 & Mint & 1.5 & -0.7684 & 0.1450 & 267 & -5.30 & $<.0001$ \\
\hline water*herb & Sun & 0.5 & Rose & 1.5 & -0.9696 & 0.1450 & 267 & -6.69 & $<.0001$ \\
\hline water*herb & Sun & 0.5 & Sun & 1.5 & -0.4655 & 0.1450 & 267 & -3.21 & 0.0015 \\
\hline water*herb & Sun & 0.5 & Thyme & 1.5 & -1.4691 & 0.1450 & 267 & $10.13^{-}$ & $<.0001$ \\
\hline water*herb & Sun & 0.5 & Basil & 2 & -1.5266 & 0.1450 & 267 & $10.53^{-}$ & $<.0001$ \\
\hline water*herb & Sun & 0.5 & Mint & 2 & -0.8271 & 0.1480 & 267 & -5.59 & $<.0001$ \\
\hline water*herb & Sun & 0.5 & Rose & 2 & -1.1619 & 0.1450 & 267 & -8.02 & $<.0001$ \\
\hline water*herb & Sun & 0.5 & Sun & 2 & -0.5820 & 0.1450 & 267 & -4.02 & $<.0001$ \\
\hline water*herb & Sun & 0.5 & Thyme & 2 & -1.3608 & 0.1450 & 267 & -9.39 & $<.0001$ \\
\hline water*herb & Sun & 0.5 & Basil & 3 & -1.5546 & 0.1450 & 267 & $10.73^{-}$ & $<.0001$ \\
\hline water*herb & Sun & 0.5 & Mint & 3 & -0.8824 & 0.1480 & 267 & -5.96 & $<.0001$ \\
\hline water*herb & Sun & 0.5 & Rose & 3 & -1.3082 & 0.1450 & 267 & -9.02 & $<.0001$ \\
\hline water*herb & Sun & 0.5 & Sun & 3 & -0.3122 & 0.1480 & 267 & -2.11 & 0.0358 \\
\hline water*herb & Sun & 0.5 & Thyme & 3 & -1.3786 & 0.1450 & 267 & -9.51 & $<.0001$ \\
\hline water*herb & Thyme & 0.5 & Basil & 1 & -0.1463 & 0.1381 & 267 & -1.06 & 0.2904 \\
\hline water*herb & Thyme & 0.5 & Mint & 1 & 0.6240 & 0.1381 & 267 & 4.52 & $<.0001$ \\
\hline water*herb & Thyme & 0.5 & Rose & 1 & 0.2888 & 0.1382 & 267 & 2.09 & 0.0375 \\
\hline
\end{tabular}




\begin{tabular}{|c|c|c|c|c|c|c|c|c|c|}
\hline \multicolumn{10}{|c|}{ Differences of Least Squares Means } \\
\hline Effect & herb & water & herb & water & Estimate & $\begin{array}{r}\text { Standard } \\
\text { Error }\end{array}$ & DF & $\begin{array}{r}\text { t } \\
\text { Value } \\
\end{array}$ & $\begin{array}{c}\operatorname{Pr}> \\
|\mathbf{t}| \\
\end{array}$ \\
\hline water*herb & Thyme & 0.5 & Sun & 1 & 0.6809 & 0.1413 & 267 & 4.82 & $<.0001$ \\
\hline water*herb & Thyme & 0.5 & Thyme & 1 & -0.1604 & 0.1381 & 267 & -1.16 & 0.2466 \\
\hline water*herb & Thyme & 0.5 & Basil & 1.5 & -0.3052 & 0.1381 & 267 & -2.21 & 0.0280 \\
\hline water*herb & Thyme & 0.5 & Mint & 1.5 & 0.3204 & 0.1381 & 267 & 2.32 & 0.0211 \\
\hline water*herb & Thyme & 0.5 & Rose & 1.5 & 0.1191 & 0.1381 & 267 & 0.86 & 0.3892 \\
\hline water*herb & Thyme & 0.5 & Sun & 1.5 & 0.6233 & 0.1381 & 267 & 4.51 & $<.0001$ \\
\hline water*herb & Thyme & 0.5 & Thyme & 1.5 & -0.3803 & 0.1381 & 267 & -2.75 & 0.0063 \\
\hline water*herb & Thyme & 0.5 & Basil & 2 & -0.4378 & 0.1381 & 267 & -3.17 & 0.0017 \\
\hline water*herb & Thyme & 0.5 & Mint & 2 & 0.2616 & 0.1413 & 267 & 1.85 & 0.0652 \\
\hline water*herb & Thyme & 0.5 & Rose & 2 & -0.07314 & 0.1381 & 267 & -0.53 & 0.5968 \\
\hline water*herb & Thyme & 0.5 & Sun & 2 & 0.5068 & 0.1381 & 267 & 3.67 & 0.0003 \\
\hline water*herb & Thyme & 0.5 & Thyme & 2 & -0.2721 & 0.1381 & 267 & -1.97 & 0.0499 \\
\hline water*herb & Thyme & 0.5 & Basil & 3 & -0.4659 & 0.1381 & 267 & -3.37 & 0.0009 \\
\hline water*herb & Thyme & 0.5 & Mint & 3 & 0.2064 & 0.1413 & 267 & 1.46 & 0.1452 \\
\hline water*herb & Thyme & 0.5 & Rose & 3 & -0.2194 & 0.1381 & 267 & -1.59 & 0.1133 \\
\hline water*herb & Thyme & 0.5 & Sun & 3 & 0.7765 & 0.1413 & 267 & 5.50 & $<.0001$ \\
\hline water*herb & Thyme & 0.5 & Thyme & 3 & -0.2899 & 0.1381 & 267 & -2.10 & 0.0368 \\
\hline water*herb & Basil & 1 & Mint & 1 & 0.7703 & 0.1389 & 214 & 5.55 & $<.0001$ \\
\hline water*herb & Basil & 1 & Rose & 1 & 0.4351 & 0.1389 & 221 & 3.13 & 0.0020 \\
\hline water*herb & Basil & 1 & Sun & 1 & 0.8272 & 0.1420 & 218 & 5.82 & $<.0001$ \\
\hline water*herb & Basil & 1 & Thyme & 1 & -0.01407 & 0.1389 & 214 & -0.10 & 0.9194 \\
\hline water*herb & Basil & 1 & Basil & 1.5 & -0.1589 & 0.1381 & 267 & -1.15 & 0.2510 \\
\hline water*herb & Basil & 1 & Mint & 1.5 & 0.4667 & 0.1381 & 267 & 3.38 & 0.0008 \\
\hline water*herb & Basil & 1 & Rose & 1.5 & 0.2654 & 0.1381 & 267 & 1.92 & 0.0557 \\
\hline water*herb & Basil & 1 & Sun & 1.5 & 0.7696 & 0.1381 & 267 & 5.57 & $<.0001$ \\
\hline water*herb & Basil & 1 & Thyme & 1.5 & -0.2340 & 0.1381 & 267 & -1.69 & 0.0913 \\
\hline water*herb & Basil & 1 & Basil & 2 & -0.2915 & 0.1381 & 267 & -2.11 & 0.0357 \\
\hline water*herb & Basil & 1 & Mint & 2 & 0.4079 & 0.1413 & 267 & 2.89 & 0.0042 \\
\hline water*herb & Basil & 1 & Rose & 2 & 0.07316 & 0.1381 & 267 & 0.53 & 0.5968 \\
\hline water*herb & Basil & 1 & Sun & 2 & 0.6531 & 0.1381 & 267 & 4.73 & $<.0001$ \\
\hline water*herb & Basil & 1 & Thyme & 2 & -0.1257 & 0.1381 & 267 & -0.91 & 0.3634 \\
\hline
\end{tabular}




\begin{tabular}{|c|c|c|c|c|c|c|c|c|c|}
\hline \multicolumn{10}{|c|}{ Differences of Least Squares Means } \\
\hline Effect & herb & water & herb & water & Estimate & $\begin{array}{r}\text { Standard } \\
\text { Error }\end{array}$ & DF & $\begin{array}{r}\text { t } \\
\text { Value } \\
\end{array}$ & $\begin{array}{c}\operatorname{Pr}> \\
|\mathbf{t}| \\
\end{array}$ \\
\hline water*herb & Basil & 1 & Basil & 3 & -0.3196 & 0.1381 & 267 & -2.31 & 0.0214 \\
\hline water*herb & Basil & 1 & Mint & 3 & 0.3527 & 0.1413 & 267 & 2.50 & 0.0131 \\
\hline water*herb & Basil & 1 & Rose & 3 & -0.07310 & 0.1381 & 267 & -0.53 & 0.5970 \\
\hline water*herb & Basil & 1 & Sun & 3 & 0.9228 & 0.1413 & 267 & 6.53 & $<.0001$ \\
\hline water*herb & Basil & 1 & Thyme & 3 & -0.1436 & 0.1381 & 267 & -1.04 & 0.2994 \\
\hline water*herb & Mint & 1 & Rose & 1 & -0.3351 & 0.1389 & 221 & -2.41 & 0.0167 \\
\hline water*herb & Mint & 1 & Sun & 1 & 0.05690 & 0.1420 & 218 & 0.40 & 0.6891 \\
\hline water*herb & Mint & 1 & Thyme & 1 & -0.7843 & 0.1389 & 214 & -5.65 & $<.0001$ \\
\hline water*herb & Mint & 1 & Basil & 1.5 & -0.9292 & 0.1381 & 267 & -6.73 & $<.0001$ \\
\hline water*herb & Mint & 1 & Mint & 1.5 & -0.3036 & 0.1381 & 267 & -2.20 & 0.0288 \\
\hline water*herb & Mint & 1 & Rose & 1.5 & -0.5048 & 0.1381 & 267 & -3.66 & 0.0003 \\
\hline water*herb & Mint & 1 & Sun & 1.5 & -0.00067 & 0.1381 & 267 & -0.00 & 0.9962 \\
\hline water*herb & Mint & 1 & Thyme & 1.5 & -1.0043 & 0.1381 & 267 & -7.27 & $<.0001$ \\
\hline water*herb & Mint & 1 & Basil & 2 & -1.0618 & 0.1381 & 267 & -7.69 & $<.0001$ \\
\hline water*herb & Mint & 1 & Mint & 2 & -0.3624 & 0.1413 & 267 & -2.56 & 0.0109 \\
\hline water*herb & Mint & 1 & Rose & 2 & -0.6971 & 0.1381 & 267 & -5.05 & $<.0001$ \\
\hline water*herb & Mint & 1 & Sun & 2 & -0.1172 & 0.1381 & 267 & -0.85 & 0.3969 \\
\hline water*herb & Mint & 1 & Thyme & 2 & -0.8960 & 0.1381 & 267 & -6.49 & $<.0001$ \\
\hline water*herb & Mint & 1 & Basil & 3 & -1.0898 & 0.1381 & 267 & -7.89 & $<.0001$ \\
\hline water*herb & Mint & 1 & Mint & 3 & -0.4176 & 0.1413 & 267 & -2.96 & 0.0034 \\
\hline water*herb & Mint & 1 & Rose & 3 & -0.8434 & 0.1381 & 267 & -6.11 & $<.0001$ \\
\hline water*herb & Mint & 1 & Sun & 3 & 0.1525 & 0.1413 & 267 & 1.08 & 0.2812 \\
\hline water*herb & Mint & 1 & Thyme & 3 & -0.9139 & 0.1381 & 267 & -6.62 & $<.0001$ \\
\hline water*herb & Rose & 1 & Sun & 1 & 0.3920 & 0.1421 & 225 & 2.76 & 0.0063 \\
\hline water*herb & Rose & 1 & Thyme & 1 & -0.4492 & 0.1389 & 221 & -3.23 & 0.0014 \\
\hline water*herb & Rose & 1 & Basil & 1.5 & -0.5940 & 0.1382 & 267 & -4.30 & $<.0001$ \\
\hline water*herb & Rose & 1 & Mint & 1.5 & 0.03154 & 0.1382 & 267 & 0.23 & 0.8196 \\
\hline water*herb & Rose & 1 & Rose & 1.5 & -0.1697 & 0.1382 & 267 & -1.23 & 0.2204 \\
\hline water*herb & Rose & 1 & Sun & 1.5 & 0.3345 & 0.1382 & 267 & 2.42 & 0.0161 \\
\hline water*herb & Rose & 1 & Thyme & 1.5 & -0.6692 & 0.1382 & 267 & -4.84 & $<.0001$ \\
\hline water*herb & Rose & 1 & Basil & 2 & -0.7266 & 0.1382 & 267 & -5.26 & $<.0001$ \\
\hline
\end{tabular}




\begin{tabular}{|c|c|c|c|c|c|c|c|c|c|}
\hline \multicolumn{10}{|c|}{ Differences of Least Squares Means } \\
\hline Effect & herb & water & herb & water & Estimate & $\begin{array}{r}\text { Standard } \\
\text { Error }\end{array}$ & DF & $\begin{array}{r}\text { t } \\
\text { Value }\end{array}$ & $\begin{array}{c}\operatorname{Pr}> \\
|t|\end{array}$ \\
\hline water*herb & Rose & 1 & Mint & 2 & -0.02721 & 0.1413 & 267 & -0.19 & 0.8475 \\
\hline water*herb & Rose & 1 & Rose & 2 & -0.3620 & 0.1382 & 267 & -2.62 & 0.0093 \\
\hline water*herb & Rose & 1 & Sun & 2 & 0.2179 & 0.1382 & 267 & 1.58 & 0.1159 \\
\hline water*herb & Rose & 1 & Thyme & 2 & -0.5609 & 0.1382 & 267 & -4.06 & $<.0001$ \\
\hline water*herb & Rose & 1 & Basil & 3 & -0.7547 & 0.1382 & 267 & -5.46 & $<.0001$ \\
\hline water*herb & Rose & 1 & Mint & 3 & -0.08243 & 0.1413 & 267 & -0.58 & 0.5602 \\
\hline water*herb & Rose & 1 & Rose & 3 & -0.5082 & 0.1382 & 267 & -3.68 & 0.0003 \\
\hline water*herb & Rose & 1 & Sun & 3 & 0.4877 & 0.1413 & 267 & 3.45 & 0.0006 \\
\hline water*herb & Rose & 1 & Thyme & 3 & -0.5787 & 0.1382 & 267 & -4.19 & $<.0001$ \\
\hline water*herb & Sun & 1 & Thyme & 1 & -0.8412 & 0.1420 & 218 & -5.92 & $<.0001$ \\
\hline water*herb & Sun & 1 & Basil & 1.5 & -0.9861 & 0.1413 & 267 & -6.98 & $<.0001$ \\
\hline water*herb & Sun & 1 & Mint & 1.5 & -0.3605 & 0.1413 & 267 & -2.55 & 0.0113 \\
\hline water*herb & Sun & 1 & Rose & 1.5 & -0.5617 & 0.1413 & 267 & -3.98 & $<.0001$ \\
\hline water*herb & Sun & 1 & Sun & 1.5 & -0.05756 & 0.1413 & 267 & -0.41 & 0.6840 \\
\hline water*herb & Sun & 1 & Thyme & 1.5 & -1.0612 & 0.1413 & 267 & -7.51 & $<.0001$ \\
\hline water*herb & Sun & 1 & Basil & 2 & -1.1187 & 0.1413 & 267 & -7.92 & $<.0001$ \\
\hline water*herb & Sun & 1 & Mint & 2 & -0.4193 & 0.1444 & 267 & -2.90 & 0.0040 \\
\hline water*herb & Sun & 1 & Rose & 2 & -0.7540 & 0.1413 & 267 & -5.34 & $<.0001$ \\
\hline water*herb & Sun & 1 & Sun & 2 & -0.1741 & 0.1413 & 267 & -1.23 & 0.2189 \\
\hline water*herb & Sun & 1 & Thyme & 2 & -0.9529 & 0.1413 & 267 & -6.75 & $<.0001$ \\
\hline water*herb & Sun & 1 & Basil & 3 & -1.1467 & 0.1413 & 267 & -8.12 & $<.0001$ \\
\hline water*herb & Sun & 1 & Mint & 3 & -0.4745 & 0.1444 & 267 & -3.29 & 0.0012 \\
\hline water*herb & Sun & 1 & Rose & 3 & -0.9003 & 0.1413 & 267 & -6.37 & $<.0001$ \\
\hline water*herb & Sun & 1 & Sun & 3 & 0.09565 & 0.1444 & 267 & 0.66 & 0.5083 \\
\hline water*herb & Sun & 1 & Thyme & 3 & -0.9708 & 0.1413 & 267 & -6.87 & $<.0001$ \\
\hline water*herb & Thyme & 1 & Basil & 1.5 & -0.1448 & 0.1381 & 267 & -1.05 & 0.2953 \\
\hline water*herb & Thyme & 1 & Mint & 1.5 & 0.4807 & 0.1381 & 267 & 3.48 & 0.0006 \\
\hline water*herb & Thyme & 1 & Rose & 1.5 & 0.2795 & 0.1381 & 267 & 2.02 & 0.0440 \\
\hline water*herb & Thyme & 1 & Sun & 1.5 & 0.7837 & 0.1381 & 267 & 5.67 & $<.0001$ \\
\hline water*herb & Thyme & 1 & Thyme & 1.5 & -0.2200 & 0.1381 & 267 & -1.59 & 0.1124 \\
\hline water*herb & Thyme & 1 & Basil & 2 & -0.2775 & 0.1381 & 267 & -2.01 & 0.0455 \\
\hline
\end{tabular}




\begin{tabular}{|c|c|c|c|c|c|c|c|c|c|}
\hline \multicolumn{10}{|c|}{ Differences of Least Squares Means } \\
\hline Effect & herb & water & herb & water & Estimate & $\begin{array}{r}\text { Standard } \\
\text { Error }\end{array}$ & DF & $\begin{array}{r}\text { t } \\
\text { Value }\end{array}$ & $\begin{array}{c}\operatorname{Pr}> \\
|t|\end{array}$ \\
\hline water*herb & Thyme & 1 & Mint & 2 & 0.4220 & 0.1413 & 267 & 2.99 & 0.0031 \\
\hline water*herb & Thyme & 1 & Rose & 2 & 0.08723 & 0.1381 & 267 & 0.63 & 0.5282 \\
\hline water*herb & Thyme & 1 & Sun & 2 & 0.6671 & 0.1381 & 267 & 4.83 & $<.0001$ \\
\hline water*herb & Thyme & 1 & Thyme & 2 & -0.1117 & 0.1381 & 267 & -0.81 & 0.4194 \\
\hline water*herb & Thyme & 1 & Basil & 3 & -0.3055 & 0.1381 & 267 & -2.21 & 0.0278 \\
\hline water*herb & Thyme & 1 & Mint & 3 & 0.3668 & 0.1413 & 267 & 2.60 & 0.0100 \\
\hline water*herb & Thyme & 1 & Rose & 3 & -0.05904 & 0.1381 & 267 & -0.43 & 0.6694 \\
\hline water*herb & Thyme & 1 & Sun & 3 & 0.9369 & 0.1413 & 267 & 6.63 & $<.0001$ \\
\hline water*herb & Thyme & 1 & Thyme & 3 & -0.1295 & 0.1381 & 267 & -0.94 & 0.3492 \\
\hline water*herb & Basil & 1.5 & Mint & 1.5 & 0.6256 & 0.1389 & 214 & 4.50 & $<.0001$ \\
\hline water*herb & Basil & 1.5 & Rose & 1.5 & 0.4243 & 0.1389 & 214 & 3.06 & 0.0025 \\
\hline water*herb & Basil & 1.5 & Sun & 1.5 & 0.9285 & 0.1389 & 214 & 6.69 & $<.0001$ \\
\hline water*herb & Basil & 1.5 & Thyme & 1.5 & -0.07515 & 0.1389 & 214 & -0.54 & 0.5890 \\
\hline water*herb & Basil & 1.5 & Basil & 2 & -0.1326 & 0.1381 & 267 & -0.96 & 0.3378 \\
\hline water*herb & Basil & 1.5 & Mint & 2 & 0.5668 & 0.1413 & 267 & 4.01 & $<.0001$ \\
\hline water*herb & Basil & 1.5 & Rose & 2 & 0.2321 & 0.1381 & 267 & 1.68 & 0.0941 \\
\hline water*herb & Basil & 1.5 & Sun & 2 & 0.8120 & 0.1381 & 267 & 5.88 & $<.0001$ \\
\hline water*herb & Basil & 1.5 & Thyme & 2 & 0.03315 & 0.1381 & 267 & 0.24 & 0.8105 \\
\hline water*herb & Basil & 1.5 & Basil & 3 & -0.1607 & 0.1381 & 267 & -1.16 & 0.2457 \\
\hline water*herb & Basil & 1.5 & Mint & 3 & 0.5116 & 0.1413 & 267 & 3.62 & 0.0004 \\
\hline water*herb & Basil & 1.5 & Rose & 3 & 0.08580 & 0.1381 & 267 & 0.62 & 0.5350 \\
\hline water*herb & Basil & 1.5 & Sun & 3 & 1.0817 & 0.1413 & 267 & 7.66 & $<.0001$ \\
\hline water*herb & Basil & 1.5 & Thyme & 3 & 0.01531 & 0.1381 & 267 & 0.11 & 0.9118 \\
\hline water*herb & Mint & 1.5 & Rose & 1.5 & -0.2012 & 0.1389 & 214 & -1.45 & 0.1488 \\
\hline water*herb & Mint & 1.5 & Sun & 1.5 & 0.3029 & 0.1389 & 214 & 2.18 & 0.0302 \\
\hline water*herb & Mint & 1.5 & Thyme & 1.5 & -0.7007 & 0.1389 & 214 & -5.05 & $<.0001$ \\
\hline water*herb & Mint & 1.5 & Basil & 2 & -0.7582 & 0.1381 & 267 & -5.49 & $<.0001$ \\
\hline water*herb & Mint & 1.5 & Mint & 2 & -0.05875 & 0.1413 & 267 & -0.42 & 0.6778 \\
\hline water*herb & Mint & 1.5 & Rose & 2 & -0.3935 & 0.1381 & 267 & -2.85 & 0.0047 \\
\hline water*herb & Mint & 1.5 & Sun & 2 & 0.1864 & 0.1381 & 267 & 1.35 & 0.1783 \\
\hline water*herb & Mint & 1.5 & Thyme & 2 & -0.5924 & 0.1381 & 267 & -4.29 & $<.0001$ \\
\hline
\end{tabular}




\begin{tabular}{|c|c|c|c|c|c|c|c|c|c|}
\hline \multicolumn{10}{|c|}{ Differences of Least Squares Means } \\
\hline Effect & herb & water & herb & water & Estimate & $\begin{array}{r}\text { Standard } \\
\text { Error }\end{array}$ & DF & Value & $\begin{array}{c}\operatorname{Pr}> \\
|\mathbf{t}|\end{array}$ \\
\hline water*herb & Mint & 1.5 & Basil & 3 & -0.7862 & 0.1381 & 267 & -5.69 & $<.0001$ \\
\hline water*herb & Mint & 1.5 & Mint & 3 & -0.1140 & 0.1413 & 267 & -0.81 & 0.4205 \\
\hline water*herb & Mint & 1.5 & Rose & 3 & -0.5398 & 0.1381 & 267 & -3.91 & 0.0001 \\
\hline water*herb & Mint & 1.5 & Sun & 3 & 0.4562 & 0.1413 & 267 & 3.23 & 0.0014 \\
\hline water*herb & Mint & 1.5 & Thyme & 3 & -0.6103 & 0.1381 & 267 & -4.42 & $<.0001$ \\
\hline water*herb & Rose & 1.5 & Sun & 1.5 & 0.5042 & 0.1389 & 214 & 3.63 & 0.0004 \\
\hline water*herb & Rose & 1.5 & Thyme & 1.5 & -0.4995 & 0.1389 & 214 & -3.60 & 0.0004 \\
\hline water*herb & Rose & 1.5 & Basil & 2 & -0.5570 & 0.1381 & 267 & -4.03 & $<.0001$ \\
\hline water*herb & Rose & 1.5 & Mint & 2 & 0.1425 & 0.1413 & 267 & 1.01 & 0.3141 \\
\hline water*herb & Rose & 1.5 & Rose & 2 & -0.1923 & 0.1381 & 267 & -1.39 & 0.1650 \\
\hline water*herb & Rose & 1.5 & Sun & 2 & 0.3876 & 0.1381 & 267 & 2.81 & 0.0054 \\
\hline water*herb & Rose & 1.5 & Thyme & 2 & -0.3912 & 0.1381 & 267 & -2.83 & 0.0050 \\
\hline water*herb & Rose & 1.5 & Basil & 3 & -0.5850 & 0.1381 & 267 & -4.24 & $<.0001$ \\
\hline water*herb & Rose & 1.5 & Mint & 3 & 0.08726 & 0.1413 & 267 & 0.62 & 0.5373 \\
\hline water*herb & Rose & 1.5 & Rose & 3 & -0.3385 & 0.1381 & 267 & -2.45 & 0.0149 \\
\hline water*herb & Rose & 1.5 & Sun & 3 & 0.6574 & 0.1413 & 267 & 4.65 & $<.0001$ \\
\hline water*herb & Rose & 1.5 & Thyme & 3 & -0.4090 & 0.1381 & 267 & -2.96 & 0.0033 \\
\hline water*herb & Sun & 1.5 & Thyme & 1.5 & -1.0036 & 0.1389 & 214 & -7.23 & $<.0001$ \\
\hline water*herb & Sun & 1.5 & Basil & 2 & -1.0611 & 0.1381 & 267 & -7.68 & $<.0001$ \\
\hline water*herb & Sun & 1.5 & Mint & 2 & -0.3617 & 0.1413 & 267 & -2.56 & 0.0110 \\
\hline water*herb & Sun & 1.5 & Rose & 2 & -0.6964 & 0.1381 & 267 & -5.04 & $<.0001$ \\
\hline water*herb & Sun & 1.5 & Sun & 2 & -0.1165 & 0.1381 & 267 & -0.84 & 0.3996 \\
\hline water*herb & Sun & 1.5 & Thyme & 2 & -0.8954 & 0.1381 & 267 & -6.48 & $<.0001$ \\
\hline water*herb & Sun & 1.5 & Basil & 3 & -1.0892 & 0.1381 & 267 & -7.89 & $<.0001$ \\
\hline water*herb & Sun & 1.5 & Mint & 3 & -0.4169 & 0.1413 & 267 & -2.95 & 0.0034 \\
\hline water*herb & Sun & 1.5 & Rose & 3 & -0.8427 & 0.1381 & 267 & -6.10 & $<.0001$ \\
\hline water*herb & Sun & 1.5 & Sun & 3 & 0.1532 & 0.1413 & 267 & 1.08 & 0.2791 \\
\hline water*herb & Sun & 1.5 & Thyme & 3 & -0.9132 & 0.1381 & 267 & -6.61 & $<.0001$ \\
\hline water*herb & Thyme & 1.5 & Basil & 2 & -0.05748 & 0.1381 & 267 & -0.42 & 0.6776 \\
\hline water*herb & Thyme & 1.5 & Mint & 2 & 0.6420 & 0.1413 & 267 & 4.54 & $<.0001$ \\
\hline water*herb & Thyme & 1.5 & Rose & 2 & 0.3072 & 0.1381 & 267 & 2.22 & 0.0270 \\
\hline
\end{tabular}




\begin{tabular}{|c|c|c|c|c|c|c|c|c|c|}
\hline \multicolumn{10}{|c|}{ Differences of Least Squares Means } \\
\hline Effect & herb & water & herb & water & Estimate & $\begin{array}{r}\text { Standard } \\
\text { Error }\end{array}$ & DF & Value & $\begin{array}{c}\operatorname{Pr}> \\
|\mathbf{t}|\end{array}$ \\
\hline water*herb & Thyme & 1.5 & Sun & 2 & 0.8871 & 0.1381 & 267 & 6.42 & $<.0001$ \\
\hline water*herb & Thyme & 1.5 & Thyme & 2 & 0.1083 & 0.1381 & 267 & 0.78 & 0.4337 \\
\hline water*herb & Thyme & 1.5 & Basil & 3 & -0.08554 & 0.1381 & 267 & -0.62 & 0.5362 \\
\hline water*herb & Thyme & 1.5 & Mint & 3 & 0.5867 & 0.1413 & 267 & 4.15 & $<.0001$ \\
\hline water*herb & Thyme & 1.5 & Rose & 3 & 0.1609 & 0.1381 & 267 & 1.17 & 0.2449 \\
\hline water*herb & Thyme & 1.5 & Sun & 3 & 1.1569 & 0.1413 & 267 & 8.19 & $<.0001$ \\
\hline water*herb & Thyme & 1.5 & Thyme & 3 & 0.09045 & 0.1381 & 267 & 0.65 & 0.5131 \\
\hline water*herb & Basil & 2 & Mint & 2 & 0.6994 & 0.1420 & 218 & 4.92 & $<.0001$ \\
\hline water*herb & Basil & 2 & Rose & 2 & 0.3647 & 0.1389 & 214 & 2.63 & 0.0093 \\
\hline water*herb & Basil & 2 & Sun & 2 & 0.9446 & 0.1389 & 214 & 6.80 & $<.0001$ \\
\hline water*herb & Basil & 2 & Thyme & 2 & 0.1658 & 0.1389 & 214 & 1.19 & 0.2339 \\
\hline water*herb & Basil & 2 & Basil & 3 & -0.02805 & 0.1381 & 267 & -0.20 & 0.8392 \\
\hline water*herb & Basil & 2 & Mint & 3 & 0.6442 & 0.1413 & 267 & 4.56 & $<.0001$ \\
\hline water*herb & Basil & 2 & Rose & 3 & 0.2184 & 0.1381 & 267 & 1.58 & 0.1149 \\
\hline water*herb & Basil & 2 & Sun & 3 & 1.2143 & 0.1413 & 267 & 8.60 & $<.0001$ \\
\hline water*herb & Basil & 2 & Thyme & 3 & 0.1479 & 0.1381 & 267 & 1.07 & 0.2851 \\
\hline water*herb & Mint & 2 & Rose & 2 & -0.3348 & 0.1420 & 218 & -2.36 & 0.0193 \\
\hline water*herb & Mint & 2 & Sun & 2 & 0.2452 & 0.1420 & 218 & 1.73 & 0.0857 \\
\hline water*herb & Mint & 2 & Thyme & 2 & -0.5337 & 0.1420 & 218 & -3.76 & 0.0002 \\
\hline water*herb & Mint & 2 & Basil & 3 & -0.7275 & 0.1413 & 267 & -5.15 & $<.0001$ \\
\hline water*herb & Mint & 2 & Mint & 3 & -0.05522 & 0.1443 & 267 & -0.38 & 0.7023 \\
\hline water*herb & Mint & 2 & Rose & 3 & -0.4810 & 0.1413 & 267 & -3.40 & 0.0008 \\
\hline water*herb & Mint & 2 & Sun & 3 & 0.5149 & 0.1443 & 267 & 3.57 & 0.0004 \\
\hline water*herb & Mint & 2 & Thyme & 3 & -0.5515 & 0.1413 & 267 & -3.90 & 0.0001 \\
\hline water*herb & Rose & 2 & Sun & 2 & 0.5799 & 0.1389 & 214 & 4.18 & $<.0001$ \\
\hline water*herb & Rose & 2 & Thyme & 2 & -0.1989 & 0.1389 & 214 & -1.43 & 0.1535 \\
\hline water*herb & Rose & 2 & Basil & 3 & -0.3927 & 0.1381 & 267 & -2.84 & 0.0048 \\
\hline water*herb & Rose & 2 & Mint & 3 & 0.2795 & 0.1413 & 267 & 1.98 & 0.0489 \\
\hline water*herb & Rose & 2 & Rose & 3 & -0.1463 & 0.1381 & 267 & -1.06 & 0.2906 \\
\hline water*herb & Rose & 2 & Sun & 3 & 0.8497 & 0.1413 & 267 & 6.01 & $<.0001$ \\
\hline water*herb & Rose & 2 & Thyme & 3 & -0.2168 & 0.1381 & 267 & -1.57 & 0.1177 \\
\hline
\end{tabular}




\begin{tabular}{|c|c|c|c|c|c|c|c|c|c|}
\hline \multicolumn{10}{|c|}{ Differences of Least Squares Means } \\
\hline Effect & herb & water & herb & water & Estimate & Standard Error & DF & t Value & $\operatorname{Pr}>|t|$ \\
\hline water*herb & Sun & 2 & Thyme & 2 & -0.7788 & 0.1389 & 214 & -5.61 & $<.0001$ \\
\hline water*herb & Sun & 2 & Basil & 3 & -0.9726 & 0.1381 & 267 & -7.04 & $<.0001$ \\
\hline water*herb & Sun & 2 & Mint & 3 & -0.3004 & 0.1413 & 267 & -2.13 & 0.0344 \\
\hline water*herb & Sun & 2 & Rose & 3 & -0.7262 & 0.1381 & 267 & -5.26 & $<.0001$ \\
\hline water*herb & Sun & 2 & Sun & 3 & 0.2697 & 0.1413 & 267 & 1.91 & 0.0573 \\
\hline water*herb & Sun & 2 & Thyme & 3 & -0.7967 & 0.1381 & 267 & -5.77 & $<.0001$ \\
\hline water*herb & Thyme & 2 & Basil & 3 & -0.1938 & 0.1381 & 267 & -1.40 & 0.1617 \\
\hline water*herb & Thyme & 2 & Mint & 3 & 0.4784 & 0.1413 & 267 & 3.39 & 0.0008 \\
\hline water*herb & Thyme & 2 & Rose & 3 & 0.05265 & 0.1381 & 267 & 0.38 & 0.7034 \\
\hline water*herb & Thyme & 2 & Sun & 3 & 1.0486 & 0.1413 & 267 & 7.42 & $<.0001$ \\
\hline water*herb & Thyme & 2 & Thyme & 3 & -0.01784 & 0.1381 & 267 & -0.13 & 0.8973 \\
\hline water*herb & Basil & 3 & Mint & 3 & 0.6723 & 0.1420 & 218 & 4.73 & $<.0001$ \\
\hline water*herb & Basil & 3 & Rose & 3 & 0.2465 & 0.1389 & 214 & 1.77 & 0.0773 \\
\hline water*herb & Basil & 3 & Sun & 3 & 1.2424 & 0.1420 & 218 & 8.75 & $<.0001$ \\
\hline water*herb & Basil & 3 & Thyme & 3 & 0.1760 & 0.1389 & 214 & 1.27 & 0.2064 \\
\hline water*herb & Mint & 3 & Rose & 3 & -0.4258 & 0.1420 & 218 & -3.00 & 0.0030 \\
\hline water*herb & Mint & 3 & Sun & 3 & 0.5701 & 0.1451 & 222 & 3.93 & 0.0001 \\
\hline water*herb & Mint & 3 & Thyme & 3 & -0.4963 & 0.1420 & 218 & -3.49 & 0.0006 \\
\hline water*herb & Rose & 3 & Sun & 3 & 0.9959 & 0.1420 & 218 & 7.01 & $<.0001$ \\
\hline water*herb & Rose & 3 & Thyme & 3 & -0.07049 & 0.1389 & 214 & -0.51 & 0.6123 \\
\hline water*herb & Sun & 3 & Thyme & 3 & -1.0664 & 0.1420 & 218 & -7.51 & $<.0001$ \\
\hline
\end{tabular}




\begin{tabular}{|r|l|r|l|r|r|r|r|l|}
\hline Obs & Effect & water & herb & Estimate & StdErr & DF & tValue & Probt \\
\hline $\mathbf{1}$ & water*herb & 0.5 & Basil & 2.0393 & 0.1780 & 1.98 & 11.45 & 0.0078 \\
\hline $\mathbf{2}$ & water*herb & 0.5 & Mint & 1.4006 & 0.1805 & 2.09 & 7.76 & 0.0143 \\
\hline $\mathbf{3}$ & water*herb & 0.5 & Rose & 1.5518 & 0.1780 & 1.98 & 8.72 & 0.0134 \\
\hline $\mathbf{4}$ & water*herb & 0.5 & Sun & 1.5288 & 0.1834 & 2.22 & 8.34 & 0.0102 \\
\hline $\mathbf{5}$ & water*herb & 0.5 & Thyme & 2.6176 & 0.1780 & 1.98 & 14.70 & 0.0048 \\
\hline $\mathbf{6}$ & water*herb & 1 & Basil & 2.7639 & 0.1780 & 1.98 & 15.52 & 0.0043 \\
\hline $\mathbf{7}$ & water*herb & 1 & Mint & 1.9936 & 0.1780 & 1.98 & 11.20 & 0.0082 \\
\hline $\mathbf{8}$ & water*herb & 1 & Rose & 2.3288 & 0.1781 & 1.98 & 13.08 & 0.0061 \\
\hline $\mathbf{9}$ & water*herb & 1 & Sun & 1.9367 & 0.1805 & 2.09 & 10.73 & 0.0074 \\
\hline $\mathbf{1 0}$ & water*herb & 1 & Thyme & 2.7779 & 0.1780 & 1.98 & 15.60 & 0.0043 \\
\hline $\mathbf{1 1}$ & water*herb & 1.5 & Basil & 2.9228 & 0.1780 & 1.98 & 16.42 & 0.0039 \\
\hline $\mathbf{1 2}$ & water*herb & 1.5 & Mint & 2.2972 & 0.1780 & 1.98 & 12.90 & 0.0062 \\
\hline $\mathbf{1 3}$ & water*herb & 1.5 & Rose & 2.4984 & 0.1780 & 1.98 & 14.03 & 0.0053 \\
\hline $\mathbf{1 4}$ & water*herb & 1.5 & Sun & 1.9943 & 0.1780 & 1.98 & 11.20 & 0.0082 \\
\hline $\mathbf{1 5}$ & water*herb & 1.5 & Thyme & 2.9979 & 0.1780 & 1.98 & 16.84 & 0.0037 \\
\hline $\mathbf{1 6}$ & water*herb & 2 & Basil & 3.0554 & 0.1780 & 1.98 & 17.16 & 0.0036 \\
\hline $\mathbf{1 7}$ & water*herb & 2 & Mint & 2.3560 & 0.1805 & 2.09 & 13.05 & 0.0049 \\
\hline $\mathbf{1 8}$ & water*herb & 2 & Rose & 2.6907 & 0.1780 & 1.98 & 15.11 & 0.0046 \\
\hline $\mathbf{1 9}$ & water*herb & 2 & Sun & 2.1108 & 0.1780 & 1.98 & 11.86 & 0.0073 \\
\hline $\mathbf{2 0}$ & water*herb & 2 & Thyme & 2.8896 & 0.1780 & 1.98 & 16.23 & 0.0040 \\
\hline $\mathbf{2 1}$ & water*herb & 3 & Basil & 3.0835 & 0.1780 & 1.98 & 17.32 & 0.0035 \\
\hline $\mathbf{2 2}$ & water*herb & 3 & Mint & 2.4112 & 0.1805 & 2.09 & 13.36 & 0.0047 \\
\hline $\mathbf{2 3}$ & water*herb & 3 & Rose & 2.8370 & 0.1780 & 1.98 & 15.93 & 0.0041 \\
\hline $\mathbf{2 4}$ & water*herb & 3 & Sun & 1.8411 & 0.1805 & 2.09 & 10.20 & 0.0082 \\
\hline $\mathbf{2 5}$ & water*herb & 3 & Thyme & 2.9075 & 0.1780 & 1.98 & 16.33 & 0.0039 \\
\hline
\end{tabular}

The UNIVARIATE Procedure

Variable: StudentResid (Studentized Residual)

\begin{tabular}{|l|l|l|l|}
\hline \multicolumn{4}{|c|}{ Moments } \\
\hline N & 293 & Sum Weights & 293 \\
\hline Mean & 0.00003127 & Sum Observations & 0.00916066 \\
\hline Std Deviation & 1.00241344 & Variance & 1.00483271 \\
\hline Skewness & -0.3569793 & Kurtosis & 2.29942647 \\
\hline Uncorrected SS & 293.411151 & Corrected SS & 293.411151 \\
\hline Coeff Variation & 3206179.23 & Std Error Mean & 0.05856162 \\
\hline
\end{tabular}

\begin{tabular}{|l|r|l|l|}
\hline \multicolumn{4}{|l|}{ Basic Statistical Measures } \\
\hline Location & & \multicolumn{2}{|c|}{ Variability } \\
\hline Mean & 0.00003 & Std Deviation & 1.00241 \\
\hline Median & -0.03876 & Variance & 1.00483 \\
\hline Mode &. & Range & 8.27092 \\
\hline & & Interquartile Range & 1.13841 \\
\hline
\end{tabular}




\begin{tabular}{|c|c|c|c|c|}
\hline \multicolumn{5}{|c|}{ Tests for Location: $\mathbf{M u} 0=0$} \\
\hline \multirow{2}{*}{$\begin{array}{l}\text { Test } \\
\text { Student's t }\end{array}$} & \multicolumn{2}{|c|}{ Statistic } & & \multirow{2}{*}{$\frac{\text { p Value }}{0.9996}$} \\
\hline & t & 0.000534 & $\operatorname{Pr}>|t|$ & \\
\hline Sign & $\mathbf{M}$ & -6.5 & $\operatorname{Pr}>=|\mathbf{M}|$ & 0.4833 \\
\hline Signed Rank & $\mathbf{S}$ & 506.5 & $\operatorname{Pr}>=|\mathbf{S}|$ & 0.7278 \\
\hline
\end{tabular}

\begin{tabular}{|c|c|c|c|c|}
\hline \multicolumn{5}{|l|}{ Tests for Normality } \\
\hline \multirow{2}{*}{$\begin{array}{l}\text { Test } \\
\text { Shapiro-Wilk }\end{array}$} & \multicolumn{2}{|c|}{ Statistic } & \multicolumn{2}{|c|}{ p Value } \\
\hline & $\mathbf{W}$ & 0.969997 & $\operatorname{Pr}<W$ & $<0.0001$ \\
\hline Kolmogorov-Smirnov & D & 0.069346 & $\operatorname{Pr}>D$ & $<0.0100$ \\
\hline Cramer-von Mises & W-Sq & 0.265622 & Pr $>$ W-Sq & $<0.0050$ \\
\hline Anderson-Darling & A-Sq & 1.771361 & $\operatorname{Pr}>\mathbf{A}-\mathrm{Sq}$ & $<0.0050$ \\
\hline
\end{tabular}

The UNIVARIATE Procedure

Variable: StudentResid (Studentized

Residual)

\begin{tabular}{|l|c|}
\hline Quantiles (Definition 5) \\
\hline Quantile & Estimate \\
\hline $\mathbf{1 0 0 \%}$ Max & 4.0844756 \\
\hline $\mathbf{9 9 \%}$ & 2.4329521 \\
\hline $\mathbf{9 5 \%}$ & 1.4841557 \\
\hline $\mathbf{9 0 \%}$ & 1.2319318 \\
\hline $\mathbf{7 5 \%}$ Q3 & 0.6418888 \\
\hline $\mathbf{5 0 \%}$ Median & -0.0387589 \\
\hline $\mathbf{2 5 \%}$ Q1 & -0.4965222 \\
\hline $\mathbf{1 0 \%}$ & -1.1117624 \\
\hline $\mathbf{5 \%}$ & -1.8100313 \\
\hline $\mathbf{1 \%}$ & -3.1231856 \\
\hline $\mathbf{0 \%}$ Min & -4.1864446 \\
\hline
\end{tabular}

\begin{tabular}{|l|c|l|c|}
\hline \multicolumn{4}{|l|}{ Extreme Observations } \\
\hline Lowest & \multicolumn{2}{|c|}{ Highest } \\
\hline Value & Obs & Value & Obs \\
\hline-4.18644 & 286 & 2.03373 & 124 \\
\hline-3.75751 & 256 & 2.35847 & 108 \\
\hline-3.12319 & 193 & 2.43295 & 163 \\
\hline-2.96717 & 243 & 2.67887 & 137 \\
\hline-2.54944 & 285 & 4.08448 & 224 \\
\hline
\end{tabular}

The UNIVARIATE Procedure

Fitted normal Distribution for StudentResid

\begin{tabular}{l|l|l|}
\hline \multicolumn{3}{|l|}{ Parameters for Normal } \\
Distribution \\
\hline Parameter & Symbol & Estimate \\
\hline Mean & $\mathrm{Mu}$ & 0.000031 \\
\hline Std Dev & Sigma & 1.002413 \\
\hline
\end{tabular}

\begin{tabular}{|l|l|l|l|l|l|}
\hline Goodness-of-Fit Tests for Normal Distribution \\
\hline Test & Statistic & \multicolumn{1}{|c|}{ p Value } \\
\hline Kolmogorov-Smirnov & D & 0.06934591 & Pr $>$ D & $<0.010$ \\
\hline Cramer-von Mises & W-Sq & 0.26562192 & Pr $>$ W-Sq & $<0.005$ \\
\hline Anderson-Darling & A-Sq & 1.77136144 & Pr $>$ A-Sq & $<0.005$ \\
\hline
\end{tabular}

\begin{tabular}{|r|r|r|}
\hline \multicolumn{3}{|c|}{ Quantiles for Normal Distribution } \\
\hline & & Quantile \\
\hline Percent & Observed & Estimated \\
\hline $\mathbf{1 . 0}$ & -3.12319 & -2.33193 \\
\hline $\mathbf{5 . 0}$ & -1.81003 & -1.64879 \\
\hline $\mathbf{1 0 . 0}$ & -1.11176 & -1.28461 \\
\hline $\mathbf{2 5 . 0}$ & -0.49652 & -0.67609 \\
\hline $\mathbf{5 0 . 0}$ & -0.03876 & 0.00003 \\
\hline $\mathbf{7 5 . 0}$ & 0.64189 & 0.67615 \\
\hline $\mathbf{9 0 . 0}$ & 1.23193 & 1.28468 \\
\hline $\mathbf{9 5 . 0}$ & 1.48416 & 1.64885 \\
\hline $\mathbf{9 9 . 0}$ & 2.43295 & 2.33199 \\
\hline
\end{tabular}


The UNIVARIATE Procedure

Variable: Estimate

Effect=bench $\left(\right.$ block $^{*}$ water $)$

\begin{tabular}{|l|l|l|l|}
\hline \multicolumn{4}{|c|}{ Moments } \\
\hline N & 60 & Sum Weights & 60 \\
\hline Mean & 0 & Sum Observations & 0 \\
\hline Std Deviation & 0.00806921 & Variance & 0.00006511 \\
\hline Skewness & -0.1245672 & Kurtosis & -0.4091733 \\
\hline Uncorrected SS & 0.00384162 & Corrected SS & 0.00384162 \\
\hline Coeff Variation &. & Std Error Mean & 0.00104173 \\
\hline
\end{tabular}

\begin{tabular}{|l|l|l|r|}
\hline \multicolumn{4}{|l|}{ Basic Statistical Measures } \\
\hline Location \\
\hline Mean & 0.000000 & Std Deviation & 0.00807 \\
\hline Median & 0.000359 & Variance & 0.0000651 \\
\hline Mode &. & Range & 0.03303 \\
\hline & & Interquartile Range & 0.01077 \\
\hline
\end{tabular}

\begin{tabular}{|c|c|c|c|c|}
\hline \multicolumn{5}{|c|}{ Tests for Location: $\mathrm{Mu} 0=0$} \\
\hline \multirow{2}{*}{$\begin{array}{l}\text { Test } \\
\text { Student's t }\end{array}$} & \multicolumn{2}{|c|}{ Statistic } & & \multirow{2}{*}{$\frac{\text { p Value }}{1.0000}$} \\
\hline & $\mathbf{t}$ & 0 & $\operatorname{Pr}>|t|$ & \\
\hline Sign & M & 1 & $\operatorname{Pr}>=|\mathbf{M}|$ & 0.8974 \\
\hline Signed Rank & $\mathbf{S}$ & 16 & $\operatorname{Pr}>=|\mathbf{S}|$ & 0.9074 \\
\hline
\end{tabular}

\begin{tabular}{|c|c|c|c|c|}
\hline \multicolumn{5}{|l|}{ Tests for Normality } \\
\hline \multirow{2}{*}{$\begin{array}{l}\text { Test } \\
\text { Shapiro-Wilk }\end{array}$} & \multicolumn{2}{|c|}{ Statistic } & \multicolumn{2}{|c|}{ p Value } \\
\hline & $\mathbf{W}$ & 0.985233 & $\operatorname{Pr}<W$ & 0.6821 \\
\hline Kolmogorov-Smirnov & D & 0.062295 & $\operatorname{Pr}>D$ & $>0.1500$ \\
\hline Cramer-von Mises & W-Sq & 0.02452 & Pr $>$ W-Sq & $>0.2500$ \\
\hline Anderson-Darling & $\mathbf{A - S q}$ & 0.185256 & $\operatorname{Pr}>A-S q$ & $>0.2500$ \\
\hline
\end{tabular}

The UNIVARIATE Procedure

Variable: Estimate

Effect=bench (block ${ }^{*}$ water)

\begin{tabular}{|l|l|}
\hline \multicolumn{2}{|l|}{ Quantiles (Definition 5) } \\
\hline Quantile & Estimate \\
\hline $\mathbf{1 0 0 \%}$ Max & 0.016483329 \\
\hline $\mathbf{9 9 \%}$ & 0.016483329 \\
\hline $\mathbf{9 5 \%}$ & 0.013130645 \\
\hline $\mathbf{9 0 \%}$ & 0.010677395 \\
\hline $\mathbf{7 5 \%}$ Q3 & 0.005492760 \\
\hline $\mathbf{5 0 \%}$ Median & 0.000358869 \\
\hline $\mathbf{2 5 \%}$ Q1 & -0.005281657 \\
\hline $\mathbf{1 0 \%}$ & -0.011804631 \\
\hline $\mathbf{5 \%}$ & -0.014670671 \\
\hline $\mathbf{1 \%}$ & -0.016543637 \\
\hline $\mathbf{0 \%}$ Min & -0.016543637 \\
\hline
\end{tabular}

\begin{tabular}{|l|r|l|r|}
\hline \multicolumn{4}{|l|}{ Extreme Observations } \\
\hline Lowest & \multicolumn{1}{|l|}{} & Highest \\
\hline Value & Obs & Value & Obs \\
\hline-0.0165436 & 47 & 0.0123028 & 60 \\
\hline-0.0162774 & 24 & 0.0129218 & 57 \\
\hline-0.0158008 & 26 & 0.0133395 & 15 \\
\hline-0.0135405 & 38 & 0.0157699 & 39 \\
\hline-0.0126729 & 29 & 0.0164833 & 33 \\
\hline
\end{tabular}


The UNIVARIATE Procedure

Variable: Estimate

Effect=block

\begin{tabular}{|l|r|l|l|}
\hline \multicolumn{3}{|c|}{ Moments } \\
\hline N & 2 & Sum Weights & 2 \\
\hline Mean & 0 & Sum Observations & 0 \\
\hline Std Deviation & 0.20876889 & Variance & 0.04358445 \\
\hline Skewness & $\cdot$ & Kurtosis &. \\
\hline Uncorrected SS & 0.04358445 & Corrected SS & 0.04358445 \\
\hline Coeff Variation & $\cdot$ & Std Error Mean & 0.14762189 \\
\hline
\end{tabular}

\begin{tabular}{|l|r|l|l|}
\hline \multicolumn{3}{|l|}{ Basic Statistical Measures } \\
\hline Location & 0 & \multicolumn{2}{|c|}{ Variability } \\
\hline Mean & Std Deviation & 0.20877 \\
\hline Median & $-445 \mathrm{E}-16$ & Variance & 0.04358 \\
\hline Mode &. & Range & 0.29524 \\
\hline & & Interquartile Range & 0.29524 \\
\hline
\end{tabular}

\begin{tabular}{|c|c|c|c|c|}
\hline \multicolumn{5}{|c|}{ Tests for Location: $\mathrm{Mu} 0=0$} \\
\hline Test & Sta & stic & & p Value \\
\hline Student's t & $\mathbf{t}$ & 0 & $\operatorname{Pr}>|\mathbf{t}|$ & 1.0000 \\
\hline Sign & M & 0 & $\operatorname{Pr}>=|\mathbf{M}|$ & 1.0000 \\
\hline Signed Rank & $\mathbf{S}$ & -0.5 & $\operatorname{Pr}>=|\mathbf{S}|$ & 1.0000 \\
\hline
\end{tabular}

\begin{tabular}{|c|c|c|c|c|}
\hline \multicolumn{5}{|l|}{ Tests for Normality } \\
\hline Test & \multicolumn{2}{|c|}{ Statistic } & \multicolumn{2}{|c|}{ p Value } \\
\hline Shapiro-Wilk & $\mathbf{W}$ & 1 & $\operatorname{Pr}<W$ & 1.0000 \\
\hline Kolmogorov-Smirnov & D & 0.26025 & $\operatorname{Pr}>\mathbf{D}$ & $>0.1500$ \\
\hline Cramer-von Mises & W-Sq & 0.041877 & Pr $>$ W-Sq & $>0.2500$ \\
\hline Anderson-Darling & $\mathrm{A}-\mathrm{Sq}$ & 0.250482 & $\operatorname{Pr}>\mathbf{A}-\mathbf{S q}$ & 0.2332 \\
\hline
\end{tabular}

\begin{tabular}{|l|r|}
\hline \multicolumn{2}{|l|}{ Quantiles (Definition 5) } \\
\hline Quantile & Estimate \\
\hline $\mathbf{1 0 0} \%$ Max & 0.147622 \\
\hline $\mathbf{9 9 \%}$ & 0.147622 \\
\hline $\mathbf{9 5} \%$ & 0.147622 \\
\hline $\mathbf{9 0} \%$ & 0.147622 \\
\hline $\mathbf{7 5 \%}$ Q3 & 0.147622 \\
\hline $\mathbf{5 0 \%}$ Median & -0.000000 \\
\hline $\mathbf{2 5 \%}$ Q1 & -0.147622 \\
\hline $\mathbf{1 0} \%$ & -0.147622 \\
\hline $\mathbf{5 \%}$ & -0.147622 \\
\hline $\mathbf{1 \%}$ & -0.147622 \\
\hline $\mathbf{0 \%}$ Min & -0.147622 \\
\hline
\end{tabular}

\begin{tabular}{|c|c|l|r|}
\hline \multicolumn{4}{|c|}{ Extreme Observations } \\
\hline \multicolumn{3}{|c|}{ Lowest } & \multicolumn{2}{c|}{ Highest } \\
\hline Value & Obs & Value & Obs \\
\hline-0.147622 & 2 & -0.147622 & 2 \\
\hline 0.147622 & 1 & 0.147622 & 1 \\
\hline
\end{tabular}




\begin{tabular}{l|l}
\hline Model Information & WORK.ABSR \\
\hline Data Set & absr \\
\hline Dependent Variable & Diagonal \\
\hline Covariance Structure & REML \\
\hline Estimation Method & Profile \\
\hline Residual Variance Method & Model-Based \\
\hline Fixed Effects SE Method & Residual \\
\hline Degrees of Freedom Method & \\
\hline
\end{tabular}

\begin{tabular}{l|r|l}
\hline \multicolumn{3}{|c}{ Class Level Information } \\
\hline Class & Levels & Values \\
\hline block & 2 & 12 \\
\hline water & 5 & 0.511 .523 \\
\hline herb & 5 & Basil Mint Rose Sun Thyme \\
\hline bench & 60 & 1234567891011121314151617181920212223242526 \\
& & 27282930313233343536373839404142434445464748 \\
& & 495051525354555657585960 \\
\hline
\end{tabular}

\begin{tabular}{l|r}
\hline \multicolumn{2}{l}{ Dimensions } \\
\hline Covariance Parameters & 1 \\
\hline Columns in X & 98 \\
\hline Columns in Z & 0 \\
\hline Subjects & 1 \\
\hline Max Obs Per Subject & 293 \\
\hline
\end{tabular}

\begin{tabular}{l|r}
\hline \multicolumn{2}{l}{ Number of Observations } \\
\hline Number of Observations Read & 293 \\
\hline Number of Observations Used & 293 \\
\hline Number of Observations Not Used & 0 \\
\hline
\end{tabular}

\begin{tabular}{|l|l|}
\hline \multicolumn{2}{|l|}{ Covariance Parameter Estimates } \\
\hline Cov Parm & Estimate \\
\hline Residual & 0.04246 \\
\hline
\end{tabular}

\begin{tabular}{|l|l|}
\hline \multicolumn{2}{|l|}{ Fit Statistics } \\
\hline -2 Res Log Likelihood & 67.5 \\
\hline AIC (smaller is better) & 69.5 \\
\hline AICC (smaller is better) & 69.6 \\
\hline BIC (smaller is better) & 72.9 \\
\hline
\end{tabular}

\begin{tabular}{|l|r|r|r|r|}
\hline \multicolumn{2}{|l|}{ Type 3 Tests of Fixed Effects } \\
\hline Effect & Num DF & Den DF & F Value & Pr > F \\
\hline water & 4 & 213 & 1.73 & 0.1444 \\
\hline herb & 4 & 213 & 6.29 & $<.0001$ \\
\hline water*herb & 16 & 213 & 1.87 & 0.0247 \\
\hline block & 1 & 213 & 2.44 & 0.1195 \\
\hline bench(block*water) & 54 & 213 & 0.98 & 0.5230 \\
\hline
\end{tabular}

\begin{tabular}{|l|l|}
\hline Model Information & WORK.VICTORIA01 \\
\hline Data Set & dry \\
\hline Dependent Variable & Variance Components \\
\hline Covariance Structure & REML \\
\hline Estimation Method & Profile \\
\hline Residual Variance Method & Kenward-Roger \\
\hline Fixed Effects SE Method & Kenward-Roger \\
\hline Degrees of Freedom Method & \\
\hline
\end{tabular}




\begin{tabular}{|l|r|l|}
\hline \multicolumn{3}{|c|}{ Class Level Information } \\
\hline Class & Levels & Values \\
\hline block & 2 & 12 \\
\hline water & 5 & 0.511 .523 \\
\hline herb & 5 & Basil Mint Rose Sun Thyme \\
\hline bench & 60 & 123456789101112131415161718192021222324 \\
& & 2526272829303132333435363738394041424344 \\
& & 45464748495051525354555657585960 \\
\hline
\end{tabular}

\begin{tabular}{|l|r|}
\hline \multicolumn{2}{|l|}{ Dimensions } \\
\hline Covariance Parameters & 3 \\
\hline Columns in X & 18 \\
\hline Columns in Z & 62 \\
\hline Subjects & 1 \\
\hline Max Obs Per Subject & 293 \\
\hline
\end{tabular}

\section{Convergence criteria met.}

\begin{tabular}{|c|c|c|c|c|}
\hline \multicolumn{4}{|c|}{ Number of Observations } & \\
\hline \multicolumn{3}{|c|}{ Number of Observations Read } & 29 & \\
\hline \multicolumn{3}{|c|}{ Number of Observations Used } & 29 & \\
\hline \multicolumn{3}{|c|}{ Number of Observations Not Used } & & \\
\hline \multicolumn{5}{|c|}{ Iteration History } \\
\hline Iteration & Evaluations & \multicolumn{2}{|c|}{-2 Res Log Like } & Criterion \\
\hline $\mathbf{0}$ & 1 & \multicolumn{2}{|c|}{296.10467594} & \\
\hline 1 & 3 & \multicolumn{2}{|c|}{248.63471927} & 0.00000002 \\
\hline 2 & 1 & \multicolumn{2}{|c|}{248.63471692} & 0.00000000 \\
\hline
\end{tabular}

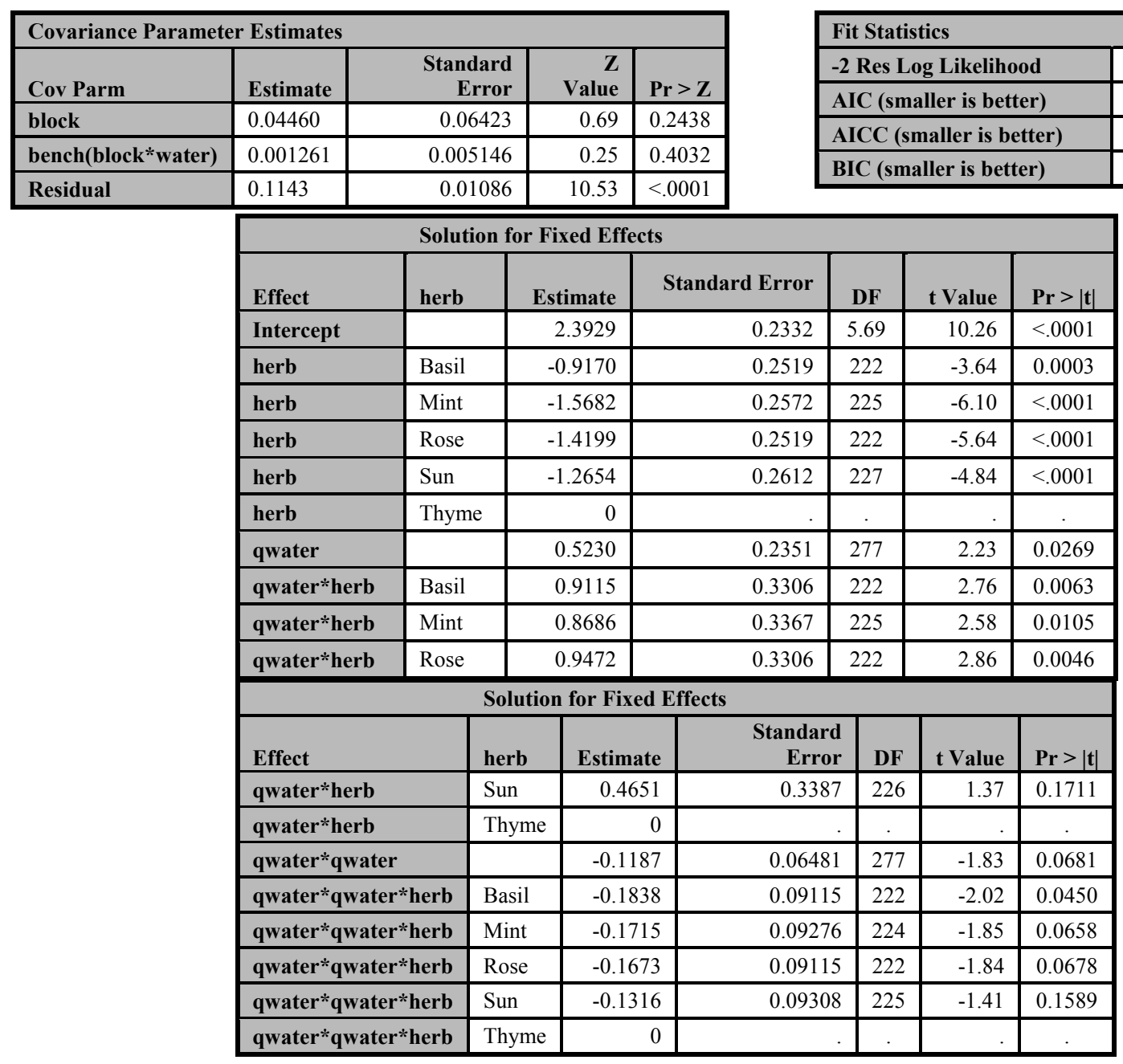




\begin{tabular}{|l|r|c|r|r|}
\hline Type 1 Tests of Fixed Effects \\
\hline Effect & Num DF & Den DF & F Value & Pr > F \\
\hline herb & 4 & 224 & 86.27 & $<.0001$ \\
\hline qwater & 1 & 57.1 & 138.63 & $<.0001$ \\
\hline qwater*herb & 4 & 225 & 10.29 & $<.0001$ \\
\hline qwater*qwater & 1 & 56.4 & 68.75 & $<.0001$ \\
\hline qwater*qwater*herb & 4 & 224 & 1.37 & 0.2446 \\
\hline
\end{tabular}

\begin{tabular}{|l|r|r|r|r|r|}
\hline \multicolumn{7}{|c|}{ Estimates } \\
\hline Label & Estimate & Standard Error & DF & t Value & Pr $>|\mathbf{t}|$ \\
\hline Int for Basil & 1.4759 & 0.2332 & 5.69 & 6.33 & 0.0009 \\
\hline B_Lin for Basil & 1.4345 & 0.2351 & 277 & 6.10 & $<.0001$ \\
\hline B_quad for Basil & -0.3025 & 0.06481 & 277 & -4.67 & $<.0001$ \\
\hline Int for Mint & 0.8248 & 0.2389 & 6.25 & 3.45 & 0.0127 \\
\hline B_Lin for Mint & 1.3916 & 0.2436 & 277 & 5.71 & $<.0001$ \\
\hline B_quad for Mint & -0.2902 & 0.06706 & 277 & -4.33 & $<.0001$ \\
\hline Int for Rose & 0.9730 & 0.2332 & 5.69 & 4.17 & 0.0066 \\
\hline B_Lin for Rose & 1.4702 & 0.2351 & 277 & 6.25 & $<.0001$ \\
\hline B_quad for Rose & -0.2860 & 0.06481 & 277 & -4.41 & $<.0001$ \\
\hline Int for Sun & 1.1275 & 0.2432 & 6.71 & 4.64 & 0.0027 \\
\hline B_Lin for Sun & 0.9881 & 0.2463 & 277 & 4.01 & $<.0001$ \\
\hline
\end{tabular}

\begin{tabular}{|l|r|r|r|r|r|}
\hline \multicolumn{5}{|c|}{ Estimates } \\
\hline Label & Estimate & Standard Error & DF & t Value & Pr $>|\mathbf{t}|$ \\
\hline B_quad for Sun & -0.2503 & 0.06749 & 277 & -3.71 & 0.0003 \\
\hline Int for Thyme & 2.3929 & 0.2332 & 5.69 & 10.26 & $<.0001$ \\
\hline B_Lin for Thyme & 0.5230 & 0.2351 & 277 & 2.23 & 0.0269 \\
\hline B_quad for Thyme & -0.1187 & 0.06481 & 277 & -1.83 & 0.0681 \\
\hline
\end{tabular}

\begin{tabular}{|l|l|}
\hline Model Information & WORK.VICTORIA01 \\
\hline Data Set & dry \\
\hline Dependent Variable & Variance Components \\
\hline Covariance Structure & REML \\
\hline Estimation Method & Profile \\
\hline Residual Variance Method & Kenward-Roger \\
\hline Fixed Effects SE Method & Kenward-Roger \\
\hline Degrees of Freedom Method & \\
\hline
\end{tabular}




\begin{tabular}{|l|r|l|}
\hline \multicolumn{3}{|c|}{ Class Level Information } \\
\hline Class & Levels & Values \\
\hline block & 2 & 12 \\
\hline water & 5 & 0.511 .523 \\
\hline herb & 5 & Basil Mint Rose Sun Thyme \\
\hline bench & 60 & 12345678910111213141516171819202122232425 \\
& & 26272829303132333435363738394041424344454647 \\
& & 48495051525354555657585960 \\
\hline
\end{tabular}

\begin{tabular}{|l|r|}
\hline Dimensions \\
\hline Covariance Parameters & 3 \\
\hline Columns in X & 11 \\
\hline Columns in Z & 62 \\
\hline Subjects & 1 \\
\hline Max Obs Per Subject & 293 \\
\hline
\end{tabular}

Convergence criteria met.

\begin{tabular}{|l|r|}
\hline Number of Observations \\
\hline Number of Observations Read & 293 \\
\hline Number of Observations Used & 293 \\
\hline Number of Observations Not Used & 0 \\
\hline
\end{tabular}

\begin{tabular}{|r|r|r|l|}
\hline \multicolumn{5}{|c|}{ Iteration History } \\
\hline Iteration & Evaluations & -2 Res Log Like & Criterion \\
\hline $\mathbf{0}$ & 1 & 288.62974950 & \\
\hline $\mathbf{1}$ & 3 & 241.26304294 & 0.00000002 \\
\hline $\mathbf{2}$ & 1 & 241.26304077 & 0.00000000 \\
\hline
\end{tabular}

\begin{tabular}{|l|l|r|r|r|}
\hline \multicolumn{2}{|l|}{ Covariance Parameter Estimates } \\
\hline Cov Parm & Estimate & Standard Error & Z Value & Pr $>$ Z \\
\hline block & 0.04468 & 0.06435 & 0.69 & 0.2437 \\
\hline bench(block*water) & 0.001059 & 0.005135 & 0.21 & 0.4183 \\
\hline Residual & 0.1151 & 0.01084 & 10.62 & $<.0001$ \\
\hline
\end{tabular}

\begin{tabular}{|l|l|}
\hline \multicolumn{2}{|l|}{ Fit Statistics } \\
\hline -2 Res Log Likelihood & 241.3 \\
\hline AIC (smaller is better) & 247.3 \\
\hline AICC (smaller is better) & 247.3 \\
\hline BIC (smaller is better) & 243.3 \\
\hline
\end{tabular}

\begin{tabular}{|c|c|c|c|c|c|c|}
\hline \multicolumn{7}{|c|}{ Solution for Fixed Effects } \\
\hline Effect & herb & Estimate & Standard Error & DF & t Value & $\operatorname{Pr}>|\mathbf{t}|$ \\
\hline herb & Basil & 1.6025 & 0.1898 & 2.5 & 8.44 & 0.0067 \\
\hline herb & Mint & 0.9232 & 0.1914 & 2.59 & 4.82 & 0.0237 \\
\hline herb & Rose & 1.0606 & 0.1898 & 2.5 & 5.59 & 0.0181 \\
\hline herb & Sun & 1.1306 & 0.1937 & 2.71 & 5.84 & 0.0132 \\
\hline herb & Thyme & 2.0849 & 0.1898 & 2.5 & 10.99 & 0.0035 \\
\hline qwater(herb) & Basil & 1.2450 & 0.1179 & 77.2 & 10.56 & $<.0001$ \\
\hline qwater(herb) & Mint & 1.2454 & 0.1189 & 79.1 & 10.47 & $<.0001$ \\
\hline qwater(herb) & Rose & 1.3391 & 0.1179 & 77.2 & 11.36 & $<.0001$ \\
\hline qwater(herb) & Sun & 0.9835 & 0.1198 & 80.8 & 8.21 & $<.0001$ \\
\hline \multicolumn{7}{|c|}{ Solution for Fixed Effects } \\
\hline Effect & herb & Estimate & Standard Error & DF & t Value & $\operatorname{Pr}>|t|$ \\
\hline qwater(herb) & Thyme & 0.9843 & 0.1179 & 77.2 & 8.35 & $<.0001$ \\
\hline qwater*qwater & & -0.2490 & 0.03000 & 56.5 & -8.30 & $<.0001$ \\
\hline
\end{tabular}

\begin{tabular}{|l|r|r|r|r|}
\hline \multicolumn{5}{|l|}{ Type 3 Tests of Fixed Effects } \\
\hline Effect & Num DF & Den DF & F Value & Pr > F \\
\hline herb & 5 & 15.2 & 29.38 & $<.0001$ \\
\hline qwater(herb) & 5 & 218 & 30.80 & $<.0001$ \\
\hline qwater* qwater & 1 & 56.5 & 68.86 & $<.0001$ \\
\hline
\end{tabular}




\section{Prediction model}

Based on the data the model shows a prediction of the response of individual species to varying watering.

Log Fresh weight $\mathbf{Y}_{\mathbf{i j k l}}=\boldsymbol{\mu}_{\mathbf{i j}}+\mathbf{r}_{\mathbf{k}}+\mathbf{w}_{\mathbf{l}(\mathbf{i k})}+\boldsymbol{\varepsilon}_{\mathbf{j l}(\mathbf{i k})}$
\begin{tabular}{|l|l|l|}
\hline $\mathrm{i}=$ & $1, \ldots .5$ & Watering level \\
\hline $\mathrm{j}=$ & $1, \ldots .5$ & Herbs \\
\hline $\mathrm{k}=$ & 1,2 & Blocks \\
\hline $\mathrm{l}==$ & $1,2, \ldots 60$ & Benches \\
\hline $\mathrm{r}_{\mathrm{k}=}$ & Random block effect & \\
\hline $\mathrm{w}_{\mathrm{l}(\mathrm{ik})=}$ & Random bench effect (w plot error) & \\
\hline$\varepsilon_{\mathrm{jl}(\mathrm{ik})=}=$ & Rendom error (s plot error) & \\
\hline
\end{tabular}

Before: $\boldsymbol{\mu}_{\mathbf{i j}=} \boldsymbol{\mu}+\boldsymbol{\delta}_{\mathbf{i}}+\boldsymbol{\tau}_{\mathbf{j}}+(\boldsymbol{\delta} \boldsymbol{\tau})_{\mathbf{i j}}$
\begin{tabular}{|l|l|}
\hline$\mu=$ & Overall Grand mean \\
\hline$\delta_{\mathrm{i}=}$ & ith water effect \\
\hline$\tau_{\mathrm{i}=}$ & jth herb effect \\
\hline$(\delta \tau)_{\mathrm{ij}=}$ & ijth water*herb interaction effect \\
\hline
\end{tabular}

\footnotetext{
Direct Regression Approach: $\mu_{\mathrm{ij}}=\mu+\tau_{\mathrm{j}}+\left(\beta_{\mathrm{L}}+\Delta_{\mathrm{Lj}}\right)[\mathrm{water}]+\left(\beta_{\mathrm{Q}}+\Delta_{\mathrm{Qj}}\right)[\mathrm{water}]^{2}$ \begin{tabular}{|l|l|}
\hline$\beta_{\mathrm{L}=}$ & Linear slope coefficient for regression water \\
\hline$\Delta_{\mathrm{Lj}}=$ & Change in slope for the jth herb \\
\hline$\beta_{\mathrm{Q}=}$ & Quadratic coefficient for regression on water \\
\hline$\Delta_{\mathrm{Qj}}=$ & Change in quadratic coefficient for the jth herb. \\
\hline
\end{tabular}
}

Example: Basil fresh weight

$\mu_{\mathrm{ij}}=3.3664+1.4136$ (water) -0.2664 (water) $^{2}$ 
Figure 7.1. Fresh weight prediction model.

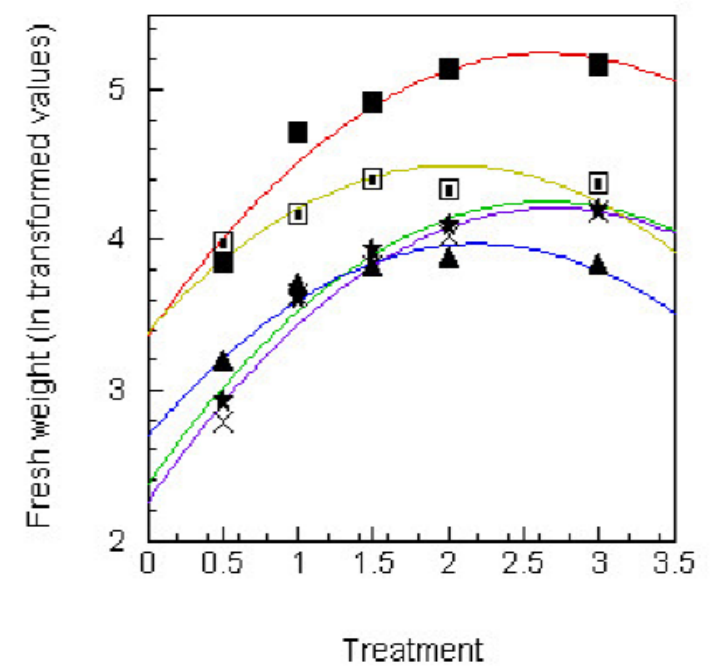

$$
\begin{aligned}
& -(2.3744)+\left(1.4152^{*} x\right)-\left(0.2664^{*} x^{n} 2\right) ; \\
& (2.2584)+\left(1.4424^{*} x\right)-\left(0.2664^{*} x^{h} 2\right) \text {; } \\
& (2.6933)+\left(1.1670^{*} x\right)-\left(0.2664^{*} x^{n} 2\right) ; \\
& (3.3859)+\left(1.0861^{*} x\right)-\left(0.2664^{*} x^{\wedge} 2\right) \\
& (3.3664)+\left(1.4136^{*} x\right)-\left(0.2664^{*} x^{n} 2\right) \text {; } \\
& \star \quad \text { Mint } \\
& \text { X Rosemary } \\
& \text { - Sunflower } \\
& \text { [ Thyme } \\
& \text { - Basil }
\end{aligned}
$$

Treatment 
Figure 7.2. Dry weight prediction model.
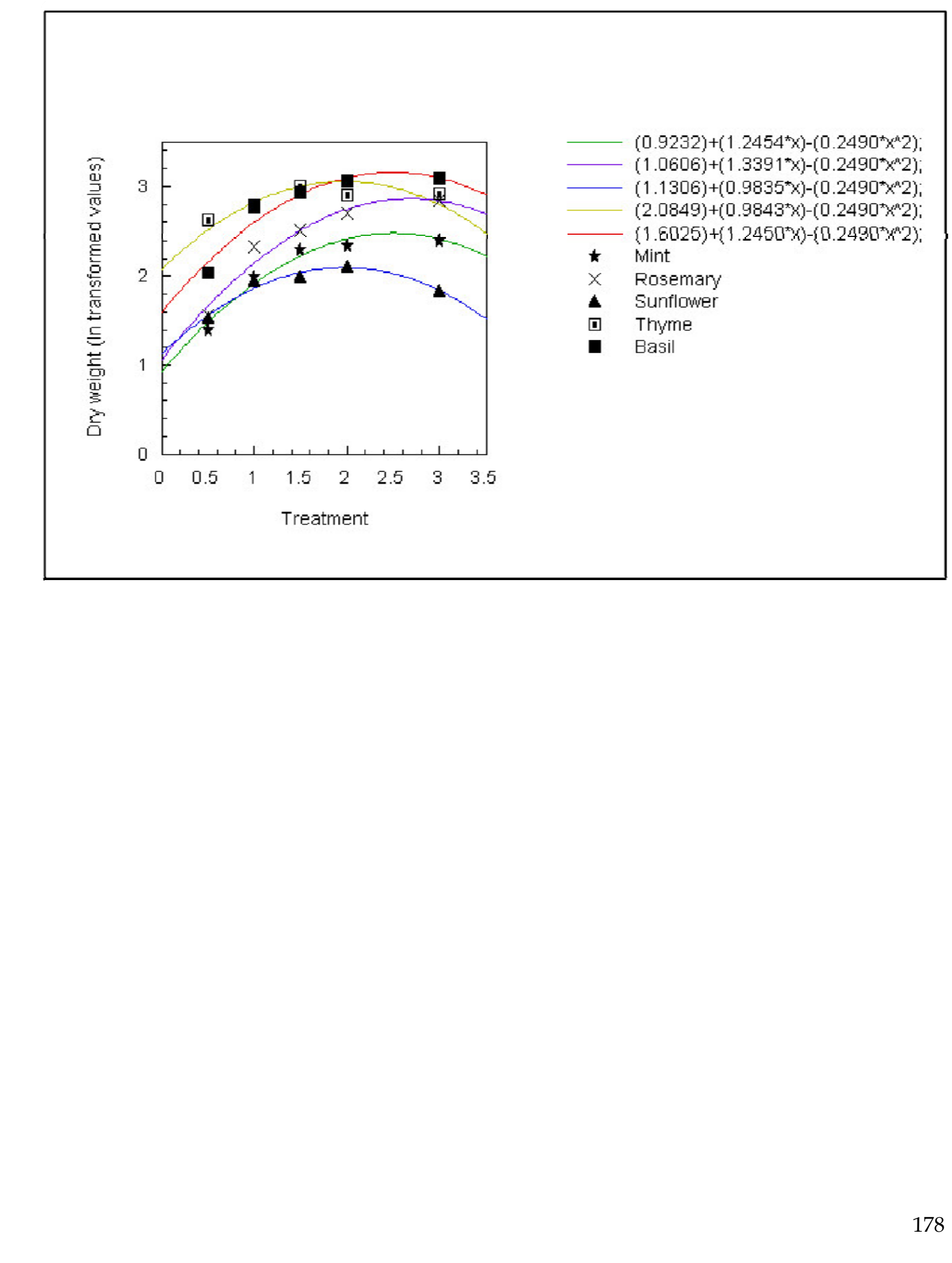